\title{
Evaluation of Compressibility, Anisotropy and At-rest Lateral Earth Pressure in Champlain Sea Clays
}

\author{
Submitted by
}

\section{Fahad Alshawmar}

B. Sc. Eng., Qassim University, Kingdom of Saudi Arabia (2008)

A thesis submitted to the Faculty of Graduate Studies and Research as partial fulfillment of the requirements for the degree of Masters of Applied Science

\author{
Department of Civil and Environmental Engineering \\ Carleton University \\ Ottawa, Ontario \\ Canada
}

(C) Fahad Alshawmar, 2014

The Master of Applied Science in Civil Engineering Program is a joint program with University of Ottawa, administrated by the Ottawa-Carleton Institute of Civil Engineering 


\begin{abstract}
An experimental study is undertaken to evaluate the characteristics of the sensitive Champlain Sea clay. Undisturbed samples obtained from a site in Ottawa were trimmed along both the vertical and horizontal orientations for consolidation and simple shear tests. The results of the one-dimensional consolidation tests indicate that the vertical orientation has greater preconsolidation pressures than the horizontal orientation. The ratio of the horizontal to vertical preconsolidation pressure varies from 0.71 to 0.95 . Consolidation along the horizontal orientation leads to higher ( $1 \%$ to $23 \%)$ compression indices than those in the vertical orientation. The values of the coefficients of consolidation and permeability in the horizontal orientation are found to be larger than those in the vertical orientation, and the ratios of both coefficients of consolidation and permeability in the horizontal orientation to that in the vertical orientation evolve as the effective vertical stress increases.
\end{abstract}

Generally, the at rest lateral earth pressure coefficient in the horizontal orientation was greater than that in the vertical orientation. The average ratio of the at rest lateral earth pressure coefficient throughout all tests $(5.82 \mathrm{~m}$ to $21.55 \mathrm{~m})$ ranges from 0.90 to 1.82 during the entire stress history. Based on the observation of one-dimensional consolidation tests, it is noted that sensitive Champlain Sea clay shows anisotropic behaviour with respect to the ratios of the horizontal-to-vertical coefficient of consolidation, permeability and the at rest lateral earth pressure coefficient.

The undrained monotonic simple shear resistance is somewhat dependent on sample orientation. Test results indicate that samples in the vertical orientation have lower peak and residual shear strengths than those sampled along the horizontal orientation. The 
horizontal to vertical peak strength ratio varied between 1.05 and 1.42 . However, the mobilized friction angle at peak and residual states appears to be not dependent on the loading orientation. 


\section{TABLE OF CONTENTS}

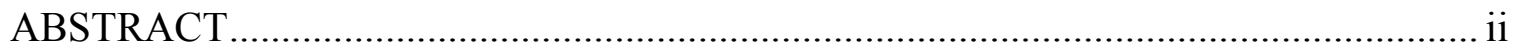

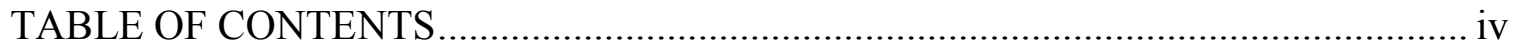

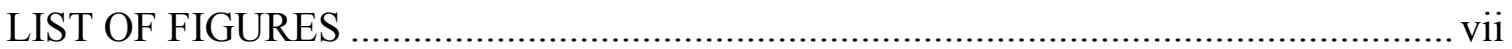

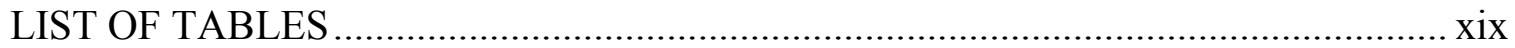

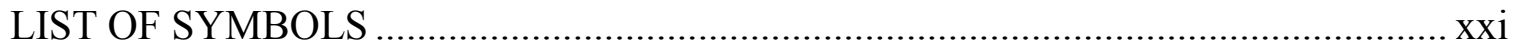

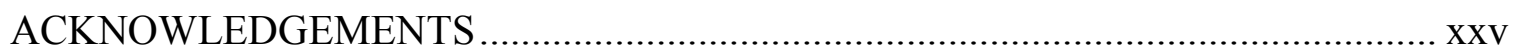

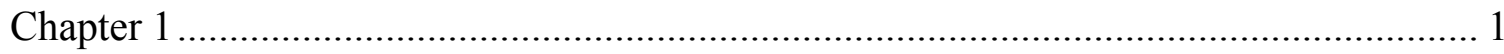

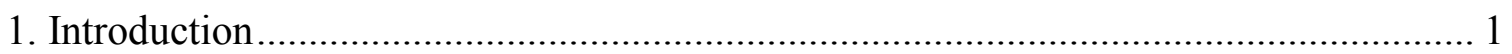

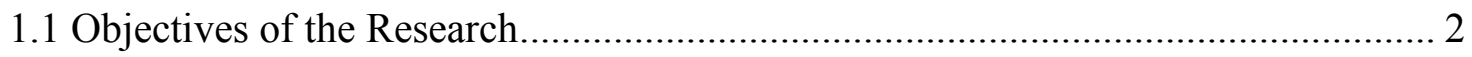

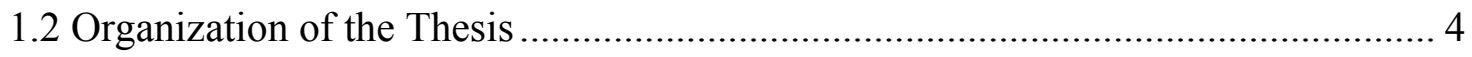

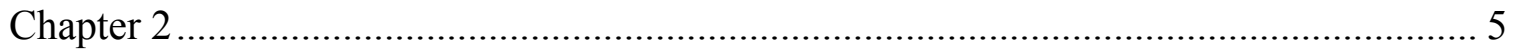

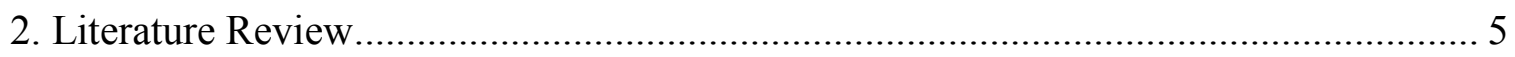

2.1 Champlain Sea Deposits ("Leda clays") …………….......................................... 5

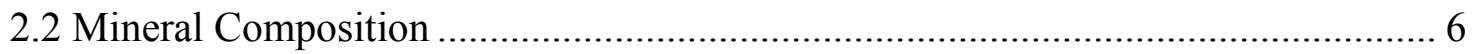

2.3 The Theory and Process of Consolidation in Clays .................................................. 16

2.4 Consolidation behaviour in Sensitive Clays ………............................................ 18

2.5 At-Rest Lateral Earth Pressure Coefficient of Sensitive Clays ............................. 25

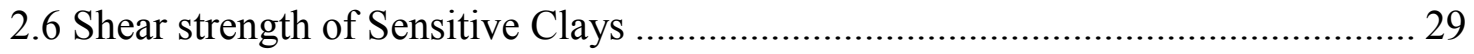

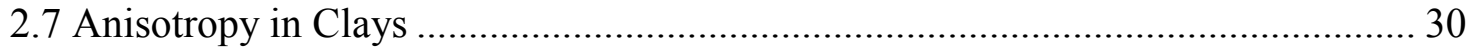




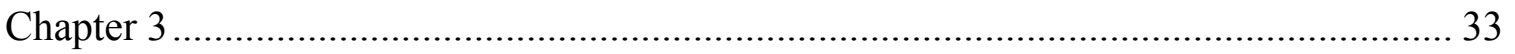

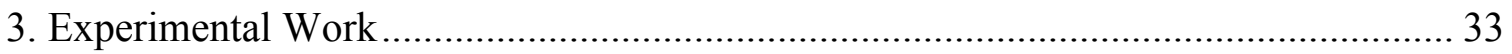

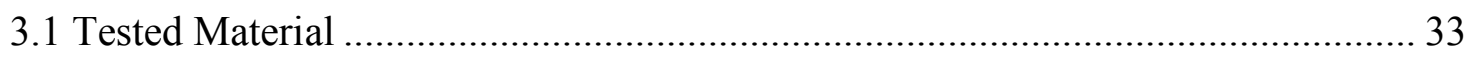

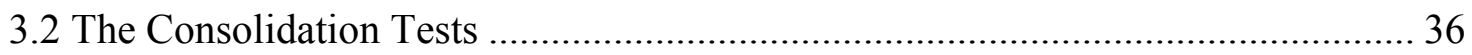

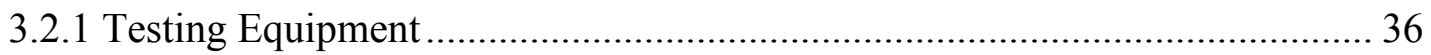

3.2.2 Specimen Preparation ................................................................................ 42

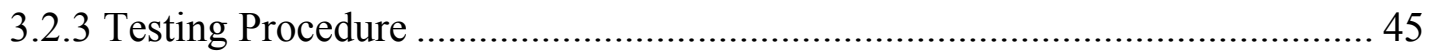

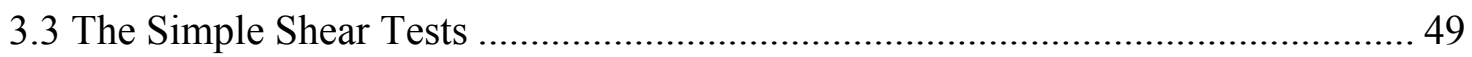

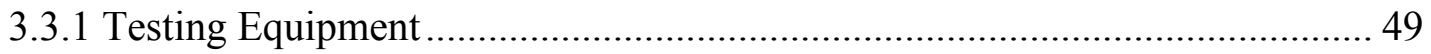

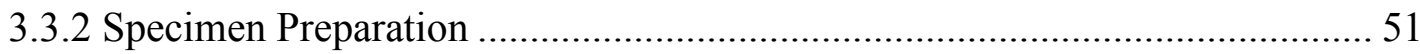

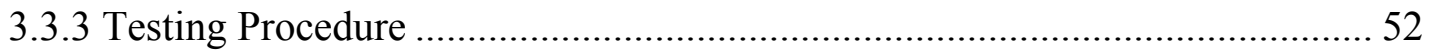

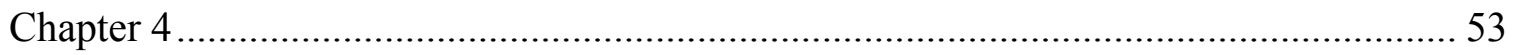

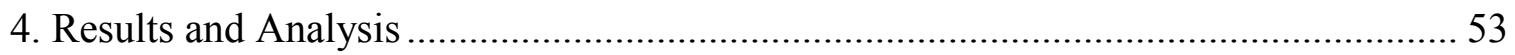

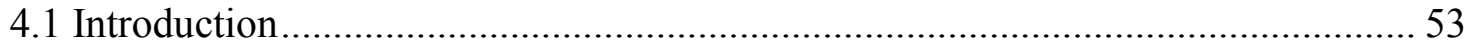

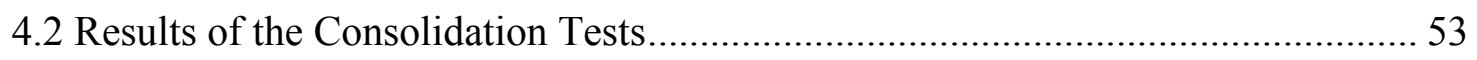

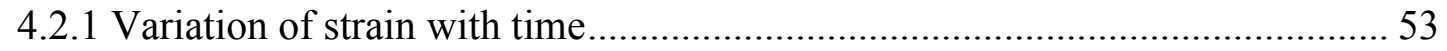

4.2.2 Compressibility of the soil in the vertical and horizontal orientations.............. 61

4.2.3 The coefficient of consolidation in the vertical and horizontal orientations .... 66

4.2.4 The coefficient of permeability in the vertical and horizontal orientations ..... 69

4.2.5 The at-rest lateral earth pressure coefficient in the vertical and horizontal

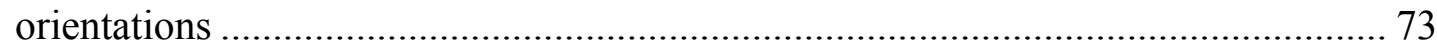


4.2.6 Anisotropy in consolidation tests 82

4.3 Results of the Simple Shear Tests..... 90

4.3.1 The peak and residual shear strengths in the vertical and horizontal orientations .90

4.3.2 The shear strength parameters in the vertical and horizontal orientations 92

Chapter 5 97

5.1 Conclusions. 97

5.2 Recommendations for Future Work. 101

Chapter 6 102

References 102

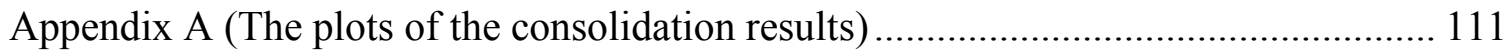

Appendix B (The plots of the simple shear results-Consolidation stage) 148 


\section{LIST OF FIGURES}

Figure 2.1: Extent of sensitive clay in Eastern Canada (Canadian Mortgage and Housing

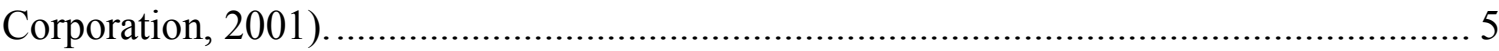

Figure 2.2: The Change of Leda Clay fabric at various steps of anisotropic consolidation (after Quigley and Thompson 1966) ...................................................................... 9

Figure 2.3: Relationship between sensitivity and salt concentration of the pore water in

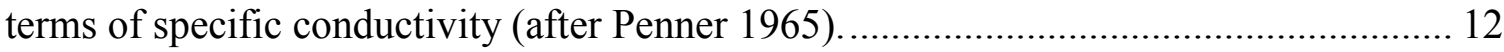

Figure 2.4: Relationship between the Sensitivity and Electrokinetic potentials of undisturbed Champlain Sea clay (after Penner 1965)................................................. 13

Figure 2.5: Typical consolidation curve of the undisturbed Champlain Sea clay (after Nagaraj et al. 1990) 20

Figure 2.6: Change in void ratio vs. Log pressure relationship for different incremental loading tests (after Hamilton and Crawford, 1959).

Figure 2.7: Compression vs. Log Pressure curves for normal and long term incremental loading (after Crawford, 1964).

Figure 2.8: The profiles of the coefficient of the earth pressure at rest, $K o$, for three locations (after Hamouche et al., 1995). 28

Figure 2.9: Typical plots of the effective horizontal stress versus effective vertical stress (after Silvestri and Morgavi, 1982) 28

Figure 3.1: Soil profile of the Canadian Museum of Nature (after Humar and

Sivathayalan, 2003) 34

Figure 3.2: Particle size distribution plot at $5.82 \mathrm{~m}$ and $21.55 \mathrm{~m}$ depths. 36 
Figure 3.3: One-dimensional consolidation apparatus at Carleton University. 39

Figure 3.4: The Oedometer ring and the position of the strain gauges......................... 40

Figure 3.5 (a): The calibration procedure of the horizontal stress measurement............. 41

Figure 3.5 (b): The calibration of the horizontal stress measurement. .......................... 41

Figure 3.6: Wrapped samples from different depths. ............................................. 43

Figure 3.7: Specimen preparation between two platens of soil lathe. ........................... 44

Figure 3.8: Specimen inside the ring, consolidation base with porous stone, water reservoir and loading cap attached to porous stone with ball. .................................... 44

Figure 3.9: The variation of the applied vertical stress with time during consolidation test.

Figure 3.10 (a): Schematic layout of Simple shear apparatus at Carleton University (Ha, 2003).

Figure 3.10 (b): Simple Shear device at Carleton University..................................... 50

Figure 4.1 (a), (b), (c), (d), (e), (f), and (g): Plots of axial strain versus time during loading stage for vertical orientation at a depth of $5.82 \mathrm{~m}$. 56

Figure 4.1 (h), (i), and (j): Plots of axial strain versus time during unloading stage for vertical orientation at a depth of $5.82 \mathrm{~m}$.

Figure $4.1(\mathrm{k}),(\mathrm{l})$, and $(\mathrm{m})$ : Plots of axial strain versus time during reloading stage for vertical orientation at a depth of $5.82 \mathrm{~m}$.

Figure 4.2 (a), (b), (c), (d), (e), (f), and (g): Plots of axial strain versus time during loading stage for horizontal orientation at a depth of $5.82 \mathrm{~m}$. 58

Figure 4.2 (h), (i), and (j): Plots of axial strain versus time during unloading stage for horizontal orientation at a depth of $5.82 \mathrm{~m}$. 59 
Figure $4.2(\mathrm{k}),(1)$, and $(\mathrm{m})$ : Plots of axial strain versus time during reloading stage for horizontal orientation at a depth of $5.82 \mathrm{~m}$.

Figure 4.3: One-dimensional consolidation curves for vertical and horizontal orientations $($ depth $=5.82 \mathrm{~m})$ 64

Figure 4.4: Typical plots of the vertical and horizontal coefficients of consolidation versus the logarithm of effective vertical stress by using Casagrande's method during the loading stage at depth of $5.82 \mathrm{~m}$. 68

Figure 4.5: Typical plots of the vertical and horizontal coefficients of consolidation versus the logarithm of effective vertical stress by using Taylor's method during the loading stage at depth of $5.82 \mathrm{~m}$

Figure 4.6: Typical plots of the vertical and horizontal coefficients of permeability versus the logarithm of effective vertical stress by using Casagrande's method during the loading stage at depth of $5.82 \mathrm{~m}$. 72 Figure 4.7: Typical plots of the vertical and horizontal coefficients of permeability versus the logarithm of effective vertical stress by using Taylor's method during the loading stage at depth of $5.82 \mathrm{~m}$.

Figure 4.8: Typical plots of the effective horizontal stress versus the effective vertical stress during the (a) loading, (b) unloading, and (c) reloading stages for vertical orientation $($ depth $=5.82 \mathrm{~m})$. 77

Figure 4.9: Typical plots of the effective horizontal stress versus the effective vertical stress during the (a) loading, (b) unloading, and (c) reloading stages for horizontal orientation $($ depth $=5.82 \mathrm{~m})$. 78 
Figure 4.10: Typical plots of the at-rest lateral earth pressure coefficient versus the effective vertical stress for vertical and horizontal orientations during the (a) loading, (b) unloading, and $(\mathrm{c})$ reloading stages $($ depth $=5.82 \mathrm{~m})$ 79

Figure 4.11: The variation of the at-rest lateral earth pressure coefficient, for the vertical orientation at depth of $5.82 \mathrm{~m}$, with the overconsolidation ratio (OCR) during the unloading and reloading stages. 80

Figure 4.12: The variation of the at-rest lateral earth pressure coefficient, for the horizontal orientation at depth of $5.82 \mathrm{~m}$, with the overconsolidation ratio (OCR) during the unloading and reloading stages. 80

Figure 4.13: Plot of depths versus the ratio of horizontal to vertical preconsolidation pressure. 83

Figure 4.14: Typical plots of the coefficient of consolidation ratio versus the effective vertical stress during the loading stage at depth of $5.82 \mathrm{~m}$ (by Casagrande's method).... 86 Figure 4.15: Typical plots of the coefficient of consolidation ratio versus the effective vertical stress during the loading stage at depth of $5.82 \mathrm{~m}$ (by Taylor's method). 86 Figure 4.16: Typical plots of the coefficient of permeability ratio versus the effective vertical stress during the loading stage at depth of $5.82 \mathrm{~m}$ (by Casagrande's method).... 88 Figure 4.17: Typical plots of the coefficient of permeability ratio versus the effective vertical stress during the loading stage at depth of $5.82 \mathrm{~m}$ (by Taylor's method). 88 Figure 4.18: Simple shear results at normal stress of $100 \mathrm{kPa}$ for specimens trimmed in the vertical and horizontal orientations. 93 Figure 4.19: Simple shear results at normal stress of $200 \mathrm{kPa}$ for specimens trimmed in the vertical and horizontal orientations. 
Figure 4.20: Simple shear results at normal stress of $400 \mathrm{kPa}$ for specimens trimmed in the vertical and horizontal orientations. 95

Figure 4.21: Plots of peak shear strength versus the effective vertical stress for vertical and horizontal orientations. 96

Figure 4.22: Plots of residual shear strength versus the effective vertical stress for vertical and horizontal orientations. 96 Figure A1: One-dimensional consolidation curves for vertical and horizontal orientations $($ depth $=8.26 \mathrm{~m})$ 112

Figure A2: One-dimensional consolidation curves for vertical and horizontal orientations $($ depth $=11 \mathrm{~m})$ 113

Figure A3: One-dimensional consolidation curves for vertical and horizontal orientations $($ depth $=17.41 \mathrm{~m})$ 114

Figure A4: One-dimensional consolidation curves for vertical and horizontal orientations $($ depth $=21.55 \mathrm{~m})$ 115

Figure A5: Typical plots of the vertical and horizontal coefficients of consolidation versus the logarithm of effective vertical stress by using Casagrande's method during the loading stage at depth of $8.26 \mathrm{~m}$. 116

Figure A6: Typical plots of the vertical and horizontal coefficients of consolidation versus the logarithm of effective vertical stress by using Taylor's method during the loading stage at depth of $8.26 \mathrm{~m}$. 116 Figure A7: Typical plots of the vertical and horizontal coefficients of consolidation versus the logarithm of effective vertical stress by using Casagrande's method during the loading stage at depth of $11 \mathrm{~m}$. 117 
Figure A8: Typical plots of the vertical and horizontal coefficients of consolidation versus the logarithm of effective vertical stress by using Taylor's method during the loading stage at depth of $11 \mathrm{~m}$.

Figure A9: Typical plots of the vertical and horizontal coefficients of consolidation versus the logarithm of effective vertical stress by using Casagrande's method during the loading stage at depth of $17.41 \mathrm{~m}$. 118 Figure A10: Typical plots of the vertical and horizontal coefficients of consolidation versus the logarithm of effective vertical stress by using Taylor's method during the loading stage at depth of $17.41 \mathrm{~m}$.

Figure A11: Typical plots of the vertical and horizontal coefficients of consolidation versus the logarithm of effective vertical stress by using Casagrande's method during the loading stage at depth of $21.55 \mathrm{~m}$. 119

Figure A12: Typical plots of the vertical and horizontal coefficients of consolidation versus the logarithm of effective vertical stress by using Taylor's method during the loading stage at depth of $21.55 \mathrm{~m}$.

Figure A13: Typical plots of the vertical and horizontal coefficients of permeability versus the logarithm of effective vertical stress by using Casagrande's method during the loading stage at depth of $8.26 \mathrm{~m}$. 120 Figure A14: Typical plots of the vertical and horizontal coefficients of permeability versus the logarithm of effective vertical stress by using Taylor's method during the loading stage at depth of $8.26 \mathrm{~m}$. 120 
Figure A15: Typical plots of the vertical and horizontal coefficients of permeability versus the logarithm of effective vertical stress by using Casagrande's method during the loading stage at depth of $11 \mathrm{~m}$.

Figure A16: Typical plots of the vertical and horizontal coefficients of permeability versus the logarithm of effective vertical stress by using Taylor's method during the loading stage at depth of $11 \mathrm{~m}$.

Figure A17: Typical plots of the vertical and horizontal coefficients of permeability versus the logarithm of effective vertical stress by using Casagrande's method during the loading stage at depth of $17.41 \mathrm{~m}$. 122

Figure A18: Typical plots of the vertical and horizontal coefficients of permeability versus the logarithm of effective vertical stress by using Taylor's method during the loading stage at depth of $17.41 \mathrm{~m}$.

Figure A19: Typical plots of the vertical and horizontal coefficients of permeability versus the logarithm of effective vertical stress by using Casagrande's method during the loading stage at depth of $21.55 \mathrm{~m}$

Figure A20: Typical plots of the vertical and horizontal coefficients of permeability versus the logarithm of effective vertical stress by using Taylor's method during the loading stage at depth of $21.55 \mathrm{~m}$. 123 Figure A21: Typical plots of the effective horizontal stress versus the effective vertical stress during the (a) loading, (b) unloading, and (c) reloading stages for vertical orientation $($ depth $=8.26 \mathrm{~m})$ 124 
Figure A22: Typical plots of the effective horizontal stress versus the effective vertical stress during the (a) loading, (b) unloading, and (c) reloading stages for horizontal orientation $($ depth $=8.26 \mathrm{~m})$ 125

Figure A23: Typical plots of the effective horizontal stress versus the effective vertical stress during the (a) loading, and (b) unloading stages for vertical orientation (depth $=11$ $\mathrm{m})$. 126 Figure A24: Typical plots of the effective horizontal stress versus the effective vertical stress during the (a) loading, and (b) unloading stages for horizontal orientation (depth = $11 \mathrm{~m})$. 127

Figure A25: Typical plots of the effective horizontal stress versus the effective vertical stress during the (a) loading, (b) unloading, and (c) reloading stages for vertical orientation $($ depth $=17.41 \mathrm{~m})$. 128

Figure A26: Typical plots of the effective horizontal stress versus the effective vertical stress during the (a) loading, (b) unloading, and (c) reloading stages for horizontal orientation $($ depth $=17.41 \mathrm{~m})$.

Figure A27: Typical plots of the effective horizontal stress versus the effective vertical stress during the (a) loading, (b) unloading, and (c) reloading stages for vertical orientation $($ depth $=21.55 \mathrm{~m})$. 130

Figure A28: Typical plots of the effective horizontal stress versus the effective vertical stress during the (a) loading, (b) unloading, and (c) reloading stages for horizontal orientation $($ depth $=21.55 \mathrm{~m})$.

Figure A29: Typical plots of the effective horizontal stress versus the effective vertical stress during the loading for vertical orientation $($ depth $=21.55 \mathrm{~m})$. 132 
Figure A30: Typical plots of the at-rest lateral earth pressure coefficient versus the effective vertical stress for vertical and horizontal orientations during the (a) loading, (b) unloading, and $(\mathrm{c})$ reloading stages $($ depth $=8.26 \mathrm{~m})$ 133

Figure A31: Typical plots of the at-rest lateral earth pressure coefficient versus the effective vertical stress for vertical and horizontal orientations during the (a) loading, and (b) unloading stages $($ depth $=11 \mathrm{~m})$.

Figure A32: Typical plots of the at-rest lateral earth pressure coefficient versus the effective vertical stress for vertical and horizontal orientations during the (a) loading, (b)

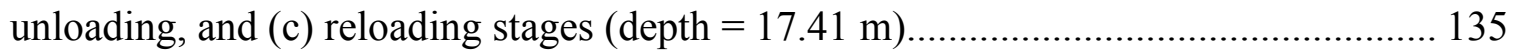
Figure A33: Typical plots of the at-rest lateral earth pressure coefficient versus the effective vertical stress for vertical and horizontal orientations during the (a) loading, (b) unloading, and $(\mathrm{c})$ reloading stages $($ depth $=21.55 \mathrm{~m})$. 136

Figure A34: The variation of the at-rest lateral earth pressure coefficient, for the vertical orientation at depth of $11 \mathrm{~m}$, with the overconsolidation ratio (OCR) during the unloading stage.

Figure A35: The variation of the at-rest lateral earth pressure coefficient, for the horizontal orientation at depth of $11 \mathrm{~m}$, with the overconsolidation ratio (OCR) during the unloading stage.

Figure A36: The variation of the at-rest lateral earth pressure coefficient, for the vertical orientation at depth of $17.41 \mathrm{~m}$, with the overconsolidation ratio (OCR) during the unloading and reloading stages 138 
Figure A37: The variation of the at-rest lateral earth pressure coefficient, for the horizontal orientation at depth of $17.41 \mathrm{~m}$, with the overconsolidation ratio (OCR) during the unloading and reloading stages.... 138

Figure A38: The variation of the at-rest lateral earth pressure coefficient, for the vertical orientation at depth of $21.55 \mathrm{~m}$, with the overconsolidation ratio (OCR) during the unloading and reloading stages

Figure 39: The variation of the at-rest lateral earth pressure coefficient, for the horizontal orientation at depth of $21.55 \mathrm{~m}$, with the overconsolidation ratio (OCR) during the unloading and reloading stages.

Figure A40: Typical plots of the coefficient of consolidation ratio versus the effective vertical stress during the loading stage at depth of $8.26 \mathrm{~m}$ (by Casagrande's method). . 140 Figure A41: Typical plots of the coefficient of consolidation ratio versus the effective vertical stress during the loading stage at depth of $8.26 \mathrm{~m}$ (by Taylor's method). 140 Figure A42: Typical plots of the coefficient of consolidation ratio versus the effective vertical stress during the loading stage at depth of $11 \mathrm{~m}$ (by Casagrande's method).... 141 Figure A43: Typical plots of the coefficient of consolidation ratio versus the effective vertical stress during the loading stage at depth of $11 \mathrm{~m}$ (by Taylor's method). 141 Figure A44: Typical plots of the coefficient of consolidation ratio versus the effective vertical stress during the loading stage at depth of $17.41 \mathrm{~m}$ (by Casagrande's method). 142 Figure A45: Typical plots of the coefficient of consolidation ratio versus the effective vertical stress during the loading stage at depth of $17.41 \mathrm{~m}$ (by Taylor's method)....... 142 Figure A46: Typical plots of the coefficient of consolidation ratio versus the effective vertical stress during the loading stage at depth of $21.55 \mathrm{~m}$ (by Casagrande's method). 143 
Figure A47: Typical plots of the coefficient of consolidation ratio versus the effective vertical stress during the loading stage at depth of $21.55 \mathrm{~m}$ (by Taylor's method)....... 143 Figure A48: Typical plots of the coefficient of permeability ratio versus the effective vertical stress during the loading stage at depth of $8.26 \mathrm{~m}$ (by Casagrande's method). . 144 Figure A49; Typical plots of the coefficient of permeability ratio versus the effective vertical stress during the loading stage at depth of $8.26 \mathrm{~m}$ (by Taylor's method). 144 Figure A50: Typical plots of the coefficient of permeability ratio versus the effective vertical stress during the loading stage at depth of $11 \mathrm{~m}$ (by Casagrande's method).... 145 Figure A51: Typical plots of the coefficient of permeability ratio versus the effective vertical stress during the loading stage at depth of $11 \mathrm{~m}$ (by Taylor's method). Figure A52: Typical plots of the coefficient of permeability ratio versus the effective vertical stress during the loading stage at depth of $17.41 \mathrm{~m}$ (by Casagrande's method). 146 Figure A53: Typical plots of the coefficient of permeability ratio versus the effective vertical stress during the loading stage at depth of $17.41 \mathrm{~m}$ (by Taylor's method). 146 Figure A54: Typical plots of the coefficient of permeability ratio versus the effective vertical stress during the loading stage at depth of $21.55 \mathrm{~m}$ (by Casagrande's method). 147 Figure A55: Typical plots of the coefficient of permeability ratio versus the effective vertical stress during the loading stage at depth of $21.55 \mathrm{~m}$ (by Taylor's method)....... 147 Figure B1: Volumetric strain versus time in the vertical orientation at vertical consolidation of $100 \mathrm{kPa}$. 149 Figure B2: Volumetric strain versus time in the horizontal orientation at vertical consolidation of $100 \mathrm{kPa}$. 149 
Figure B3: Volumetric strain versus time in the vertical orientation at vertical

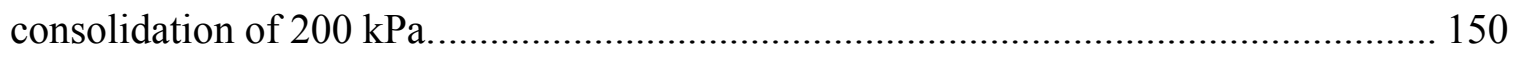

Figure B4: Volumetric strain versus time in the horizontal orientation at vertical

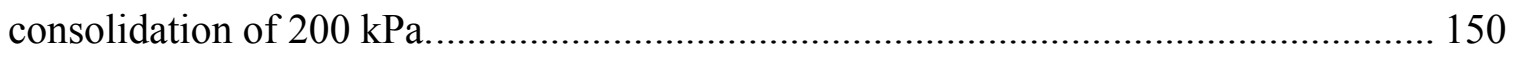

Figure B5: Volumetric strain versus time in the vertical orientation at vertical consolidation of $400 \mathrm{kPa}$ 151

Figure B6: Volumetric strain versus time in the horizontal orientation at vertical consolidation of $400 \mathrm{kPa}$. 151 


\section{LIST OF TABLES}

Table 2.1: General properties of sensitive clays in Eastern Canada from literature review.

Table 2.2: Factors leading to high sensitivity in clayey sediments (after Torrance, 1983

modified from Quigley, 1980). 14

Table 2.3: Different classifications for the range of sensitivity. 16

Table 2.4: Summary of coefficients of consolidation, compressibility, and permeability (after Hamilton and Crawford, 1959). 20

Table 2.5: Summary of Consolidation characteristics (after Javed, 2011).................... 22

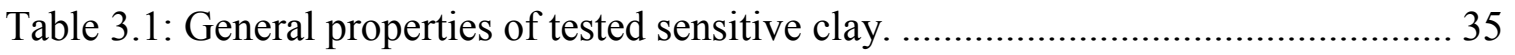

Table 3.2: Load increments for boreholes at depths of 5.82 and $21.55 \mathrm{~m}$...................... 46

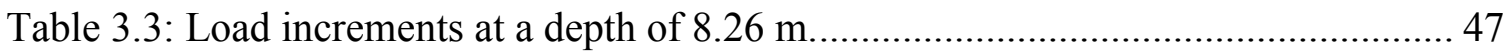

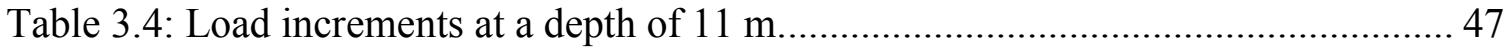

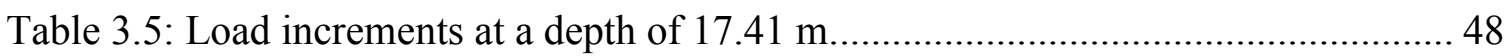

Table 4.1: The amount of strain during different stress history in all tested samples. ..... 60

Table 4.2: Summary of the values of preconsolidation pressure, and compression index

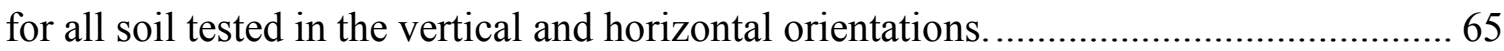

Table 4.3: Summary of the results of the at-rest lateral earth pressure coefficients for

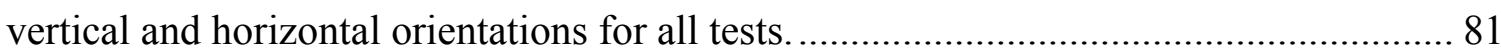

Table 4.4: Summary of the vertical and horizontal preconsolidation pressures with anisotropy degree for all tests.

Table 4.5: Summary of the vertical and horizontal compression indices with anisotropy degree for all tests. 
Table 4.6: Summary of the ratio of the at rest lateral earth pressure coefficient in the horizontal orientation to the at rest lateral earth pressure coefficient in the vertical orientation during the stress history for all tests. 


\section{LIST OF SYMBOLS}

$C_{u} \quad$ The undrained shear strength

$c^{\prime} \quad$ The effective cohesion (drained)

$\phi^{\prime} \quad$ The effective angle of internal friction (drained)

$K_{0} \quad$ The at rest lateral earth pressure coefficient

$\mathrm{W}_{\mathrm{c}} \quad$ The natural water content

LL The Liquid Limit

PL The Plastic Limit

PI The Plasticity Index

LI The Liquidity Index

$\mathrm{S}_{\mathrm{t}} \quad$ Sensitivity

$\lambda_{\mathrm{s}} \quad$ Specific conductivity

$\mathrm{m}_{\mathrm{v}} \quad$ Electrokinetic potential

$\mathrm{S}_{\mathrm{T}} \quad$ Total settlement

CFEM The Canadian Foundation Engineering Manual

$a_{v} \quad$ The coefficient of compressibility

$\mathrm{u} \quad$ The excess pore water pressure

$\mathrm{t} \quad$ Time

z Depth

$\gamma_{\mathrm{w}} \quad$ Unit weight of water

$\mathrm{H}_{\mathrm{dr}} \quad$ The drainage length path 
$\Delta \mathrm{u}(\mathrm{z}, \mathrm{t}) \quad$ Pore water pressure at any depth ( $\mathrm{z})$ and at any time $(\mathrm{t})$

$\Delta \mathbf{u}_{0} \quad$ Initial pore water pressure

$\mathrm{m} \quad$ Positive integer ranges from 0 to $\infty$

$\mathrm{T}_{\mathrm{v}} \quad$ The time factor (dimensionless)

$\mathrm{U}_{\mathrm{z}} \quad$ The degree of consolidation

e Initial void ratio

$\sigma_{\mathrm{t}} \quad$ The transition stress

CFS Canadian Forces Station

$\Delta \mathrm{e} \quad$ Change in void ratio

$\sigma_{\mathrm{v}}^{\prime} \quad$ The effective vertical stress

$\sigma_{\mathrm{h}}^{\prime} \quad$ The effective horizontal stress

e Void ratio

$S \quad$ The shear strength based on effective stress

$\phi_{u} \quad$ The effective cohesion based on total stress

NGI Norwegian Geotechnical Institute

$\sigma_{\mathrm{vc}}^{\prime} \quad$ The preconsolidation pressure in the vertical orientation

$\sigma_{\mathrm{hc}}^{\prime} \quad$ The preconsolidation pressure in the horizontal orientation

$\mathrm{C}_{\mathrm{cv}} \quad$ The compression index in the vertical orientation

$\mathrm{C}_{\mathrm{ch}} \quad$ The compression index in the horizontal orientation

$\mathrm{C}_{\mathrm{v}} \quad$ The vertical coefficient of consolidation

$\mathrm{C}_{\mathrm{h}} \quad$ The horizontal coefficient of consolidation 


\begin{tabular}{|c|c|}
\hline $\mathrm{k}_{\mathrm{v}}$ & The vertical coefficient of permeability \\
\hline $\mathrm{k}_{\mathrm{h}}$ & The horizontal coefficient of permeability \\
\hline $\mathrm{m}_{\mathrm{v}}$ & The coefficient of volume compressibility in the vertical orientation \\
\hline $\mathrm{m}_{\mathrm{h}}$ & The coefficient of volume compressibility in the horizontal orientation \\
\hline $\mathrm{K}_{0 \mathrm{v}}$ & The at-rest lateral earth pressure coefficient in the vertical orientation \\
\hline $\mathrm{K}_{0 \mathrm{~h}}$ & The at-rest lateral earth pressure coefficient in the horizontal orientation \\
\hline OCR & The overconsolidation ratio \\
\hline$\sigma_{\mathrm{hc}}^{\prime} / \sigma_{\mathrm{vc}}^{\prime}$ & The preconsolidation ratio \\
\hline $\mathrm{C}_{\mathrm{c}}=\mathrm{C}_{\mathrm{ch}} / \mathrm{C}_{\mathrm{cv}}$ & The ratio of horizontal to vertical compression index \\
\hline $\mathrm{C}_{\mathrm{h}} / \mathrm{C}_{\mathrm{v}}$ & The ratio of horizontal to vertical coefficient of consolidation \\
\hline $\mathrm{k}_{\mathrm{h}} / \mathrm{k}_{\mathrm{v}}$ & The ratio of horizontal to vertical coefficient of permeability \\
\hline $\mathrm{K}_{0 \mathrm{~h}} / \mathrm{K}_{0 \mathrm{v}}$ & The ratio of horizontal to vertical at rest lateral earth pressure coefficient \\
\hline$S_{\text {upv }}$ & The normalized undrained peak strength in the vertical orientation \\
\hline $\mathrm{S}_{\text {uph }}$ & The normalized undrained peak strength in the horizontal orientation \\
\hline $\mathrm{S}_{\mathrm{urv}}$ & The normalized undrained residual strength in the vertical orientation \\
\hline $\mathrm{S}_{\text {urh }}$ & The normalized undrained residual strength in the horizontal orientation \\
\hline $\mathrm{S}_{\text {uph }} / \mathrm{S}_{\mathrm{upv}}$ & The ratio of normalized horizontal to vertical undrained peak strength \\
\hline $\mathrm{S}_{\text {urr }} / \mathrm{S}_{\text {urv }}$ & The ratio of normalized horizontal to vertical undrained residual strength \\
\hline$\varphi_{\mathrm{pv}}^{\prime}$ & The peak effective internal friction angle in the vertical orientation \\
\hline$\varphi_{\mathrm{ph}}^{\prime}$ & The peak effective internal friction angle in the horizontal orientation \\
\hline $\mathrm{r}^{\mathrm{r}}$ & The residual effective internal friction angle in the vertical direction \\
\hline
\end{tabular}


$\varphi_{\text {rh }}^{\prime}$

$\varphi_{\mathrm{ph}}^{\prime} / \varphi_{\mathrm{pv}}^{\prime}$

$\varphi_{\mathrm{rh}}^{\prime} / \varphi^{\prime}{ }_{\mathrm{rv}}$

$\mathrm{c}_{\mathrm{pv}}^{\prime}$

$\mathrm{c}_{\mathrm{ph}}^{\prime}$

$\varepsilon_{\mathrm{V}}$
The residual effective internal friction angle in the horizontal orientation

The ratio of peak effective horizontal to vertical internal friction angle

The ratio of residual effective horizontal to vertical internal friction angle

The peak effective cohesion in the vertical orientation

The peak effective cohesion in the horizontal orientation

The volumetric strain 


\section{ACKNOWLEDGEMENTS}

First and foremost, all thanks are due to Allah (the Merciful Creator and Cherisher) for providing me health, strength, patience, and determination in order to undertake this thesis. In particular, I would like to sincerely thank my thesis's supervisor, Professor Siva Sivathayalan, for providing consistent guidance, encouragement, and academic support to overcome the difficulties and challenges during all the stages of this thesis. As well, I would like to thank Carleton University and its staff for their support in accessing the necessary resources on and off campus. In particular, I would like to dedicate this thesis to my parents and siblings for their continuous support and encouragement during my study at Carleton University. Finally, I would like to thank my wife, Khawlah, and children, Lateen and Abdulaziz, for their patience and assistance in completing this thesis project. 


\section{Chapter 1}

\section{Introduction}

Sensitive clays are prevalent in several parts of the world such as Canada, the state of Alaska in the United States, Norway, Sweden, and Russia. Regions of Eastern Canada along the St. Lawrence, and most of the City of Ottawa are underlain by a sensitive marine clay, generally called Champlain Sea clay given its origins, and sometimes Leda clay. Sir

William Dawson is considered to be the researcher who named this soil Leda clay (Crawford, 1968). The term sensitive clay is used to describe the significant loss of shear strength when the material is remoulded.

Several catastrophic failures, most in the form of landslides, have occurred in Champlain Sea silt-clay deposits over the years, causing loss of life and property. These landslides often occur with little or no warning, and have mobilized a significant volume of soil in some cases. For example, the April 6, 1908 landslide in Notre-Dame-de-la-Salette killed 34 people. In addition, the 1993 Lemieux landslide (just east of Ottawa on the South Nation River) covered 17-hectares and dumped almost 3-million cubic metres of debris into the river valley. Even though direction independent (isotropic) soil properties are typically used in geotechnical analysis and design, many natural soils exhibit anisotropic stress-strain and compressibility characteristics. A better understanding of the nature and extent of anisotropy is essential for more confident and economical designs. For example, slope stability analysis is generally conducted using one value of shear strength $\left(C_{u}\right.$ if undrained, $c^{\prime}, \phi^{\prime}$ if drained) even though failure occurs in different directions along the failure plane. A better understanding of the anisotropic characteristics of shear strength 
might enable the use of more appropriate shear strength values that vary along the failure surface. Studies conducted to evaluate the anisotropy of Champlain Sea clays have been fairly limited. Leroueil et al. (1990) evaluated direction dependence of permeability, and Mitchell and Wong (1973), Eden and Law (1980), Silvestri and Aubertin (1988), and Silvestri et al. (1989) have conducted limited research on shear strength anisotropy. However, prior research on the shear strength of Leda clays has often been conducted using the triaxial or vane shear devices.

Buildings, and other engineering structures placed on soft soils can experience problems related to settlement and stability. Moreover, the lack of a comprehensive understanding of the factors affecting the compressibility and shear strength in sensitive clays causes serious challenges for geotechnical engineers. Therefore, it is essential to thoroughly investigate the two important characteristics of the sensitive clays: consolidation and shear strength behaviour. A better understanding of these parameters in the Champlain Sea clays will lead to the safe design of structures for the residents of the City of Ottawa, and other regions of Eastern Canada.

\subsection{Objectives of the Research}

The purpose of this research is to provide a better understanding of the nature of anisotropy in Champlain Sea clay, by determining its compressibility characteristics and shear strength under a simple shear loading mode, representing the field loading conditions during an earthquake. An experimental study is undertaken in the laboratory using an advanced (instrumented) oedometer to conduct one-dimensional consolidation tests and an NGI type simple shear device to conduct undrained monotonic simple shear tests on highquality 'undisturbed' clay samples obtained from different depths at a site in Ottawa. 
While several studies have been conducted on the consolidation and shear behaviour of Champlain Sea clays in the past, to the best knowledge of the author, this is the first time consolidation tests on Champlain Sea clays are conducted with lateral stress measurement to enable the calculation of $K_{0}$ and facilitate an evaluation of the change in $K_{0}$ in-situ with depth. Similarly, the attempt to evaluate the strength anisotropy using simple shear tests is novel. After conducting this work, it will be possible to show the degree of anisotropy in this soil by making a comparison between the parameters measured during consolidation and shear tests on samples trimmed in the vertical and horizontal orientations.

The main aim of this thesis is to evaluate the degree of anisotropy of sensitive Champlain Sea clay, in terms of consolidation and shear strength characteristics. Anisotropy in consolidation characteristics is investigated by obtaining the following parameters from the results of a one-dimensional consolidation apparatus: the preconsolidation pressure; the compression index; the coefficients of consolidation and permeability; and the at-rest lateral earth pressure coefficient in both the vertical and horizontal orientations. The shear characteristics anisotropy are investigated by obtaining the following parameters from the results of the undrained monotonic simple shear apparatus: the peak and residual shear strengths, and the peak and residual effective shear strength parameters in both the vertical and horizontal orientations. 


\subsection{Organization of the Thesis}

In addition to this introductory chapter, this thesis consists of four other chapters that are organized as follows:

- A review of the relevant literature is provided in Chapter 2. This chapter includes background information about the general characteristics of sensitive Champlain Sea clays, the consolidation behaviour for this type of soil, the at rest lateral earth pressure coefficient for this soil, and the shear strength of this soil. Finally, the degree of anisotropy for different clayey soils is discussed.

- Chapter 3 describes the experimental setup, the sample preparation, and a description of the material tested. In addition, it presents the results of the index tests conducted on the material (Liquid and Plastic limits and the hydrometer tests). Furthermore, a complete discussion about the one-dimensional consolidation and the simple shear apparatuses are presented together with the procedure for performing the tests in both apparatuses.

- Chapter 4 presents the test results and discussion. Results of the consolidation tests are presented first, followed by the results of the constant volume simple shear tests.

- Chapter 5 includes the conclusions that were deduced from the test results and suggests recommendations for future work. 


\section{Chapter 2}

\section{Literature Review}

\subsection{Champlain Sea Deposits ("Leda clays")}

Sensitive clays are prevalent in several parts of the world such as Canada, the state of Alaska in the United States, Norway, Sweden, Russia, the coastal areas of India and South East Asia. Regions of Eastern Canada along the St. Lawrence, and most of the City of Ottawa are underlain by a sensitive marine clay, generally called Champlain Sea clay or Leda clay. The extent of sensitive clay in Eastern Canada is shown in Figure 2.1. The Champlain Sea existed for almost 4,000 years, from 12,000 years before present to 8,000 years before present (Karrow, 1961). According to Karrow (1961), the formation of sediments in the Champlain Sea resulted principally from three sources: streams, shoreline erosion, and glacial ice.

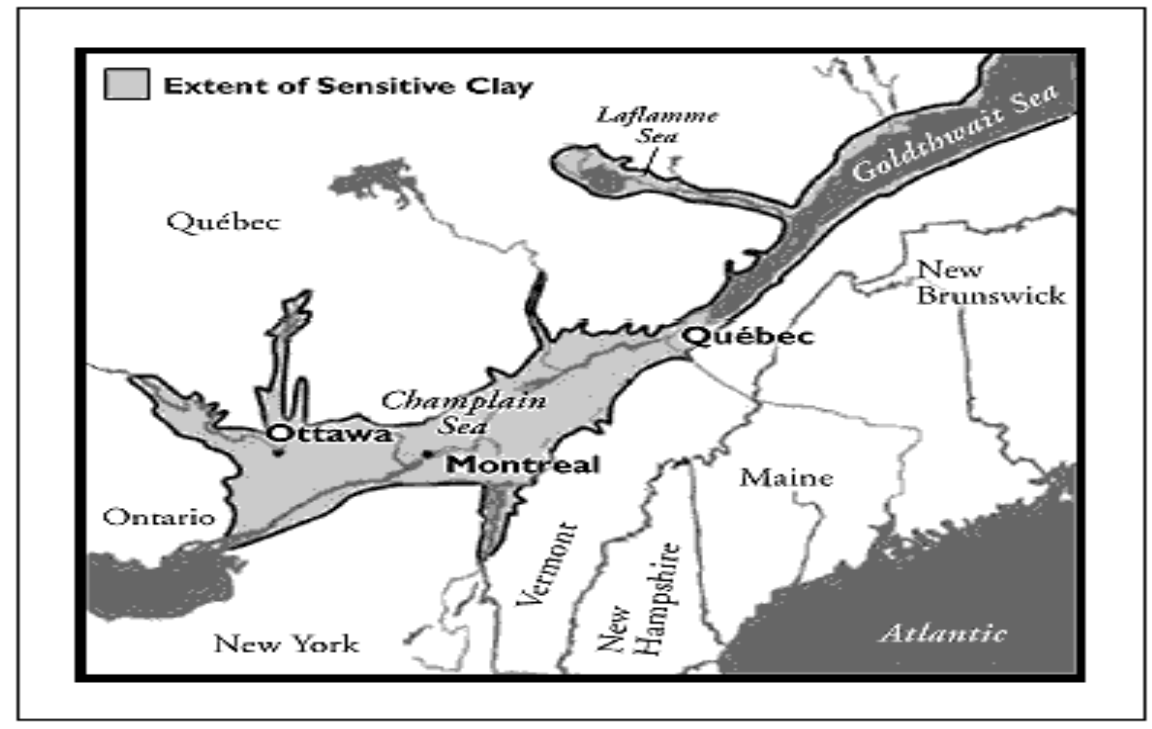

Figure 2.1: Extent of sensitive clay in Eastern Canada (Canadian Mortgage and Housing Corporation, 2001). 


\subsection{Mineral Composition}

Several researchers have used a variety of techniques to study the mineral composition of different samples of sensitive Champlain Sea clay obtained from Eastern Canada. Brydon and Patry (1961) carried out mechanical, chemical, and mineralogical analyses on samples that were obtained from the Valleys of Ottawa and St. Lawrence, and a Rideau Clay soil profile. Their test results indicated that all samples in those sites had similar mineralogy, which include quartz, feldspars, amphiboles, micas, and chlorites in the fractions of clay. X-ray diffraction and differential thermal analyses investigations on samples from undisturbed Toulnustouc clay, from Quebec, indicated that this clay contained large quantities of quartz, feldspar, and amphibole as non-clay minerals; large quantities of illite and chlorite as clay minerals; and small quantities of swelling minerals clay and vermiculite (Quigley, 1968). In a mineralogical study on six samples of Champlain Sea clays obtained from the provinces of Quebec and Ontario, Gillott (1979) indicated that all samples contained the main non-clay minerals quartz, feldspar, green amphibole, and garnet. Also, layer-structure silicates; illite and chlorite were found in large quantities in all samples, which are considered the clay minerals; and swelling clay minerals presented in some samples (Gillott, 1979). Bentley and Smalley (1979) examined the mineralogical composition of Champlain clay samples obtained from Gloucester, Ontario, using X-ray diffraction, X-ray fluorescence spectroscopy, thermogravimetry and selective dissolution analyses. The test results indicated that the Gloucester clay contained large quantities of quartz and feldspars as the main mineral, an amorphous material, illite and chlorite as the clay minerals, and calcite and dolomite as the carbonate minerals (Bentley and Smalley, 1979). X-ray diffraction studies on six samples from La Baie, 
Quebec, showed quartz, feldspar, amphibole, calcite, and illite as the predominant clay minerals (Lessard and Mitchell, 1985).

Quigley and Thompson (1966) divided the structure of soil into two parts: the geometrical arrangement of the soil particles or "fabric"; and the inherent and strength of cementation bonds that hold the soil particles together. The plastic and rigid bonds are responsible about holding the soil particles that form the structure of Champlain Sea clay (Crawford, 1968). Gillott (1979) investigated the fabric of 6 samples of Champlain Sea clays obtained from the provinces of Quebec and Ontario using different techniques such as optical microscopy, and scanning electron microscopy. His test results show that the Champlain Sea clays generally contain card-house or random fabrics; however the fabric orientation of a number of the samples was considered inadequate to draw firm conclusions (Gillott, 1970 \& 1979). Penner and Burn (1978) stated that the open fabric of Champlain Sea clay was created by sedimentation in salt water at different stages of electrolyte concentration. Quigley and Thompson (1966) investigated the fabric (or structure) of undisturbed and remoulded samples of Leda clay from Ottawa by using X-ray diffraction techniques during anisotropic consolidation. First, the specimens were subjected to diverse vertical stresses of up to 64 tons/sq. $\mathrm{ft}$. (6130 $\mathrm{kPa})$, with a load incremental ratio of one kept on the specimen for $24 \mathrm{hr}$. After that, the specimens were removed from the consolidation apparatus and small blocks cut from the specimens were impregnated with a polyethylene glycol for a period of nine days. Next, a smooth horizontal surface was made and finally every specimen was subjected to an X-ray technique to measure the fabric. Figure 2.2 shows the changes in the fabric of Champlain Sea clay at various steps of anisotropic consolidation (after Quigley and Thompson, 1966). Generally, Figure 2.2 
shows that specimens of Champlain Sea clay originally had a card-house fabric, and then the fabric experienced increased fabric parallelism as consolidation stress increments were applied. Their test results indicated that anisotropic consolidation of undisturbed samples generated reorientation of the clay platelets into the plane perpendicular to the vertical consolidation stress. In addition, in the case of undisturbed specimens there was slight or no reorientation of particles for stresses lower than the preconsolidation stress (or pressure). As soon as the preconsolidation stress pressure was exceeded, the structure started to collapse and there was a sudden increase in particle parallelism. Moreover, the test results of Quigley and Thompson (1966) revealed that the remoulded specimens had higher parallelism and lower void ratios at all pressures, and as the void ratio decreases, the particle parallelism increases.

The liquid limit of sensitive clay is usually lower than the natural water content (Eden and Crawford, 1957) and the liquidity index is generally above than unity (Gillott, 1979). According to Mitchell and Klugman (1979), sensitive clay can have a plasticity index ranging from a minimum of 4 to a maximum of 40 . Moreover, the clay fraction $(<2 \mu \mathrm{m})$ in this type of soil ranges from $80 \%$ in the lowlands regions to $30 \%$ at the boundaries (Mitchell and Klugman, 1979). Mitchell and Soga (2005) reported that the activity of sensitive clay is usually lower than 0.5 . Table 2.1 provides the general properties of sensitive clays reported in the literature from different areas in Eastern Canada. 


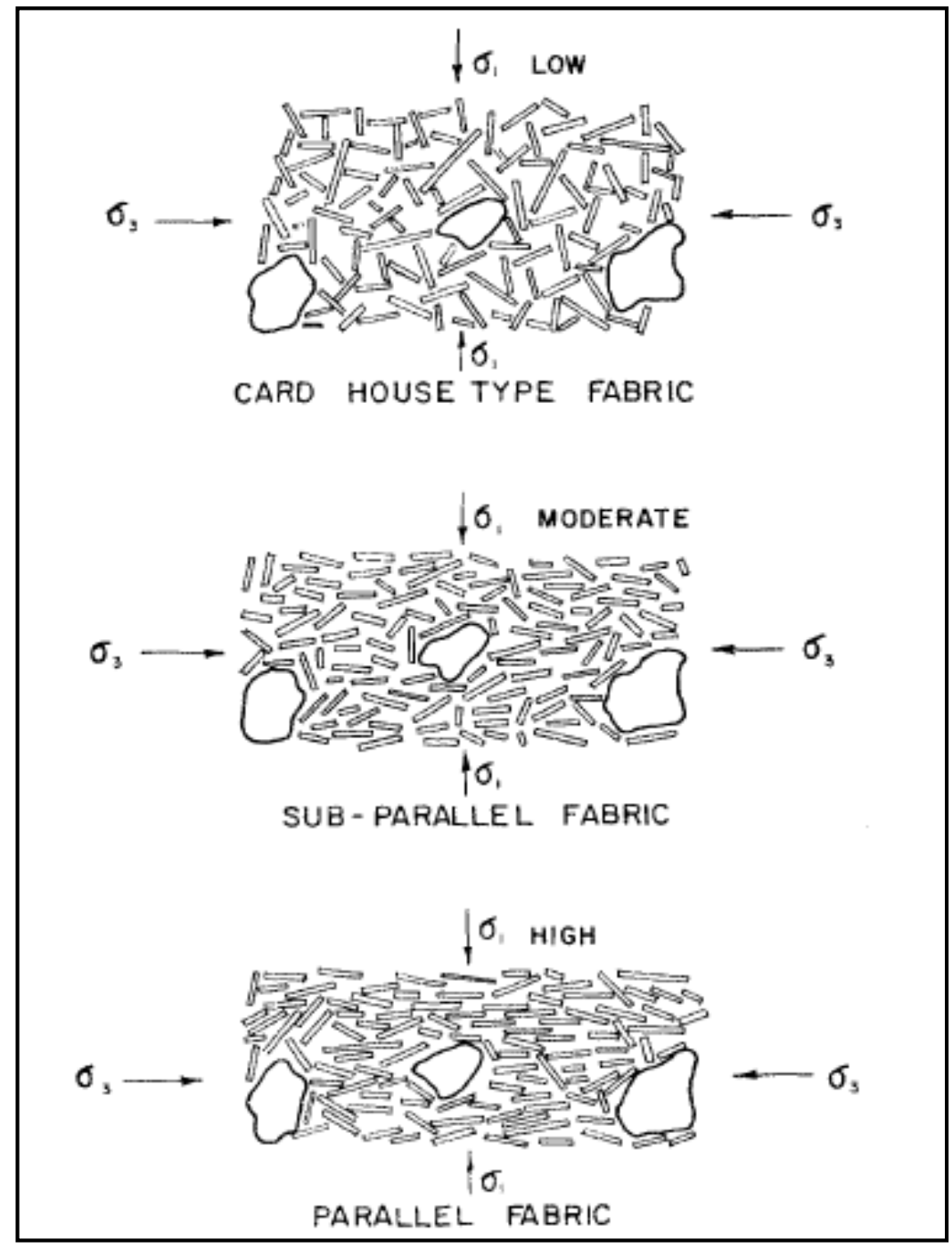

Figure 2.2: The Change of Leda Clay fabric at various steps of anisotropic consolidation (after Quigley and Thompson 1966). 


\begin{tabular}{|c|c|c|c|c|c|c|c|}
\hline Location & Depth (m) & $W_{c}(\%)$ & LL (\%) & PL (\%) & LI & $\begin{array}{c}\text { Clay content } \\
(<2 \mu \mathrm{m})\end{array}$ & Reference \\
\hline \multirow{2}{*}{ Gloucester, Ottawa } & 1.52 & 70 & 60 & 25 & 1.29 & 74 & \multirow{2}{*}{$\begin{array}{l}\text { Bechai } \\
(1974)\end{array}$} \\
\hline & 2.13 & $85-95$ & 73 & 27 & $1.26-1.48$ & 78 & \\
\hline Casselman, Ontario & 1.8 & 91 & 66 & 20 & 1.38 & 55 & $\begin{array}{l}\text { Raymond } \\
\text { et al. } \\
\text { (1979) }\end{array}$ \\
\hline St. Marcel, Quebec & 5.2 & 80 & 60 & 25 & 1.57 & 80 & $\begin{array}{l}\text { Delage } \\
\text { and } \\
\text { Lefebvre } \\
(1984)\end{array}$ \\
\hline Louiseville, Quebec & 9.2 & 72 & 68 & 30 & 1.1 & 80 & \multirow{5}{*}{$\begin{array}{l}\text { Leroueil et } \\
\text { al. (1990) }\end{array}$} \\
\hline \multirow{3}{*}{ Saint-Esprit, Quebec } & 3.4 & 89 & 74 & 26 & 1.3 & 78 & \\
\hline & 5.9 & 78 & 64 & 28 & 1.4 & 65 & \\
\hline & 9.2 & 76 & 50 & 27 & 2.1 & 63 & \\
\hline Saint-Alban, Quebec & 2.5 & 75 & 45 & 25 & 2.5 & 75 & \\
\hline Gloucester, Ottawa & $3.6-3.8$ & 79 & 55 & 23 & 1.75 & 74 & \multirow{5}{*}{$\begin{array}{l}\text { Lefebvre } \\
\text { et al. } \\
\text { (1991) }\end{array}$} \\
\hline St. Marcel, Quebec & $5.0-5.3$ & 87 & 60 & 25 & 1.77 & 80 & \\
\hline Ottawa NRC & $8.6-8.9$ & $75-80$ & 60 & 27 & $1.45-1.61$ & 72 & \\
\hline Varennes & $7.0-7.3$ & 64 & 66 & 25 & 1 & 80 & \\
\hline Ottawa SP & $8.5-8.8$ & 66 & 65 & 28 & 1.03 & 76 & \\
\hline $\begin{array}{l}\text { The Tenth Line } \\
\text { Road, Ottawa }\end{array}$ & $8-12$ & 82 & 66 & 25 & 1.39 & 84 & $\begin{array}{l}\text { Taha } \\
(2010)\end{array}$ \\
\hline
\end{tabular}

Table 2.1: General properties of sensitive clays in Eastern Canada from literature review. 
Generally, the sensitivity of sensitive clay is higher than 20 (Crawford, 1968). In order to investigate the influence of both salt concentrations in pore water (i.e. by measuring the specific conductivities of the pore liquid) and the electrokinetic potential on sensitivity, Penner (1965) conducted tests on 16 samples of Champlain Sea clay from different sites and depths. Generally, the test results indicated that there was no association between the concentration of salt in pore water and the sensitivity of Champlain Sea clay but dependency of sensitivity on salinity has been found in some Norwegian marine soils (Penner, 1963). Figure 2.3 shows a large range of variations in sensitivity at specific conductivities of less than $4 \times 10^{-3} \mathrm{ohm}^{-1} \mathrm{~cm}^{-1}$, but for higher levels the sensitivity stayed low (Penner, 1965\&1963). Due to the flocculating effect, soils with a high salt concentration do not have very high sensitivities. However, the sensitivity might be low or high when the concentration of salt is low. To measure the electrokinetic potential, Penner used the electro-osmosis technique and found that the electrokinetic potential of most samples of Leda clay increased as the sensitivity increased excluding two samples that had low surface areas as shown in Figure 2.4. This relationship between the electrokinetic potential and the sensitivity of Leda clay is in accordance with the inter-particle repulsion theory. 


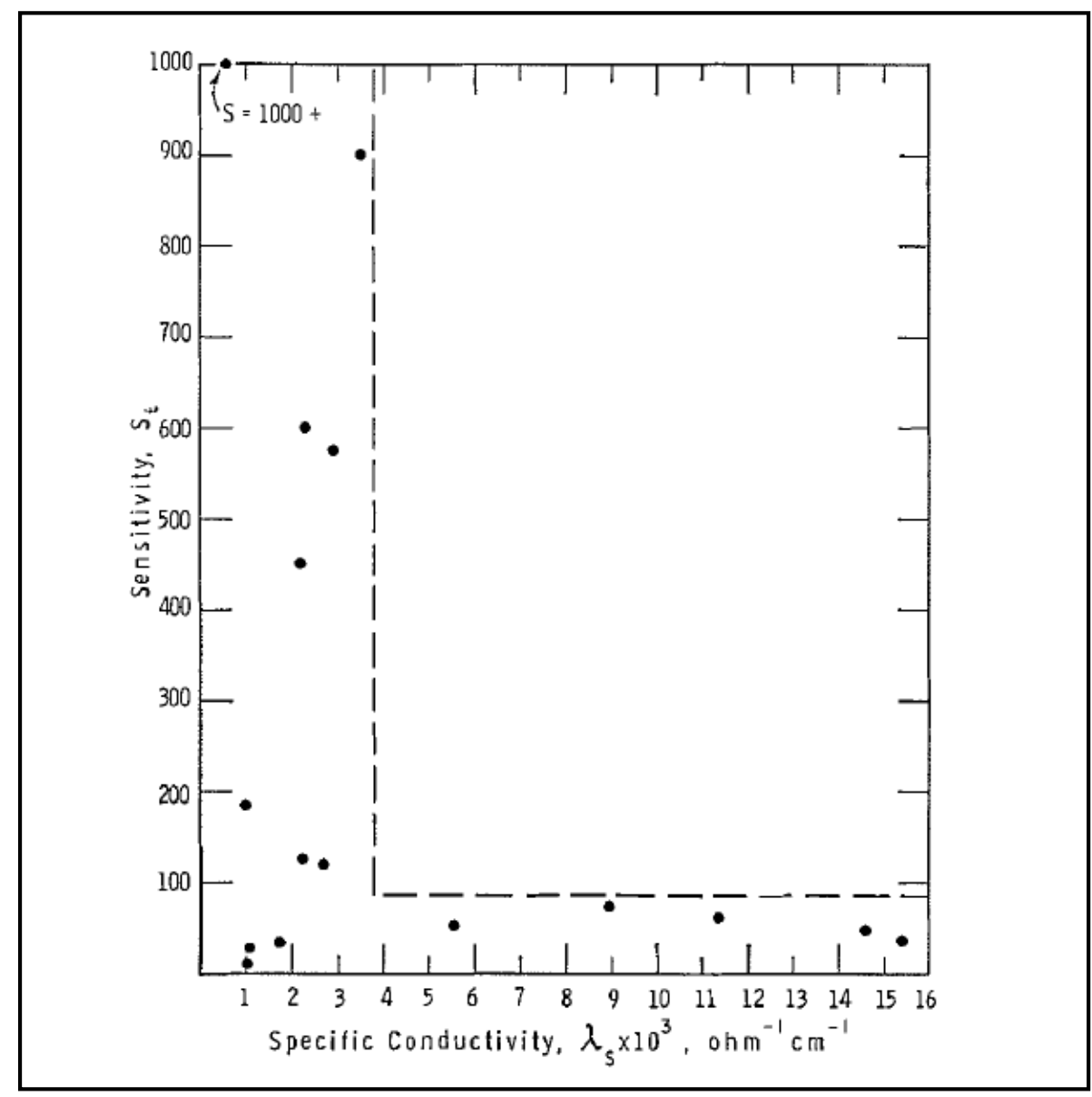

Figure 2.3: Relationship between sensitivity and salt concentration of the pore water in terms of specific conductivity (after Penner 1965). 


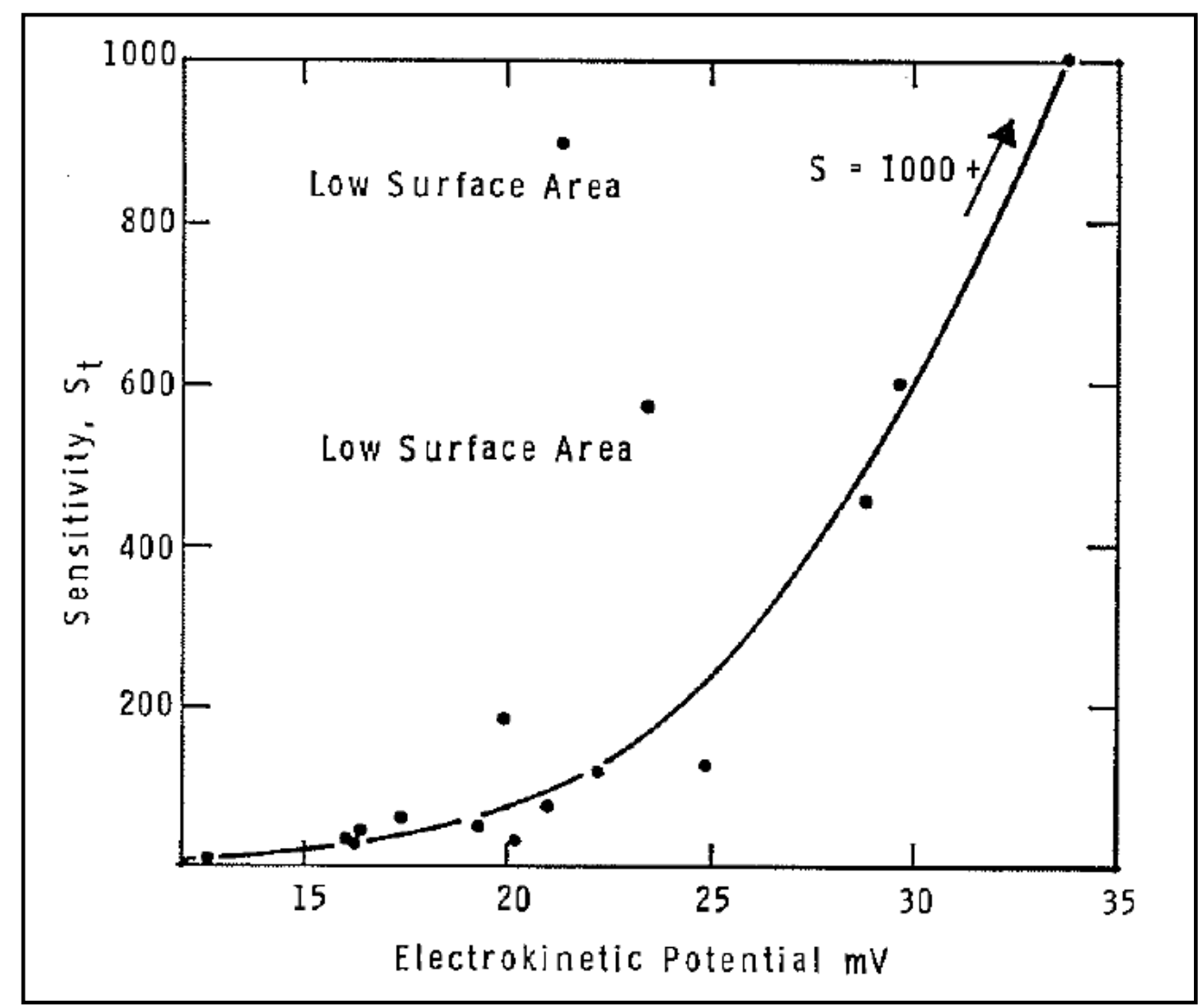

Figure 2.4: Relationship between the Sensitivity and Electrokinetic potentials of undisturbed Champlain Sea clay (after Penner 1965).

From an investigation on two samples, one with high sensitivity and the other one with low sensitivity, Penner (1963) found that both samples had slight differences in low salt concentration. Mitchell and Soga (2005) provide six factors that may generate the development of sensitivity, these include: metastable fabric; cementation; weathering; thixotropic hardening; leaching (ion exchange and change in the monovalent/divalent cation ratio); and formation or addition of dispersing agents. 
Torrance (1983 modified from Quigley, 1980) indicated that depositional and postdepositional factors can generate quick clay behaviour (or a clay with high sensitivity) as shown in Table 2.2.

\begin{tabular}{|c|c|}
\hline \multicolumn{2}{|c|}{ Factors generating a high undisturbed strength } \\
\hline Depositional & Post-depositional \\
\hline $\begin{array}{l}\text { Flocculation } \\
\text { salinity } \\
\text { divalent cation } \\
\text { adsorption } \\
\text { high suspension } \\
\text { concentration }\end{array}$ & $\begin{array}{l}\text { Cementation bonds } \\
\text { rapidly developed } \\
\text { slowly developed } \\
\text { Slow load increase for: } \\
\text { cementation } \\
\text { thixotropic processes }\end{array}$ \\
\hline \multicolumn{2}{|c|}{ Factors generating a low remoulded strength } \\
\hline Depositional & Post-depositional \\
\hline $\begin{array}{l}\text { Material properties } \\
\text { low activity } \\
\text { minerals dominate }\end{array}$ & $\begin{array}{l}\text { Minimal consolidation } \\
\text { Leaching } \\
\text { decrease in } L L>\text { decrease in } W_{c} \\
\text { Dispersants } \\
\text { decrease in } L L>\text { decrease in } W_{c}\end{array}$ \\
\hline
\end{tabular}

Table 2.2: Factors leading to high sensitivity in clayey sediments (after Torrance, 1983 modified from Quigley, 1980).

Classifications for sensitivity have been proposed by numerous researchers. For instance, Table 2.3 includes some of the classifications for sensitivity. The classifications proposed by Skempton and Northey, and Rosenqvist are based on the classical meaning of the sensitivity (Brand and Brenner, 1981). The classification proposed by Soderblom is 
based on the fall-cone results. Rankka et al., (2004) provided a more recent classification which is related to Swedish sensitive clays. The Canadian Foundation Engineering Manual (CFEM 2006) uses a classification similar to that of Skempton and Northey (1952).

\begin{tabular}{|c|c|c|}
\hline $\mathbf{S}_{\mathbf{t}}$ & Condition(state) & Reference \\
\hline 1 & Insensitive & $\overparen{\widetilde{n}}$ \\
\hline $1-2$ & Low sensitivity & 希 \\
\hline $2-4$ & Medium sensitivity & : \\
\hline $4-8$ & Sensitive & $\bar{\sigma}$ \\
\hline $8-16$ & Extra sensitive & : \\
\hline$>16$ & Quick clays & $\frac{\bar{D}}{\frac{D}{\mathscr{V}}}$ \\
\hline 1 & Insensitive & \\
\hline $1-2$ & Slightly sensitive & \\
\hline $2-4$ & Medium sensitive & $\hat{n}$ \\
\hline $4-8$ & Very sensitive &. \\
\hline $8-16$ & Slightly quick & $\overline{\bar{d}}$ \\
\hline $16-32$ & Medium quick & 0 \\
\hline $32-64$ & Very quick & \\
\hline$>64$ & Extra quick & \\
\hline$<20$ & Normal & $\widehat{\partial}$ \\
\hline $20-50$ & Semi-quick & $\Xi$ \\
\hline$>50$ & Quick & 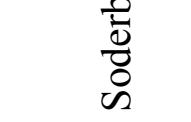 \\
\hline
\end{tabular}




\begin{tabular}{|c|c|c|}
\hline$<8$ & Low sensitive & $\dot{\sigma}$ \\
\hline $8-30$ & Medium sensitive & 高 \\
\hline$>30$ & High sensitive & \\
\hline
\end{tabular}

Table 2.3: Different classifications for the range of sensitivity.

\subsection{The Theory and Process of Consolidation in Clays}

Consolidation can be defined as the reduction in volume associated with increasing effective stress. When a clay layer is subjected to loading due to a structure, consolidation and settlement will occur. Total settlement $\left(\mathrm{S}_{\mathrm{T}}\right)$ consists of three components: the immediate settlement; the primary or consolidation settlement; and the secondary compression. During the first stage, immediate settlement occurs instantaneously after the structural load is applied, and results in no change to the water content. This stage represents elastic compression. The second stage is a time dependant process. During this stage primary or consolidation settlement occurs due to the dissipation of pore water pressure from the soil. The third stage, secondary settlement, begins after the dissipation of all pore water pressure at a constant effective stress. This stage is also a time-dependent process. In 1923, Terzaghi presented the one-dimensional consolidation theory that takes into account the following assumptions: soil is entirely saturated and is homogenous; the pore water and the particles of soil are non-compressible; the flow of pore water and the consolidation of clay are considered to occur only in the vertical direction; Darcy's law is valid; the coefficient of permeability $\left(\mathrm{k}_{\mathrm{v}}\right)$ and the coefficient of compressibility $\left(\mathrm{a}_{\mathrm{v}}\right)$ of the clay stay constant during the consolidation process; the low permeability of the soil is 
completely responsible for the time lag of consolidation; and throughout any period of the consolidation, the total stresses are equal to the effective stresses (Terzaghi, 1943), (Das, 2001), and (Budhu, 2010).

The governing differential equation of Terzaghi's one-dimensional consolidation that is based on the earlier assumptions can be written as the following:

$$
\frac{\partial \mathrm{u}}{\partial \mathrm{t}}=\mathrm{C}_{\mathrm{v}} \frac{\partial^{2} u}{\partial \mathrm{z}^{2}}
$$

Where

$\mathrm{u}=$ the excess pore water pressure

$\mathrm{t}=$ the time

$\mathrm{z}=$ the depth

$C_{v}=$ the coefficient of consolidation $=\frac{k_{v}}{\gamma_{\mathrm{w}} m_{\mathrm{v}}}$

Where

$\mathrm{k}_{\mathrm{v}}=$ the coefficient of permeability

$\gamma_{\mathrm{w}}=$ Unit weight of water

$\mathrm{m}_{\mathrm{v}}=$ the coefficient of volume compressibility

For a homogenous layer of clay with a height of $2 \mathrm{H}_{\mathrm{dr}}$ and with the allowed drainage at the top and the bottom of boundaries, the boundary conditions of the governing differential equation can be written as: 
When $\mathrm{t}=0, \Delta \mathrm{u}=\Delta \mathrm{u}_{0}=\Delta \sigma_{\mathrm{z}}$

At the top boundary, $\mathrm{z}=0, \Delta \mathrm{u}=0$

At the bottom boundary, $\mathrm{z}=2 \mathrm{H}_{\mathrm{dr}}, \Delta \mathrm{u}=0$, where $\mathrm{H}_{\mathrm{dr}}$ is the drainage length path

Based on the preceding (above) boundary conditions, the solution of the governing differential equation of Terzaghi's one-dimensional consolidation can be solved by using the Fourier series as the following:

$$
\Delta \mathrm{u}(\mathrm{z}, \mathrm{t})=\sum_{m=0}^{\infty} \frac{2 \Delta \mathrm{u}_{0}}{M} \sin \left(\frac{M z}{H_{d r}}\right) \mathrm{e}^{\left(-\mathrm{M}^{2} \mathrm{~T}_{\mathrm{v}}\right)}
$$

Where

$\Delta \mathrm{u}(\mathrm{z}, \mathrm{t})=$ pore water pressure at any depth $(\mathrm{z})$ and at any time $(\mathrm{t})$

$\Delta \mathrm{u}_{0}=$ initial pore water pressure

$M=(2 m+1)(\pi / 2)$, where $m$ is a positive integer ranges from 0 to $\infty$

$\mathrm{T}_{\mathrm{V}}=$ the time factor (dimensionless) $=\frac{\mathrm{C}_{\mathrm{V}} \mathrm{t}}{\mathrm{H}^{2} \mathrm{dr}}$

The degree of consolidation, $\mathrm{U}_{\mathrm{z}}$, of a sample at specific depth and time can be written as

$$
\mathrm{U}_{\mathrm{z}}=1-\sum_{m=0}^{\infty} \frac{2}{M} \sin \left(\frac{M z}{H_{d r}}\right) \mathrm{e}^{\left(-\mathrm{M}^{2} \mathrm{~T}_{\mathrm{v}}\right)}
$$

\subsection{Consolidation behaviour in Sensitive Clays}

Jarret (1967) noted that the consolidation process in a sensitive clay goes through three stages. The first stage was called elastic compression and occurs up to the preconsolidation 
pressure region. During elastic compression, the influence of time and settlement are slight. In the second stage, the original bond between particles starts to collapse and subsequently the structure of the flocculated sensitive clay is collapsed. The effects of time are considered large during this stage. During the last stage, the usual appearance of the consolidation process is improved considering that the void ratio is the main principle for settlement and the time effects are decreased. The e- $\log \sigma_{\mathrm{v}}^{\prime}$ laboratory curve of undisturbed sensitive clay passes through three zones, namely non-particulate (up to the preconsolidation pressure), transitional (between the preconsolidation pressure and until the $\sigma_{t}$ where the curve is bent outward), and particulate (beyond $\sigma_{t}$ ) zones as shown in Figure 2.5 (Nagaraj et al., 1990). The first zone has inherent cementation bonds which can provide rigidity to the soil against compression. In the middle zone, the inherent cementation bonds begin to collapse progressively causing a sharp slope. As a result the curve of undisturbed sensitive clay can be close to the disturbed condition. In the last zone, the structure of the soil is fully collapsed and the soil has a disturbed condition.

Hamilton and Crawford (1959) calculated the coefficient of consolidation $\left(\mathrm{C}_{\mathrm{v}}\right)$, the coefficient of compressibility $\left(a_{\mathrm{v}}\right)$, and the coefficient of permeability $\left(\mathrm{k}_{\mathrm{v}}\right)$ of sensitive clay for each load increment using Taylor's method and modified Casagrande's method, as shown in Table 2.4 . 


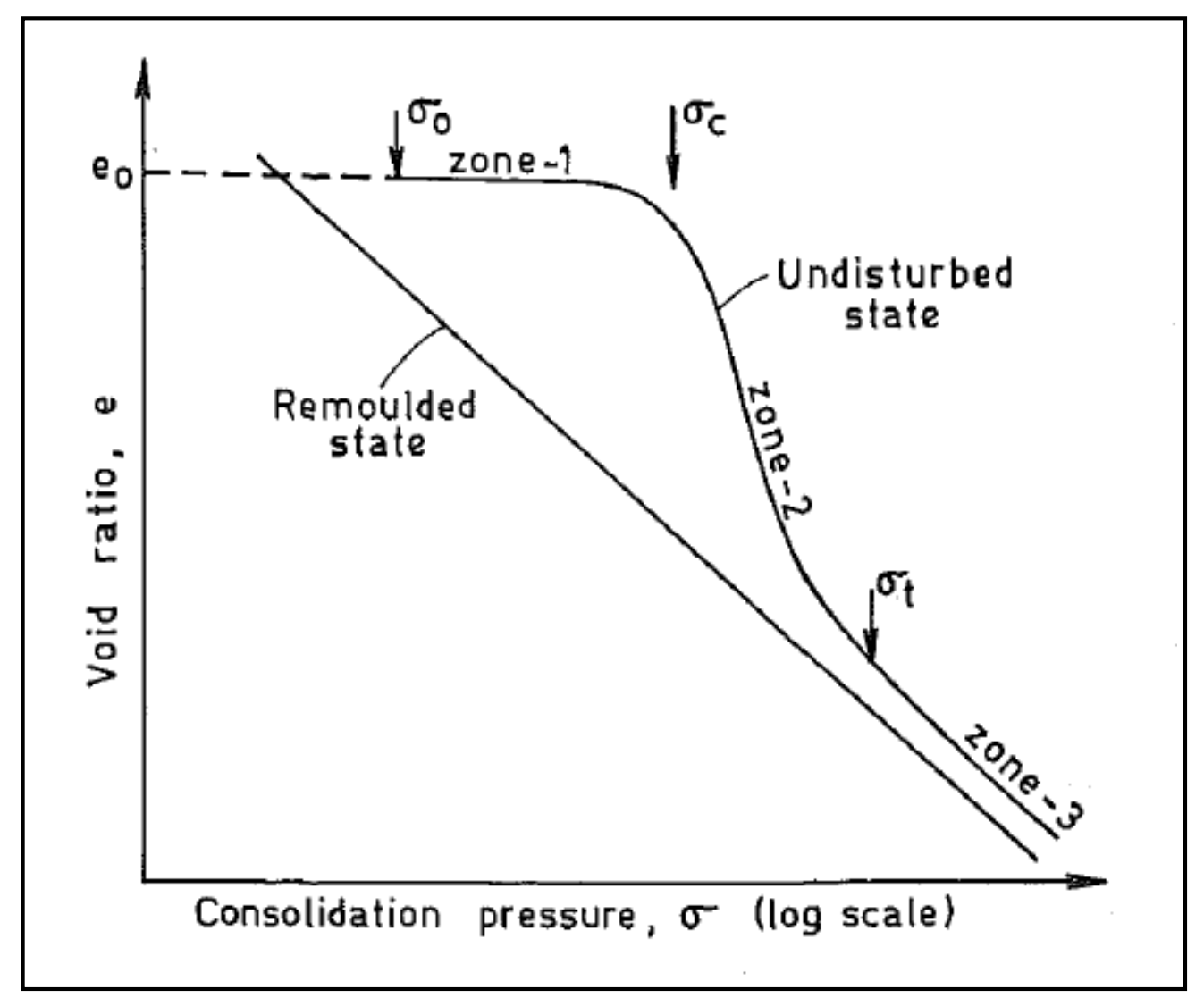

Figure 2.5: Typical consolidation curve of the undisturbed Champlain Sea clay (after Nagaraj et al. 1990).

\begin{tabular}{|c|c|c|c|c|c|c|c|}
\hline $\begin{array}{c}\text { Load } \\
\text { increment } \\
\text { ratio }\end{array}$ & $\begin{array}{c}\text { Increment } \\
\left(\mathbf{k g} / \mathbf{c m}^{2}\right)\end{array}$ & \multicolumn{2}{|c|}{$\mathbf{C}_{\mathbf{v}}\left(\mathrm{cm}^{2} / \mathbf{s e c}\right)$} & \multicolumn{2}{|c|}{$\mathbf{a v}_{\mathbf{v}}\left(\mathrm{cm}^{2} / \mathrm{g}\right)$} & \multicolumn{2}{c|}{$\mathbf{k}_{\mathbf{v}}(\mathrm{cm} / \mathbf{s e c})$} \\
\cline { 3 - 8 } & & $\begin{array}{c}\text { Taylor } \\
\text { Method }\end{array}$ & $\begin{array}{c}\text { Modified } \\
\text { Casagrande } \\
\text { Method }\end{array}$ & $\begin{array}{c}\text { Taylor } \\
\text { Method }\end{array}$ & $\begin{array}{c}\text { Modified } \\
\text { Casagrande } \\
\text { Method }\end{array}$ & $\begin{array}{c}\text { Taylor } \\
\text { Method }\end{array}$ & $\begin{array}{c}\text { Modified } \\
\text { Casagrande } \\
\text { Method }\end{array}$ \\
\hline \multirow{3}{*}{ One } & 1.2 to 2.40 & $1.2 \times 10^{-5}$ & $2.8 \times 10^{-4}$ & $6.7 \times 10^{-5}$ & $4.5 \times 10^{-5}$ & $3.15 \times 10^{-10}$ & $4.9 \times 10^{-9}$ \\
\cline { 2 - 8 } & 2.40 to 4.82 & $9.69 \times 10^{-3}$ & $5.16 \times 10^{-3}$ & $1.08 \times 10^{-4}$ & $1.41 \times 10^{-4}$ & $4.35 \times 10^{-7}$ & $3.10 \times 10^{-7}$ \\
\cline { 2 - 8 } & 4.82 to 9.62 & $2.51 \times 10^{-2}$ & $1.09 \times 10^{-2}$ & $5.11 \times 10^{-5}$ & $3.72 \times 10^{-5}$ & $5.96 \times 10^{-7}$ & $1.96 \times 10^{-7}$ \\
\hline
\end{tabular}

Table 2.4: Summary of coefficients of consolidation, compressibility, and permeability (after Hamilton and Crawford, 1959). 
From three one dimensional consolidation tests on undisturbed sensitive clay that obtained from around the City of Rigaud in Quebec, Silvestri and Morgavi (1982) found that the compression index was almost 2.8 and the recompression index was ranged between 0.03 and 0.09 .

Investigations on sensitive clay at the CFS Gloucester site (close to Ottawa) by Bozozuk (1972), indicated that the value of the compression index ranged between 0.8 and 3.1.

In 2012, Rasmussen carried out 10 consolidation tests on sensitive clay obtained from the Ottawa area. In all tests, he found that the compression index diminished as the preconsolidation stress increased. For stresses below the preconsolidation stress, specifically between 5 and $50 \mathrm{kPa}$, the values of the recompression index ranged between 0.011 and 0.072 and in case of the unloading stage, after the ending of loading stage at $1500 \mathrm{kPa}$, the values of the recompression index ranged between 0.028 and 0.12 . Crawford (1968) attributed the low recompression index in Leda clay to its rigid structure.

Javed (2002) performed consolidation tests, including loading and unloading stages, on a sample of sensitive clay obtained from the City of Rigaud, Quebec. His test results showed that the compression index was 0.00498 , which confirms that this type of clay is fairly compressible and typical of brittle sensitive clay (Holtz and Kovacs, 1981). However, this compression index value is considered small and is therefore questionable. In addition, the calculated coefficient of consolidation, using the logarithm-of-time method proposed by Casagrande and Fadum (1940) ranged between $0.101 \mathrm{~mm}^{2} / \mathrm{sec}$ (at $277.3 \mathrm{kPa}$ loading stage) and $1.509 \mathrm{~mm}^{2} / \mathrm{sec}$ (at $138.7 \mathrm{kPa}$ unloading stage). 
Taha (2010) tested undisturbed sensitive clay that was obtained from the city of Ottawa and found that the compression index was about 2.44 on average.

In 2011 Javed conducted consolidation tests on samples of sensitive clays obtained from four different sites in the City of Riguad, Quebec in order to calculate the preconsolidation stress, the compression index, and the coefficient of consolidation. The summary of his test results are provided in Table 2.5.

\begin{tabular}{|c|c|c|c|}
\hline Sample Site & $\begin{array}{c}\text { Preconsolidation } \\
\text { Stress (kPa) }\end{array}$ & $\begin{array}{c}\text { Compression } \\
\text { Index }\end{array}$ & $\begin{array}{c}\text { Coefficient of } \\
\text { Consolidation } \\
\text { (cm } / \mathbf{s e c )}\end{array}$ \\
\hline Petite-Patrie \& Chambly & 323 to 64 & 0.541 to 0.33 & 0.068 to 0.015 \\
\hline Grande Balene \& St Nicolas & 473 to 56 & 0.52 to 0.144 & 0.098 to 0.019 \\
\hline St Huges \& Terrebonne & 298 to 117 & 0.5 to 0.273 & 0.07 to 0.04 \\
\hline Mont. St Hilarie & 279 to 127 & 0.561 to 0.28 & 0.08 to 0.013 \\
\hline
\end{tabular}

Table 2.5: Summary of Consolidation characteristics (after Javed, 2011).

There are several factors that can influence the results of consolidation tests on sensitive clays such as sample disturbance, content of gas in specimen, type of the test technique that is used, load increment ratio, load increment duration, etc. The ratio of pressure increment to the previous pressure is known as the load increment ratio. Hamilton and Crawford (1959) investigated the influence of load increment ratio on the consolidation of sensitive clay by using the different load increment ratios of $1,1 / 2,1 / 3$, and $1 / 10$. They 
found that the load increment ratio did not influence the consolidation curve, as shown on Figure 2.6. However, small load increment ratios are a more accurate interpretation of probable preconsolidation pressure than large load increment ratios. Due to the difficulty of finding the point of $100 \%$ primary consolidation, either by using the square root fitting method or the log time fitting method in case of small load increments, Hamilton and Crawford (1959) proposed a modification of the log time fitting method (Casagrande's fitting method) in that the primary consolidation completed at rate of 0.0008 in. per hr per in. of specimen thickness.

Crawford (1964) loaded undisturbed specimens of sensitive clay for different durations, including daily increments, weekly increments, and increments at the end of primary consolidation. He found that load duration significantly influences the consolidation curves and therefore the values of the preconsolidation pressure (Figure 2.7).

From test results from two undisturbed specimens of sensitive clay, that had similar load increment ratio of 0.5 but had different loading durations of $24 \mathrm{hr}$ and $1 / 2 \mathrm{hr}$, Bechi (1974) found that the smaller duration test led to a larger preconsolidation pressure value. 


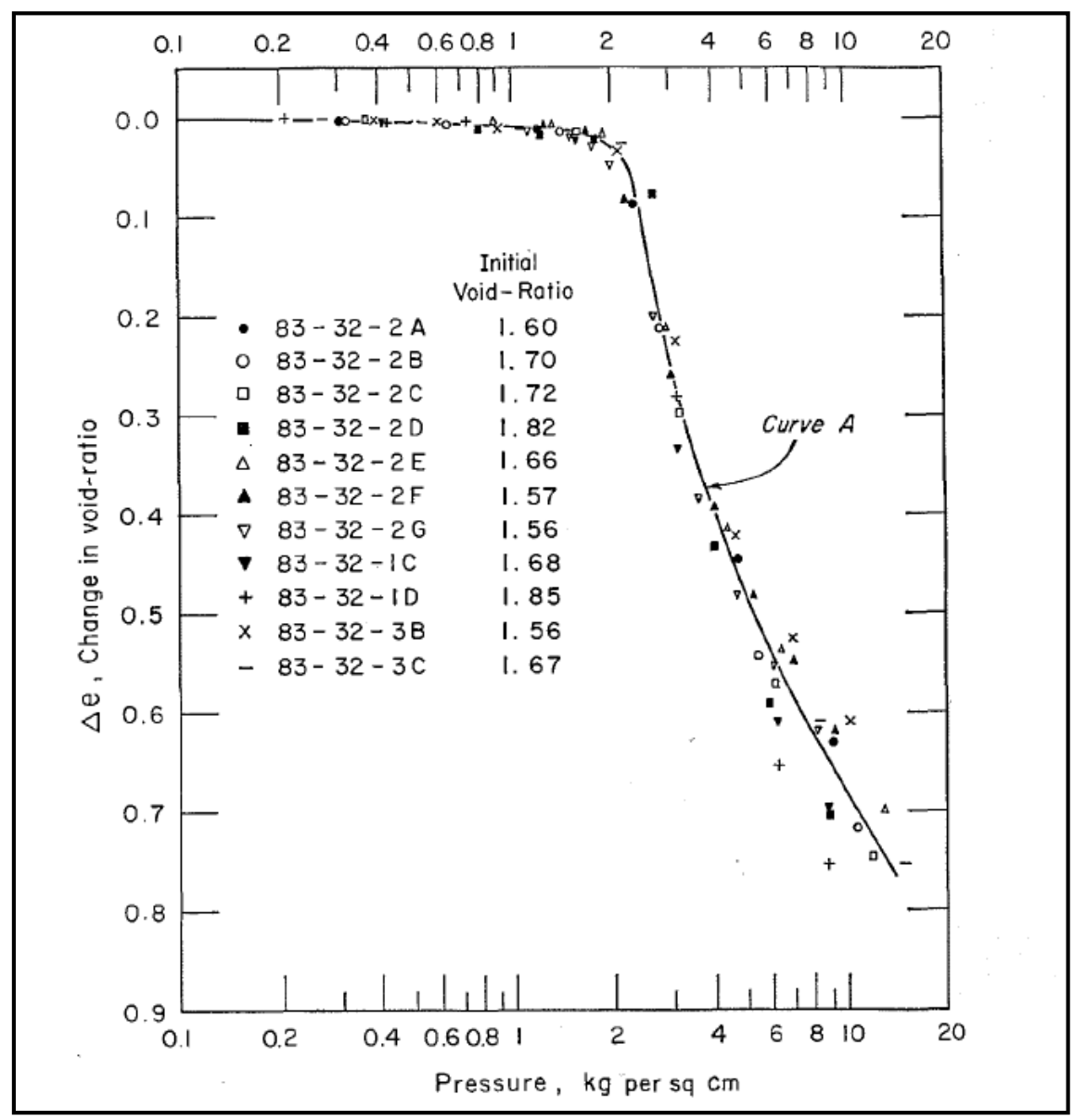

Figure 2.6: Change in void ratio vs. Log pressure relationship for different incremental loading tests (after Hamilton and Crawford, 1959). 


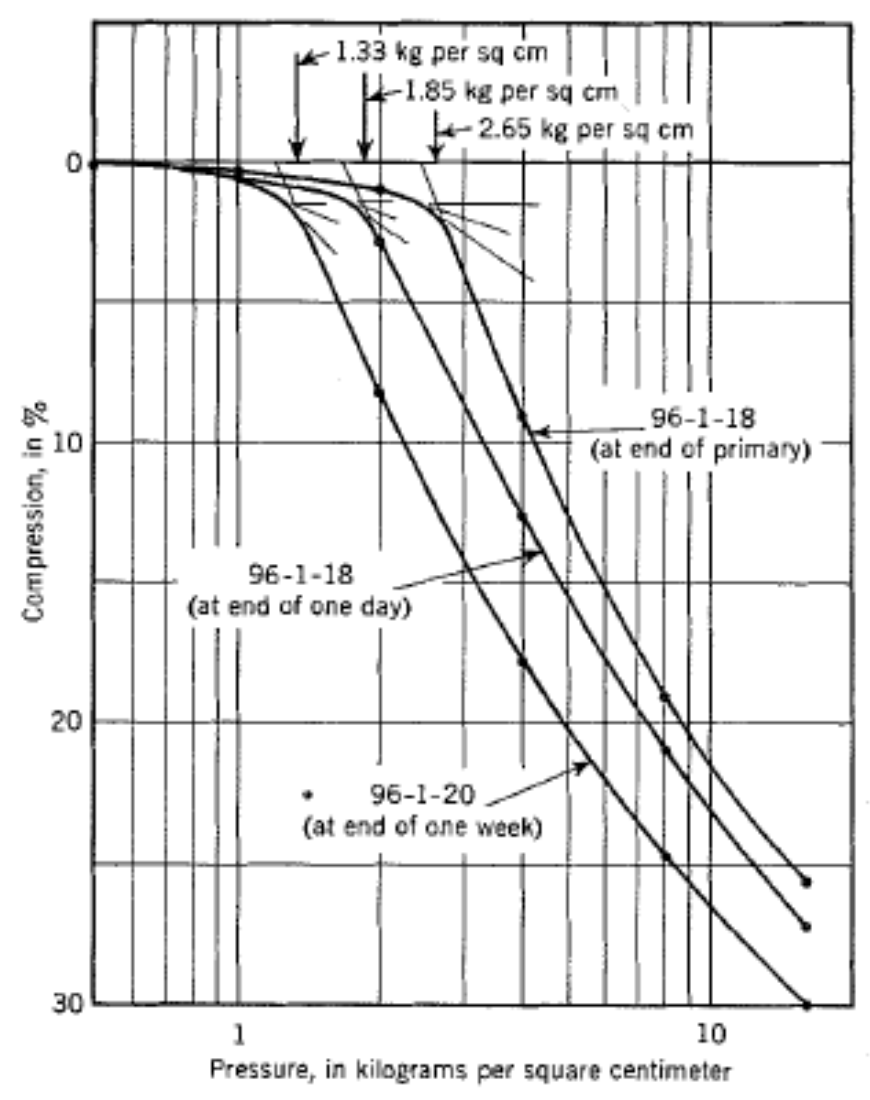

Figure 2.7: Compression vs. Log Pressure curves for normal and long term incremental loading (after Crawford, 1964).

\subsection{At-Rest Lateral Earth Pressure Coefficient of Sensitive Clays}

The ratio of the horizontal effective stress to the vertical effective stress, under zero lateral strain, is termed the coefficient of the earth pressure at rest, $K_{o}=\sigma_{h}^{\prime} / \sigma_{v}^{\prime}$. The coefficient of earth pressure at rest is quite important in the design and analysis of numerous geotechnical problems such as earth retaining structures, piles and other deep foundations. Thus, the use of $K_{o}$ is quite widespread among geotechnical engineers, who often use Jaky's (1944) equation $\left(K_{0} \approx 1-\sin \phi\right)$. However, only limited attempts have been made over many years to accurately determine $K_{o}$ in different soils. Liu and Evett 
(2004) pointed out that the coefficient of the earth pressure at rest, $K_{o}$, can be influenced by factors such as the plasticity index, and the stress history of the soil, in addition to the internal friction angle. Chi-in (1958) found that the coefficient of the earth pressure at rest, $K_{o}$, for cohesive soils relied on the following factors: the natural water content, the loading, and the consolidation status. Three methods are available to determine the coefficient of the earth pressure at rest, $K_{o}$ : the in situ methods (such as Self-boring Pressuremeter, Total Pressure Cells, Hydraulic Fracturing, Dilatometers, $K_{o}$ Stepped Blade); the laboratory methods (such as Odometer and Triaxial devices); and the correlation methods that are based on the results of the in situ and laboratory tests (such as Jaky's equation, 1944, and Brooker and Ireland's equation, 1965).

Several studies have been conducted to measure the coefficient of the earth pressure at rest, $K_{o}$, of sensitive clays in situ. For example, Hamouche et al. in 1995 used three insitu apparatuses (the Cambridge self-boring pressuremeter, the hydraulic fracturing, and the dilatometer) to determine the coefficient of the earth pressure at rest, $K_{o}$, of three locations in the province of Quebec (Berthierville, Louiseville, and Mascouche). Their test results of the coefficient of the earth pressure at rest, $K_{o}$, of the three locations are shown in Figure 2.8. They found that the coefficient of the earth pressure at rest, $K_{o}$, the Berthierville location was about 0.64 at depths between 3.3 and $4.5 \mathrm{~m}$; at the Louiseville location it ranged from 1.2 to 1.7 at depths between 3 and $14 \mathrm{~m}$; and at the Mascouche location it ranged from 3.17 to 3.3 at depths between 4.5 and $7.7 \mathrm{~m}$ by using the Cambridge self-boring pressuremeter and ranged from 2.2 to 3.5 at similar depths by using the hydraulic fracturing. By using a hydraulic fracture technique, Bozozuk (1974) found that 
the coefficient of the earth pressure at rest, $K_{o}$, of sensitive clay at CFS Gloucester, close to Ottawa area was approximately an average of 1 .

Silvestri and Morgavi (1982) carried out two one-dimensional consolidation tests on block samples of undisturbed sensitive clay that were obtained at depths ranging between 3.7 and $4.5 \mathrm{~m}$, from a region close to the Rigaud City, Quebec, in order to determine the coefficient of lateral earth pressure at rest, $K_{o}$. They found that $K_{o}$ had different values when it was passed through the three different phases of the consolidation tests, as shown in Figure 2.9. Through the first phase, which is represented by lower vertical stresses than the preconsolidation pressure, $K_{o}$ was almost 0.29 . Through the second phase, which is represented by the sharp curve in the plot of e- $\log \sigma_{\mathrm{v}}^{\prime}, K_{o}$ was increased up to 0.96 . Through the last phase, which represents the normally consolidation condition, $K_{o}$ was decreased to 0.54. In order to investigate the coefficient of the earth pressure at rest, $K_{o}$, in a triaxial cell, Bozozuk (1972) tested undisturbed specimens of sensitive clay that were obtained at the CFS Gloucester, close to the Ottawa area. He found that the value of $K_{o}$ was about 0.5 , under keeping the ratio of principal stress at 0.5 during the consolidation stage. 


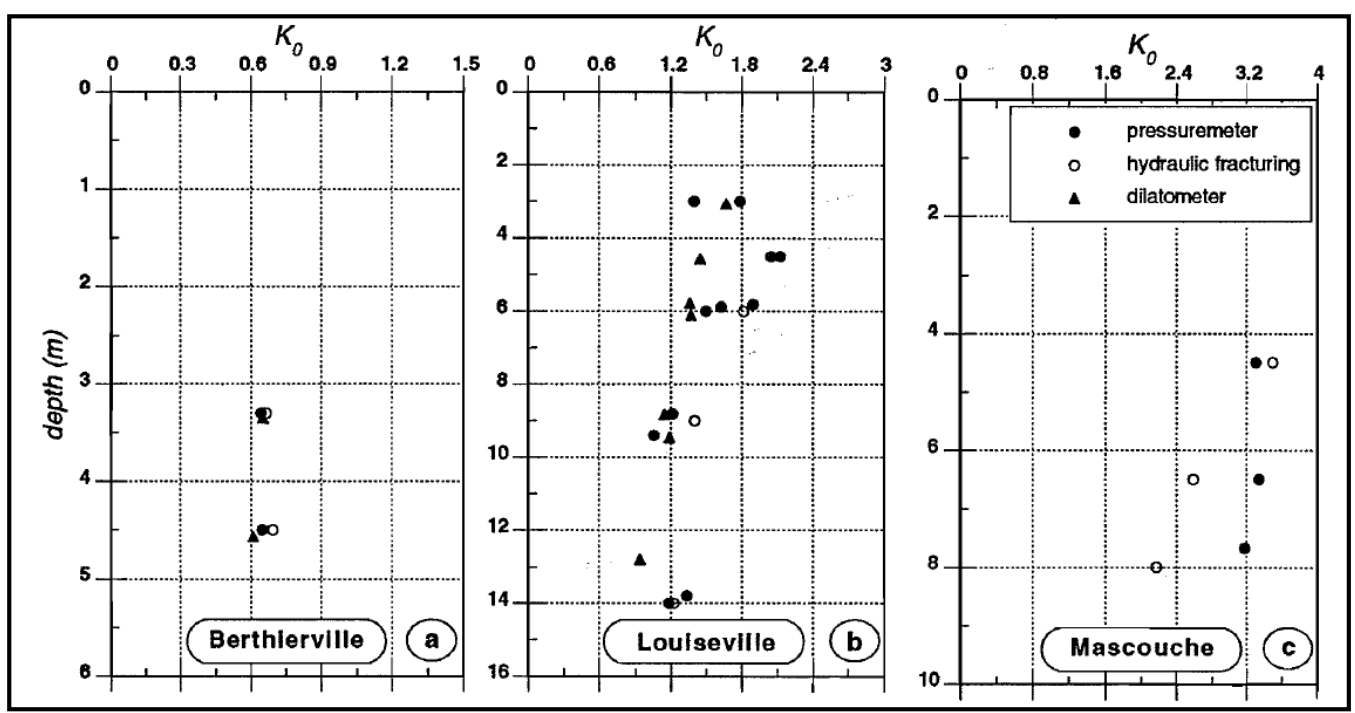

Figure 2.8: The profiles of the coefficient of the earth pressure at rest, $K_{o}$, for three locations (after Hamouche et al., 1995).

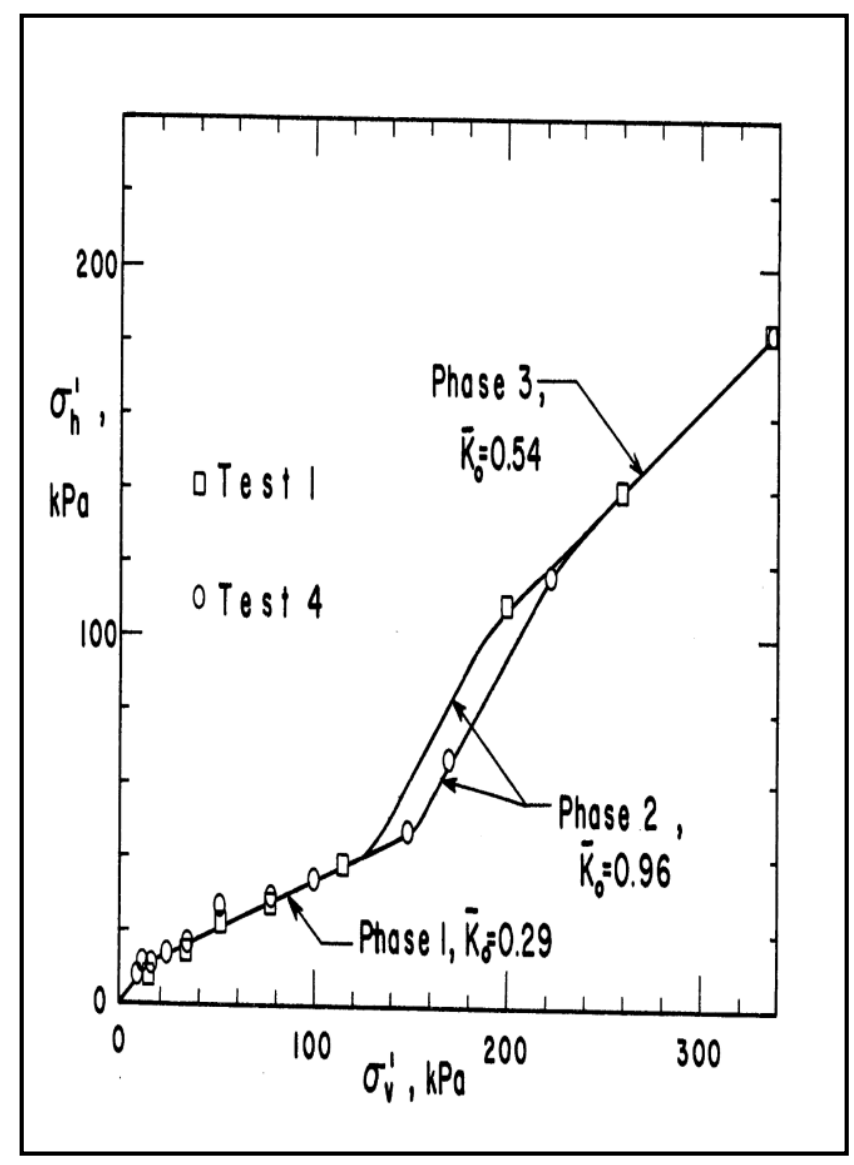

Figure 2.9: Typical plots of the effective horizontal stress versus effective vertical stress (after Silvestri and Morgavi, 1982). 


\subsection{Shear strength of Sensitive Clays}

Shear strength of soils is one of the most critical design parameters used in geotechnical engineering. Typically, shear strength is expressed in terms of the cohesion and the angle of internal friction of a soil using the Mohr-coulomb failure criterion, $S=$ $c^{\prime}+\sigma^{\prime} \tan \phi^{\prime}$. Even though the effective stress formulation is the most universal approach to calculating the shear strength of soils, total stress analysis based $C_{u}$ and $\phi_{u}$ have also been used in the literature to specify the shear strength. Shear strength is significant in several geotechnical engineering conditions such as the stability of slope analysis, and the design of foundations. According to Brand and Brenner (1981), four factors that can control the measured undrained shear strength of a soft clay, including the applied loading rate; the test and device type; the specimen dimensions; and the planes direction of the maximum shear stress. In addition, Kenney (1968) stated that the undrained shear strength of clay relies on two factors, including the moisture content and the history of consolidation. Three undrained simple shear tests were performed by Yong and Tang (1983) on sensitive clay specimens, that were obtained from a location near the Yamaska river, St. Louis de Bonsecours, Quebec, with a normal stress of $74.6 \mathrm{kPa}$ in the consolidation stage for all three tests, under average strain rate for these specimens varied between 2.2 and $2.6 \% / \mathrm{min}$. Their test results indicated that the peak strength failure ranged between 4.5 and 6.2\%. Lefebvre and Pfendler (1996) carried out three undrained monotonic direct simple shear tests at a constant rate of strain of $2.1 \% /$ hour, under a normal stresses of $37.8,42.3$, and $45 \mathrm{kPa}$ in the consolidation stage, on specimens of sensitive clay that were obtained at the St. Alban location, Quebec City. They found that the peak strength failure almost happened at a strain of $2.55 \%$. 
Rasmussen (2012) performed eight monotonic simple shear tests with a strain rate of $5 \% /$ hour on undisturbed sensitive clay, which were obtained from the Ottawa area, and found that the failure at the peak strength was realised at strain levels varying from 2 to $4 \%$.

\subsection{Anisotropy in Clays}

The term anisotropy is used to express the differences in soil properties in different directions. Generally, the variations in soil properties in the vertical and horizontal directions are used as an indication of the degree of anisotropy. Soil properties such as permeability, consolidation, and shear strength are known to show anisotropic characteristics.

Seah and Koslanant (2003) used the constant rate of strain device to study the behaviour of the anisotropic consolidation of sensitive Bangkok clay. Specifically the study was concentrated on the comparison between the horizontal and vertical orientations of the coefficients of consolidation and the coefficients permeability. They found that this type of clay has higher coefficients of consolidation and coefficients of permeability in the horizontal than the vertical orientations. In addition, both the ratios of the coefficients of consolidation and the coefficients of permeability in the horizontal to the vertical orientations ranged from almost 1.1 to 1.3 at a stress lower than the preconsolidation pressure and reached almost 2.8 at stress of eight times the preconsolidation pressure.

In 2008, Arulrajah and Bo investigated in the laboratory the permeability anisotropy

of Singapore Marine Clay and found the ratio of horizontal to vertical permeability coefficient to be about 1.5 . 
Leroueil et al. (1990) found, from the examination of the permeability anisotropy of five soft marine clays that the ratios of horizontal to vertical permeability coefficient of nearly 1.10 to 1.55 .

Eden and Law (1980) investigated the undrained shear strength anisotropy of Leda clay at the South Gloucester site in the Ottawa area by using three different techniques: the triaxial compression tests on specimens trimmed at various angles; the triaxial compression and extension tests on vertical specimens; and the triaxial-vane device. Their test results indicated that the triaxial compression and extension tests on vertical specimens provided the lowest anisotropy and the triaxial compression tests on specimens trimmed at various angles provided the highest anisotropy among the three techniques. In addition, for the first technique, the undrained strength ratios were ranged between 0.78 and 1 ; for the second technique, the average undrained strength of extension to compression was about 0.57 ; and for the last technique, the ratio of horizontal to vertical undrained shear strength was between of 0.64 and 0.71 .

Yimsiri and Soga (2011) used a triaxial testing device, which can measure the local strain and elastic wave velocity, to investigate the cross-anisotropic elastic parameters of London Clay and Gault Clay. For London Clay, they found that the ratio of horizontal to vertical Young's modulus of 2.18 and the ratio of horizontal to vertical shear modulus of 1.20 , however, for Gault Clay, they found that the ratio of horizontal to vertical Young's modulus of 2.32 and the ratio of horizontal to vertical shear modulus of 1.68 .

Silvestri and Aubertin (1988) conducted field vane tests in order to investigate the undrained shear strength anisotropy behaviour of Canadian sensitive clay. Their tests 
results showed that the horizontal undrained shear strength was higher than the vertical undrained shear strength, specifically the ratio of horizontal undrained shear strength to vertical undrained shear strength ranged from 1.14 to 1.41 . 


\section{Chapter 3}

\section{Experimental Work}

This chapter presents details of the tested material and the laboratory test equipment used in this research. An instrumented Oedometer that enables the measurement of horizontal and vertical stresses, vertical compression, and pore water pressure at the base was used to conduct the consolidation tests, and an NGI type simple shear apparatus was used to run the shear tests.

\subsection{Tested Material}

One-dimensional consolidation and Simple Shear tests were performed on high quality 'undisturbed' samples of sensitive Champlain Sea clay obtained from depths ranging from 5.82 to $21.55 \mathrm{~m}$, from a site located close to the Canadian Museum of Nature in downtown Ottawa. The soil profile in this neighbourhood (the Canadian Museum of Nature) consists of four distinct layers followed by hard rock at a depth of about $36 \sim 40$ $\mathrm{m}$ as shown in Figure 3.1 (Humar and Sivathayalan, 2003). This building is known as the Victoria Memorial Museum Building, and is often referred to as such in the literature.

The general characteristics of the clay samples were determined using liquid and plastic limit (Atterberg limit) tests, and particle size analysis. The liquid and plastic limit tests were carried out on each sample as per the ASTM D4318 (2010) specifications. The liquid limit was determined by using the Casagrande device. The plastic limit is considered the water content at which the soil will thread at a diameter of $3 \mathrm{~mm}$ when it is subjected to rolling. In order to find fraction of clay of less than $0.002 \mathrm{~mm}$, the hydrometer analysis method was used based on the procedure that is provided in the ASTM D422 (2007). The 
type of the hydrometer that was used in the investigation was a $151 \mathrm{H}$, and it also provided the particle gradation. Two hydrometer tests were performed; one on shallow depths and the other on deep depths $(5.82 \mathrm{~m}$ and $21.55 \mathrm{~m})$. During the specimen preparation for the consolidation and simple shear tests, samples from the trimmed soils were collected and weighed before and after being placed in the oven in order to determine the natural water content.

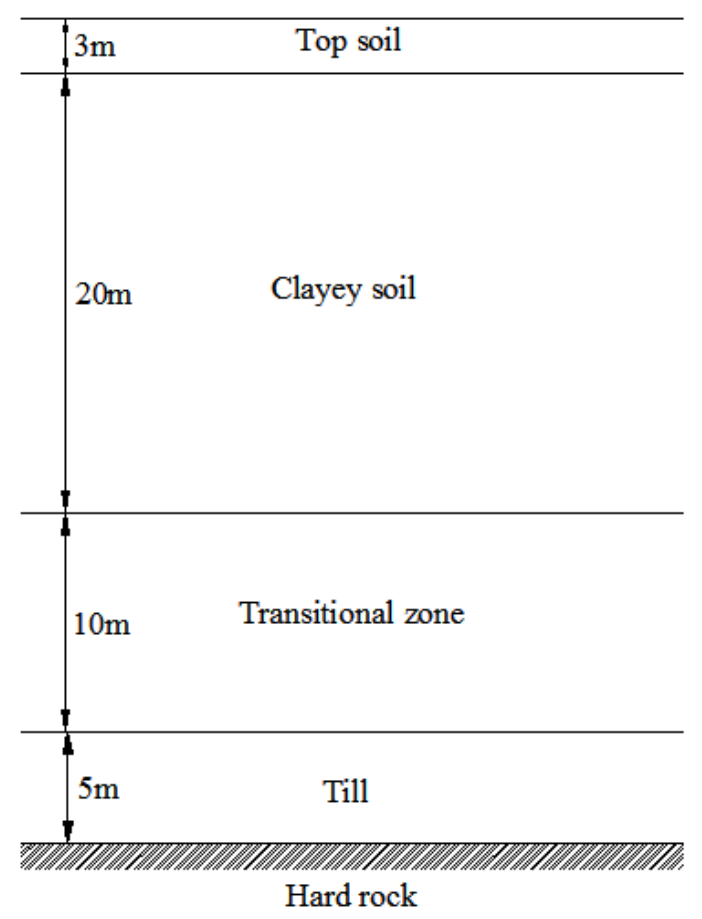

Figure 3.1: Soil profile of the Canadian Museum of Nature (after Humar and Sivathayalan, 2003).

The tests results of the natural water content, liquid and plastic limit, plasticity index, and liquidity index of the tested samples are shown in Table 3.1. The test results indicated that the natural water content ranged from 76.8 to $34.5 \%$. The liquid limit ranged from 54.2 to $29.7 \%$ and the plastic limit ranged from 37.0 to $20.7 \%$. The plasticity index ranged from 17.2 to $7.2 \%$ and the liquidity index ranged from 2.60 to 1.44 . The liquid limit, plastic limit 
and plasticity index values decrease with depth at this site. Similar observations have been made at other sites in in this region (Mitchell and Klugman, 1979). Table 3.1 also shows that all of the samples have lower liquid limits than their water content, leading to a liquidity index value of greater than unity. This characteristics is also quite common in Leda clays, and has been previously reported by Eden and Crawford (1957) and Gillott (1979).

\begin{tabular}{|c|c|c|c|c|c|c|}
\hline $\begin{array}{c}\text { Borehole } \\
\text { ID }\end{array}$ & $\begin{array}{c}\text { Depth } \\
(\mathbf{m})\end{array}$ & $\mathbf{W}_{\mathbf{c}}(\mathbf{\%})$ & LL (\%) & PL (\%) & PI (\%) & LI \\
\hline BH1 & 5.82 & 76.8 & 54.2 & 37.0 & 17.2 & 2.32 \\
\hline BH1 & 8.26 & 69.3 & 48.6 & 32.3 & 16.4 & 2.26 \\
\hline BH1 & 9.42 & 64.3 & 45.9 & 31.4 & 14.5 & 2.27 \\
\hline BH1 & 11 & 61.5 & 44.9 & 33.2 & 11.7 & 2.41 \\
\hline BH1 & 17.41 & 34.5 & 29.7 & 20.7 & 9.0 & 1.54 \\
\hline BH1 & 20 & 41.2 & 29.7 & 22.4 & 7.2 & 2.60 \\
\hline BH1 & 21.55 & 35.9 & 31.6 & 21.8 & 9.8 & 1.44 \\
\hline
\end{tabular}

Table 3.1: General properties of tested sensitive clay.

Figure 3.2 shows the gradation of the material at $5.82 \mathrm{~m}$ and $21.55 \mathrm{~m}$ depths. The plots show that the tested soil contained about $79 \%$ of clay fraction (at $2 \mu \mathrm{m}$ ) at shallow depth 
and about $38 \%$ of clay fraction at deep depth. This finding is consistent with the data presented in Table 3.1, which indicates that the soil at shallow depth has higher plasticity index than the soil at deeper depth. In addition, the average of the soil activity at the two depths is about 0.24, which it is consistent with Mitchell and Soga (2005) criteria for sensitive soils, which suggests that sensitive clay will have an activity lower than 0.5 .

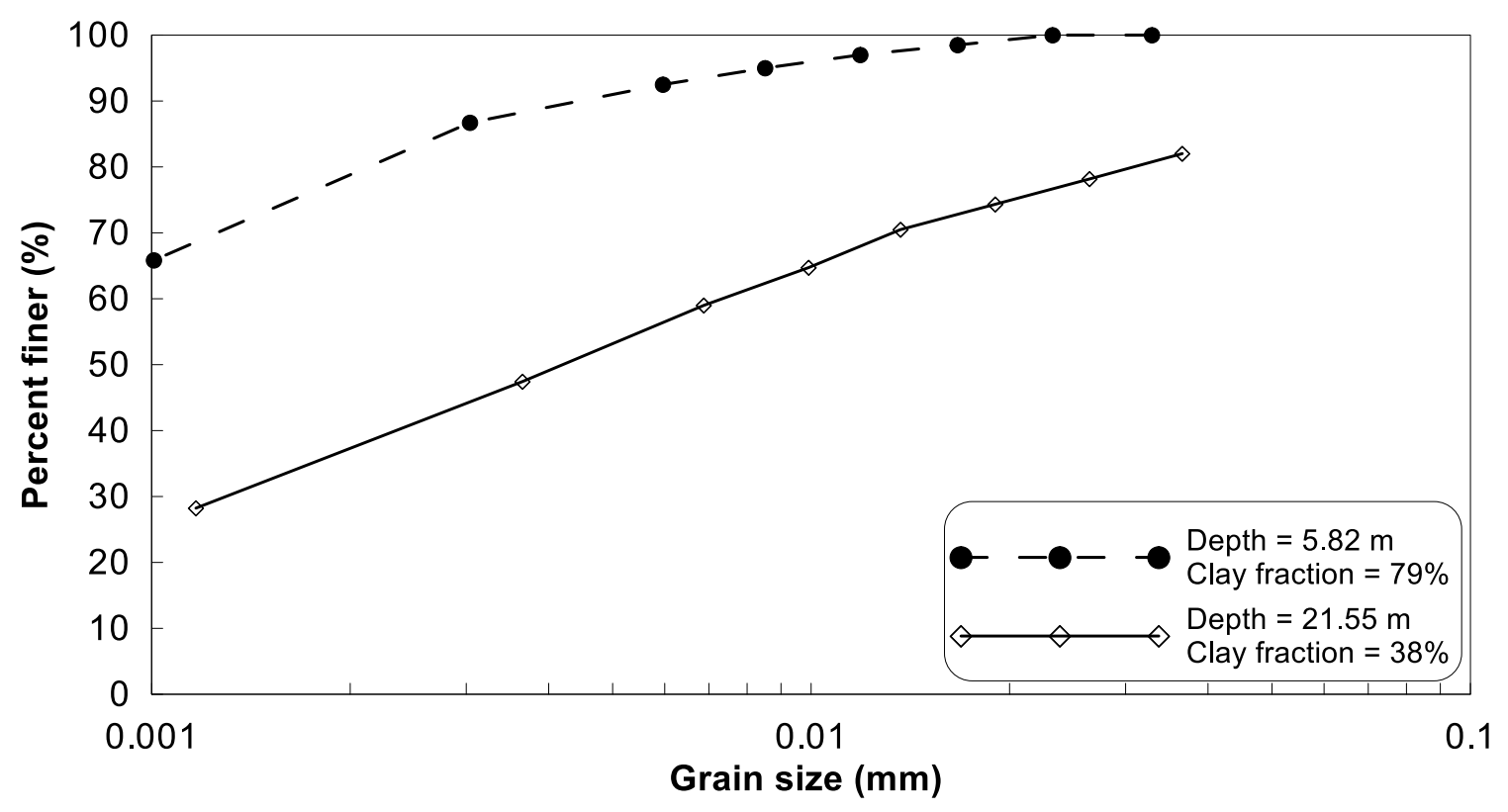

Figure 3.2: Particle size distribution plot at $5.82 \mathrm{~m}$ and $21.55 \mathrm{~m}$ depths.

\subsection{The Consolidation Tests}

\subsubsection{Testing Equipment}

Typically consolidation tests are conducted using oedometers that permit the measurement of vertical stress and displacement. Advanced configurations allow for the measurement of pore water pressure at one boundary (at the bottom, if the vertical stress is 
applied at the top). The consolidation apparatus used in this investigation also enables the measurement of horizontal stress in addition to the vertical stress, vertical displacement and pore water pressure at the base. A photograph of the consolidation apparatus is shown in Figure 3.3. The apparatus consists of several parts, which are briefly described below.

The soil specimen is contained in a 76-mm diameter stainless steel ring that has a cutting edge on one side (to facilitate sample preparation). This ring has a height of $38 \mathrm{~mm}$ to facilitate the placement of the strain gauges for measuring the lateral stresses as noted below. The ring is sealed on a base that has a porous stone connected to a drainage port, and a pore pressure transducer.

An SS type Bellofram air cylinder with a 5.5-inch bore and 5.24-inch stroke lies below the Nullmatic 40-100 pressure regulator and sits on a base connected to the load cell. The required vertical stress was applied on the specimen by using the pressure regulator which is connected to a 200 psi line supply that translates to a maximum applied stress on a 76mm diameter sample of $2800 \mathrm{kPa}$.

The applied vertical load on the soil specimen is measured using a 3000-lb capacity Honeywell load cell. Using the data acquisition system associated with the test setup, this load cell enables a measurement resolution of $0.10 \mathrm{~N}$, which translates to $0.02 \mathrm{kPa}$ of vertical stress. Four strain gauges that were attached on the outer wall of the consolidation ring measure the horizontal stress on the specimen. Figure 3.4 shows a schematic illustration of the oedometer ring and the position of the strain gauges. Figure 3.5 (a) and (b) show the calibration of the horizontal stress measurement. Pore-water pressure at the base of the sample is monitored during the entire duration of the test, and was measured by 
using a Honeywell model FPG pressure transducer with a range of 100 psi. The vertical displacement was measured by using the linear variable differential transformer (LVDT) (Model 7DCDT-1000), which is placed on the outside of the apparatus.

A metal loading cap (pressure pad) is used to transfer the applied load vertically to the specimen by means of a ball seating. The porous stone glued to the top loading cap facilitates free drainage at the top during the loading. The assembly is connected to a water reservoir in order to create a saturated test system to ensure that pressure measurements do not suffer due to system compliance. The data acquisition program collected one data point every 0.1 second immediately after the load increment was applied, but the time interval between data points was gradually increased and the program saved about 2400 data points over a period of $24 \mathrm{hr}$. 


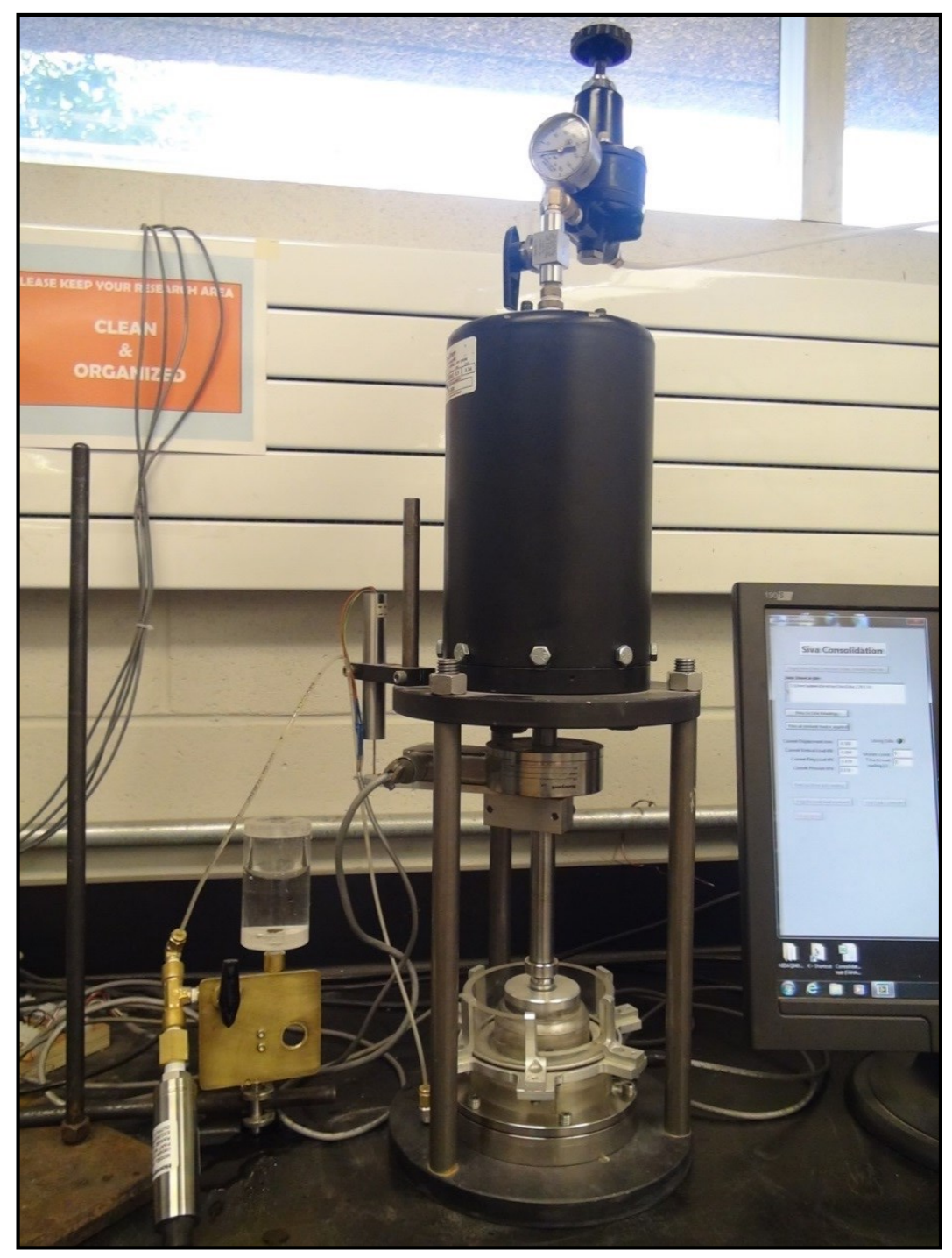

Figure 3.3: One-dimensional consolidation apparatus at Carleton University. 


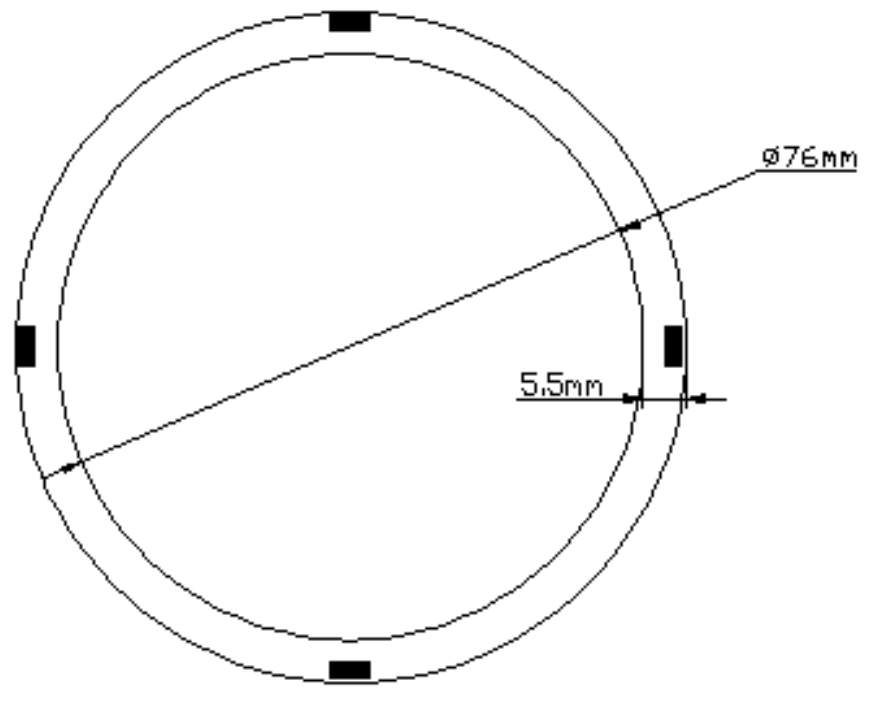

PLAN VIEW

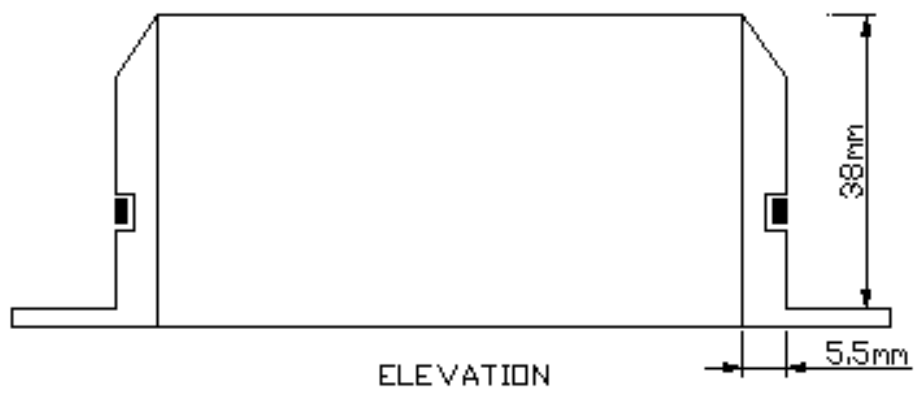

Figure 3.4: The Oedometer ring and the position of the strain gauges. 


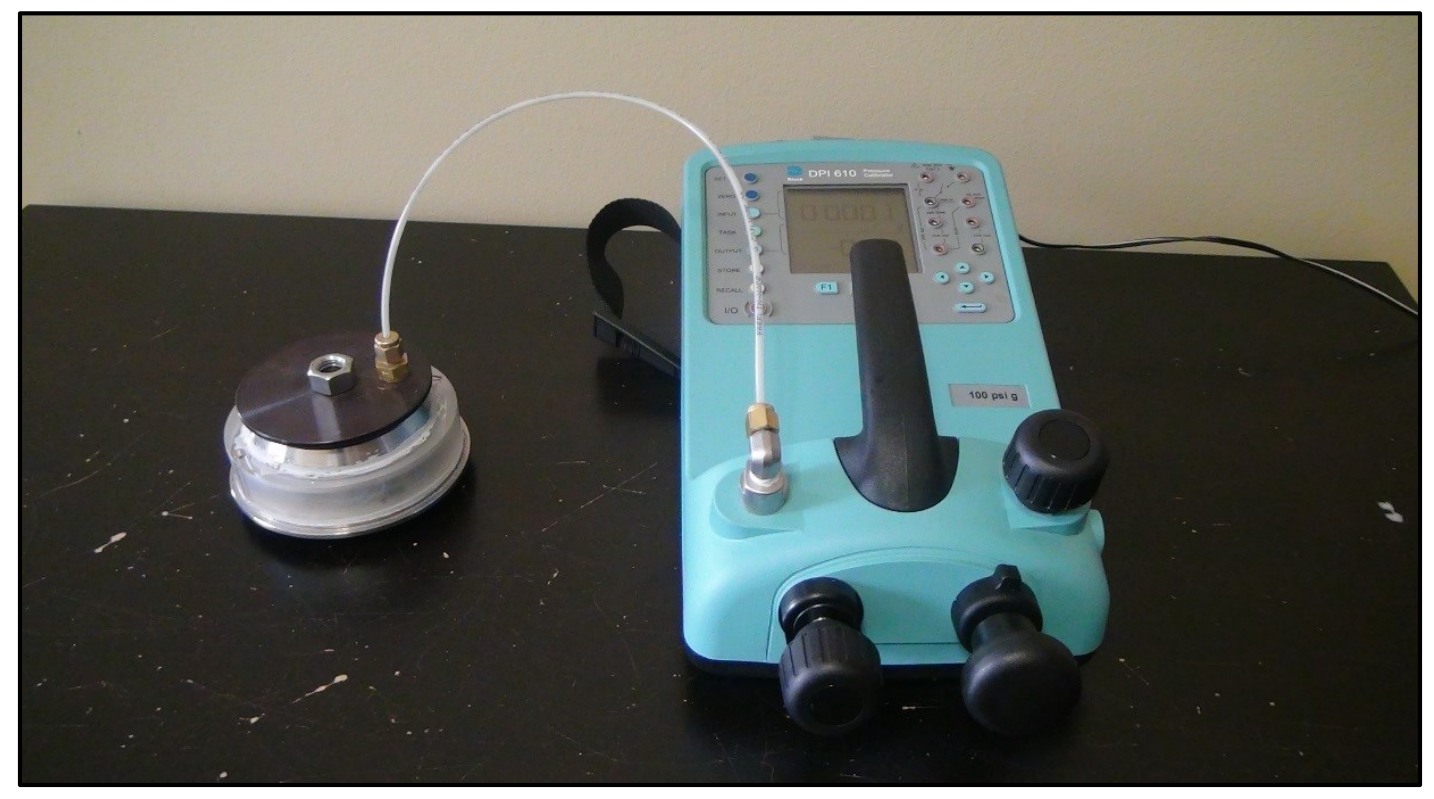

Figure 3.5 (a): The calibration procedure of the horizontal stress measurement.

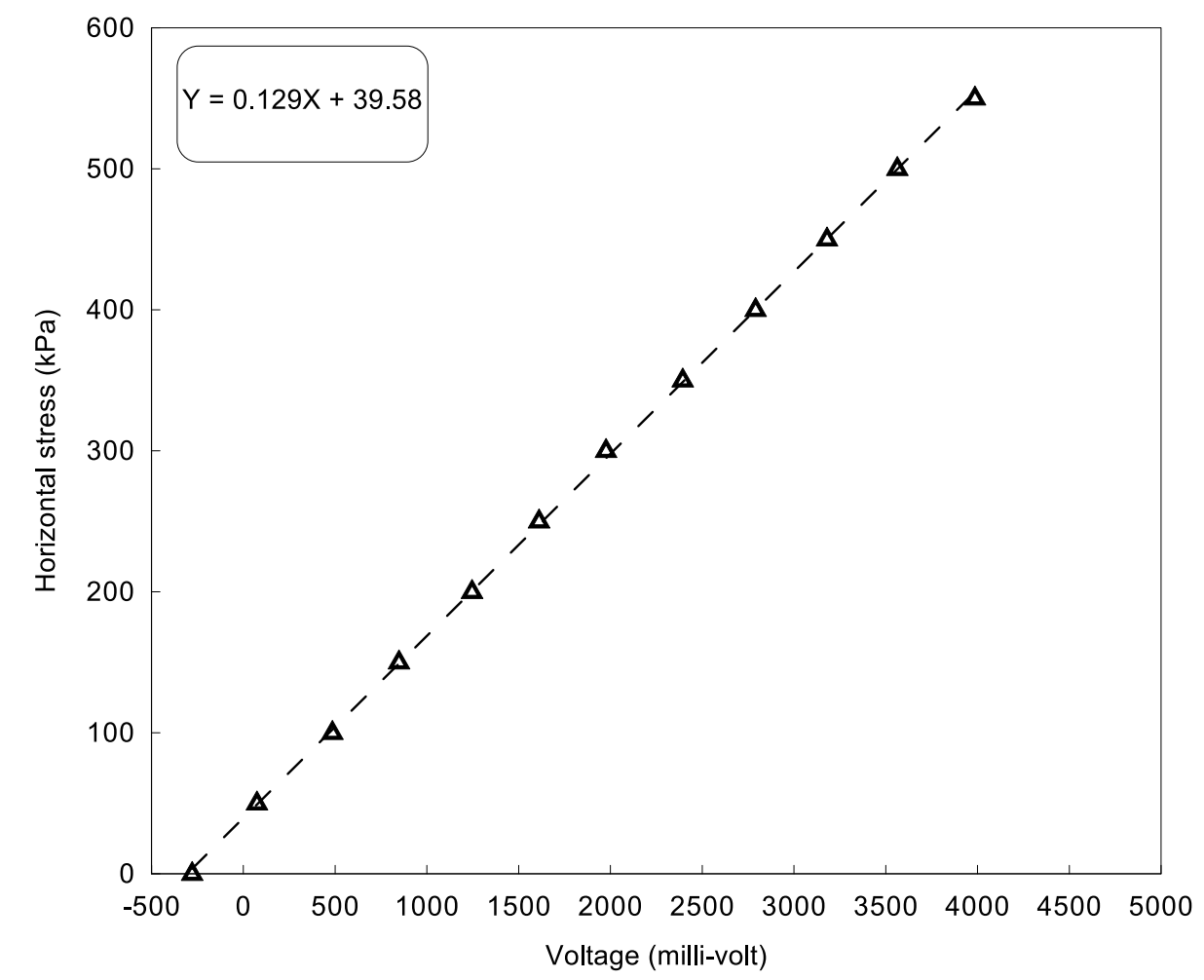

Figure 3.5 (b): The calibration of the horizontal stress measurement. 


\subsubsection{Specimen Preparation}

As noted earlier, all tests were conducted on samples obtained from high quality undisturbed sampling near the Victoria Memorial Museum in Ottawa. The 5-inch diameter samples ranged in height from 6 to 8 -inches, and were wrapped with wax as shown in Figure 3.6. Each block yielded two consolidation tests specimens. Depending on the requirement, test specimens were trimmed either along the vertical orientation or the horizontal orientation. The preparation steps of specimen for both the vertical and horizontal orientations were similar. At the beginning, the sample was carefully placed on the top of a clean flat surface to avoid any disturbance. By using a sharp blade, the sample was trimmed in order to get a size larger (by about $1.5 \mathrm{~cm}$ ) than the required size of the specimen. After that the wax around the specimen was removed the end faces were trimmed by a wire saw, so that they were smooth and parallel. Then, the upper and bottom faces of the specimen were mounted between the two lathe platens as shown in Figure 3.7. The leftover specimen was covered by plastic wrap and then in wax prior to storage for the next test (in order to keep it from losing water content).

The upper platen was brought down to touch the top upper face in order to prevent the specimen from moving. The specimen was rotated slightly between each vertical cut using a wire-saw guided by the vertical plate. The position of the vertical plates was set so such that the trimming would yield a specimen that had a diameter slightly larger (a few millimeters) than the desired size of the specimen (i.e., inner diameter of the consolidation ring). The specimen was then removed carefully from the soil lathe and placed on top of a clean flat glass surface. Then, the inner wall of the consolidation ring was coated by a thin layer of silicon grease and weighed using a balance with a $0.1 \mathrm{~g}$ resolution. The cutting edge 
of the ring was placed on the specimen, and the ring was carefully and slowly pushed into the specimen with a minimum of force to avoid any disturbance. The ring was pushed in until $0.5 \mathrm{~cm}$ of the specimen protruded above the consolidation ring.

The excess soil at the top and bottom of the consolidation ring was then trimmed by a wire saw and used for the determination of the initial natural water content. The consolidation ring and the soil specimen were then weighed to obtain the initial wet weight of the soil specimen. Figure 3.8 shows the various components of the ring, and the trimmed soil specimen inside the ring ready to be assembled for testing.

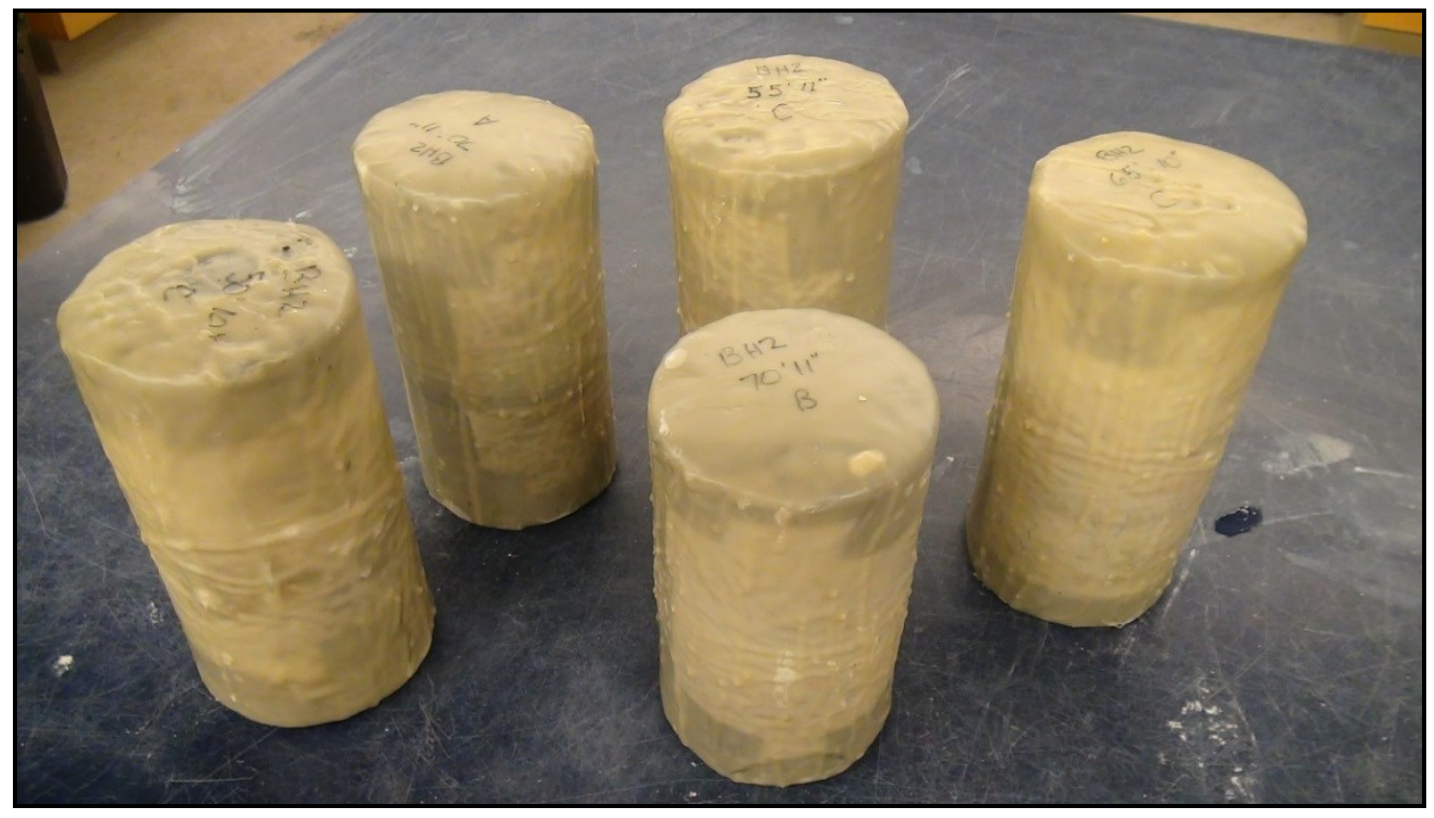

Figure 3.6: Wrapped samples from different depths. 


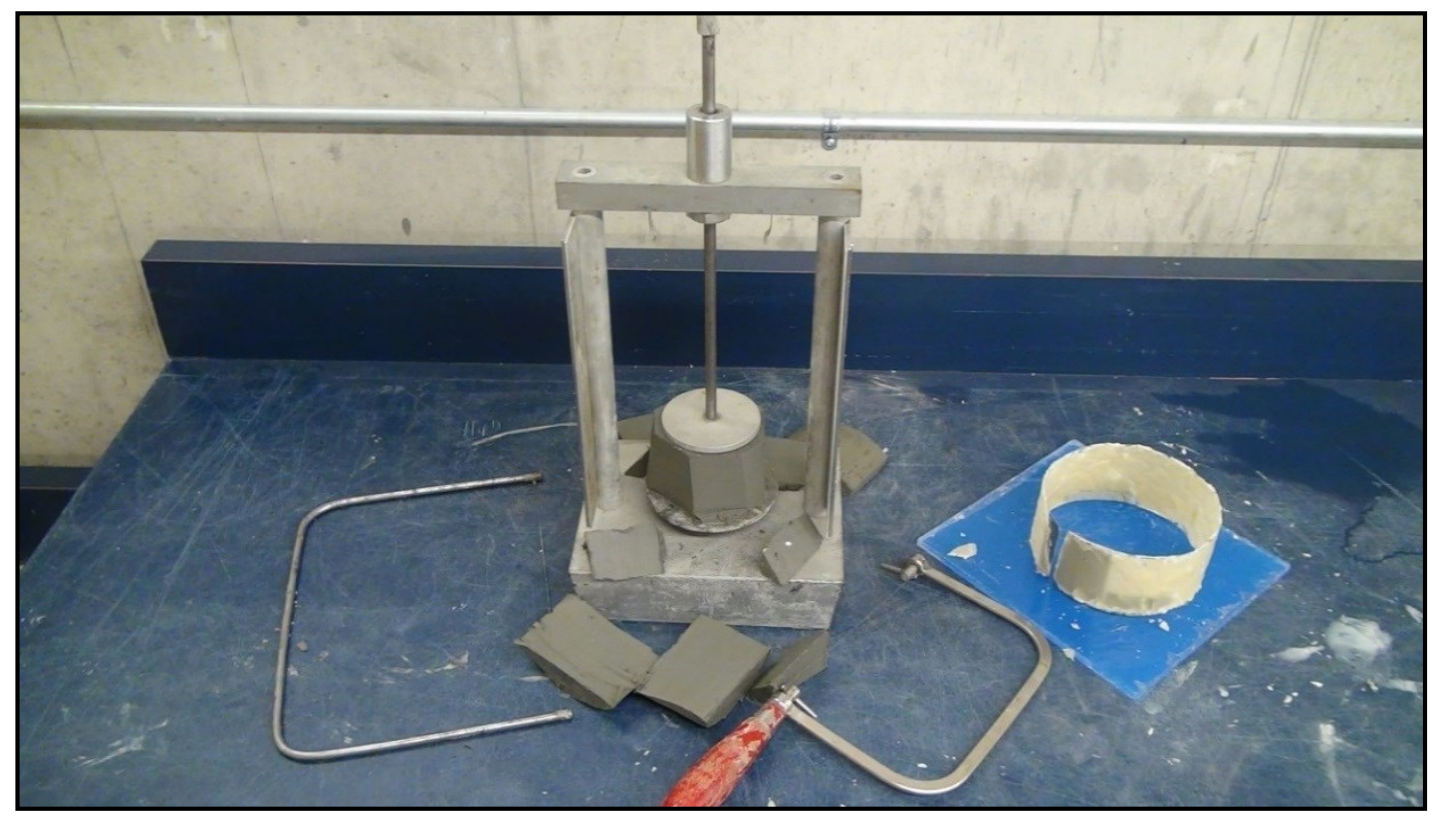

Figure 3.7: Specimen preparation between two platens of soil lathe.

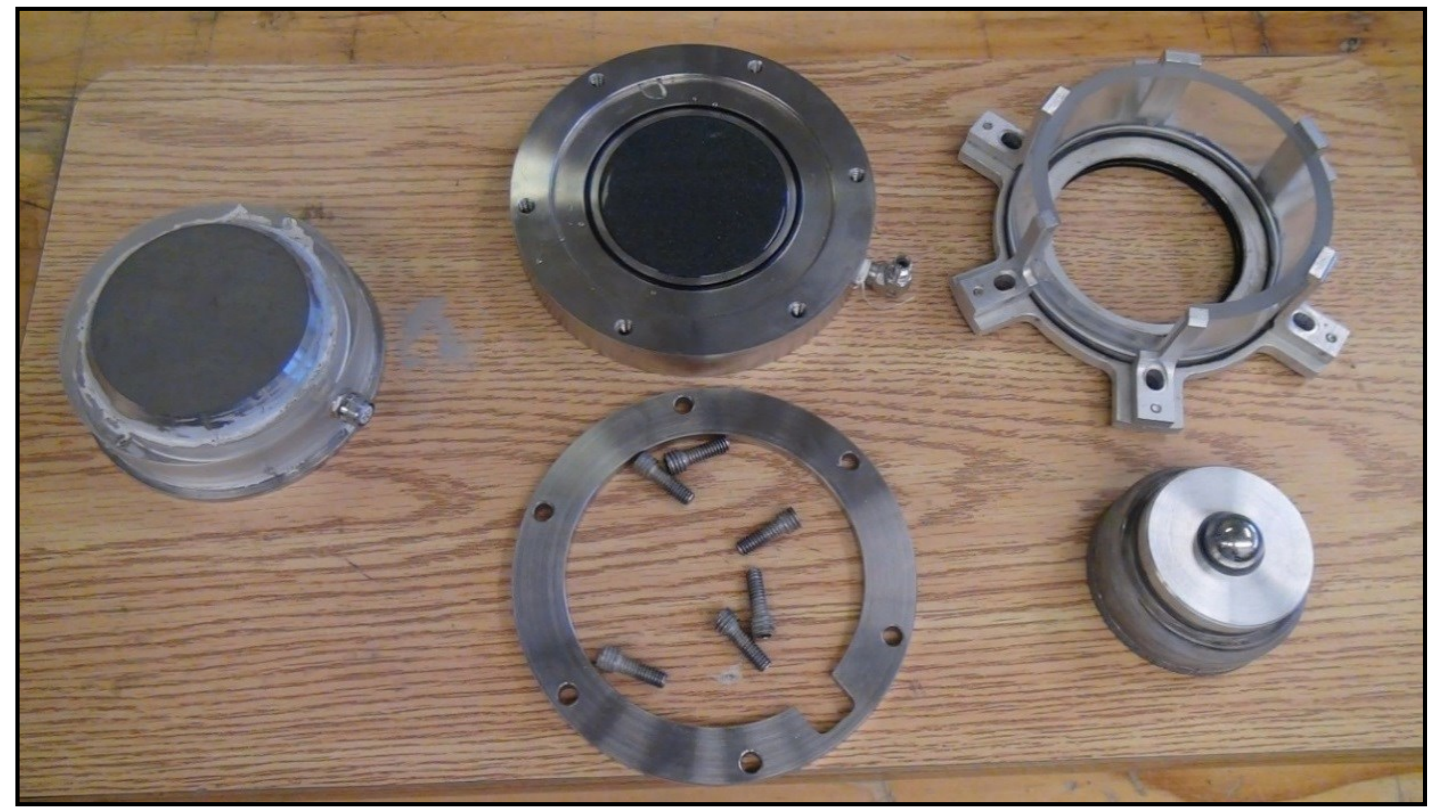

Figure 3.8: Specimen inside the ring, consolidation base with porous stone, water reservoir and loading cap attached to porous stone with ball. 


\subsubsection{Testing Procedure}

The bottom porous stone was saturated by boiling it for about 30 minutes, and allowing it to cool down to room temperature prior to the testing. The water reservoir was filled with de-aired water, and water passing through the drainage line was used to fill the well at the bottom platen before the lower porous stone was placed in it. The specimen ring was then placed on the base at a slant and then carefully tilted into position. This allowed water standing above the porous stone to run out toward one side, as the specimen sat on the other side. Then, six screws were used to secure the consolidation ring and base firmly together. Next, the consolidation base with the ring was placed on the center of the rigid plate in the consolidation apparatus. The lower drainage line that is attached to the consolidation base was connected with the pressure transducer and the valve was closed to measure the pore water pressure. Finally, the loading cap, with the fixed top porous stone, was placed carefully on top of the specimen.

Before starting the consolidation test, the specimen was inundated with water in order to keep it under the condition of saturation. Then, a seating load of $12.5 \mathrm{kPa}$ was applied, by using the pressure regulator for a few hours in order to ensure that the specimen did not swell. Following that, the specimen was subjected to a consolidation pressure ranging from 25 to $2200 \mathrm{kPa}$. Each load/pressure was kept on the specimen for 24 hours and a load increment ratio of one was used in all of the tests. Eight tests (four on vertical and four on horizontal orientations) consisted of loading, unloading, and reloading stages. Two tests (one on vertical and one on horizontal orientations) consisted of loading and unloading stages only. Table $3.2,3.3,3.4$, and 3.5 present in detail the schedule of loading that was followed in all tests at the different depths of 5.82, 8.26, 11, 17.41, and $21.55 \mathrm{~m}$ both in the 
vertical and the horizontal orientations. After the end of the test, the specimen was removed from the consolidation ring and weighed. It was then placed in an oven and the final dry weight was recorded after about 24 hours, in order to determine the final water of the specimen. Figure 3.9 shows the variation of the applied vertical stress with time during consolidation test and demonstrates excellent control of the applied load.

\begin{tabular}{|c|c|}
\hline Step & Vertical Stress $(\mathrm{kPa})$ \\
\hline 1 & 12.5 \\
\hline 2 & 25 \\
\hline 3 & 50 \\
\hline 4 & 100 \\
\hline 5 & 200 \\
\hline 6 & 400 \\
\hline 7 & 800 \\
\hline 8 & 1600 \\
\hline 9 & 800 \\
\hline 10 & 400 \\
\hline 11 & 200 \\
\hline 12 & 400 \\
\hline 13 & 800 \\
\hline 14 & 1600 \\
\hline
\end{tabular}

Table 3.2: Load increments for boreholes at depths of 5.82 and $21.55 \mathrm{~m}$. 


\begin{tabular}{|c|c|}
\hline Step & Vertical Stress $(\mathrm{kPa})$ \\
\hline 1 & 12.5 \\
\hline 2 & 25 \\
\hline 3 & 50 \\
\hline 4 & 100 \\
\hline 5 & 200 \\
\hline 6 & 400 \\
\hline 7 & 200 \\
\hline 8 & 400 \\
\hline 9 & 800 \\
\hline 10 & 1600 \\
\hline
\end{tabular}

Table 3.3: Load increments at a depth of $8.26 \mathrm{~m}$.

\begin{tabular}{|c|c|}
\hline Step & Vertical Stress (kPa) \\
\hline 1 & 12.5 \\
\hline 2 & 25 \\
\hline 3 & 50 \\
\hline 4 & 100 \\
\hline 5 & 200 \\
\hline 6 & 400 \\
\hline 7 & 800 \\
\hline 8 & 1600 \\
\hline 9 & 800 \\
\hline 10 & 400 \\
\hline 11 & 200 \\
\hline
\end{tabular}

Table 3.4: Load increments at a depth of $11 \mathrm{~m}$. 


\begin{tabular}{|c|c|}
\hline Step & Vertical Stress $(\mathrm{kPa})$ \\
\hline 1 & 12.5 \\
\hline 2 & 25 \\
\hline 3 & 50 \\
\hline 4 & 100 \\
\hline 5 & 200 \\
\hline 6 & 400 \\
\hline 7 & 200 \\
\hline 8 & 100 \\
\hline 9 & 200 \\
\hline 10 & 400 \\
\hline 11 & 800 \\
\hline 12 & 1600 \\
\hline 13 & 2200 \\
\hline
\end{tabular}

Table 3.5: Load increments at a depth of $17.41 \mathrm{~m}$.

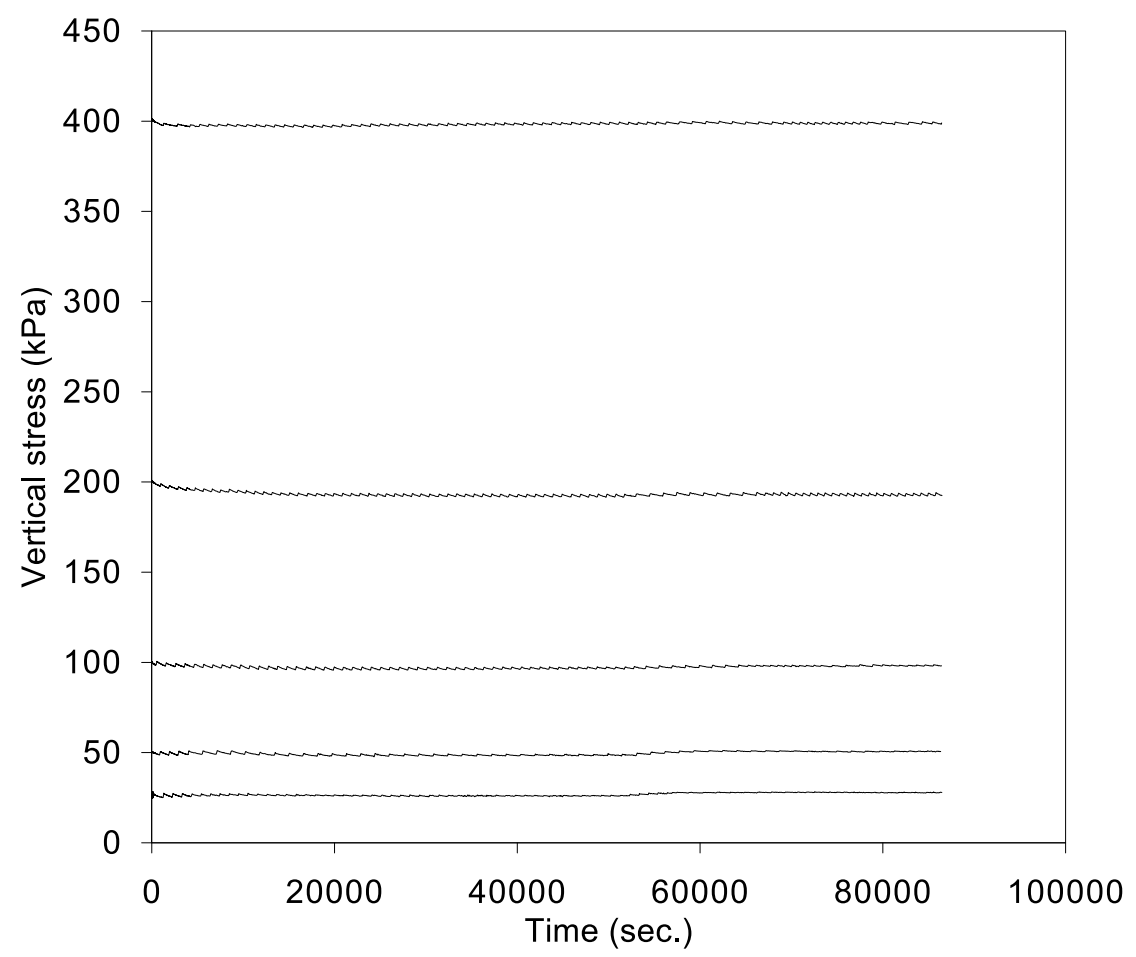

Figure 3.9: The variation of the applied vertical stress with time during consolidation test. 


\subsection{The Simple Shear Tests}

\subsubsection{Testing Equipment}

Norwegian Geotechnical Institute (NGI) type simple shear apparatus was used in this research to carry out all of the simple shear tests. The specific device was manufactured by Seiken Inc. (Model No. ASK DTC 148) but changes to the horizontal loading assembly have been made in house to facilitate strain controlled loading (Vipulanantham, 2011). Simple shear tests were conducted on specimens that were trimmed along vertical and horizontal orientations. The vertical normal stress, shear stress on the horizontal plane, vertical and horizontal displacements were measured in this test. The diameter and height of the apparatus specimen were $69.95 \mathrm{~mm}$ and $21 \mathrm{~mm}$, respectively. A Schematic diagram of the simple shear apparatus is provided in Figure 3.10 (a) and a photograph in 3.10 (b).

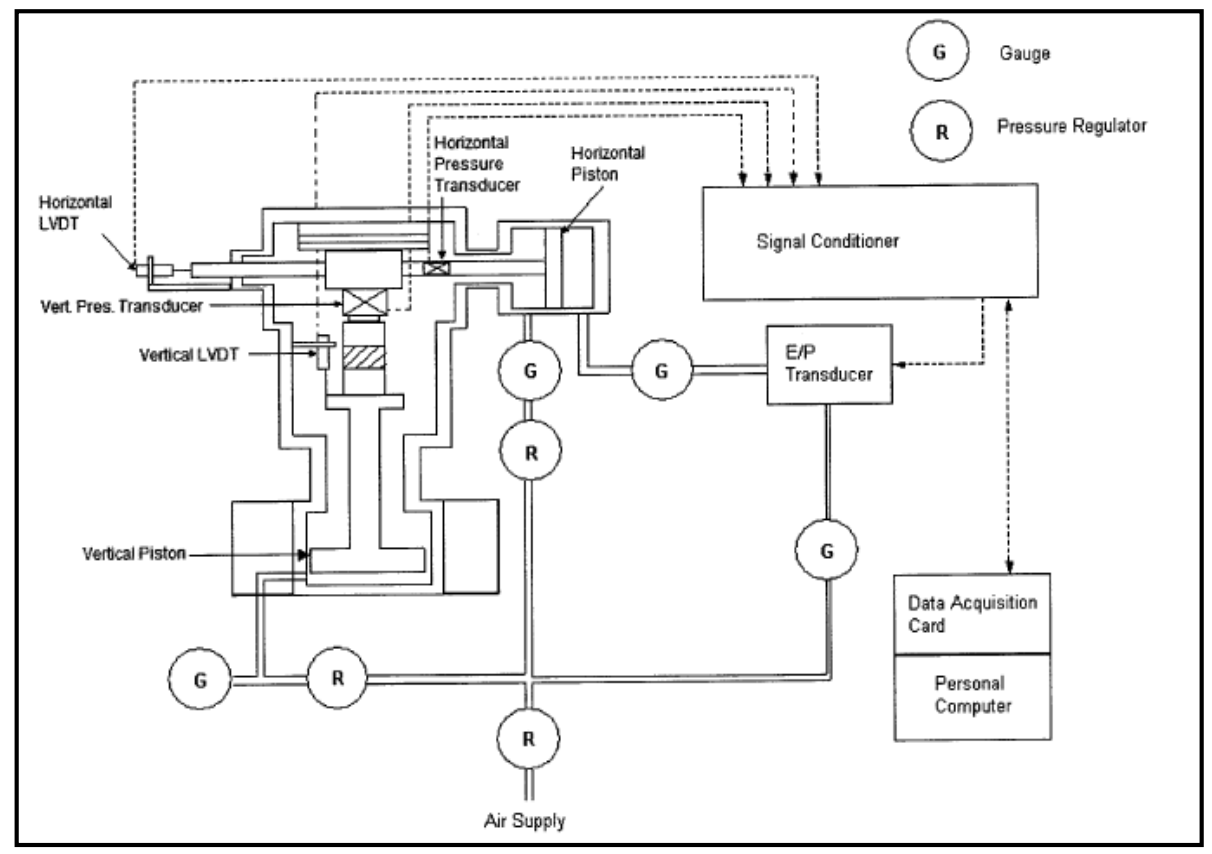

Figure 3.10 (a): Schematic layout of Simple shear apparatus at Carleton University (Ha, 2003). 


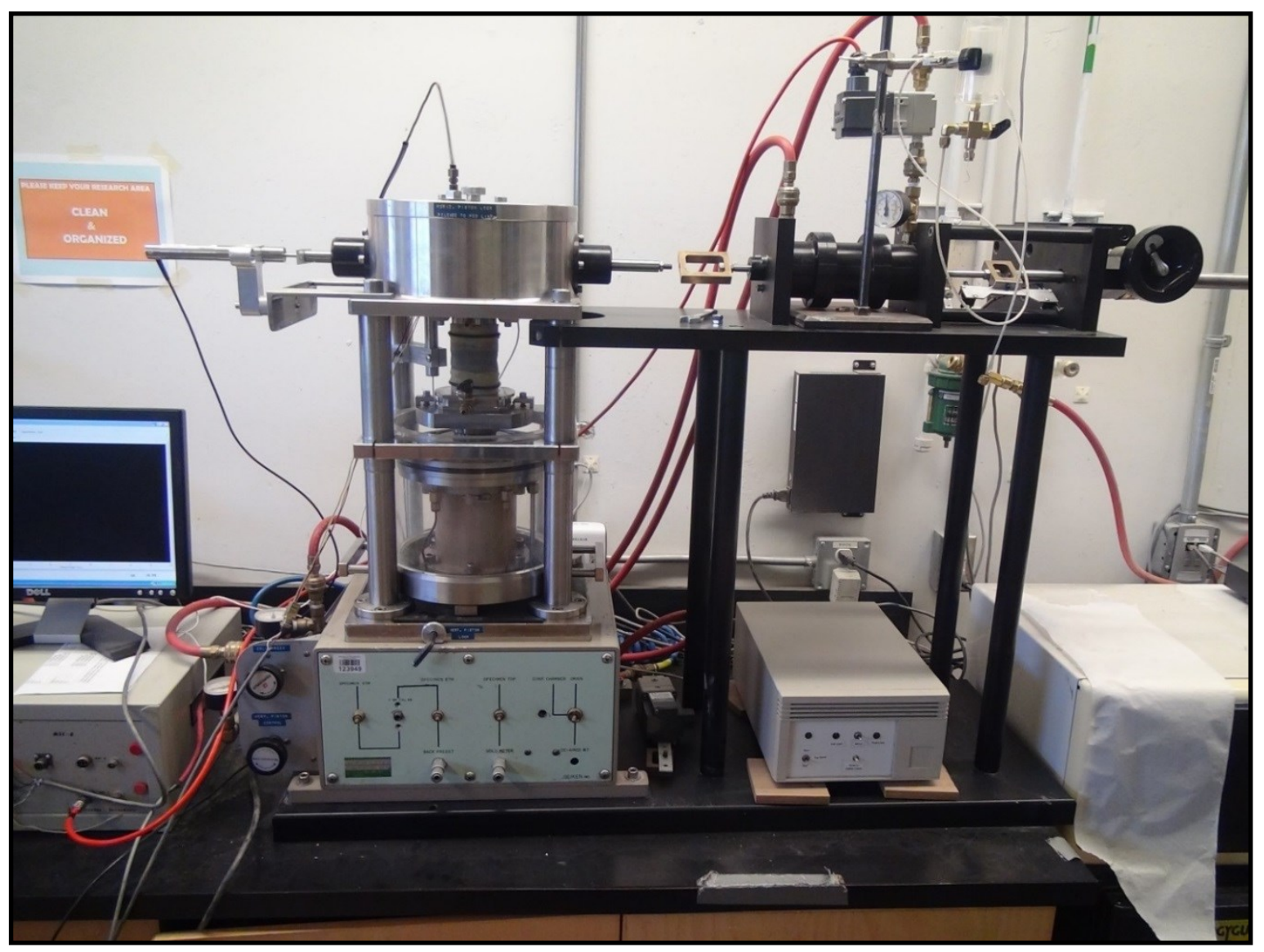

Figure 3.10 (b): Simple Shear device at Carleton University.

The simple shear apparatus has several components, that have been detailed elsewhere (Ha, 2003; Vipulanantham, 2011). The bottom and upper platens contain ribs to facilitate the transfer of shear stress and avoid (or minimize) slip between the soil and the loading platen. The porous stones are placed in a recess in the platens. A steel-wire reinforced rubber membrane is used to provide constant volume conditions during the shearing phase, and $K_{o}$ (coefficient of lateral earth pressure at rest) condition during the consolidation phase. The vertical load applied to the specimen through an air piston, and the pressure in the piston is regulated by using a Fairchild pressure regulator. The applied vertical load on the soil specimen is measured using a 1100-lb capacity Honeywell load cell. 
A stepper motor (Model No. 5 624-39) was used to apply the shear loading to the specimen at a constant rate of strain. Two linear variable differential transducers (LVDTs) were used to measure the vertical and horizontal displacements. All stresses were measured with a resolution better than $0.2 \mathrm{kPa}$ and strains with a resolution of about $0.01 \%$.

\subsubsection{Specimen Preparation}

Although 10 simple shear tests were planned, due to problems with the maintenance of the apparatus only 6 tests were conducted. Four specimens were obtained along the vertical and horizontal orientations at a depth of $9.42 \mathrm{~m}$, and two specimens at a depth of $20 \mathrm{~m}$. The preparation steps for the specimens for both the vertical and horizontal orientations were similar. As with the consolidation tests, the preparation began by trimming a sample that was a few millimeters larger than the actual diameter and height of the specimen for the simple shear apparatus $(69.95 \mathrm{~mm}$ diameter $\times 21 \mathrm{~mm}$ height $)$.

Once the soil specimen was retained in the cutting ring using the soil-lathe, the specimen was transferred to the membrane lines cavity in the simple shear tests. The bottom part of the reinforced rubber membrane was stretched over the bottom pedestal, and an O-ring was placed over the membrane. The two parts of the split mold were attached around the reinforced rubber membrane and secured by a clamp. The upper part of the reinforced rubber membrane was flipped over the upper edge of the split mold and then a vacuum line was connected to the two openings that are built on the outer wall of the specimen mold, in order to hold the reinforced rubber membrane taut against the inner wall of the mold. The specimen was inserted into the ring was placed at the top, and slowly pushed into the cavity, while the bottom drainage valve was kept open. Once the sample was in the cavity, the upper loading platen was placed, and the rubber membrane was 
stretched over the bottom part of the upper platen and sealed by an O-ring. The specimen was then moved to the loading assembly.

\subsubsection{Testing Procedure}

After placing the specimen and the mold together in the simple shear apparatus, the pressure in the vertical piston was increased to raise the platform up to make contact with the top loading assembly. The initial height reading was recorded once contact was made at a vertical stress level of 5 to $10 \mathrm{kPa}$. The split mold was carefully removed without disturbing the specimen and the vertical load was increased to $25 \mathrm{kPa}$ seating load prior to the beginning of consolidation. Consolidation stress was applied in stages, and the specimen was subjected to a final consolidation stress of 100,200 or $400 \mathrm{kPa}$. A load increment ratio of one was used in all tests during the staged consolidation. In order to save time, the duration of each applied normal stress increment on the specimen was varied, and based on the pore water dissipation/rate of settlement. The settlement-time curve was monitored in real time, and the next loading increment was applied when the settlement flattened out. Specimens at a depth of $9.42 \mathrm{~m}$ were consolidated at two increments (50 and $100 \mathrm{kPa})$, the specimens at a depth of $9.42 \mathrm{~m}$ were consolidated at three increments (50, 100 and $200 \mathrm{kPa}$ ), and the specimens at a depth of $20 \mathrm{~m}$ were consolidated in four increments (50 and 100, 200 and $400 \mathrm{kPa}$ ). Specimens were allowed to consolidate overnight under the final consolidation stress prior to monotonic shear loading. A Constant rate of strain monotonic loading was applied at a rate of about $12 \%$ per hour, which was the slowest rate possible using the data acquisition program (about $0.03 \mathrm{~mm} / \mathrm{minute}$ ). Finally, the specimen was removed from the apparatus to determine the final water content. 


\section{Chapter 4}

\section{Results and Analysis}

\subsection{Introduction}

This chapter presents the results obtained from both the one-dimensional consolidation and the simple shear tests, and discusses them in order to assess the degree of anisotropy in the sensitive Champlain clay. Consolidation and shear tests were conducted on samples from depths ranging from 5.82 to $21.55 \mathrm{~m}$. For the one-dimensional consolidation tests, the following parameters were obtained from vertical and horizontal specimens: the preconsolidation pressure, the compression index, the coefficients of consolidation and permeability, and the at-rest lateral earth pressure coefficient. The following parameters were obtained in the case of the simple shear tests from vertical and horizontal specimens: the normalized undrained peak and residual shear strengths; the peak and residual shear strength parameters (effective friction angle and cohesion).

\subsection{Results of the Consolidation Tests}

\subsubsection{Variation of strain with time}

The plots of the strain versus time for vertical and horizontal specimens that were trimmed at a depth of $5.82 \mathrm{~m}$ are presented in this section. Figure 4.1 (a) through Figure $4.1(\mathrm{~m})$ show the plots for vertical orientation at a depth of $5.82 \mathrm{~m}$. First, the specimen was loaded from $25 \mathrm{kPa}$ to $1600 \mathrm{kPa}$ as shown in Figure 4.1 (a) to Figure 4.1 (g). Then, it was unloaded to reach $200 \mathrm{kPa}$ as shown in Figure 4.1 (h) to Figure 4.1 (j). Finally, the specimen was reloaded to reach a vertical stress of $1600 \mathrm{kPa}$ as shown in Figure $4.1(\mathrm{k})$ to Figure 4.1 
(m). Observations of these plots indicate that the amount of strain at the end of loading stage was about $44.11 \%$. At the end of the unloading stage, it was found that the amount of the strain decreased to about $41.95 \%$. Furthermore, the amount of strain increased slightly to be about $44.74 \%$ at the end of reloading stage. It is clear that this soil does not show large swelling behaviour. Also, the strain at the end of the test does not differ significantly from the strain at end of the loading stage. Only about a $0.63 \%$ difference over $44 \%$ was found. The largest amount of strain occurred at $400 \mathrm{kPa}$, in the loading stage, and was about $16.67 \%$. This could be due to the collapse of the structure when the vertical stress increased from 200 to $400 \mathrm{kPa}$, as shown in Figure 4.1 (e).

Figure 4.2 (a) through Figure $4.2(\mathrm{~m})$ show the plots for horizontal orientation at a depth of $5.82 \mathrm{~m}$. A loading schedule similar to the vertical orientation was followed. At the beginning, the specimen was loaded from $25 \mathrm{kPa}$ to $1600 \mathrm{kPa}$ as shown in Figure 4.2 (a) to Figure $4.2(\mathrm{~g})$. Then, it was unloaded to reach $200 \mathrm{kPa}$ as shown in Figure $4.2(\mathrm{~h})$ to Figure 4.2 (j). Finally, the specimen was reloaded to reach a vertical stress of $1600 \mathrm{kPa}$ as shown in Figure $4.2(\mathrm{k})$ to Figure $4.2(\mathrm{~m})$. The amount of strain was found to be almost $41.11 \%$ at the end of the loading stage, $39.34 \%$ at the end of unloading stage, and 41.52 $\%$ at the end of reloading stage. At the end of the unloading stage, the horizontal orientation showed similar swelling behaviour as observed in vertical orientation, in that the specimen had small amount of swelling. The strains at end of loading stage and at the end of the test were approximately equal as in the previous case. Figure 4.2 (e) indicates that the $400 \mathrm{kPa}$ at loading stage has the largest amount of strain during the whole test, which it is about $15.19 \%$, because of the collapse of the structure as the vertical stress increased from 200 to $400 \mathrm{kPa}$. 
Table 4.1 presents the amount of strain at the end of loading stage, the amount of swelling strain at the end of unloading stage, and the amount of strain at the end of each test in both vertical and horizontal orientations for all consolidation tests. This table shows that all tested specimens (for both vertical and horizontal orientations) with loadingunloading-reloading stages have a strain at the end of each test that is slightly higher than the strain at the end of loading stage. Also, the table indicates that the tested specimens on the vertical orientation have somewhat higher amounts of strain than those on the horizontal orientation at the end of each test, except at a depth of $17.41 \mathrm{~m}$, which could be due to an experimental error. Moreover, the table shows that swelling strain in both vertical and horizontal orientations are varied between $0.36 \%$ and $2.16 \%$ in all tested specimens. This finding indicates that the sensitive Champlain clay has low swelling behaviour due to its low composition of swelling minerals, such as vermiculite and pseudo-montmorillonite (De Wit, 1967, and Saran, 1970). 

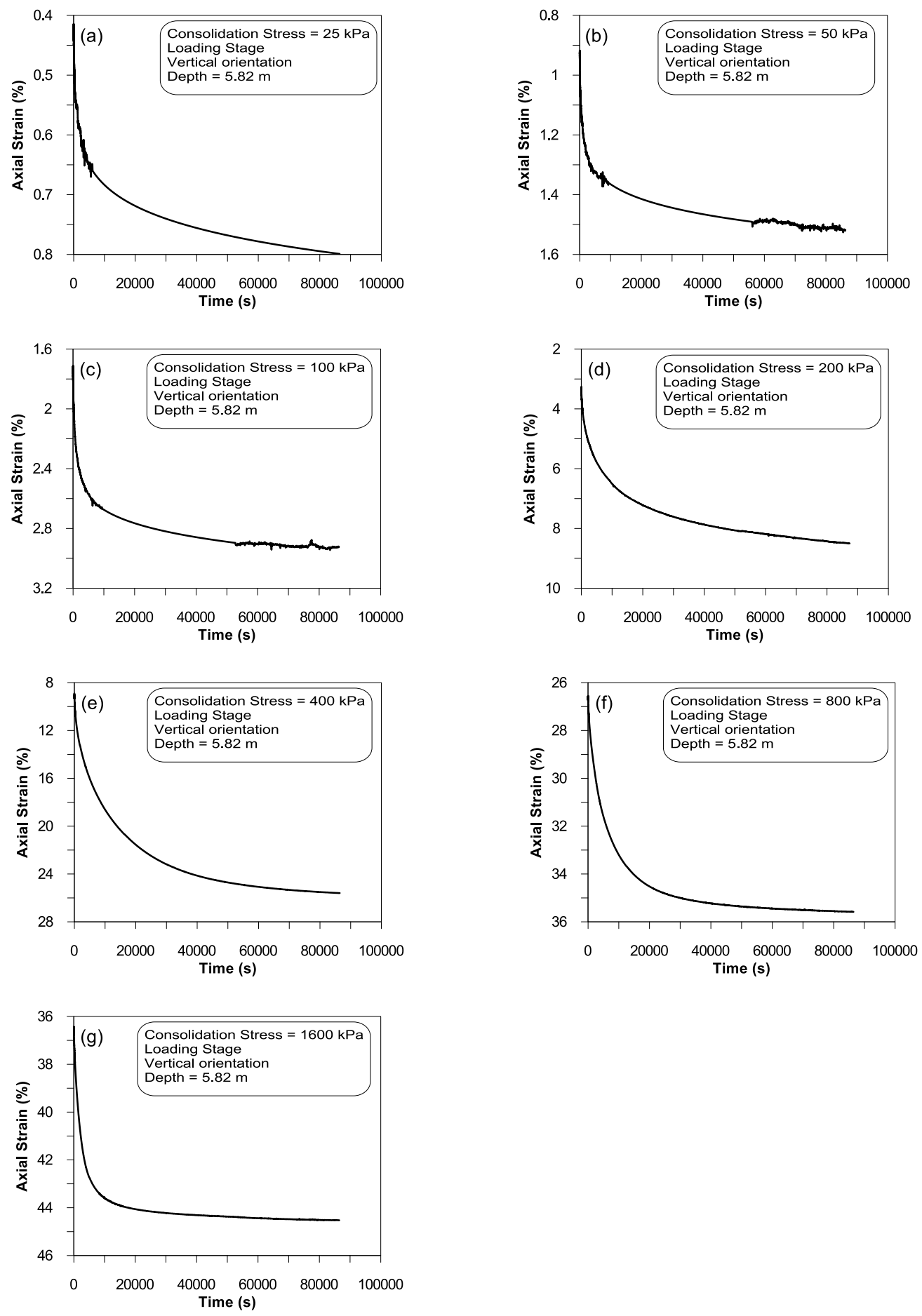

Figure 4.1 (a), (b), (c), (d), (e), (f), and (g): Plots of axial strain versus time during loading stage for vertical orientation at a depth of $5.82 \mathrm{~m}$. 

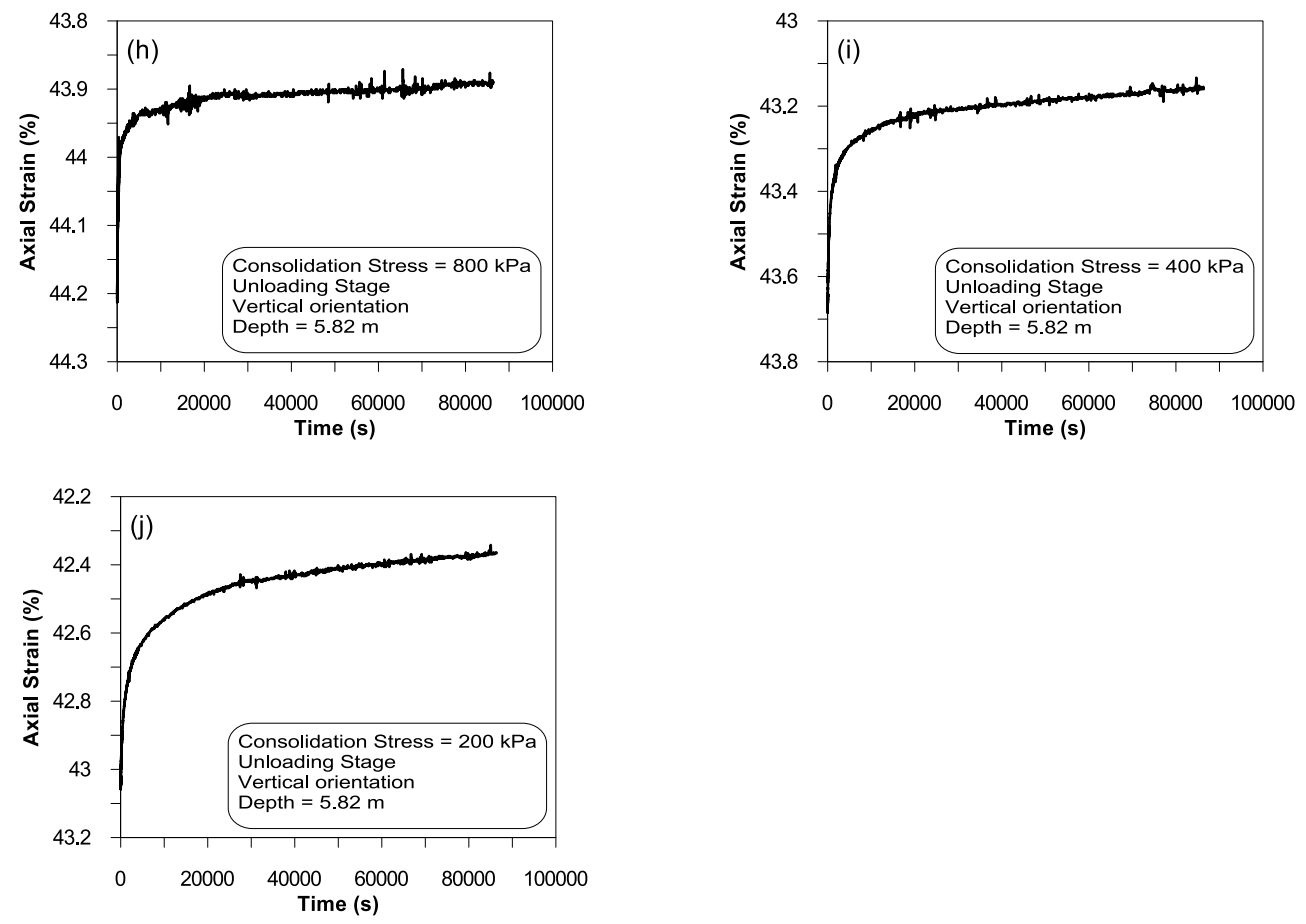

Figure 4.1 (h), (i), and (j): Plots of axial strain versus time during unloading stage for vertical orientation at a depth of $5.82 \mathrm{~m}$.
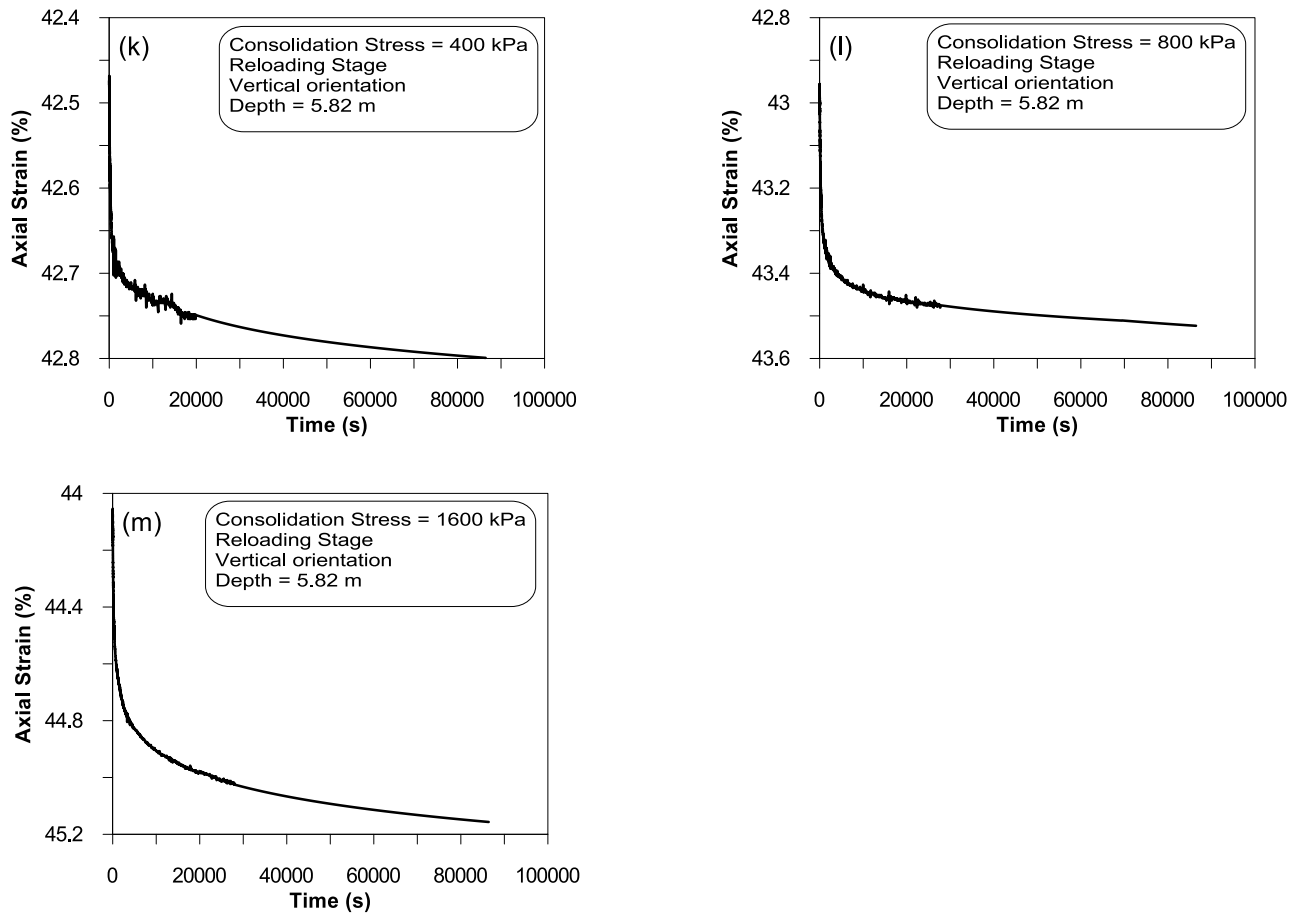

Figure $4.1(\mathrm{k}),(\mathrm{l})$, and $(\mathrm{m})$ : Plots of axial strain versus time during reloading stage for vertical orientation at a depth of $5.82 \mathrm{~m}$. 

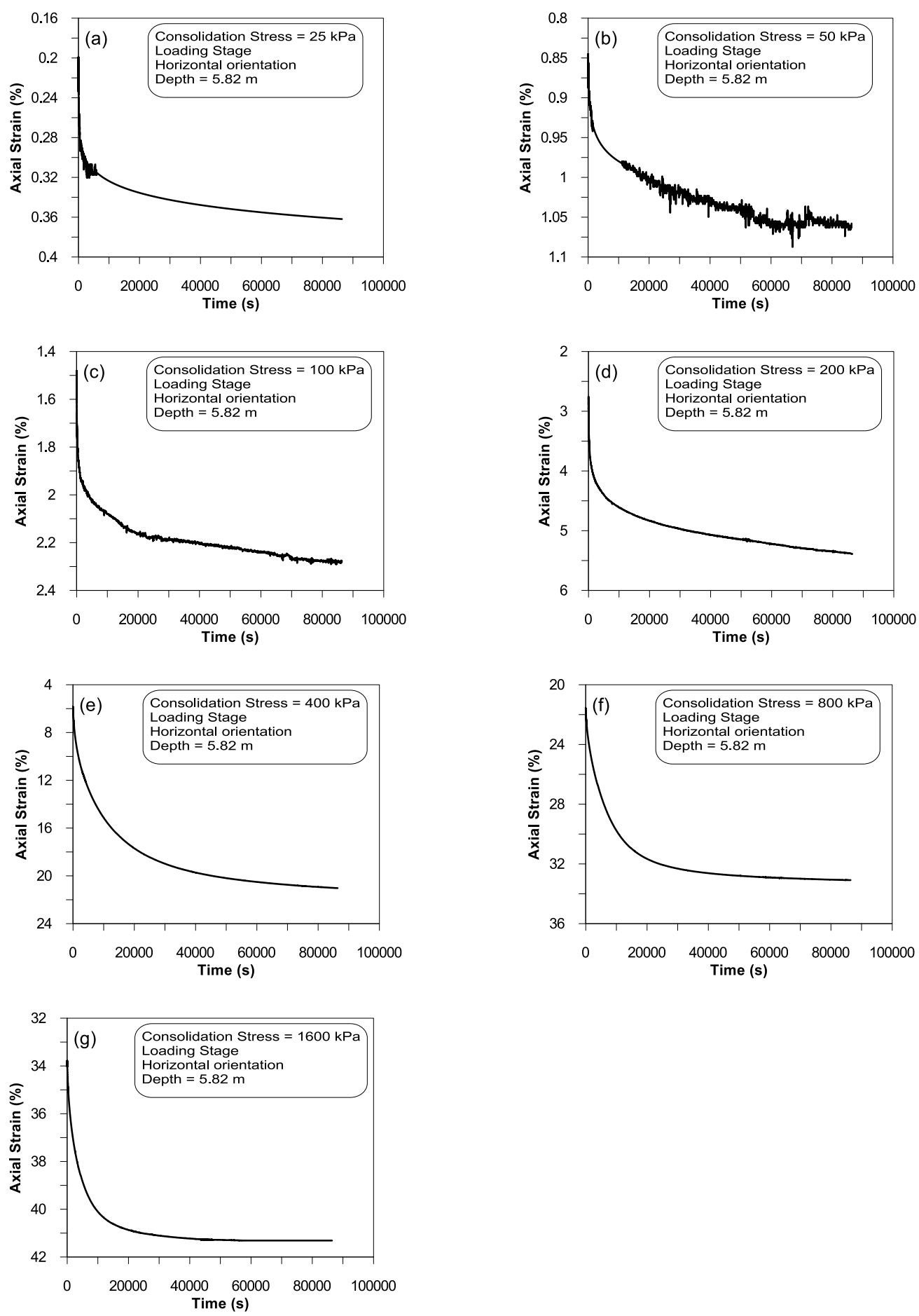

Figure 4.2 (a), (b), (c), (d), (e), (f), and (g): Plots of axial strain versus time during loading stage for horizontal orientation at a depth of $5.82 \mathrm{~m}$. 

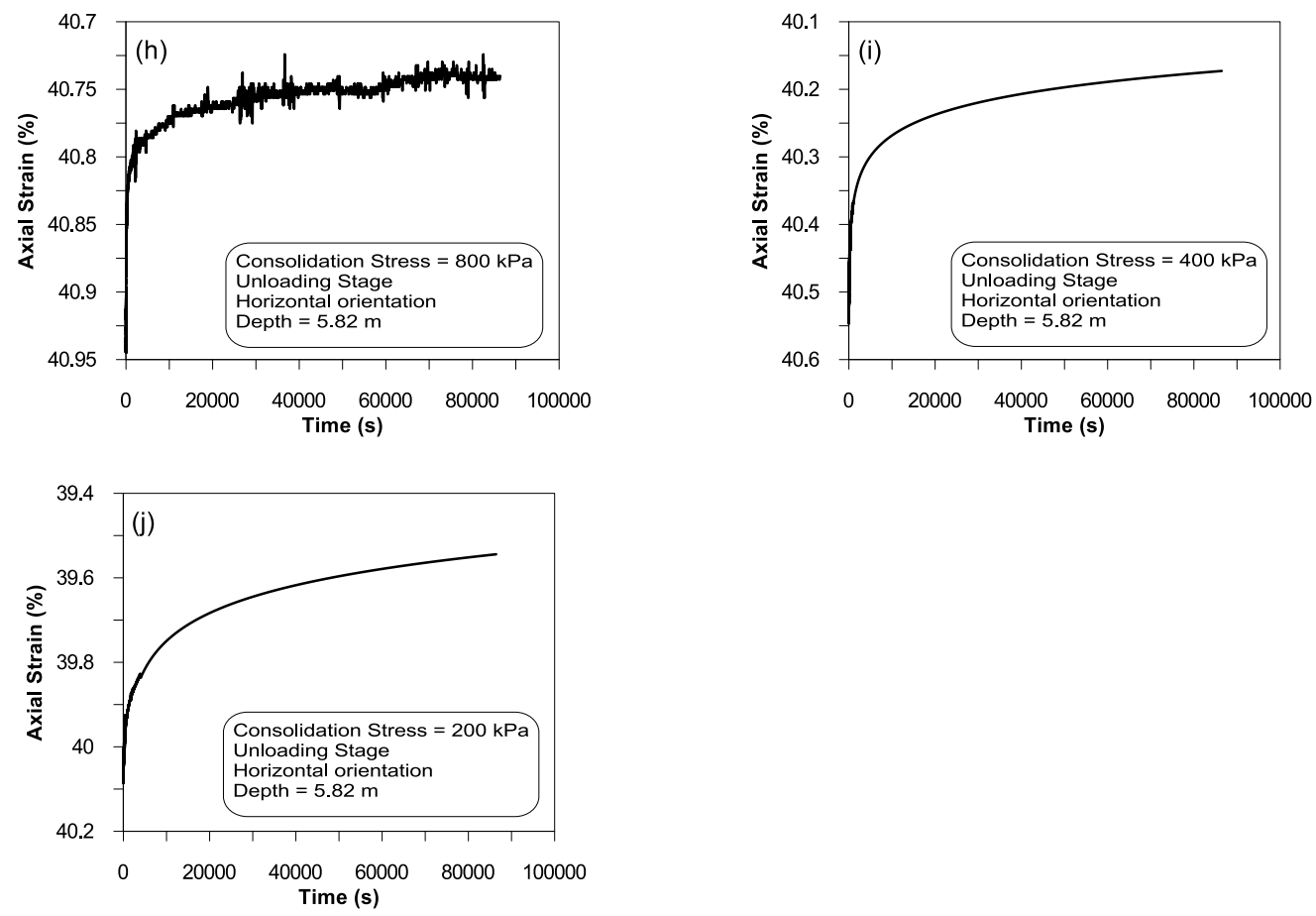

Figure 4.2 (h), (i), and (j): Plots of axial strain versus time during unloading stage for horizontal orientation at a depth of $5.82 \mathrm{~m}$.
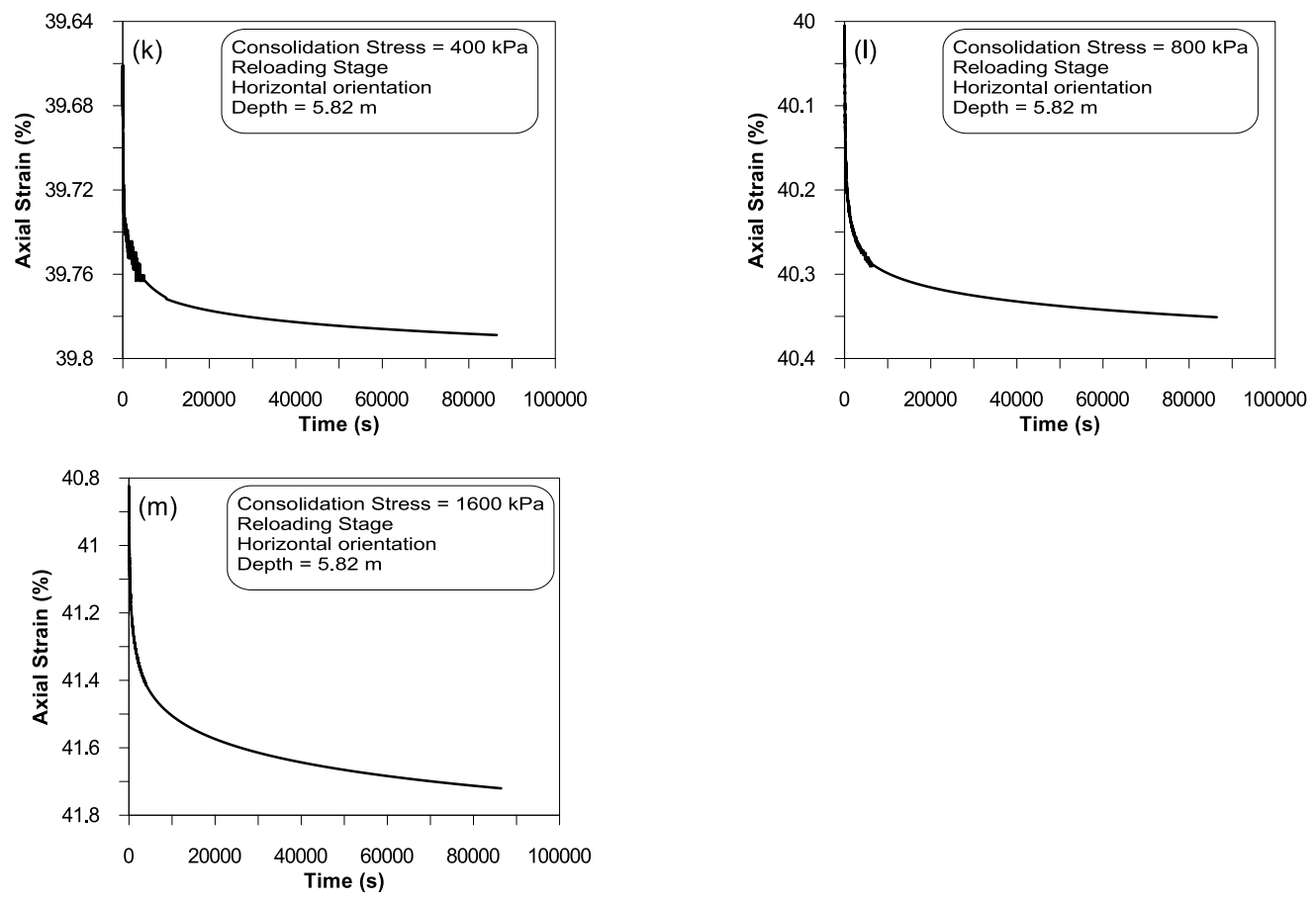

Figure $4.2(\mathrm{k}),(\mathrm{l})$, and $(\mathrm{m})$ : Plots of axial strain versus time during reloading stage for horizontal orientation at a depth of $5.82 \mathrm{~m}$. 


\begin{tabular}{|c|c|c|c|c|c|c|c|}
\hline \multirow{2}{*}{$\begin{aligned} \begin{array}{l}\text { Depth } \\
\text { (m) }\end{array} \\
\\
5.82\end{aligned}$} & \multirow{2}{*}{$\begin{array}{l}\begin{array}{l}\text { Orientation } \\
\text { of tested } \\
\text { specimen }\end{array} \\
\text { Vertical }\end{array}$} & \multicolumn{2}{|c|}{$\begin{array}{l}\text { Strain at the } \\
\text { end of loading } \\
\text { stage }(\%)\end{array}$} & \multicolumn{2}{|c|}{$\begin{array}{l}\text { Swelling strain } \\
\text { at the end of } \\
\text { unloading stage } \\
\text { (\%) }\end{array}$} & \multicolumn{2}{|c|}{$\begin{array}{l}\text { Strain at the end } \\
\text { of the test (\%) }\end{array}$} \\
\hline & & $1600 \mathrm{kPa}$ & 44.11 & $200 \mathrm{kPa}$ & 2.16 & $1600 \mathrm{kPa}$ & 44.74 \\
\hline 5.82 & Horizontal & $1600 \mathrm{kPa}$ & 41.11 & $200 \mathrm{kPa}$ & 1.77 & $1600 \mathrm{kPa}$ & 41.52 \\
\hline 8.26 & Vertical & $400 \mathrm{kPa}$ & 24.63 & $200 \mathrm{kPa}$ & 0.45 & $1600 \mathrm{kPa}$ & 45.77 \\
\hline 8.26 & Horizontal & $400 \mathrm{kPa}$ & 22.61 & $200 \mathrm{kPa}$ & 0.36 & $1600 \mathrm{kPa}$ & 42.90 \\
\hline 11 & Vertical & $1600 \mathrm{kPa}$ & 48.03 & $200 \mathrm{kPa}$ & 1.93 & - & 46.10 \\
\hline 11 & Horizontal & $1600 \mathrm{kPa}$ & 43.06 & $200 \mathrm{kPa}$ & 1.68 & - & 41.38 \\
\hline 17.41 & Vertical & $400 \mathrm{kPa}$ & 12.27 & $100 \mathrm{kPa}$ & 0.44 & $2200 \mathrm{kPa}$ & 29.07 \\
\hline 17.41 & Horizontal & $400 \mathrm{kPa}$ & 13.95 & $100 \mathrm{kPa}$ & 0.45 & $2200 \mathrm{kPa}$ & 31.82 \\
\hline 21.55 & Vertical & $1600 \mathrm{kPa}$ & 25.04 & $200 \mathrm{kPa}$ & 1.63 & $1600 \mathrm{kPa}$ & 25.82 \\
\hline 21.55 & Horizontal & $1600 \mathrm{kPa}$ & 20.51 & $200 \mathrm{kPa}$ & 0.99 & $1600 \mathrm{kPa}$ & 21.96 \\
\hline 21.55 & Vertical & $1600 \mathrm{kPa}$ & 31.76 & - & & - & 31.76 \\
\hline
\end{tabular}

Table 4.1: The amount of strain during different stress history in all tested samples. 


\subsubsection{Compressibility of the soil in the vertical and horizontal orientations}

In this section one-dimensional consolidation curves, for both vertical and horizontal orientations, of specimens at a depth of $5.82 \mathrm{~m}$ are presented. The consolidation curves of the remaining tests are presented in Appendix A. The one-dimensional consolidation curve illustrates the relationship between the void ratio, e, and the effective vertical stress, $\sigma^{\prime}{ }_{v}$.

The consolidation curves in the vertical and horizontal orientations at a depth of 5.82 $\mathrm{m}$ are shown in Figure 4.3. It can be noted from Figure 4.3 that the consolidation curves of the soil, in both vertical and horizontal orientations, are similar to the curves of the sensitive clays that were reported in the literature (Quigley and Thompson, 1966, Mitchell, 1970, Nagaraj et al., 1990, and Taha, 2010). All test depths at both orientations have similar e$\log \sigma_{\mathrm{v}}^{\prime}$ curves as at a depth of $5.82 \mathrm{~m}$. No such consistency was noted at a depth of 21.55 $m$ in the horizontal orientation. This could be due to specimen disturbance. In both orientations, in Figure 4.3, the virgin compression curves are very steep, which largely results from the breakdown of soil particles. In addition, the rebound curves are very flat. Rokhsar (1973) postulated that this was due to the recreation of the cementation bonds in another place and that hold the soil particles together. Also, it can be observed that the unloading and reloading curves in both orientations are almost identical given the elastic nature of the response in this region.

It can be seen that during loading stage the curves pass through three zones; these have been named non-particulate, transitional, and particulate by Nagaraj et al. (1990). The preconsolidation pressures are calculated according to the Casagrande method. The first zone occurs from the first applied stress of $25 \mathrm{kPa}$ up to the preconsolidation pressure, $\sigma_{\mathrm{vc}}^{\prime}$, of $200 \mathrm{kPa}$ in the vertical orientation. In the case of the horizontal orientation it occurs from 
the first applied stress of $25 \mathrm{kPa}$ up to the preconsolidation pressure of $190 \mathrm{kPa}, \sigma^{\prime} \mathrm{hc}$. The soil in this zone has inherent cementation bonds that provide rigidity to the soil against the deformation. The second zone starts from the preconsolidation pressure of $200 \mathrm{kPa}$ and ends at an applied stress of about $600 \mathrm{kPa}$ in the vertical orientation. However, the horizontal orientation starts from the preconsolidation stress of $190 \mathrm{kPa}$ and ends at about $700 \mathrm{kPa}$, indicating that in this zone the inherent cementation bonds start to breakdown gradually causing a steep slope. The last zone, in the vertical orientation, starts from an applied stress of about $600 \mathrm{kPa}$ and continues to the last loading stage (1600 kPa). The last zone, in the horizontal orientation, starts from an applied stress of about $700 \mathrm{kPa}$ and continues to the last loading stage ( $1600 \mathrm{kPa})$. Consequently, the soil condition beyond 600 $\mathrm{kPa}$ (for vertical orientation) and $700 \mathrm{kPa}$ (for horizontal orientation) matches the response noted in normal (not sensitive) clays.

From the two curves in Figure 4.3, it is found that the compression index is about 0.627 in the vertical orientation $\left(\mathrm{C}_{\mathrm{cv}}\right)$ and about 0.635 in the horizontal orientation $\left(\mathrm{C}_{\mathrm{ch}}\right)$. Although this implies that the compression index in the horizontal orientation is somewhat higher than the compression index in the vertical orientation, they do not differ significantly. Generally, throughout all tests the horizontal orientation provides somewhat higher $(1 \%$ to $23 \%)$ compression indices than those in the vertical orientation, with the exception at a depth of $21.55 \mathrm{~m}$. This finding could be attributed to the specimen disturbance in the case of the horizontal orientation. This is because the specimens in the horizontal orientation are less rigid than the specimens in the vertical orientation, which might be due to the directional differences in the soil fabric and in the stress history during soil sedimentation (Khan, 1993). Furthermore, it is found that the preconsolidation pressure 
at the vertical orientation $(200 \mathrm{kPa})$ is not identical to the preconsolidation pressure at the horizontal orientation $(190 \mathrm{kPa})$. Generally, it is noted that the vertical orientation has larger preconsolidation pressures than those in the horizontal orientation for all tests. This observation is in agreement with the results reported by Chai et al. (2012) based on tests on undisturbed Ariake clay, Khan (1993) whose studied Eastern Canadian clay deposits (a weathered clay crust), and Silvesrti et al. (1989) who performed tests on two Canadian sensitive clays. The reason for this finding is similar to the compression index condition.

Table 4.2 illustrates the calculated preconsolidation pressure, and the compression index in both orientations for all tests. It can be observed that the preconsolidation pressure, $\sigma_{\mathrm{vc}}^{\prime}$, ranges between $200 \mathrm{kPa}$ and $350 \mathrm{kPa}$ in the vertical orientation and between $150 \mathrm{kPa}$ and $250 \mathrm{kPa}$ in the horizontal orientation, $\sigma^{\prime} \mathrm{hc}$, depending on the depth of the samples. The compression index varies from 0.445 to 0.627 in the vertical orientation, $\mathrm{C}_{\mathrm{cv}}$, and from 0.411 to 0.675 in the horizontal orientation, $\mathrm{C}_{\mathrm{ch}}$, at the same depths. The compression indices on the vertical orientation are similar to the values presented in the literature review section (Javed, 2011). The level of swelling during unloading is fairly small and resulted in a recompression index to compression index average ratio of 0.11 and 0.07 through all tests for vertical and horizontal orientations respectively. 


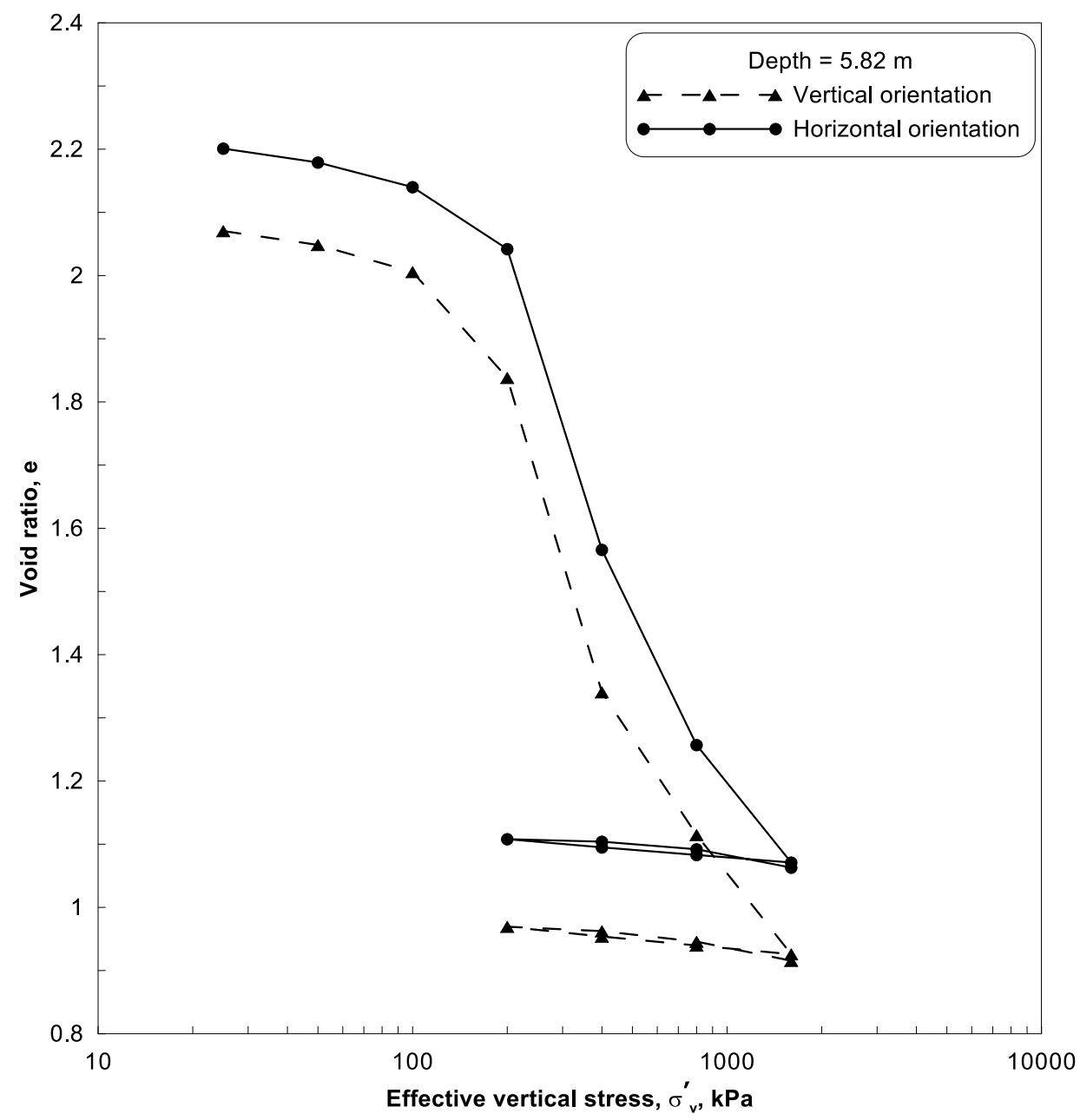

Figure 4.3: One-dimensional consolidation curves for vertical and horizontal orientations $($ depth $=5.82 \mathrm{~m})$. 


\begin{tabular}{|c|c|c|c|}
\hline $\begin{array}{l}\text { Depth } \\
(\mathbf{m})\end{array}$ & $\begin{array}{l}\text { Orientation of } \\
\text { tested specimen }\end{array}$ & $\begin{array}{l}\text { Preconsolidation } \\
\text { pressure (kPa) }\end{array}$ & $\begin{array}{l}\text { Compression } \\
\text { index }\end{array}$ \\
\hline 5.82 & Vertical & 200 & 0.627 \\
\hline 5.82 & Horizontal & 190 & 0.635 \\
\hline 8.26 & Vertical & 200 & 0.551 \\
\hline 8.26 & Horizontal & 175 & 0.675 \\
\hline 11 & Vertical & 225 & 0.507 \\
\hline 11 & Horizontal & 190 & 0.573 \\
\hline 17.41 & Vertical & 200 & 0.466 \\
\hline 17.41 & Horizontal & 150 & 0.488 \\
\hline 21.55 & Vertical & 350 & 0.445 \\
\hline 21.55 & Horizontal & 250 & 0.411 \\
\hline 21.55 & Vertical & 350 & \\
\hline & & & \\
\hline
\end{tabular}

Table 4.2: Summary of the values of preconsolidation pressure, and compression index for all soil tested in the vertical and horizontal orientations. 


\subsubsection{The coefficient of consolidation in the vertical and horizontal orientations}

The coefficients of consolidation, used in both orientations, for each load increment are calculated based on commonly used methods; the time logarithm method (Casagrande's method) and the time square root method (Taylor's method). Equation 4.1 and 4.2 are used for the determination of the coefficient of consolidation:

$$
\begin{array}{ll}
\mathrm{C}_{\mathrm{v}} \text { or } \mathrm{C}_{\mathrm{h}}=0.197\left(\frac{H^{2} d r}{t_{50}}\right) & 4.1 \text { (Casagrande's method) } \\
\mathrm{C}_{\mathrm{v}} \text { or } \mathrm{C}_{\mathrm{h}}=0.848\left(\frac{H^{2} d r}{t_{90}}\right) & 4.2 \text { (Taylor's method) }
\end{array}
$$

The plots of the coefficients of consolidation for vertical and horizontal specimens that were trimmed at a depth of $5.82 \mathrm{~m}$ are presented in this section. The plots of the remaining tests are provided in Appendix A. Figure 4.4 shows the variation of the coefficient of consolidation calculated using Casagrande's method with the stress level for samples obtained along the vertical $\left(\mathrm{C}_{\mathrm{v}}\right)$ and horizontal $\left(\mathrm{C}_{\mathrm{h}}\right)$ orientations. Similar data using Taylor's method is shown in Figure 4.5.

During the loading stage, the coefficient of consolidation (both $\mathrm{C}_{\mathrm{v}}$ and $\mathrm{C}_{\mathrm{h}}$ ) increases with the effective vertical stress $\left(\sigma^{\prime}{ }_{\mathrm{v}}\right)$ until they reached the maximum values near their corresponding preconsolidation pressures. This is because at stresses below the preconsolidation pressure, the orientation of clay particles do not change significantly (Quigley and Thompson, 1966). Then beyond the preconsolidation pressures region both $\mathrm{C}_{\mathrm{v}}$ and $\mathrm{C}_{\mathrm{h}}$ decrease gradually with the continuous increment of the effective vertical stress $\left(\sigma_{\mathrm{v}}^{\prime}\right)$. The reason for this is most likely due to the abrupt development in the parallelism of 
the soil particles, which could result from the gradual breakdown of the soil structure after exceeding the preconsolidation region (Quigley and Thompson, 1966). Generally, all remaining tests with different depths have similar behaviour to the $5.82 \mathrm{~m}$ depth in the loading stage. This trend seen in the coefficient of consolidation (both $C_{v}$ and $C_{h}$ ) in the loading stage is consistent with the trend reported by Bechi (1974) for $C_{v}$. In the Casagrande's method, the vertical coefficient of consolidation is found to be about $3.70 \times 10^{-}$ ${ }^{7} \mathrm{~m}^{2} / \mathrm{sec}$ at the initial stress and at the final stress about $6.80 \times 10^{-8} \mathrm{~m}^{2} / \mathrm{sec}$ with a maximum value of $4.40 \times 10^{-7} \mathrm{~m}^{2} / \mathrm{sec}$ near the preconsolidation pressure of $200 \mathrm{kPa}$. However, Taylor' $\mathrm{s}$ method shows that the vertical coefficient of consolidation is indicated to be almost $1.20 \times 10^{-6} \mathrm{~m}^{2} / \mathrm{sec}$ at the initial stress and at the final stress almost $1.83 \times 10^{-7} \mathrm{~m}^{2} / \mathrm{sec}$ with a maximum value of $1.43 \times 10^{-6} \mathrm{~m}^{2} / \mathrm{sec}$ near the preconsolidation pressure of $200 \mathrm{kPa}$. The vertical coefficient of consolidation values that found herein are close to those values reported by Javed (2011). In addition, Casagrande's method shows that the horizontal coefficient of consolidation is about $4.75 \times 10^{-7} \mathrm{~m}^{2} / \mathrm{sec}$ at the initial stress and about $1.05 \times 10^{-7} \mathrm{~m}^{2} / \mathrm{sec}$ at the final stress with a maximum value of $8.38 \times 10^{-7} \mathrm{~m}^{2} / \mathrm{sec}$ near the preconsolidation pressure of $190 \mathrm{kPa}$. However, Taylor's method indicates that the horizontal coefficient of consolidation is almost $1.72 \times 10^{-6} \mathrm{~m}^{2} / \mathrm{sec}$ at the initial stress and at the final stress almost $3.04 \times 10^{-7} \mathrm{~m}^{2} / \mathrm{sec}$ with a maximum value of $2.71 \times 10^{-6} \mathrm{~m}^{2} / \mathrm{sec}$ near the preconsolidation pressure of $190 \mathrm{kPa}$. It can be seen in Figure 4.4 and Figure 4.5 that the values of the coefficient of consolidation in the horizontal orientation, $\mathrm{C}_{\mathrm{h}}$, are higher than those in the vertical orientation, $\mathrm{C}_{\mathrm{v}}$. This behaviour agrees, for example, with the findings obtained by Seah and Koslanant (2003) on sensitive Bangkok clay. This can be explained by the orientation of the in situ clay particles that are directed parallel to the 
horizontal orientation, which can leave more surface area for the vertical orientation (Khan, 1993). All remaining tests at different depths have similar behaviours to the depth of 5.82 $\mathrm{m}$ in the loading stage. Generally, the findings herein show that Taylor's method leads to higher values of the vertical and horizontal coefficients of consolidation than those obtained by Casagrande's method throughout the loading stage. Hossain (1995), Sridharan and Prakash (1995), Robinson (1999), Seah and Koslanant (2003), and Al-Zoubi (2008) reported that Taylor's method provides higher vertical coefficient of consolidation than Casagrande's method.

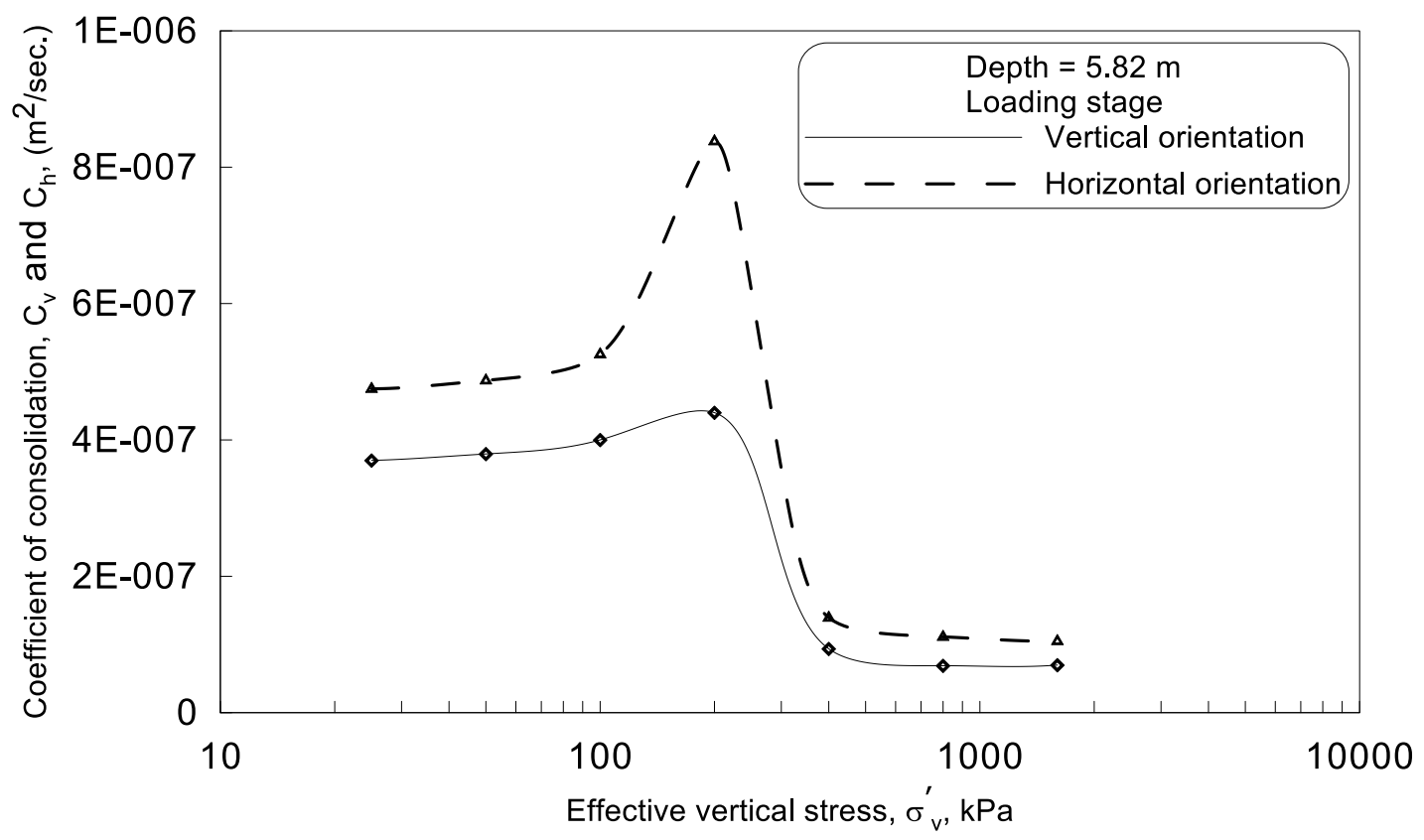

Figure 4.4: Typical plots of the vertical and horizontal coefficients of consolidation versus the logarithm of effective vertical stress by using Casagrande's method during the loading stage at depth of $5.82 \mathrm{~m}$. 


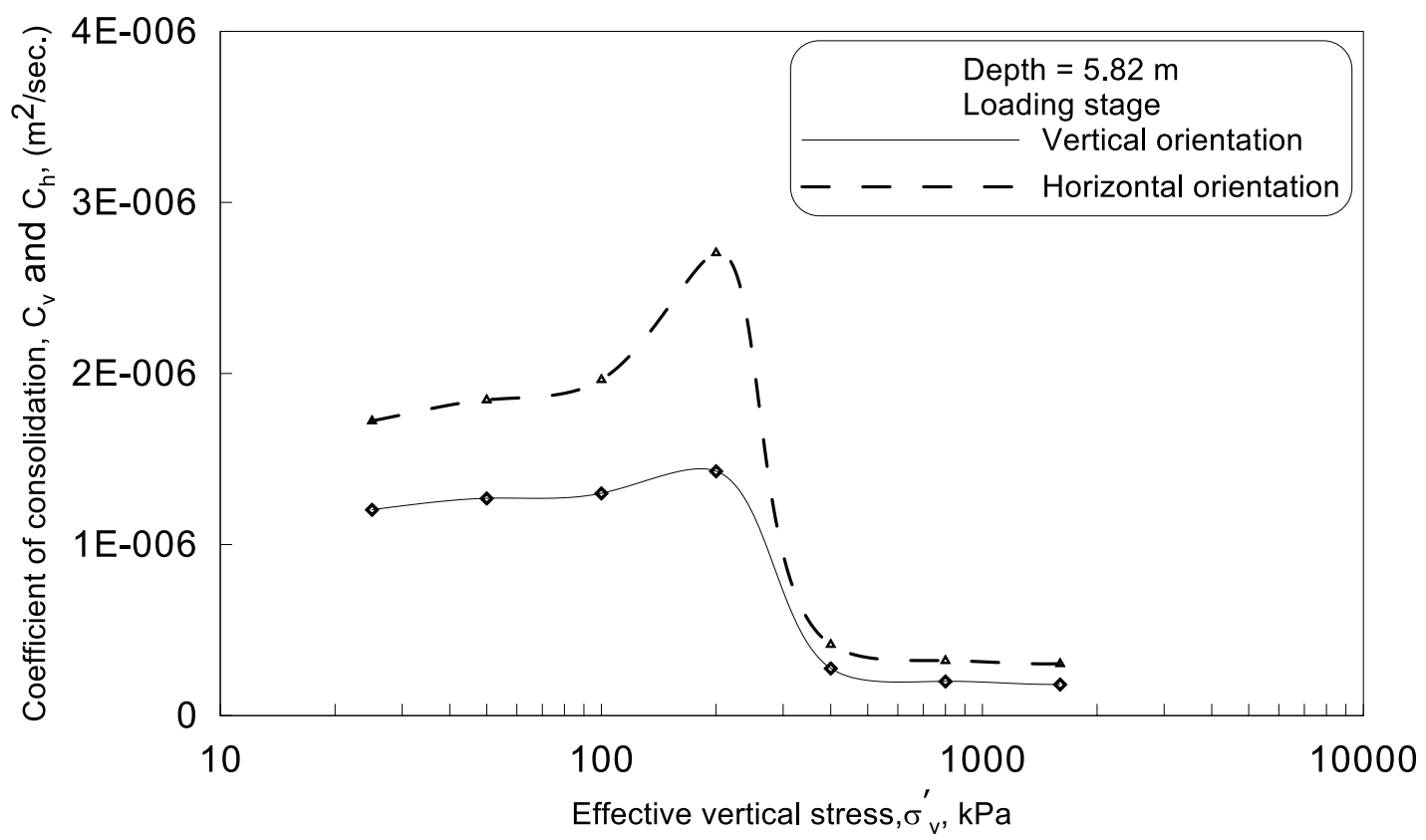

Figure 4.5: Typical plots of the vertical and horizontal coefficients of consolidation versus the logarithm of effective vertical stress by using Taylor's method during the loading stage at depth of $5.82 \mathrm{~m}$.

\subsubsection{The coefficient of permeability in the vertical and horizontal orientations}

The vertical and horizontal coefficients of permeability values, $\mathrm{k}_{\mathrm{v}}$ and $\mathrm{k}_{\mathrm{h}}$, are calculated by using the following two equations 4.3 and 4.4 :

$$
\begin{array}{ll}
\mathrm{k}_{\mathrm{v}}=\mathrm{C}_{\mathrm{v}} \mathrm{m}_{\mathrm{v}} \gamma_{\mathrm{w}} & 4.3 \text { (based on Casagrande's method Taylor's method) } \\
\mathrm{k}_{\mathrm{h}}=\mathrm{C}_{\mathrm{h}} \mathrm{m}_{\mathrm{h}} \gamma_{\mathrm{w}} & 4.4 \text { (based on Casagrande's method Taylor's method) }
\end{array}
$$

Data for two specimens, one trimmed on the vertical orientation and another one on the horizontal orientation from the same depth of $5.82 \mathrm{~m}$, are shown in Figure 4.6 and Figure 4.7. Data for the remaining tests are provided in Appendix A. 
Figure 4.6 and Figure 4.7 show the relationship between the vertical and horizontal coefficients of permeability against the logarithm of effective vertical stress during the loading stage. It can be seen that the coefficient of permeability, due to the vertical and horizontal drainages, increases as the effective vertical stress $\left(\sigma^{\prime}{ }_{\mathrm{v}}\right)$ is increased up to their corresponding preconsolidation pressures region. Once the effective vertical stress $\left(\sigma_{\mathrm{v}}^{\prime}\right)$ exceeds the preconsolidation pressure, both the $\mathrm{k}_{\mathrm{v}}$ and $\mathrm{k}_{\mathrm{h}}$ start to decrease gradually, and the trend continues until the end of the loading stage. The reason for the initially increasing and subsequently decreasing, $\mathrm{k}_{\mathrm{v}}$ and $\mathrm{k}_{\mathrm{h}}$, prior and after exceeding the preconsolidation pressures, is similar to the coefficient of consolidations $\left(\mathrm{C}_{\mathrm{v}}\right.$ and $\left.\mathrm{C}_{\mathrm{h}}\right)$ explanation, since the coefficient of permeability is calculated from the coefficient of consolidation. Therefore, the shape of the vertical and horizontal coefficients of permeability curves (Figure 4.6 and Figure 4.7) are similar to the variations of the vertical and horizontal coefficients of consolidation (Figure 4.4 and Figure 4.5) with the logarithm of effective vertical stress. There is a consistency between the trend of vertical coefficient of permeability that is found herein and the trend reported by Bechi (1974). From the Casagrande's method, it can observed that the vertical coefficient of permeability is about $1.06 \times 10^{-9} \mathrm{~m} / \mathrm{sec}$ at the initial stress and about $7.64 \times 10^{-11} \mathrm{~m} / \mathrm{sec}$ at the final stress with a maximum value of $2.41 \times 10^{-9}$ $\mathrm{m} / \mathrm{sec}$ near the preconsolidation pressure of $200 \mathrm{kPa}$. In the case of Taylor's method, the results indicate that the vertical coefficient of permeability is almost $3.30 \times 10^{-9} \mathrm{~m} / \mathrm{sec}$ at the initial stress and almost $2 \times 10^{-10} \mathrm{~m} / \mathrm{sec}$ at the final stress, with a maximum value of $7.82 \times 10^{-}$ ${ }^{9} \mathrm{~m} / \mathrm{sec}$ at the corresponding preconsolidation pressure of $200 \mathrm{kPa}$. The values of vertical coefficient of permeability that found herein fall within the range that reported by Hamilton and Crawford (1959). However, the horizontal coefficient of permeability that is calculated 
based on Casagrande's method is found to be about $1.11 \times 10^{-9} \mathrm{~m} / \mathrm{sec}$ at the initial stress and about $1.28 \times 10^{-10} \mathrm{~m} / \mathrm{sec}$ at the final stress with a maximum value of $2.55 \times 10^{-9} \mathrm{~m} / \mathrm{sec}$ near the preconsolidation pressure of $190 \mathrm{kPa}$. In case of Taylor's method, the horizontal coefficient of permeability is found to be almost $3.69 \times 10^{-9} \mathrm{~m} / \mathrm{sec}$ at the initial stress and about $3.07 \times 10^{-10} \mathrm{~m} / \mathrm{sec}$ at the final stress with a maximum value of $8.22 \times 10^{-9} \mathrm{~m} / \mathrm{sec}$ near the preconsolidation pressure of $190 \mathrm{kPa}$. It can be observed in Figure 4.6 and Figure 4.7 that the coefficient of permeability in the horizontal orientation, $\mathrm{k}_{\mathrm{h}}$, is higher than that in the vertical orientation, $\mathrm{k}_{\mathrm{v}}$. This observation is in agreement with the findings obtained by Seah and Koslanant (2003) on sensitive Bangkok clay. The cause of this finding is similar to that mentioned in the previous section, since the coefficient of permeability is related to the coefficient of consolidation, as shown in equations 4.3 and 4.4. All remaining tests with different depths have comparable behaviours to a depth of $5.82 \mathrm{~m}$ in the loading stage. Taylor's method provides higher values of the vertical and horizontal coefficients of permeability than those calculated by Casagrande's method throughout the loading stage of all tests as occurred with the vertical and horizontal coefficients of consolidation. 


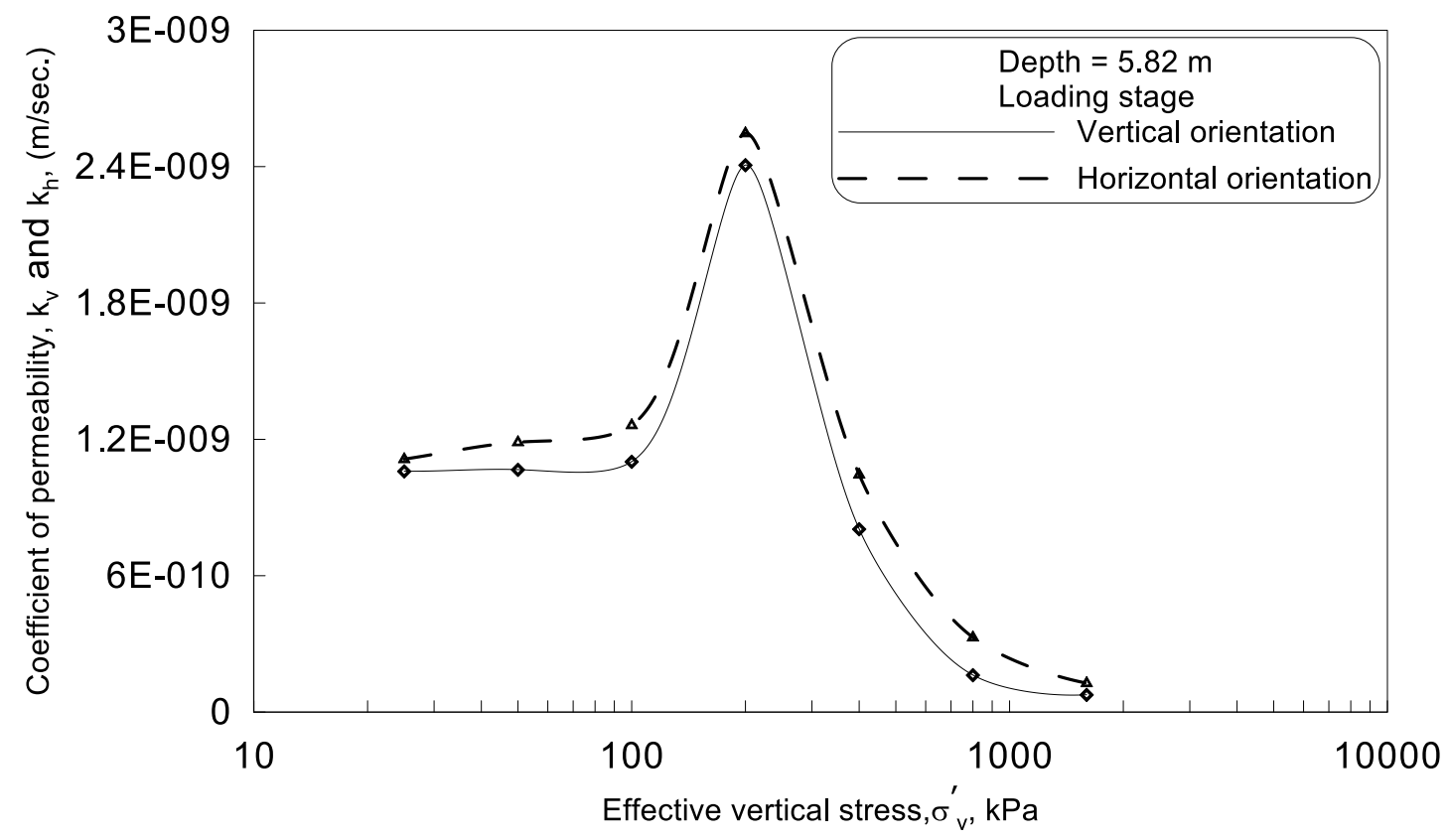

Figure 4.6: Typical plots of the vertical and horizontal coefficients of permeability versus the logarithm of effective vertical stress by using Casagrande's method during the loading stage at depth of $5.82 \mathrm{~m}$.

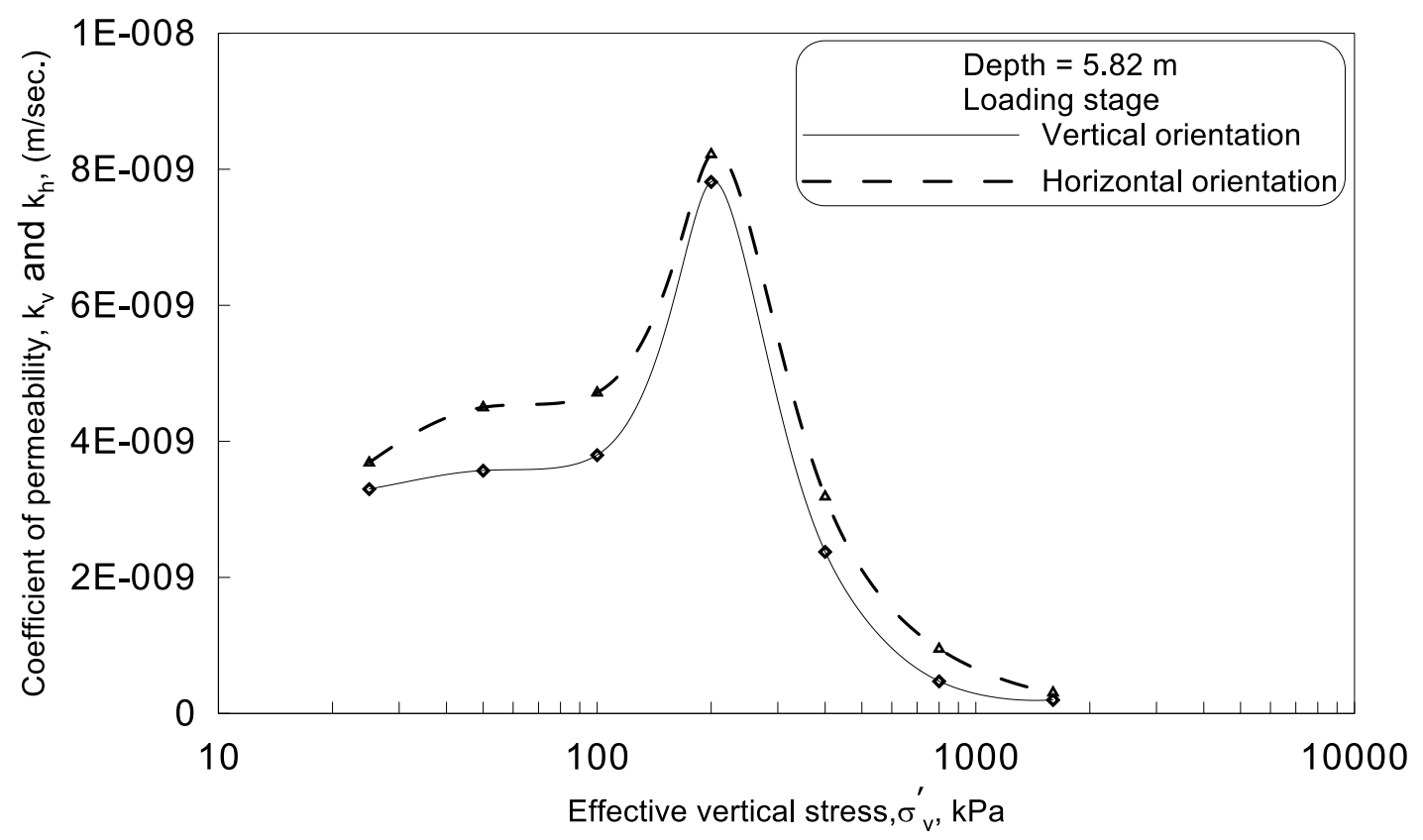

Figure 4.7: Typical plots of the vertical and horizontal coefficients of permeability versus the logarithm of effective vertical stress by using Taylor's method during the loading stage at depth of $5.82 \mathrm{~m}$. 


\subsubsection{The at-rest lateral earth pressure coefficient in the vertical and horizontal orientations}

The variation of the at-rest lateral earth pressure coefficient in vertical and horizontal specimens, which were trimmed at a depth of $5.82 \mathrm{~m}$, are presented in this section. The data for the remaining tests are provided in Appendix A. This section includes the typical plots of effective horizontal stress $\left(\sigma_{h}^{\prime}\right)$ versus effective vertical stress $\left(\sigma^{\prime}{ }_{\mathrm{v}}\right)$, and the relationship between the at-rest lateral earth pressure coefficient versus the effective vertical stress for vertical and horizontal specimens $\left(\mathrm{K}_{0 \mathrm{v}}\right.$ and $\left.\mathrm{K}_{0 \mathrm{~h}}\right)$ at a depth of $5.82 \mathrm{~m}$. Figure 4.8 (a) to Figure 4.8 (c) and Figure 4.9 (a) to Figure 4.9 (c) show the typical plots of the effective horizontal stress versus the effective vertical stress during the loadingunloading-reloading stages for specimens trimmed along both vertical and horizontal orientations (at a depth of $5.82 \mathrm{~m}$ ) respectively.

The plots in Figure 4.8 (a) and Figure 4.9 (a) show the variation of the effective horizontal stress with the effective vertical stress for the loading stage. An almost linear variation during the loading stage (Figure 4.8 (a) and Figure 4.9 (a)) indicates $\mathrm{K}_{0 \mathrm{v}}$ and $\mathrm{K}_{0 \mathrm{~h}}$ are essentially constant during this phase. The reaming tests also show a linear relationship between the effective vertical stresses and the effective horizontal stresses during the loading stage. These results are similar to the trend that was found by Brooker and Ireland (1965) on remoulded cohesive soils and Campanella and Vaid (1972) on undisturbed sensitive clay (Haney clay).

In the case of the unloading stage as shown in Figure 4.8 (b) and Figure 4.9 (b) for vertical and horizontal specimens, the relationship between the effective horizontal stresses and the effective vertical stresses is non-linear. In addition, it is observed that the decrease 
in the effective vertical stress gradually leads to a higher ratio of the effective horizontal stress $\left(\sigma_{\mathrm{h}}^{\prime}\right)$ to the effective vertical stress $\left(\sigma_{\mathrm{v}}^{\prime}\right)$ during the unloading stage. The trend that is found herein is similar to the trend that is reported by Brooker and Ireland (1965) on remoulded cohesive soils and Campanella and Vaid (1972) on undisturbed sensitive clay (Haney clay).

In the reloading stage, as shown in Figure 4.8 (c) and Figure 4.9 (c) for vertical and horizontal specimens, the relationship between the effective horizontal stresses and the effective vertical stresses is non-linear, which is similar to the unloading stage. The trend in this stage is similar to that reported by Campanella and Vaid (1972) on undisturbed sensitive clay (Haney clay). Generally, almost all remaining tests (during unloading and reloading stages) have comparable behaviours to a depth of $5.82 \mathrm{~m}$.

The at-rest lateral earth pressure coefficient is, $K_{o}$, calculated based on the ratio of the effective horizontal stress to the effective vertical stress. The relationship between the atrest lateral earth pressure coefficient and the effective vertical stress during loadingunloading-reloading stages for vertical and horizontal trimmed specimens at a depth of $5.82 \mathrm{~m}$ is illustrated in Figures 4.10 (a) to 4.10 (c).

During the loading stage for both the vertical and horizontal trimmed specimens $\left(\mathrm{K}_{0 \mathrm{v}}\right.$ and $\mathrm{K}_{0 \mathrm{~h}}$ ), as shown in Figure 4.10 (a), the at-rest lateral earth pressure coefficient values decrease slightly until the preconsolidation pressure, and become almost constant as the effective vertical stresses are increased beyond the preconsolidation pressure. The two plots in Figure 4.10 (a) reveal that as the overconsolidation ratio is decreased the at-rest lateral earth pressure coefficient values are decreased. All remaining tests have consistent 
behaviours to a depth of $5.82 \mathrm{~m}$. The results, at a depth of $5.82 \mathrm{~m}$, indicate that the average value of the at-rest lateral earth pressure coefficient during the loading stage, in the case of vertical specimen is about 0.52 , which is close to the values reported in the literature by Bozozuk (1972), Campanella and Vaid (1972), and Silvestri and Morgavi (1982). In addition, the remaining tests in the vertical orientation have average values of the at-rest lateral earth pressure coefficient close to that at a depth of $5.82 \mathrm{~m}$, excepting at a depth of $11 \mathrm{~m}$. However, the results at a depth of $5.82 \mathrm{~m}$, indicate that the average value of the atrest lateral earth pressure coefficient during the loading stage in case of horizontal specimen is about 0.61 .

During the unloading stage for both the vertical and horizontal specimens, as shown in Figure 4.10 (b), the at-rest lateral earth pressure coefficient values increase as the effective vertical stress is decreased. This means that as the overconsolidation ratio is increased the at-rest lateral earth pressure coefficient values are increased. This is consistent with the formulation of Jaky (1944) for $K_{o}$ in overconsoildation soils. The observation in the remaining tests is similar to that at a depth of $5.82 \mathrm{~m}$. Figure 4.10 (b) indicates that the at-rest lateral earth pressure coefficients at the end of this stage, for both vertical and horizontal orientations, are larger than 1 . The values of the at-rest lateral earth pressure coefficient are varied between 0.62 and 1.34 for the vertical trimmed specimen and between 0.9 and 1.89 for the horizontal trimmed specimen.

During the reloading stage (Figure 4.10 (c)), the at-rest lateral earth pressure coefficient values are seen to decrease as the effective vertical stress is increased for both the vertical and horizontal specimens. In other words, as the overconsolidation ratio is decreased the at-rest lateral earth pressure coefficient values are decreased. Generally, all 
remaining tests have comparable behaviour to a depth of $5.82 \mathrm{~m}$. The at-rest lateral earth pressure coefficient values are varied between 0.42 and 0.65 for the vertical trimmed specimen and between 0.61 and 1.09 for the horizontal trimmed specimen. Figure 4.11 and Figure 4.12 show the variation of the at-rest lateral earth pressure coefficient, for the vertical and horizontal orientations at a depth of $5.82 \mathrm{~m}$, with the overconsolidation ratio (OCR) during the unloading and reloading stages. The remaining tests are provided in Appendix A.

In all vertical and horizontal tested specimens throughout different stress histories, the relationship between the overconsolidation ratio and the at-rest lateral earth pressure coefficient is consistent with the data reported in the literature by (Brooker and Ireland, 1965) and (Campanella and Vaid, 1972). It can be seen from the three figures (at a depth of $5.82 \mathrm{~m}$ ) that the at-rest lateral earth pressure coefficient in the horizontal orientation is higher than those in the vertical orientation during the loading-unloading-reloading stages. Generally, almost all remaining tests are in agreement at a depth of $5.82 \mathrm{~m}$ in that $\mathrm{K}_{0 \mathrm{~h}}>$ $\mathrm{K}_{0 \mathrm{v}}$ even though the samples at different depths have been subjected to different stress histories. However, at a depth of $17.41 \mathrm{~m}$ shows an inverse behaviour, which may possibly be due to the sample preparation. The difference between the at-rest lateral earth pressure coefficient in the vertical and horizontal orientations could be attributed mostly to the variation in the stress history during sedimentation stage. 

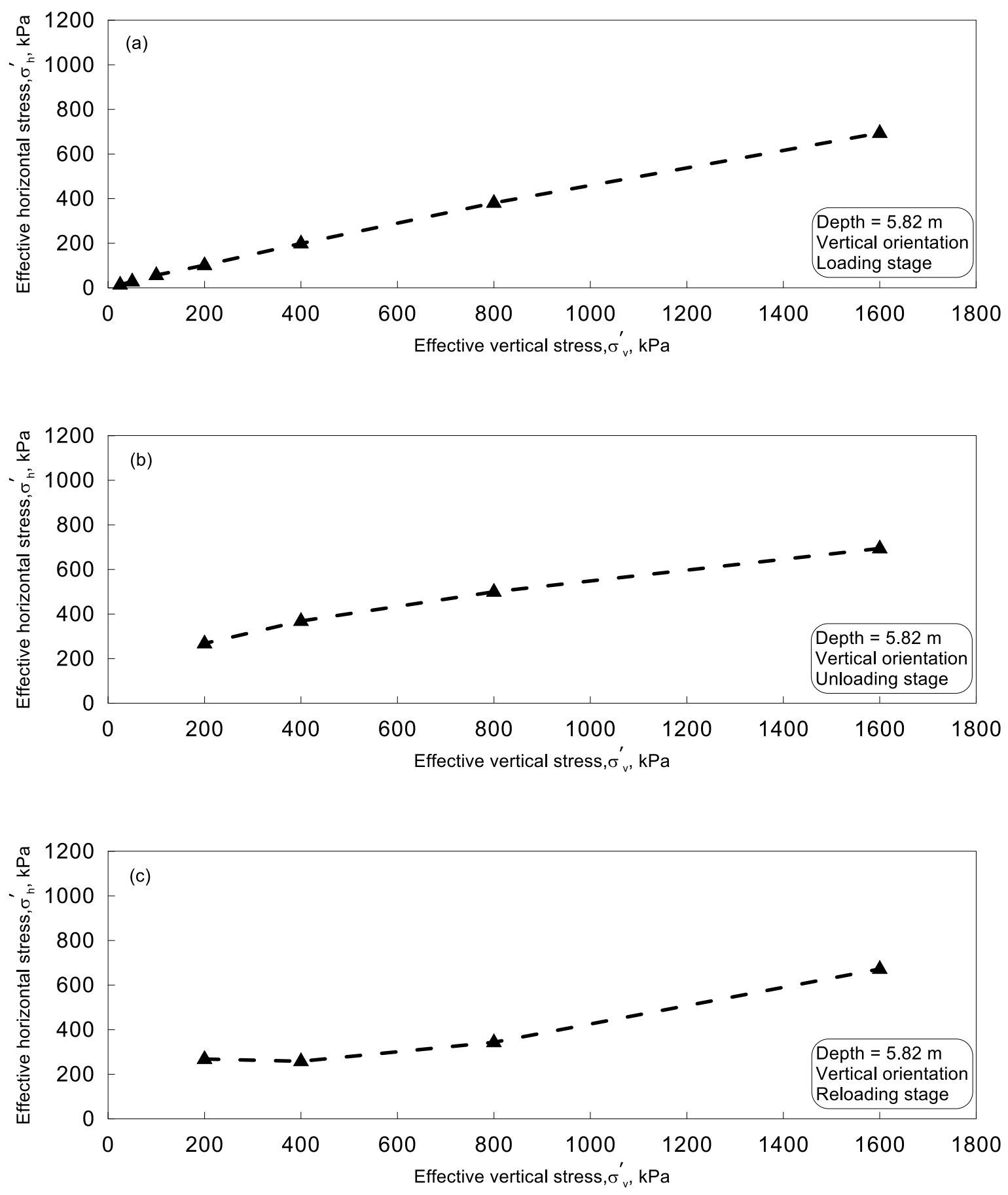

Figure 4.8: Typical plots of the effective horizontal stress versus the effective vertical stress during the (a) loading, (b) unloading, and (c) reloading stages for vertical orientation (depth $=5.82 \mathrm{~m})$. 

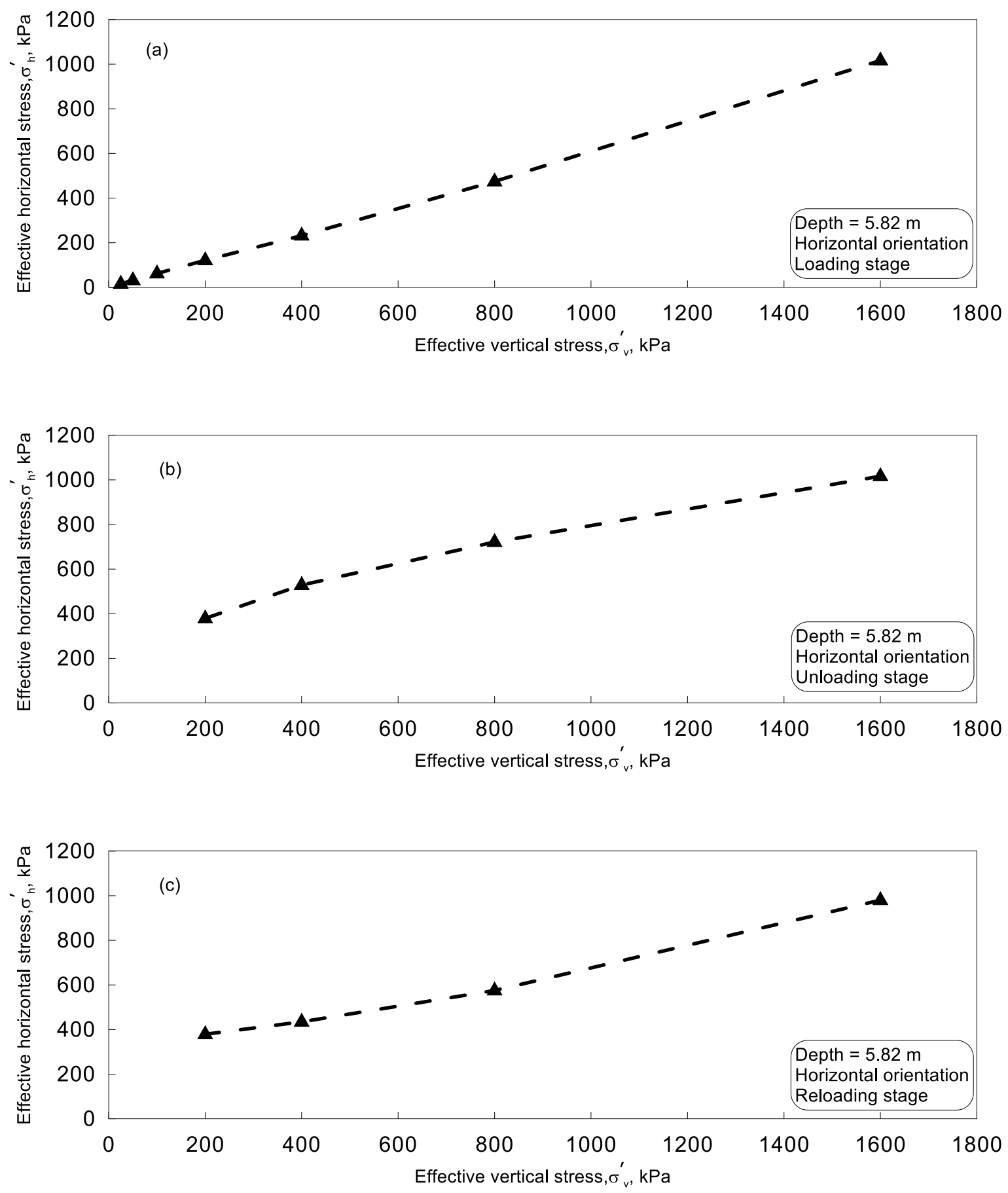

Figure 4.9: Typical plots of the effective horizontal stress versus the effective vertical stress during the (a) loading, (b) unloading, and (c) reloading stages for horizontal orientation $($ depth $=5.82 \mathrm{~m})$. 

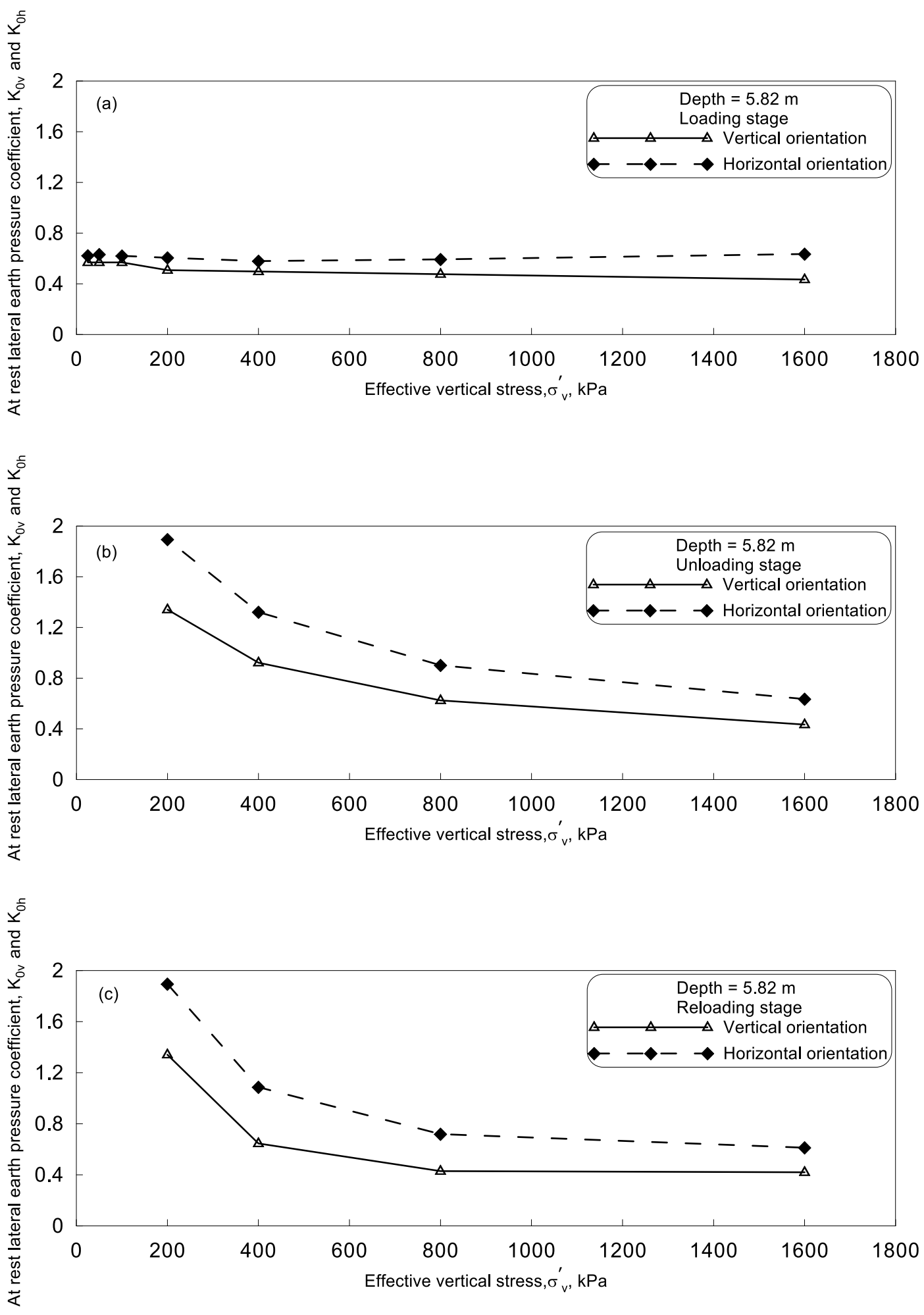

Figure 4.10: Typical plots of the at-rest lateral earth pressure coefficient versus the effective vertical stress for vertical and horizontal orientations during the (a) loading, (b) unloading, and $(\mathrm{c})$ reloading stages $(\mathrm{depth}=5.82 \mathrm{~m})$. 


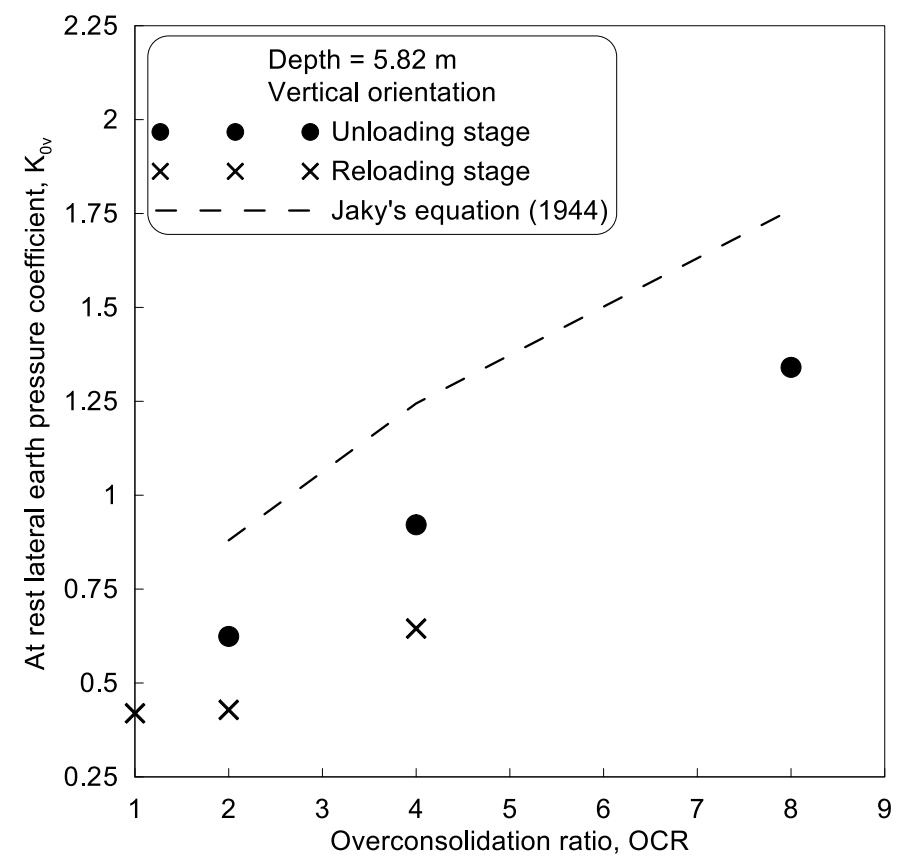

Figure 4.11: The variation of the at-rest lateral earth pressure coefficient, for the vertical orientation at depth of $5.82 \mathrm{~m}$, with the overconsolidation ratio (OCR) during the unloading and reloading stages.

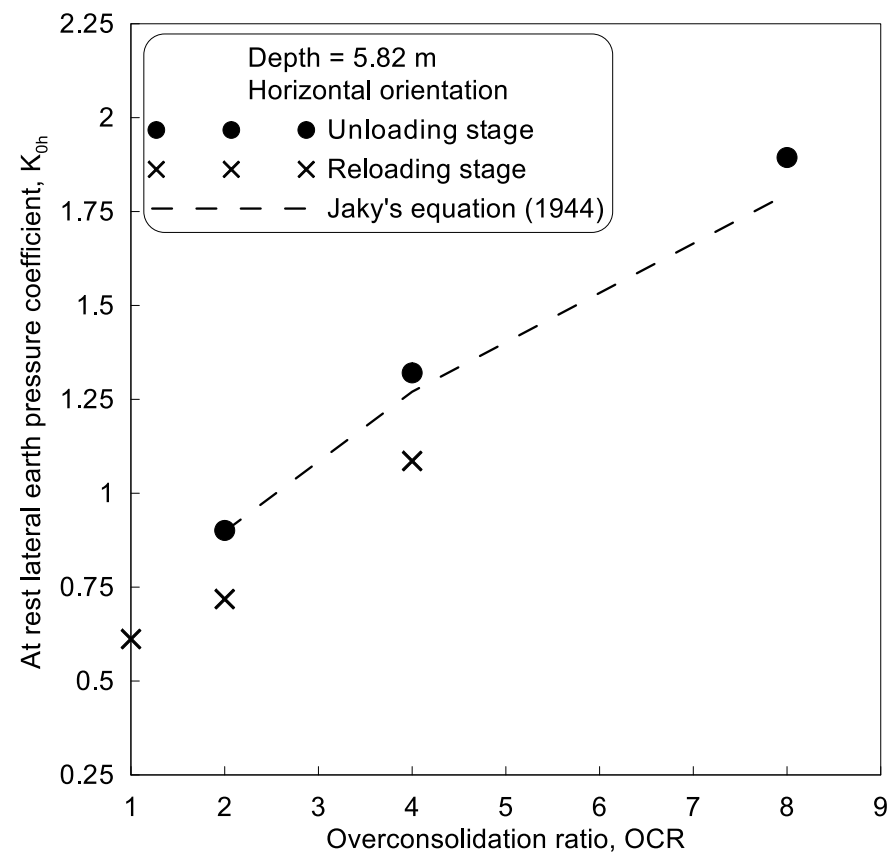

Figure 4.12: The variation of the at-rest lateral earth pressure coefficient, for the horizontal orientation at depth of $5.82 \mathrm{~m}$, with the overconsolidation ratio (OCR) during the unloading and reloading stages. 
Table 4.3 summarizes the test results of the at-rest lateral earth pressure coefficient, for both the vertical and horizontal orientations, for all tests used in this investigation during different loading stages. This table shows that the at-rest lateral earth pressure coefficient during the loading stage for all test depths on vertically trimmed specimens ranges between 0.25 and 0.67 , and between 0.47 , and 0.64 for horizontally trimmed specimens. In the case of the unloading stage, Table 4.3 indicates that the at-rest lateral earth pressure coefficient ranges between 0.38 and 1.14 for vertically trimmed specimens and between 0.56 and 1.89 for horizontally trimmed specimens. For the reloading stage, the table shows that the at-rest lateral earth pressure coefficient ranges between 0.35 and 0.76 for vertically trimmed specimens and between 0.44 and 1.09 for horizontally trimmed specimens.

\begin{tabular}{|c|c|c|c|c|}
\hline \multirow{2}{*}{$\begin{array}{c}\text { Depth } \\
(\mathbf{m})\end{array}$} & $\begin{array}{c}\text { Orientation } \\
\text { of tested } \\
\text { specimen }\end{array}$ & \multicolumn{2}{|l|}{ The at-rest lateral earth pressure coefficient } \\
\cline { 3 - 5 } & Vertical & 0.43 to 0.57 & 0.62 to 1.34 & 0.42 to 0.65 \\
\hline 5.82 & Horizontal & 0.58 to 0.64 & 0.9 to 1.89 & 0.61 to 1.09 \\
\hline 5.82 & Vertical & 0.52 to 0.56 & 0.65 & 0.35 to 0.51 \\
\hline 8.26 & Horizontal & 0.53 to 0.58 & 0.64 & 0.48 to 0.52 \\
\hline 8.26 & Vertical & 0.25 to 0.54 & 0.38 to 0.79 & - \\
\hline 11 & Horizontal & 0.47 to 0.61 & 0.65 to 1.44 & - \\
\hline 11 & Vertical & 0.51 to 0.52 & 0.54 to 0.61 & 0.58 to 0.60 \\
\hline 17.41 & Horizontal & 0.47 to 0.50 & 0.56 to 0.73 & 0.44 to 0.50 \\
\hline 17.41 & Vertical & 0.65 to 0.67 & 0.79 to 1.14 & 0.63 to 0.76 \\
\hline 21.55 & Horizontal & 0.58 to 0.63 & 0.83 to 1.63 & 0.58 to 0.98 \\
\hline 21.55 & Vertical & 0.36 to 0.55 & & - \\
\hline 21.55 & & & \\
\hline
\end{tabular}

Table 4.3: Summary of the results of the at-rest lateral earth pressure coefficients for vertical and horizontal orientations for all tests. 


\subsubsection{Anisotropy in consolidation tests}

This section will discuss the degree of the anisotropy of the all tested specimens in terms of the following ratios: the ratio of the horizontal preconsolidation pressure to the vertical preconsolidation pressure; the ratio of the horizontal compression index to the vertical compression index; the ratio of the horizontal coefficient of consolidation to the vertical coefficient of consolidation; the ratio of the horizontal coefficient of permeability to the vertical coefficient of permeability; and the ratio of the at rest lateral earth pressure coefficient in the horizontal orientation to the at rest lateral earth pressure coefficient in the vertical orientation.

Table 4.4 shows the vertical and horizontal preconsolidation pressures, and the preconsolidation pressure ratio for all the tests. It can be observed from the table that the preconsolidation pressure in vertical orientation is higher than the preconsolidation pressure in horizontal orientation for all tests. The preconsolidation pressure ratio, $\sigma^{\prime}{ }_{\mathrm{hc}} /$ $\sigma_{\mathrm{vc}}^{\prime}$, varies between 0.71 and 0.95 with average value of 0.83 . This range falls within the range reported by Chai et al. (2012) who performed tests on Ariake Clay. In addition, the average value of the preconsolidation pressure ratio falls between the two values that reported by Silvestri et al. (1989) who tested two Canadian sensitive clays. Figure 4.13 illustrates the variation of ratio of horizontal to vertical preconsolidation pressure with depths of tested boreholes. It can be seen that the ratio of preconsolidation pressure is decreased as the sample depth is increased. The differences in the preconsolidation pressure can be a factor in the measured response along vertical and horizontal orientations. One of the potential reasons for such variations is a reduction in OCR with depth. This will be case, if overconsolidation was caused by surface-ice-loads, which would cause the 
preconsolidation pressure ratio to decrease as the depth is increased. It is also recognized that both salinity clay content varies with depth in Champlain Sea clays, and the variations in those parameters might also be contribute to the differences observed with depth.

\begin{tabular}{|c|c|c|c|}
\hline \multirow{2}{*}{ Depth (m) } & \multicolumn{2}{|c|}{$\begin{array}{c}\text { Preconsolidation pressure } \\
\text { (kPa) }\end{array}$} & The ratio of $\boldsymbol{\sigma}^{\prime}{ }_{\mathrm{hc}} / \boldsymbol{\sigma}_{\mathbf{v c}}^{\prime}$ \\
\cline { 2 - 4 } & $\boldsymbol{\sigma}^{\prime}{ }_{\mathrm{vc}}$ & $\boldsymbol{\sigma}^{\prime} \mathbf{h c}$ & \\
\hline 5.82 & 200 & 190 & 0.95 \\
\hline 8.26 & 200 & 175 & 0.88 \\
\hline 11 & 225 & 190 & 0.84 \\
\hline 17.41 & 200 & 150 & 0.75 \\
\hline 21.55 & 350 & 250 & 0.71 \\
\hline
\end{tabular}

Table 4.4: Summary of the vertical and horizontal preconsolidation pressures with anisotropy degree for all tests.

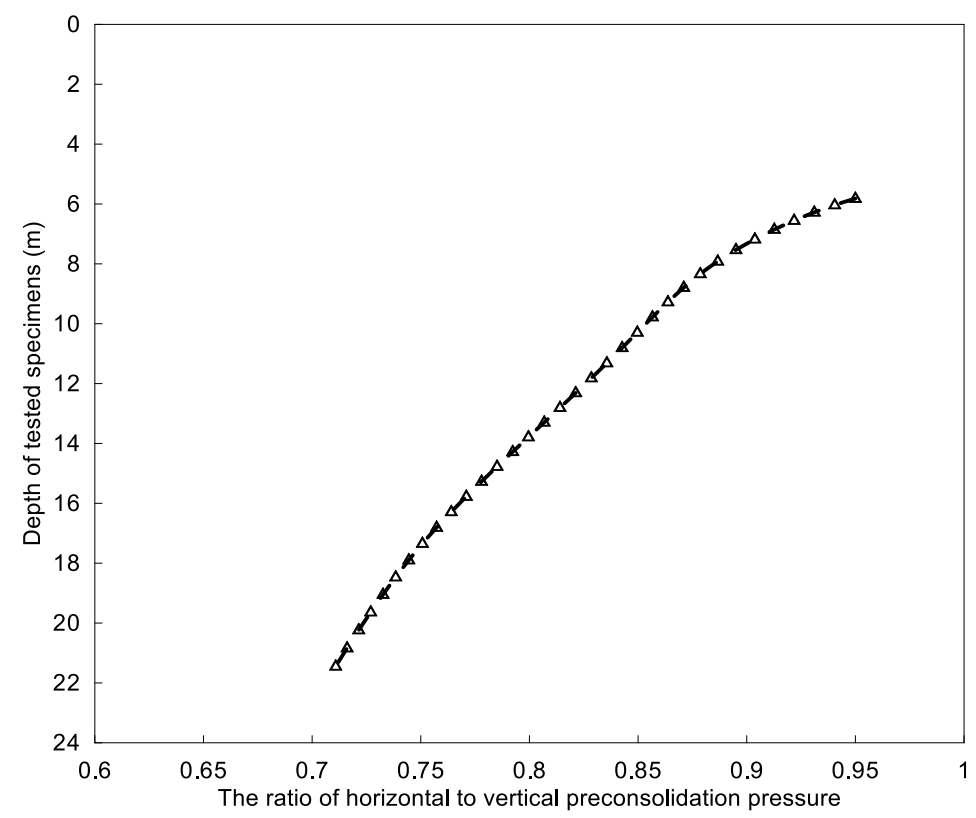

Figure 4.13: Plot of depths versus the ratio of horizontal to vertical preconsolidation pressure. 
Table 4.5 illustrates the vertical and horizontal compression indices measured together with the ratio of $\mathrm{C}_{\mathrm{c}}=\mathrm{C}_{\mathrm{ch}} / \mathrm{C}_{\mathrm{cv}}$ to facilitate an evaluation of the degree of anisotropy for all tests. Generally, it can be noticed from the table that the compression indices in the horizontal orientation, $\mathrm{C}_{\mathrm{ch}}$, are generally higher than the compression indices in the vertical orientation, $\mathrm{C}_{\mathrm{cv}}$, with the exception of a specimen in the horizontal orientation at depth of $21.55 \mathrm{~m}$. The ratio of the horizontal to the vertical compression index, $\mathrm{C}_{\mathrm{ch}} / \mathrm{C}_{\mathrm{cv}}$, ranges between 1.01 and 1.23 with an average value of 1.11 in all tests (excluding the sample for $21.55 \mathrm{~m}$ depth). This anisotropy could be attributed to the variation in the soil rigidity between the two orientations. The degree of anisotropy herein is similar to the findings reported by O'Kelly (2006) who carried out tests on soft soils. This means that the sensitive clay is subject to slight anisotropy in terms of the compression index parameter. The lack of a consistent pattern in the compression index ratio might be a reflection of the effects other parameters (such as salinity, clay content) on compression index in the different orientations.

\begin{tabular}{|c|c|c|c|}
\hline \multirow{2}{*}{ Depth (m) } & \multicolumn{2}{|c|}{ Compression index } & Compression index ratio \\
\cline { 2 - 4 } & $\mathbf{C}_{\mathbf{c v}}$ & $\mathbf{C}_{\mathbf{c h}}$ & $\mathbf{C}_{\mathbf{c h}} / \mathbf{C}_{\mathbf{c v}}$ \\
\hline 5.82 & 0.627 & 0.635 & 1.01 \\
\hline 8.26 & 0.551 & 0.675 & 1.23 \\
\hline 11 & 0.507 & 0.573 & 1.13 \\
\hline 17.41 & 0.466 & 0.488 & 1.05 \\
\hline 21.55 & 0.445 & 0.411 & 0.92 \\
& 0.472 & 0.411 & 0.87 \\
\hline
\end{tabular}

Table 4.5: Summary of the vertical and horizontal compression indices with anisotropy degree for all tests. 
The degree of the anisotropy with respect to the coefficient of consolidation is determined based on the ratio of the coefficient of consolidation in the horizontal orientation to the coefficient of consolidation in the vertical orientation. Figure 4.14 and Figure 4.15 show the relationship between the coefficient of consolidation ratio, $\mathrm{C}_{\mathrm{h}} / \mathrm{C}_{\mathrm{v}}$, versus the effective vertical stress, $\sigma_{\mathrm{v}}^{\prime}$, during the loading stage at a depth of $5.82 \mathrm{~m}$ for both the Casagrande's method and Taylor's method, respectively. However, the plots for the remaining tests are presented in Appendix A. From both Casagrande's method and Taylor's method as shown in Figure 4.14 and Figure 4.15, it can be observed that the trend of the ratio of the horizontal-to-vertical coefficient of consolidation is an increasing one with the effective vertical stress, $\sigma_{\mathrm{v}}^{\prime}$, except for one data point at about $200 \mathrm{kPa}$, which is the state of the preconsolidation pressure. A significant collapse in the structure of the clay may be responsible for the outlier. The trend found in this thesis is in agreement with that reported by Seah and Koslanant's (2003) investigation on sensitive Bangkok clay. Generally, all remaining tests have similar trends to that found at a depth of $5.82 \mathrm{~m}$. Figures 4.14 and 4.15 show that the ratio of $C_{h} / C_{v}$ ranges from 1.28 to 1.60 with average value of 1.41 during the entire stage (if using Casagrande's method), or from 1.43 to 1.66 with average value of 1.53 during the entire stage (if using Taylor's method). The average ratio of the horizontal-to-vertical coefficient of consolidation throughout all tests $(5.82 \mathrm{~m}$ to $21.55 \mathrm{~m}$ ) ranges between 1.49 and 1.72 by Casagrande's method and between 1.38 and 1.71 by Taylor's method. This range falls within the range that is reported in the literature by Seah and Koslanant (2003). 


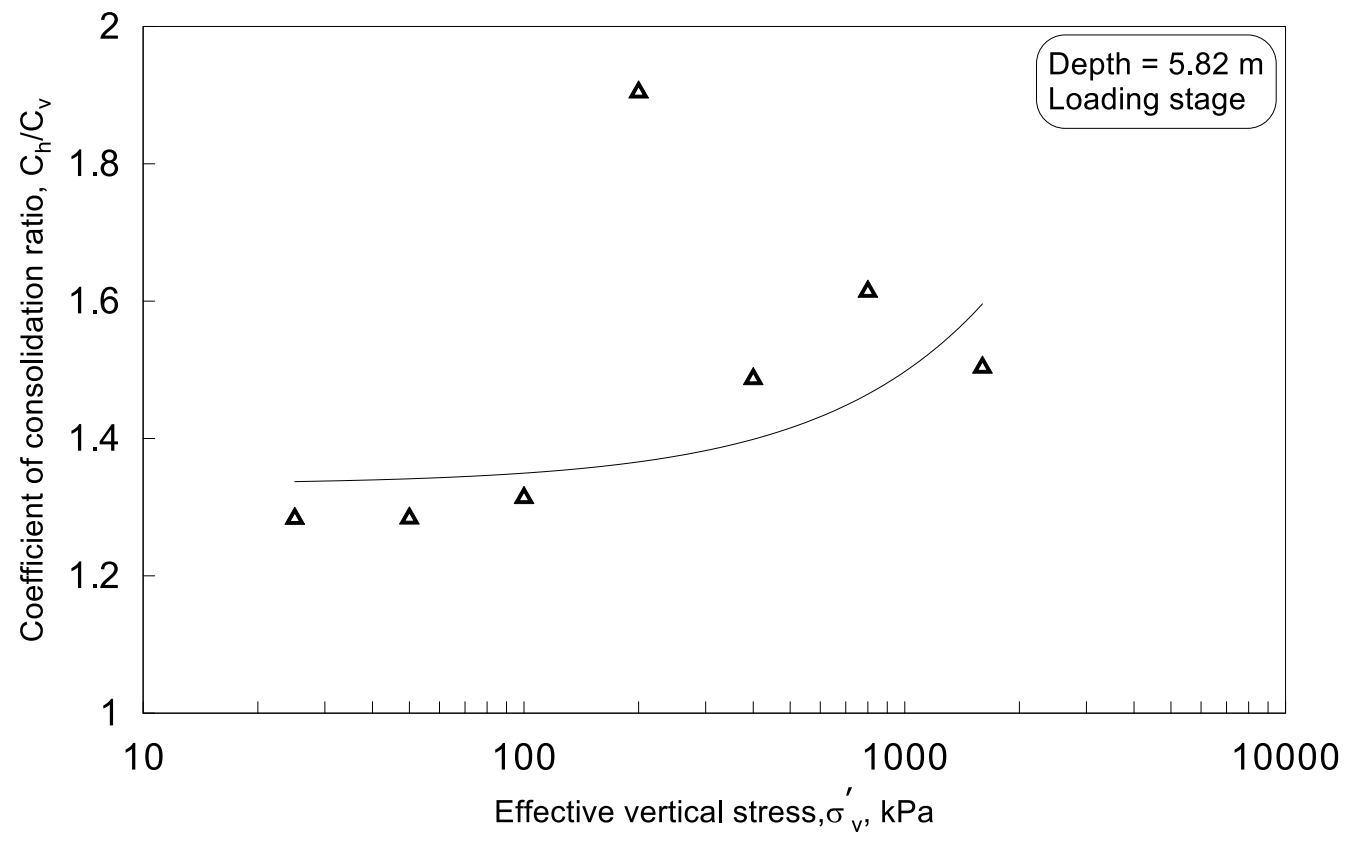

Figure 4.14: Typical plots of the coefficient of consolidation ratio versus the effective vertical stress during the loading stage at depth of $5.82 \mathrm{~m}$ (by Casagrande's method).

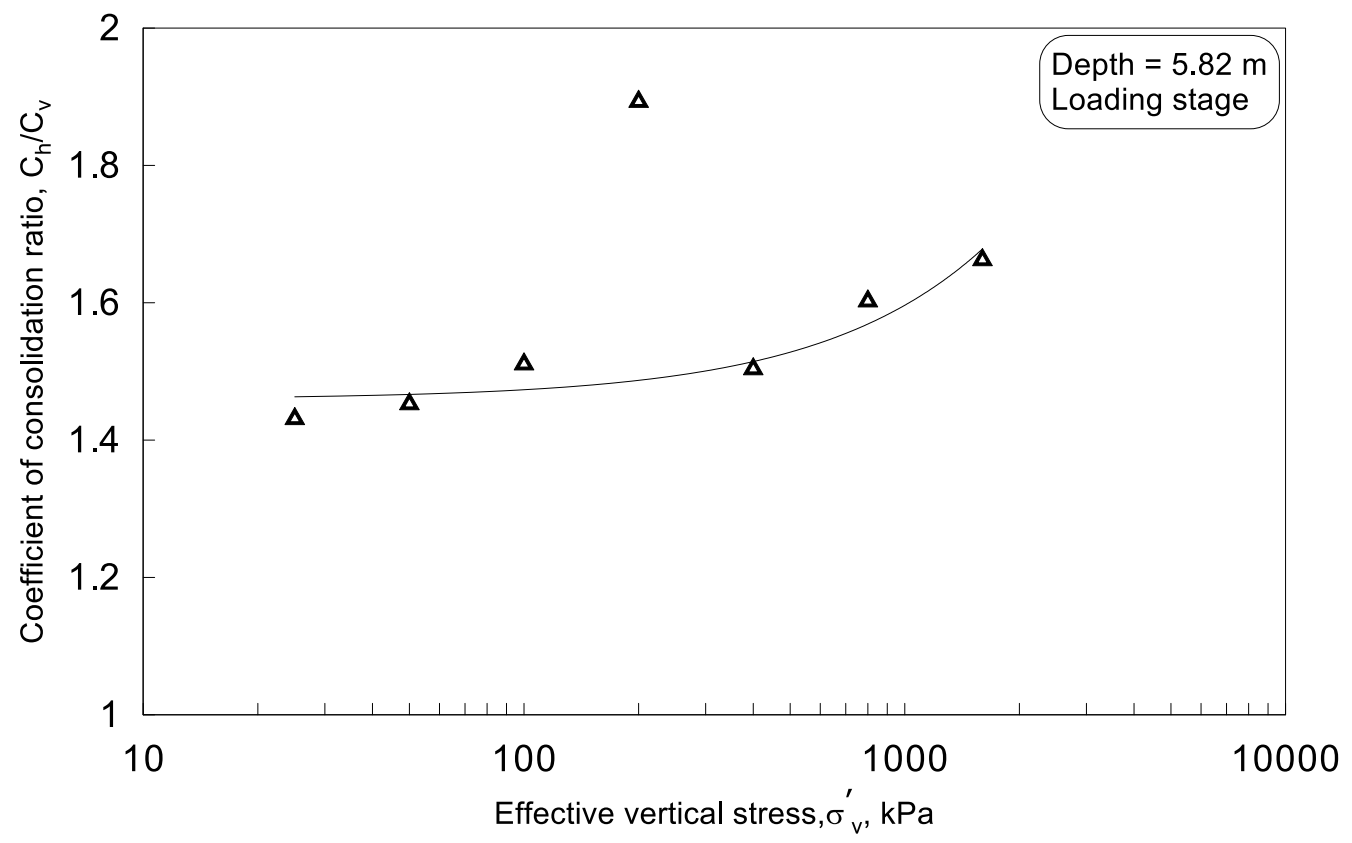

Figure 4.15: Typical plots of the coefficient of consolidation ratio versus the effective vertical stress during the loading stage at depth of $5.82 \mathrm{~m}$ (by Taylor's method). 
The degree of the anisotropy in terms of the coefficient of permeability is determined based on the ratio of the horizontal coefficient of permeability to the vertical coefficient of permeability. Figure 4.16 and Figure 4.17 show the relationship between the coefficient of permeability ratio, $\mathrm{k}_{\mathrm{h}} / \mathrm{k}_{\mathrm{v}}$, versus the effective vertical stress, $\sigma_{\mathrm{v}}^{\prime}$, during the loading stage at a depth of $5.82 \mathrm{~m}$ (for both the Casagrande's method and Taylor's method). The results of the tests conducted at other depths are presented in Appendix A. These two figures show that the ratio of the horizontal-to-vertical coefficient of permeability increases with the increasing effective vertical stress, $\sigma_{v}^{\prime}$, which it is similar to the behaviour of the ratio of the coefficient of consolidation. This trend is consistent with that found by Seah and Koslanant (2003) who conducted tests on sensitive Bangkok clay. Almost, all of the remaining testes have comparable trends to that found at a depth of $5.82 \mathrm{~m}$. From Figure 4.16 and Figure 4.17, the ratio of $k_{h}$ to $k_{v}$ varies between 1.05 and 2.02 with an average value of 1.38 during the entire stage in the case of Casagrande's method, and between 1.05 and 2 with average value of 1.42 during the entire stage in the case of Taylor's method. The average ratio of the horizontal-to-vertical coefficient of permeability throughout all tested boreholes $(5.82 \mathrm{~m}$ to $21.55 \mathrm{~m})$ ranges between 1.34 and 1.93 by Casagrande's method and between 1.36 and 1.93 by Taylor's method. This range is close to the range reported by Seah and Koslanant (2003). 


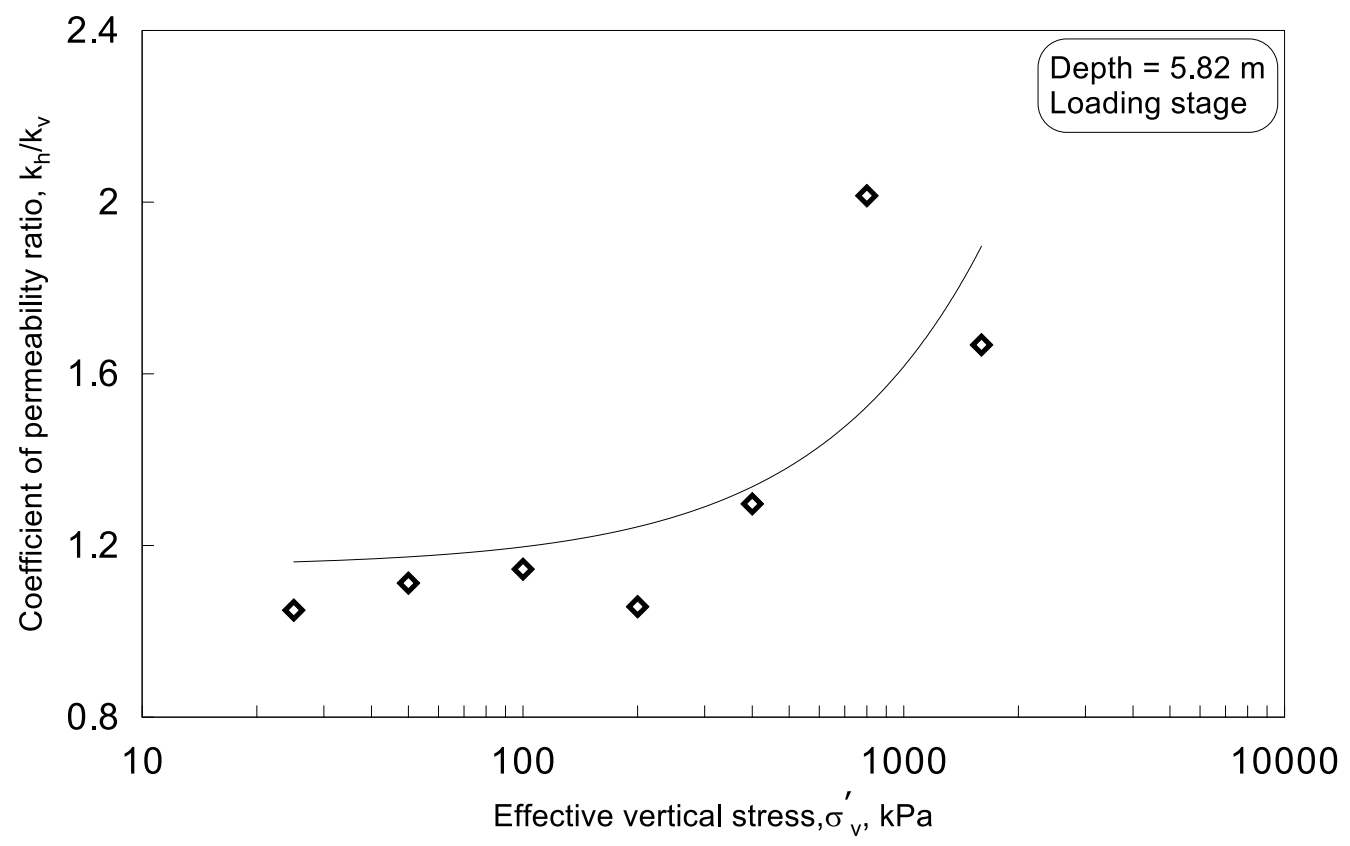

Figure 4.16: Typical plots of the coefficient of permeability ratio versus the effective vertical stress during the loading stage at depth of $5.82 \mathrm{~m}$ (by Casagrande's method).

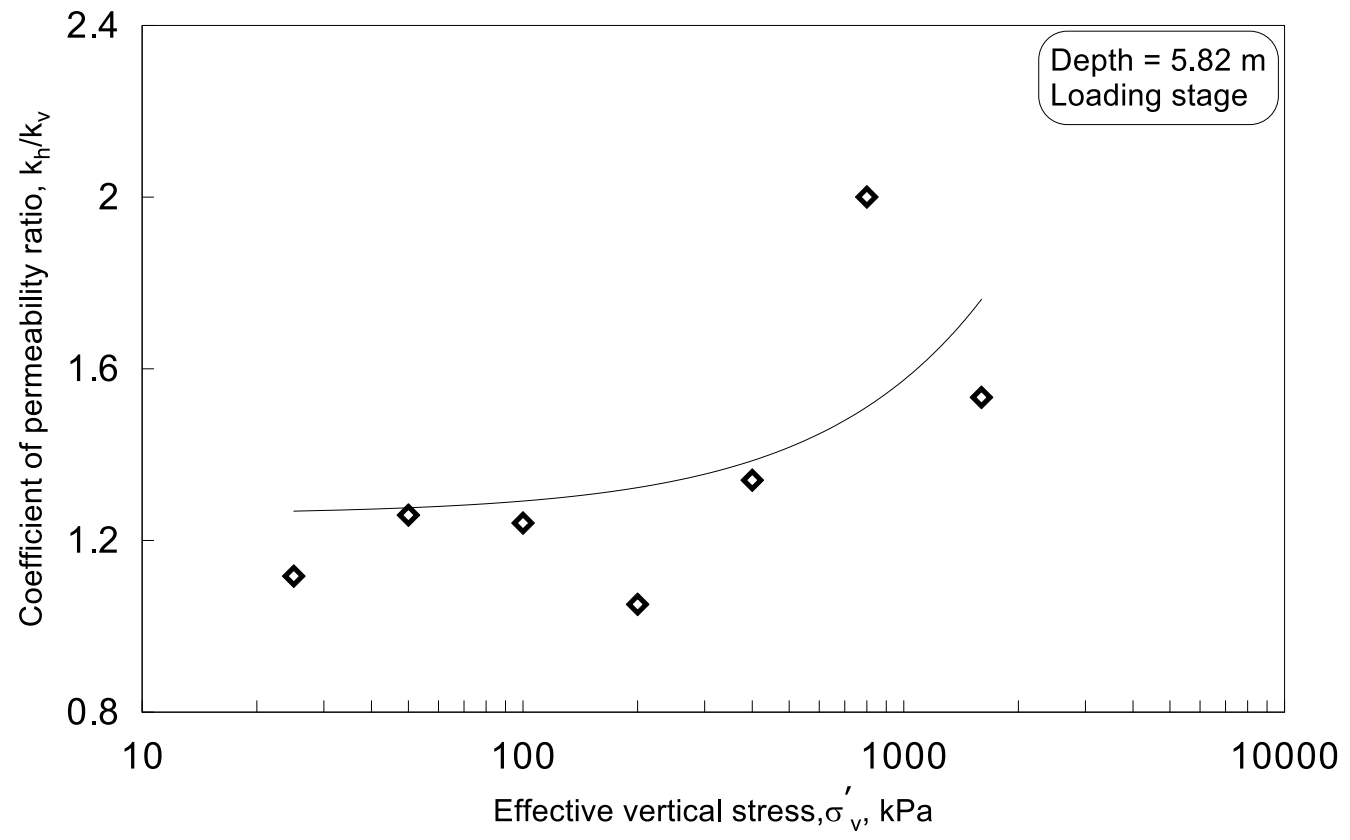

Figure 4.17: Typical plots of the coefficient of permeability ratio versus the effective vertical stress during the loading stage at depth of $5.82 \mathrm{~m}$ (by Taylor's method). 
In general, based on the observation of the ratios of the horizontal-to-vertical coefficient of consolidation and the coefficient of permeability for all tested samples, the sensitive clay is considered anisotropic. The reason for the increasing degree of anisotropy (in terms of the coefficient of consolidation and the coefficient of permeability ratios) with the increase in the effective vertical stress can be attributed to the soil structure, which becomes more flocculated as the effective vertical stress is increased. In addition, the soil structure becomes more flocculated as the void ratio gradually decreases. Moreover, because the void spaces between soil particles in the horizontal orientation are larger than those in the vertical orientation (Gofar, 2006) the horizontal coefficients of consolidation and permeability are higher than those in the vertical orientation. These void spaces decrease as the effective vertical stress increases, and consequently the anisotropic behaviour in sensitive clay increases with the stress level.

Table 4.6 shows the ratio of the at rest lateral earth pressure coefficient in the horizontal orientation to the at rest lateral earth pressure coefficient in the vertical orientation, $\mathrm{K}_{0 \mathrm{~h}} / \mathrm{K}_{0 \mathrm{v}}$, during different stress histories for all tests. For example, at a depth of $5.82 \mathrm{~m}$ the ratio of $\mathrm{K}_{0 \mathrm{~h}}$ to $\mathrm{K}_{0 \mathrm{v}}$ varies from 1.09 to 1.46 in the loading stage, 1.41 to 1.44 in the unloading stage, and 1.46 to 1.68 in the reloading stage with an average value of 1.34 during the entire soil history. During the entire stress history, the average ratio of the at rest lateral earth pressure coefficient $\left(\mathrm{K}_{0 \mathrm{~h}} / \mathrm{K}_{0 \mathrm{v}}\right)$ throughout all tests $(5.82 \mathrm{~m}$ to $21.55 \mathrm{~m})$ ranges from 0.90 to 1.82 . Generally, it can be noticed from the table that the ratio of $\mathrm{K}_{0 \mathrm{~h}}$ to $\mathrm{K}_{0 \mathrm{v}}$ demonstrates anisotropy in the sensitive clay for all tests during the stress history of the soil. Even though there is no benefit from the at rest lateral earth pressure coefficient in the 
horizontal orientation in the geotechnical practice, it is a valuable indicator of the anisotropy.

\begin{tabular}{|c|c|c|c|c|}
\hline \multirow[b]{2}{*}{ Depth (m) } & $\mathrm{K}_{\mathrm{oh}} / \mathbf{K}_{\mathbf{0 v}}$ & $\mathrm{K}_{0 \mathrm{~h}} / \mathbf{K}_{\mathbf{0 v}}$ & $\mathrm{K}_{\mathrm{oh}} / \mathrm{K}_{\mathbf{0 v}}$ & \multirow{2}{*}{$\begin{array}{c}\text { Average of } \mathrm{K}_{0 \mathrm{~h}} / \mathrm{K}_{0 \mathrm{v}} \\
\text { during all stages }\end{array}$} \\
\hline & Loading stage & Unloading stage & Reloading stage & \\
\hline 5.82 & 1.09 to 1.46 & 1.41 to 1.44 & 1.46 to 1.68 & 1.34 \\
\hline 8.26 & 1.01 to 1.04 & 1.00 & 1.02 to 1.34 & 1.06 \\
\hline 11 & 1.13 to 2.13 & 1.71 to 1.82 & - & 1.82 \\
\hline 17.41 & 0.91 to 0.96 & 1.03 to 1.19 & 0.75 to 0.84 & 0.90 \\
\hline 21.55 & $\begin{array}{l}0.88 \text { to } 0.96 \\
1.16 \text { to } 1.63\end{array}$ & $\begin{array}{c}1.06 \text { to } 1.43 \\
-\end{array}$ & $\begin{array}{c}0.92 \text { to } 1.29 \\
-\end{array}$ & $\begin{array}{l}1.03 \\
1.29\end{array}$ \\
\hline
\end{tabular}

Table 4.6: Summary of the ratio of the at rest lateral earth pressure coefficient in the horizontal orientation to the at rest lateral earth pressure coefficient in the vertical orientation during the stress history for all tests.

\subsection{Results of the Simple Shear Tests}

\subsubsection{The peak and residual shear strengths in the vertical and horizontal orientations}

The results of the monotonic simple shear tests for specimens that tested on the vertical and horizontal orientations are presented in terms of the relationship between the normalized shear stress and the shear strain. Figure 4.18 to Figure 4.20 show the measured response, and indicate the specimens sampled along the horizontal orientations have a somewhat larger shear capacity. It can be observed from the three figures that the normalized horizontal peak and normalized residual strengths are located above the normalized vertical peak and normalized residual strengths. The failure at the normalized 
peak strength, for specimens tested on the vertical orientation $\left(\mathrm{S}_{\text {upv }}\right)$, is realised at strain levels between 2.25 to $6.56 \%$. This shear strain range is close to the minimum and maximum values pointed out by other researchers (Yong and Tang, 1983; Lefebvre and Pfendler, 1996; and Rasmussen 2012). However, the failure at the normalized peak strength, for specimens tested on the horizontal orientation $\left(\mathrm{S}_{\mathrm{uph}}\right)$, is realised at strain levels between 3.79 to $6.57 \%$. The ratio of the normalized peak horizontal undrained shear strength to the normalized peak vertical undrained shear strength $\left(\mathrm{S}_{\text {uph }} / \mathrm{S}_{\text {upv }}\right)$, for specimens consolidated at $100 \mathrm{kPa}$, is about 1.15 . The ratio of the normalized residual horizontal undrained shear strength to the normalized residual vertical undrained shear strength $\left(\mathrm{S}_{\text {urr }} / \mathrm{S}_{\text {urv }}\right)$, for specimens consolidated at $100 \mathrm{kPa}$, is about 1.42 . The ratio of the normalized peak horizontal undrained shear strength to the normalized peak vertical undrained shear strength $\left(\mathrm{S}_{\text {uph }} / \mathrm{S}_{\text {upv }}\right)$, for specimens consolidated at $200 \mathrm{kPa}$, is about 1.42 . The ratio of the normalized residual horizontal undrained shear strength to the normalized residual vertical undrained shear strength $\left(\mathrm{S}_{\text {urh }} / \mathrm{S}_{\text {urv }}\right)$, for specimens consolidated at $200 \mathrm{kPa}$, is about 1.09 . The ratio of the normalized peak horizontal undrained shear strength to the peak normalized vertical undrained shear strength $\left(\mathrm{S}_{\text {uph }} / \mathrm{S}_{\text {upv }}\right)$, for specimens consolidated at 400 $\mathrm{kPa}$, is about 1.05 . The ratio of the normalized residual horizontal undrained shear strength to the normalized residual vertical undrained shear strength $\left(\mathrm{S}_{\text {urh }} / \mathrm{S}_{\text {urv }}\right)$, for specimens consolidated at $400 \mathrm{kPa}$, is about 1.05 . The previous ratios imply that the sensitive clay shows some anisotropy with respect to shear strength. Moreover, the degree of the anisotropy in this investigation is almost similar to that obtained by Silvestri and Aubertin (1988) who used the field vane technique. Therefore, the reason why the horizontal 
specimens provide higher shear strength than the vertical specimens could be attributed to the variations in the soil stress history during the deposition stage.

\subsubsection{The shear strength parameters in the vertical and horizontal orientations}

Figure 4.21 and Figure 4.22 show the relationship between the peak shear strength against the effective vertical stress and the residual shear strength against the effective vertical stress for the vertical and horizontal orientations, respectively. The two figures indicate that the vertical orientation has similar peak and residual effective internal friction angles, $\varphi_{\mathrm{pv}}^{\prime}$ and $\varphi_{\mathrm{rv}}^{\prime}$, to those in the horizontal orientation, $\varphi_{\mathrm{ph}}^{\prime}$ and $\varphi_{\mathrm{rh}}^{\prime}$. This finding is expected since the friction between the particles in both the vertical and horizontal orientations are similar and dependent on mineralogy only. The ratio of the peak effective horizontal internal friction angle to the peak effective vertical internal friction angle, $\varphi_{\mathrm{ph}}^{\prime} / \varphi_{\mathrm{pv}}^{\prime}$, is about 0.96 . The ratio of the residual effective horizontal internal friction angle to the residual effective vertical internal friction angle, $\varphi_{\mathrm{rh}}^{\prime} / \varphi_{\mathrm{rv}}^{\prime}$, is about 0.97 . These ratios imply that sensitive clay has almost isotropic behaviour in terms of the effective internal friction angle. Furthermore, Figure 4.21 shows that the peak effective cohesion in the vertical orientation, $c_{p v}^{\prime}$, is about zero and the peak effective cohesion in the horizontal orientation, $\mathrm{c}_{\mathrm{ph}}^{\prime}$, is about $9 \mathrm{kPa}$. This indicates that the vertical orientation has normally consolidated behaviour, however, the horizontal orientation has overconsolidated behaviour. In addition, this result reveals a higher cohesion between soil particles for the higher shear strength in the horizontal samples. 


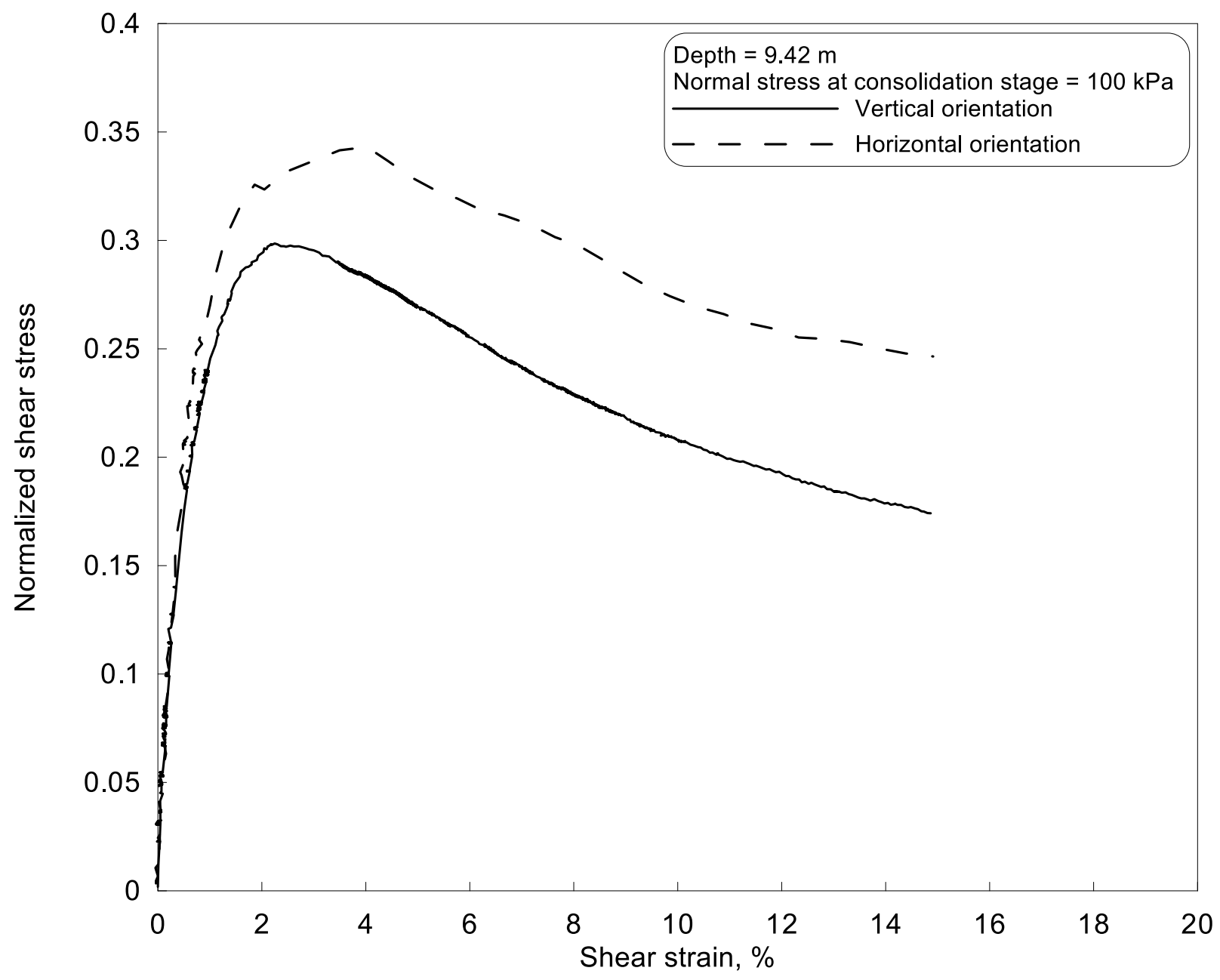

Figure 4.18: Simple shear results at normal stress of $100 \mathrm{kPa}$ for specimens trimmed in the vertical and horizontal orientations. 


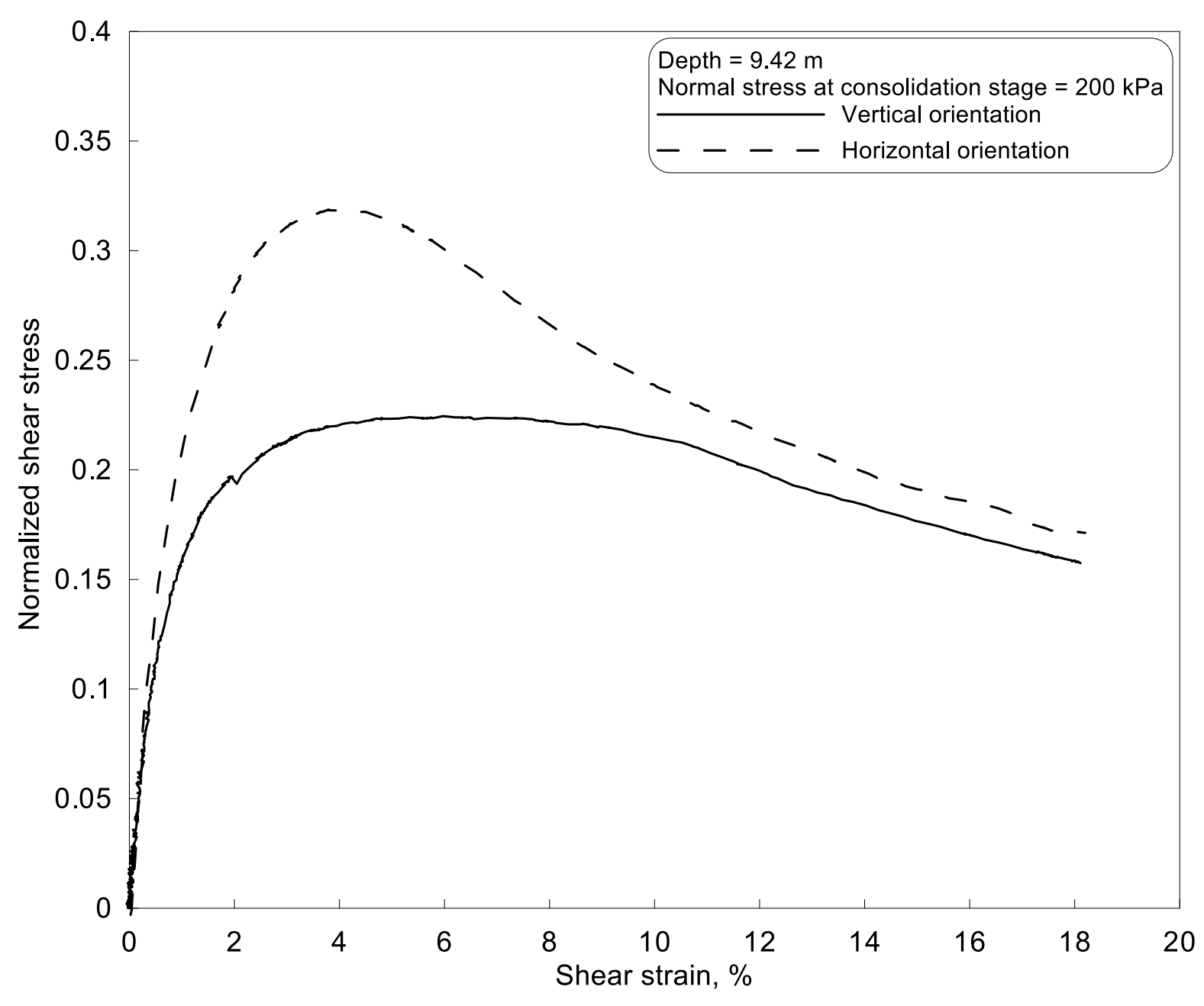

Figure 4.19: Simple shear results at normal stress of $200 \mathrm{kPa}$ for specimens trimmed in the vertical and horizontal orientations. 


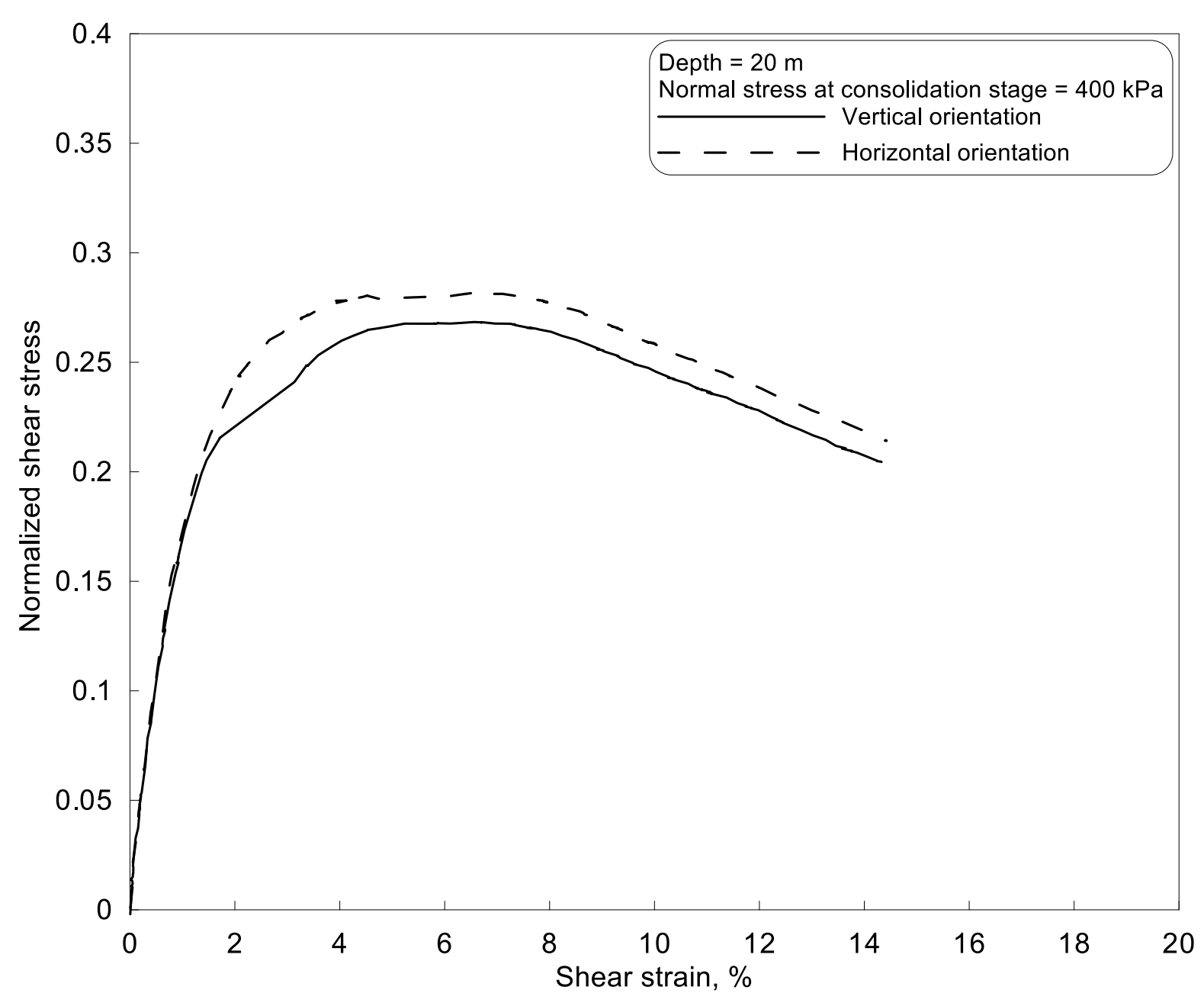

Figure 4.20: Simple shear results at normal stress of $400 \mathrm{kPa}$ for specimens trimmed in the vertical and horizontal orientations. 


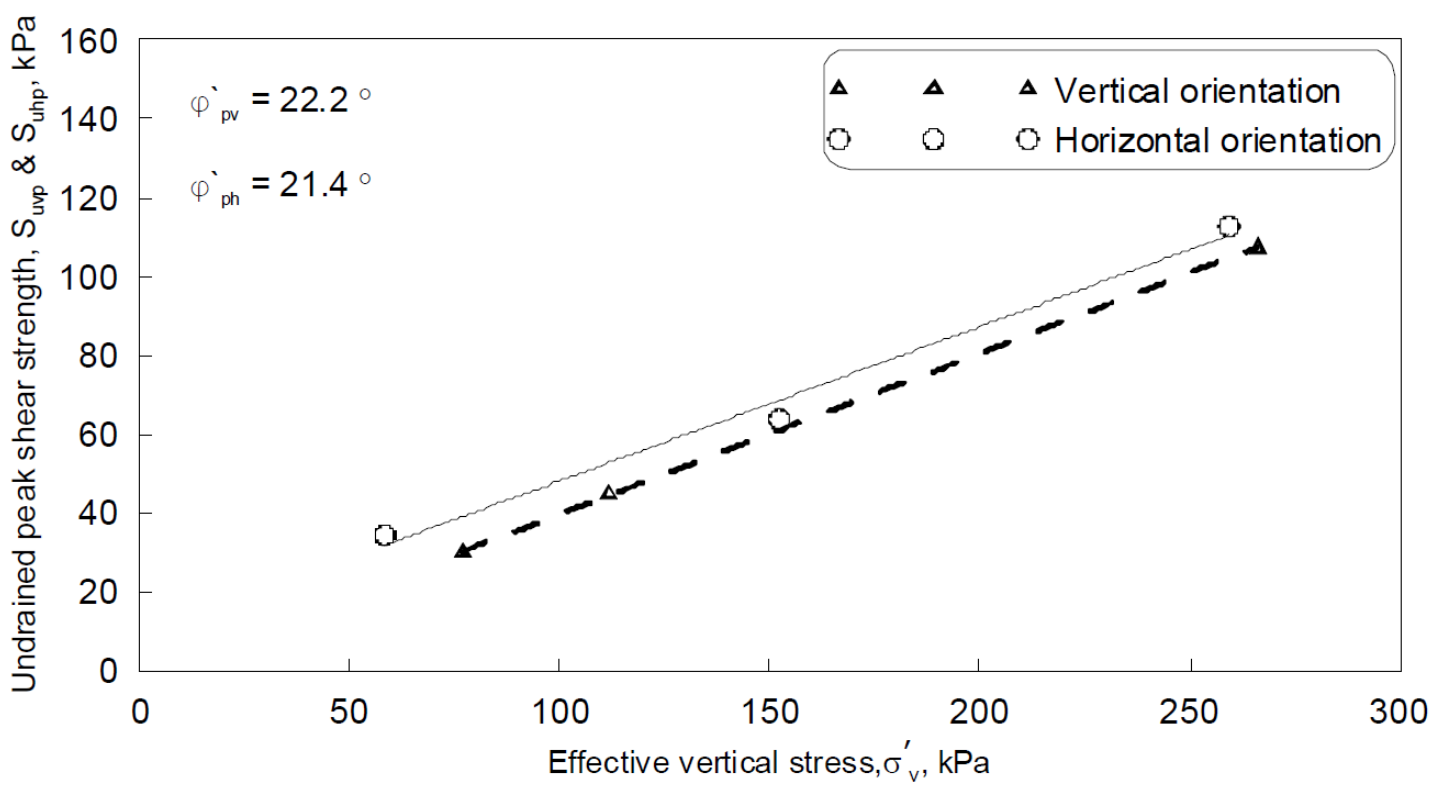

Figure 4.21: Plots of peak shear strength versus the effective vertical stress for vertical and horizontal orientations.

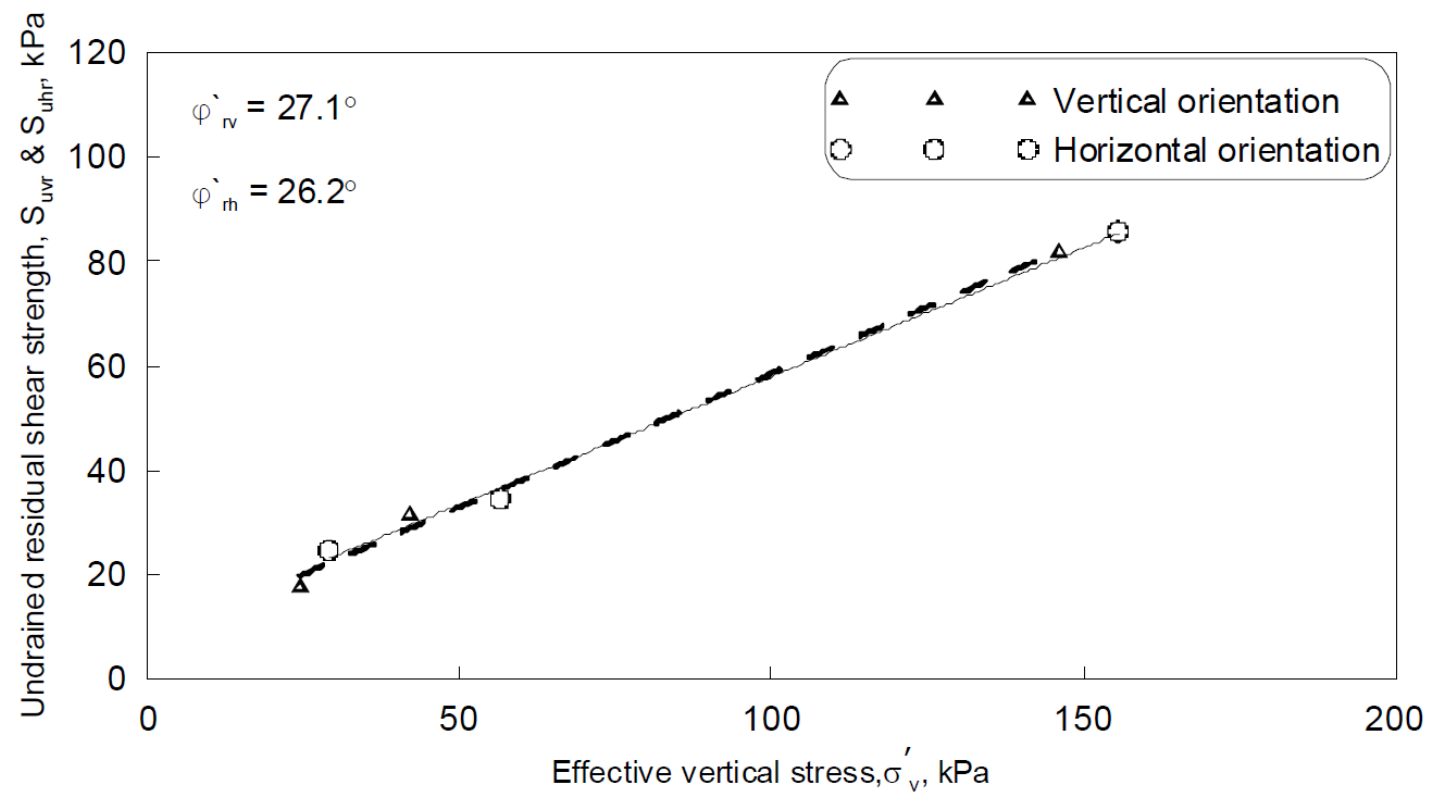

Figure 4.22: Plots of residual shear strength versus the effective vertical stress for vertical and horizontal orientations. 


\section{Chapter 5}

\section{Conclusions and Recommendations}

\subsection{Conclusions}

An experimental investigation in this study assessed the level of anisotropy in sensitive Champlain Sea clay in terms of its consolidation characteristics (by using an instrumented Oedometer) and shear strength characteristics (by using the simple shear apparatus). The specimens studied were trimmed along the vertical and horizontal orientation for testing in consolidation and simple shear devices. The results of the consolidation and simple shear tests presented in this thesis allows one to draw the following conclusions.

First, the measured consolidation behaviour is consistent with that expected in a sensitive clay in that there is a significant level of deformation due to the collapse of the structure. This occurs at a stress level of about $150-350 \mathrm{kPa}$ in the tested material. The unloading and reloading phases were close to elastic, and as expected, reloading following unloading shows typical consolidation behaviour that is expected in remoulded clays. Finally, reloading to the maximum past pressure causes some inelastic compression.

In addition, tested specimens that have loading-unloading-reloading stages show that the strain at the end of each test is somewhat higher than the strain at the end of loading stage (regardless of the orientation of the specimen). The level of swelling during unloading is fairly small and resulted in a recompression index to compression index

average ratio of 0.11 and 0.07 through all tests for the vertical and the horizontal orientations respectively. 
Moreover, the one-dimensional consolidation curves for all of the tests show that the values of the preconsolidation pressure in the vertical orientation are higher than those in the horizontal orientation regardless of the depth of the sample. The ratio of the horizontal to vertical preconsolidation pressure ranges between 0.71 and 0.95 with average value of 0.83 in these tests. The horizontal-to-vertical preconsolidation pressure ratio decreases as the depth of soil is increased. This suggests that the changes are primarily due to over consolidation caused by surface ice-loads.

In general, all of the consolidation tests along the horizontal orientation provides somewhat higher ( $1 \%$ to $23 \%$ ) compression indices than the corresponding specimens in the vertical orientation (with the exception of a specimen in the horizontal orientation at depth of $21.55 \mathrm{~m}$ ). As noted earlier, the shape of the consolidation curve suggests this is due to specimen disturbance, and thus the results from this test are not considered reliable. The ratio of the horizontal to vertical compression index varies between 1.01 and 1.23 with 1.11 as an average value. This indicates that the sensitive clay has insignificant anisotropy with respect to the compression index.

Both Casagrande's and Taylor's methods indicate that the horizontal coefficients of consolidation and permeability are higher than the vertical coefficients of consolidation and permeability in all tests. Moreover, Taylor's method provides higher values of vertical and horizontal coefficients of consolidation and permeability than those calculated by Casagrande's method for all tests during loading stage. The degree of the anisotropy in terms of the ratios of horizontal to vertical coefficients of consolidation and permeability seem to increase as the effective vertical stress is increased (except for one data point near the preconsolidation pressure). The average ratio of the horizontal-to-vertical coefficient 
of consolidation throughout all tests $(5.82 \mathrm{~m}$ to $21.55 \mathrm{~m})$ ranges from 1.49 to 1.72 by Casagrande's method and from 1.38 to 1.71 by Taylor's method. The average ratio of the horizontal-to-vertical coefficient of permeability throughout all tests (5.82 $\mathrm{m}$ to $21.55 \mathrm{~m}$ ) ranges from 1.34 to 1.93 by Casagrande's method and from 1.36 to 1.93 by Taylor's method. The ratios of the horizontal-to-vertical coefficients of consolidation and permeability indicate that sensitive Champlain Sea clay shows anisotropic behaviour (with respect to these parameters).

The at rest lateral earth pressure coefficient, $K_{0 v}$ and $K_{0 h}$, determined from the consolidation tests in the vertical and horizontal orientations, decreases during the loading and reloading stages since the stresses increase as the test progresses, and increases in the unloading stage since the stress level decreases as the test progresses. The at rest lateral earth pressure coefficient, $\mathrm{K}_{0 \mathrm{v}}$ and $\mathrm{K}_{0 \mathrm{~h}}$, is clearly dependent on the over consolidation ratio, as it increases with increasing OCR. A comparison of the at rest lateral earth pressure coefficient between the vertical and horizontal orientations, $\mathrm{K}_{0 \mathrm{v}}$ and $\mathrm{K}_{0 \mathrm{~h}}$, showed that the at rest lateral earth pressure coefficient in the horizontal orientation, $\mathrm{K}_{0 \mathrm{~h}}$, is higher than that in the vertical orientation in general, $\mathrm{K}_{0 \mathrm{v}}$. The specimens at a depth of $17.41 \mathrm{~m}$ did not match this trend. The average ratio of the at rest lateral earth pressure coefficient throughout all tests $(5.82 \mathrm{~m}$ to $21.55 \mathrm{~m})$ ranged from 0.90 to 1.82 during the entire stress history. This range suggests that sensitive Champlain Sea clay has direction dependent normal stress-normal strain characteristics. 
As noted previously, only a limited number of simple shear tests were completed due to equipment break down, but the limited data collected is consistent and shows trends related to the loading direction. The monotonic simple tests showed somewhat higher peak and residual shear strengths in specimens obtained along the horizontal orientation compared to those obtained along the vertical orientation at a given depth. The peak strength was realized in specimens in the vertical orientation at shear strain ranging between 2.25 to $6.56 \%$. On the other hand, the peak strength in specimens along the horizontal orientation was realized at strain shear levels that ranged between 3.79 to $6.57 \%$. This indicates direction dependence of the shear modulus in this clay. The ratio of peak horizontal to peak vertical undrained shear strength ranged from 1.05 to 1.42 , which shows that sensitive Champlain Sea clay is somewhat anisotropic in terms of shear strength.

Unlike the shear strength, the friction angles obtained from the tests are fairly comparable, regardless of the orientation of the specimen. The ratio of the peak and residual effective internal friction angles in specimens in the horizontal to vertical orientation are approximately unity ( 0.96 and 0.97 respectively). Therefore, it can be concluded that the friction angle obtained in sensitive Champlain Sea clay is not dependent on the loading direction. The results also indicated that the peak effective cohesion in the vertical orientation has normally consolidated behaviour, on the other hand, the horizontal orientation has overconsolidated behaviour. 


\subsection{Recommendations for Future Work}

The test program completed provides some insights in to the existence of anisotropy in the sensitive Champlain Sea clays, but there are several additional factors that need to be considered for a more comprehensive understanding of the topic. In addition, a more comprehensive data set with a larger number of simple shear tests would be helpful in establishing more confidence in the findings. Therefore, it is recommended that additional simple shear tests on specimens in both horizontal and vertical orientations be conducted at difference stress levels and OCR. Further, triaxial compression and extension tests provide better means of evaluating the existence of anisotropy on specimens in a given orientation, and the availability of triaxial equipment will enable a series of such tests. It is also recommended to conduct more one-dimensional consolidation tests on the same sensitive clay with different load increment ratios in order to make a comparison with the established nature of the anisotropy in this thesis. Furthermore, different test techniques, such as constant rate of strain (CRS) and controlled gradient (CG) consolidation tests may be used for comparison with the standard incremental consolidation tests reported in this thesis. 


\section{Chapter 6}

\section{References}

Al-Zoubi, M.S., (2008). "Consolidation Characteristics Based on a Direct Analytical Solution of the Terzaghi Theory.” Jordan Journal of Civil Engineering, 2(2): 91-99.

Arulrajah, A., and Bo, M. W. (2008). "Characteristics of Singapore marine clay at Changi." Geotechnical and Geological Engineering, 26(4): 431-441.

ASTM D422. (2007). Standard Test Method for Particle-Size Analysis of Soils. D422 63 (07). ASTM International.

ASTM D4318. (2010). Standard Test Methods for Liquid Limit, Plastic Limit, and Plasticity Index of Soils. D4318 - 10. ASTM International.

Bechai, M. (1974). "Determination of Preconsolidation Pressure for a Sensitive Clay." MASc Thesis, University of Ottawa, Ottawa, Canada, pp. 51-122.

Bentley, S. P., and Smalley, I. J. (1979). "Mineralogy of a Leda/Champlain clay from Gloucester (Ottawa, Ontario).” Engineering Geology, 14(2): 209-217.

Bozozuk, M. (1972). “The Gloucester test fill.” PhD Thesis, Purdue University, Lafayette, USA, pp. 64-74. 
Bozozuk, M. (1974). "Minor Principal Stress Measurements in Marine Clay with Hydraulic Fractures Tests.” Proceedings, American Society of Civil Engineers (ASCE) Conference on Subsurface Exploration for Underground Excavation and Heavy Construction, Henniker, N.H., pp. 333-349.

Brand, E.W., and Brenner, R.P. (1981). "Soft clay engineering.” Elsevier Science Ltd., Amsterdam, The Netherlands, 20p.

Brooker, E. W., and Ireland, H. O. (1965). "Earth pressures at rest related to stress history." Canadian Geotechnical Journal, 2(1): 1-15.

Brydon, J. E., and Patry, L. M. (1961). "Mineralogy of Champlain Sea sediments and a Rideau Clay soil profile.” Canadian Journal of Soil Science, 41(2): 169-181.

Budhu, M. (2010). "Soil mechanics and foundations.” $3_{\text {rd }}$ edition, John Wiley and Sons Inc., New York.

Campanella, R. G., and Vaid, Y. P. (1972). "A Simple $K_{o}$ Triaxial Cell.” Canadian Geotechnical Journal, 9(3): 249-260.

Canadian Mortgage and Housing Corporation. (2001). "Know about your house: Understanding and dealing with interactions between trees, sensitive clay soils and foundations." Canada.

CFEM (2006). "Identification and classification of soil and rock". Chapter 3 of the $4^{\text {th }}$ edition of Canadian Foundation Engineering Manual, BiTech, Vancouver, BC, Canada. 
Chai, J. C., Jia, R., and Hino, T. (2012). "Anisotropic consolidation behavior of Ariake clay from three different CRS tests." Geotechnical Testing Journal, 35(6): 1-9.

Chi-in, H. (1958). "A new apparatus for the determination of the coefficient of lateral earth pressure at rest.” Journal of Scientia Sinica, 7(6): 648-660.

Crawford, C. B. (1964). "Interpretation of the consolidation test." Journal of Soil Mechanics and Foundations Division, proc. Of the American Society of Civil Engineers, 90(5): 87-102.

Crawford, C. B. (1968). “Quick clays of eastern Canada.” Engineering Geology, 2(4): 239265.

Das, B. M. (2001). "Principles of geotechnical engineering." $5^{\text {th }}$ edition, Thomson Learning Inc.

De Wit, C. (1967). "The influence of swelling clay minerals of the permeability of Leda clay.” M.E.Sc Thesis, University of Western Ontario, London Ontario, Canada, p. 3.

Delage, P., and Lefebvre, G. (1984). "Study of the structure of a sensitive Champlain clay and of its evolution during consolidation." Canadian Geotechnical Journal, 21(1): 21-35.

Eden, W. J., and Crawford, C. B. (1957). "Geotechnical properties of Leda clay in the Ottawa area." Proc. of the 4th Int. Conf. on Soil Mech. and Found. Eng., London, England, 1: $22-27$. 
Eden, W. J., and Law, K. T. (1980). "Comparison of undrained shear strength results obtained by different test methods in soft clays." Canadian Geotechnical Journal, 17(3): 369-381.

Gillott, J. E. (1970). "Fabric of Leda clay investigated by optical, electron-optical, and Xray diffraction methods.” Engineering Geology, 4(2): 133-153.

Gillott, J. E. (1979). "Fabric, composition and properties of sensitive soils from Canada, Alaska and Norway.” Engineering Geology, 14(2): 149-172.

Gofar, N. (2006). "Determination of coefficient of rate of horizontal consolidation of Peat Soil.” MASc Thesis, Universiti Teknologi Malaysia, Skudai, Malaysia, p. 57.

Ha, D. (2003). "Effect of Initial Stress State on the Undrained Cyclic Behaviour of Sands." MASc Thesis, Carleton University, Ottawa, Canada, pp. 38-40.

Hamilton, J. J., and Crawford, C. B. (1959). “Improved determination of preconsolidation pressure of a sensitive clay.” ASTM, 254: 254-271.

Hamouche, K. K., Leroueil, S., Roy, M., and Lutenegger, A. J. (1995). "In situ evaluation of $K_{o}$ in Eastern Canada clays." Canadian Geotechnical Journal, 32(4): 677-688.

Holtz, R. D., and Kovacs, W. D. (1981). "An introduction to geotechnical engineering." Prentice-Hall, Inc., Englewood Cliffs, New Jersey, USA.

Hossain, D. (1995). Discussion on "Limitations of Conventional Analysis of Consolidation Settlement.” ASCE Journal of Geotechnical Engineering, 121(6): 514-515. 
Humar, J. and Sivathayalan, S. (2003). Report on Seismic Design Response Spectrum for Victoria Memorial Museum, Ottawa, Ontario. Carleton University. 23p.

Jarrett, P. M. (1967). "Time-dependent consolidation of a sensitive clay." Materials Research and Standards, 7(7): 300-304.

Javed, K. (2002). "Strength of sensitive clay under cyclic loading." MASc Thesis, Concordia University, Montreal, Canada, p. 50.

Javed, K. (2011). "Behavior of Sensitive Clay Subjected to Static and Cyclic Loading." PhD Thesis, Concordia University, Montreal, Canada, p. 69.

Karrow, P. F. (1961). "The Champlain Sea and its sediments." Soils in Canada: Geological, pedological and engineering studies. Roy. Soc. Canada, Publ., 3: 97-108.

Kenney, T. C. (1968). "A review of recent research on strength and consolidation of soft sensitive clays." Canadian Geotechnical Journal, 5(2): 97-119.

Khan, M. M. A. (1993). "Strength-deformation behaviour of a weathered clay crust." PhD Thesis, University of Ottawa, Ottawa, Canada, p. 183.

Lefebvre, G., and Pfendler, P. (1996). "Strain rate and preshear effects in cyclic resistance of soft clay." Journal of Geotechnical Engineering, 122(1): 21-26.

Lefebvre, G., Bozozuk, M., Philibert, A., and Hornych, P. (1991). "Evaluating $K_{o}$ in Champlain clays with hydraulic fracture tests." Canadian Geotechnical Journal, 28(3): 365377. 
Leroueil, S., Bouclin, G., Tavenas, F., Bergeron, L., and Rochelle, P. L. (1990). "Permeability anisotropy of natural clays as a function of strain." Canadian Geotechnical Journal, 27(5): 568-579.

Lessard, G., and Mitchell, J. K. (1985). "The causes and effects of aging in quick clays." Canadian Geotechnical Journal, 22(3): 335-346.

Liu, C., and Evett, J.B. (2004). "Soils and Foundations." 6th edition, Pearson Prentice Hall.

Mitchell, J. K., and Soga, K. (2005). "Fundamentals of soil behavior." $3_{\text {rd }}$ edition, John Wiley and Sons Inc., New York.

Mitchell, R. J. (1970). "On the yielding and mechanical strength of Leda clays.” Canadian Geotechnical Journal, 7(3), 297-312.

Mitchell, R. J., and Wong, K. K. (1973). "The Generalized failure of an Ottawa Valley Champlain sea clay." Canadian Geotechnical Journal, 10(4): 607-616.

Mitchell, R.J., and Klugman, M.A. (1979). "Mass instabilities in sensitive Canadian soils." Engineering Geology, 14(2): 109-134.

Nagaraj, T. S., Murthy, B. S., Vatsala, A., and Joshi, R. C. (1990). "Analysis of compressibility of sensitive soils.” Journal of Geotechnical Engineering, 116(1): 105-118.

O'Kelly, B. C. (2006). "Compression and consolidation anisotropy of some soft soils." Geotechnical and Geological Engineering, 24(6): 1715-1728. 
Penner, E. (1963). “Sensitivity in Leda clay.” Nature, 197(4865): 347-348.

Penner, E. (1965). "A study of sensitivity in Leda clay." Canadian Journal of Earth Sciences, 2(5): 425-441.

Penner, E., and Burn, K. N. (1978). "Review of engineering behaviour of marine clays in Eastern Canada.” Canadian Geotechnical Journal, 15(2): 269-282.

Quigley, R. M. (1968). Discussion on "Landslide on the Toulnustouc River, Quebec." Canadian Geotechnical Journal, 5(3): 175-177.

Quigley, R. M., and Thompson, C. D. (1966). "The fabric of anisotropically consolidated sensitive marine clay." Canadian Geotechnical Journal, 3(2): 61-73.

Rankka, K., Andersson-Sköld, Y., Hultén, C., Larsson, R., Leroux, V., and Dahlin, T. (2004). “Quick clay in Sweden.” Swedish Geotechnical Institute Report, 65: 1-145.

Rasmussen, K. K. (2012). “An Investigation of Monotonic and Cyclic Behaviour of Leda Clay." MASc Thesis, University of Western Ontario, London, Canada. pp. 30-73.

Raymond, G. P., Gaskin, P. N., and Addo-Abedi, F. Y. (1979). "Repeated compressive loading of Leda clay." Canadian Geotechnical Journal, 16(1): 1-10.

Robinson, R. G. (1999). "Consolidation analysis with pore water pressure measurements." Geotechnique, 49(1): 127-132.

Rokhsar, A. (1973). "A Theoretical and experimental study of one-dimensional consolidation of clays." PhD Thesis, University of Illinois at Urbana-Champaign, IL, USA, p. 159. 
Rosenqvist, I.Th. (1953). "Considerations on the Sensitivity of Norwegian Quick Clays." Geotechnique, 3(5): 195-200.

Saran, D. (1970). "Removal of swelling clay minerals from Leda clay and influence on the permeability.” M.E.Sc Thesis, University of Western Ontario, London Ontario, Canada, p. 4.

Seah, T. H., and Koslanant, S. (2003). “Anisotropic consolidation behavior of soft Bangkok clay.” Geotechnical Testing Journal, 26(3): 266-276.

Silvestri, V., and Aubertin, M. (1988). "Anisotropy and in-situ vane tests." Vane shear strength testing in soils: field and laboratory studies, ASTM STP1014: 88-103.

Silvestri, V., and Morgavi, R. (1982). "Measurement of lateral stresses in one-dimensional tests on a sensitive clay of Eastern Canada." Proceedings of the $19^{\text {th }}$ Annual Engineering Geology and Soils Engineering Symposium, Idaho State University, Pocatello, Idaho, USA, 19: 201-216.

Silvestri, V., Karam, G., Tonthat, A., and St-Amour, Y. (1989). "Direct and Simple Shear Testing of Two Canadian Sensitive Clays." ASTM Geotechnical Testing Journal, 12(1): $11-21$.

Skempton, A.W., and Northey, R.D. (1952). "The Sensitivity of Clays." Geotechnique, 3(1): $30-53$.

Söderblom, R. (1969). "Salt in Swedish clays and its importance for quick clay formation." Swedish Geotechnical Institute., Proc. No.26, p. 89. 
Sridharan, A. and Prakash, K. (1995). Discussion on "Limitations of Conventional Analysis of Consolidation Settlement.” ASCE Journal of Geotechnical Engineering, 121(6): 517.

Taha, A. M. (2010). "Interface Shear Behavior of Sensitive Marine Clays-Leda Clay." MASc Thesis, University of Ottawa, Ottawa, Canada, p. 69.

Terzaghi, K. (1943). “Theoretical soil mechanics.” John Wiley and Sons Inc., New York.

Torrance, J. K. (1983). "Towards a general model of quick clay development." Sedimentology, 30(4): 547-555.

Vipulanantham, M. (2011). "Initial stress state and stress history effects on liquefaction susceptibility of sands." MASc Thesis, Carleton University, Ottawa, Canada, pp. 30-31.

Yimsiri, S., \& Soga, K. (2011). "Cross-anisotropic elastic parameters of two natural stiff clays." Geotechnique, 61(9): 809-814.

Yong, R. N. and Tang, K. Y. (1983). "Soil Remolding and Sensitivity Measurements." Geotechnical Testing Journal, 6(2): 73-80. 
Appendix A

(The plots of the consolidation results) 


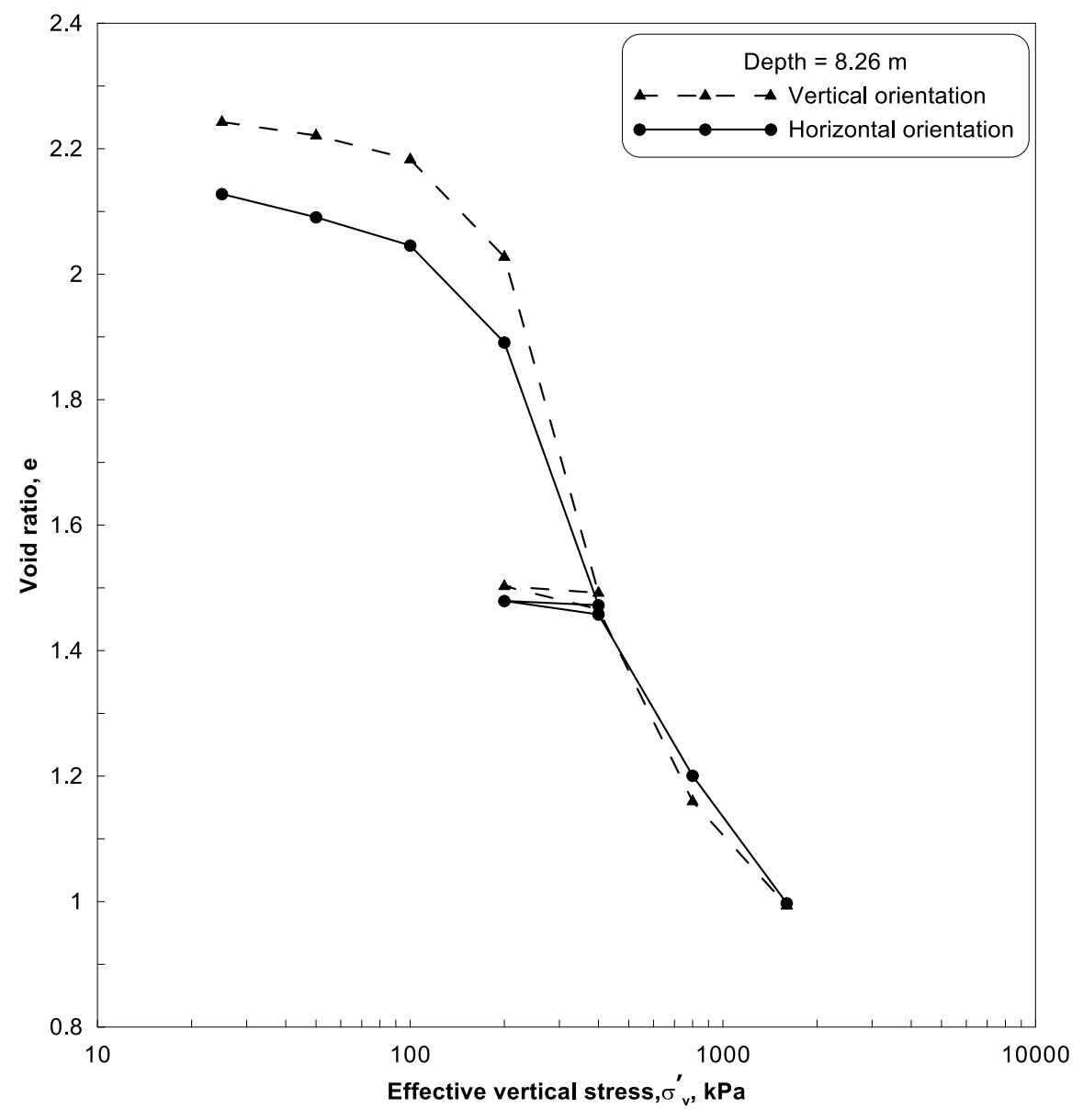

Figure A1: One-dimensional consolidation curves for vertical and horizontal orientations $($ depth $=8.26 \mathrm{~m})$. 


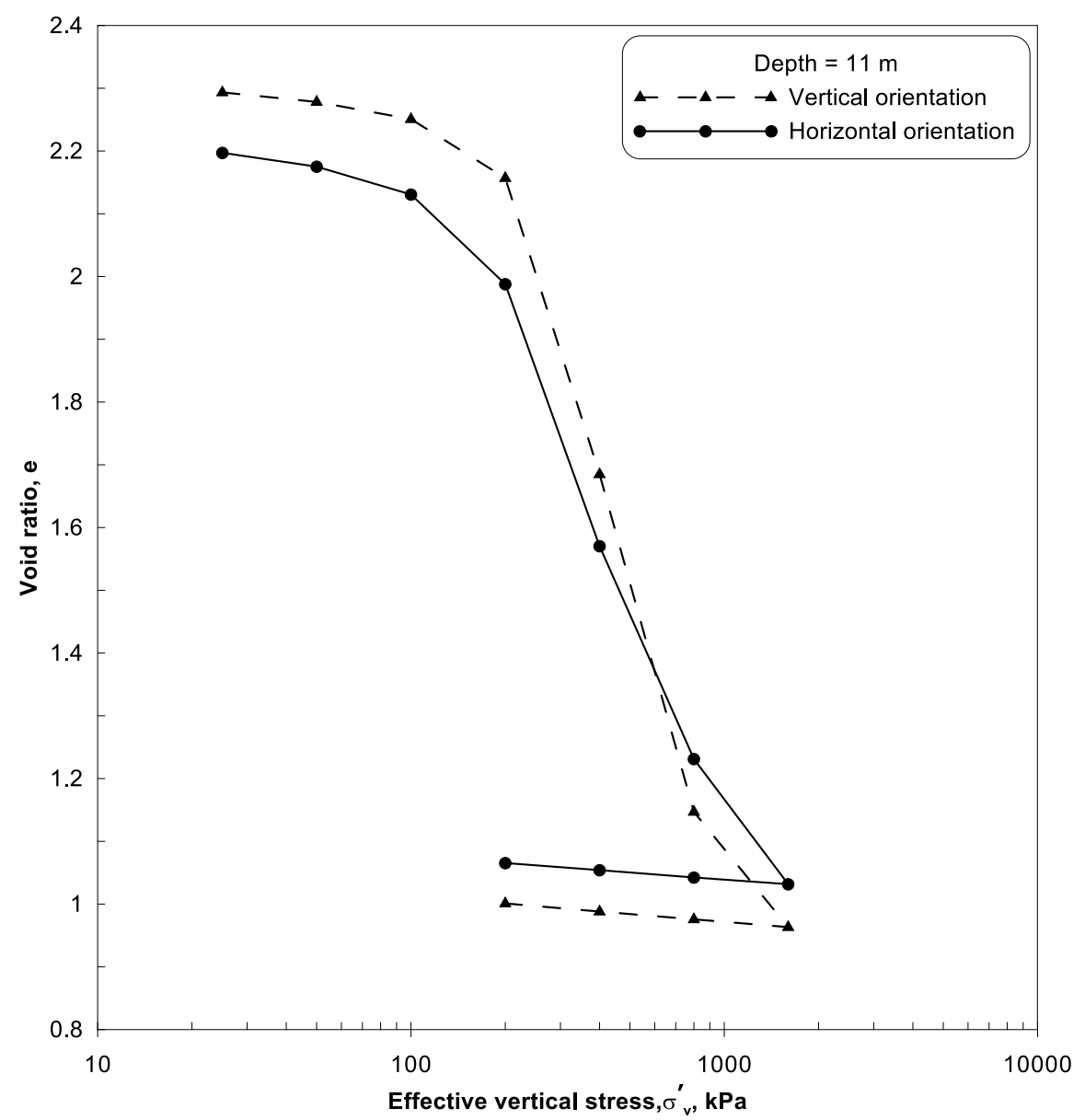

Figure A2: One-dimensional consolidation curves for vertical and horizontal orientations $($ depth $=11 \mathrm{~m})$. 


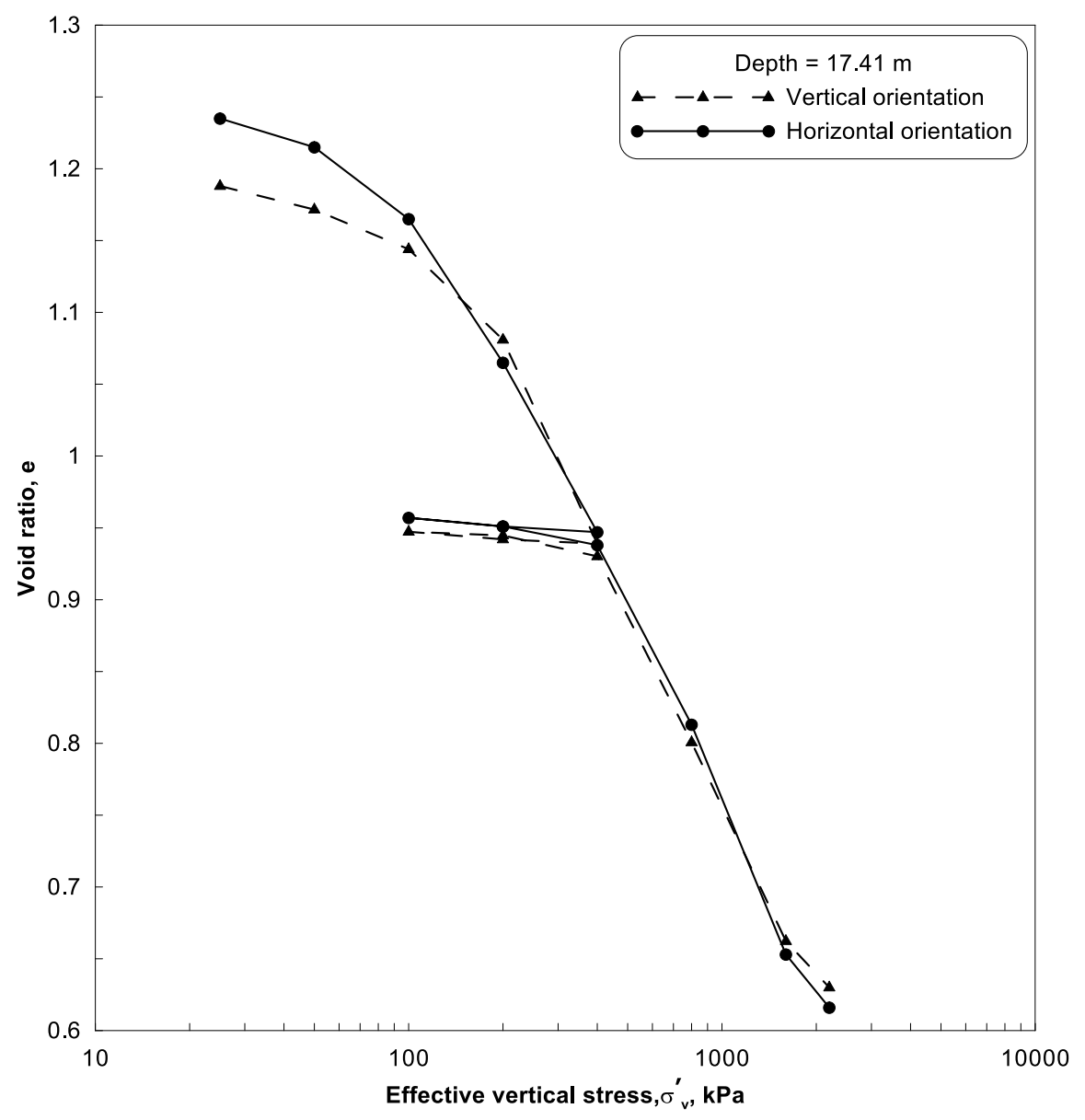

Figure A3: One-dimensional consolidation curves for vertical and horizontal orientations $($ depth $=17.41 \mathrm{~m})$. 


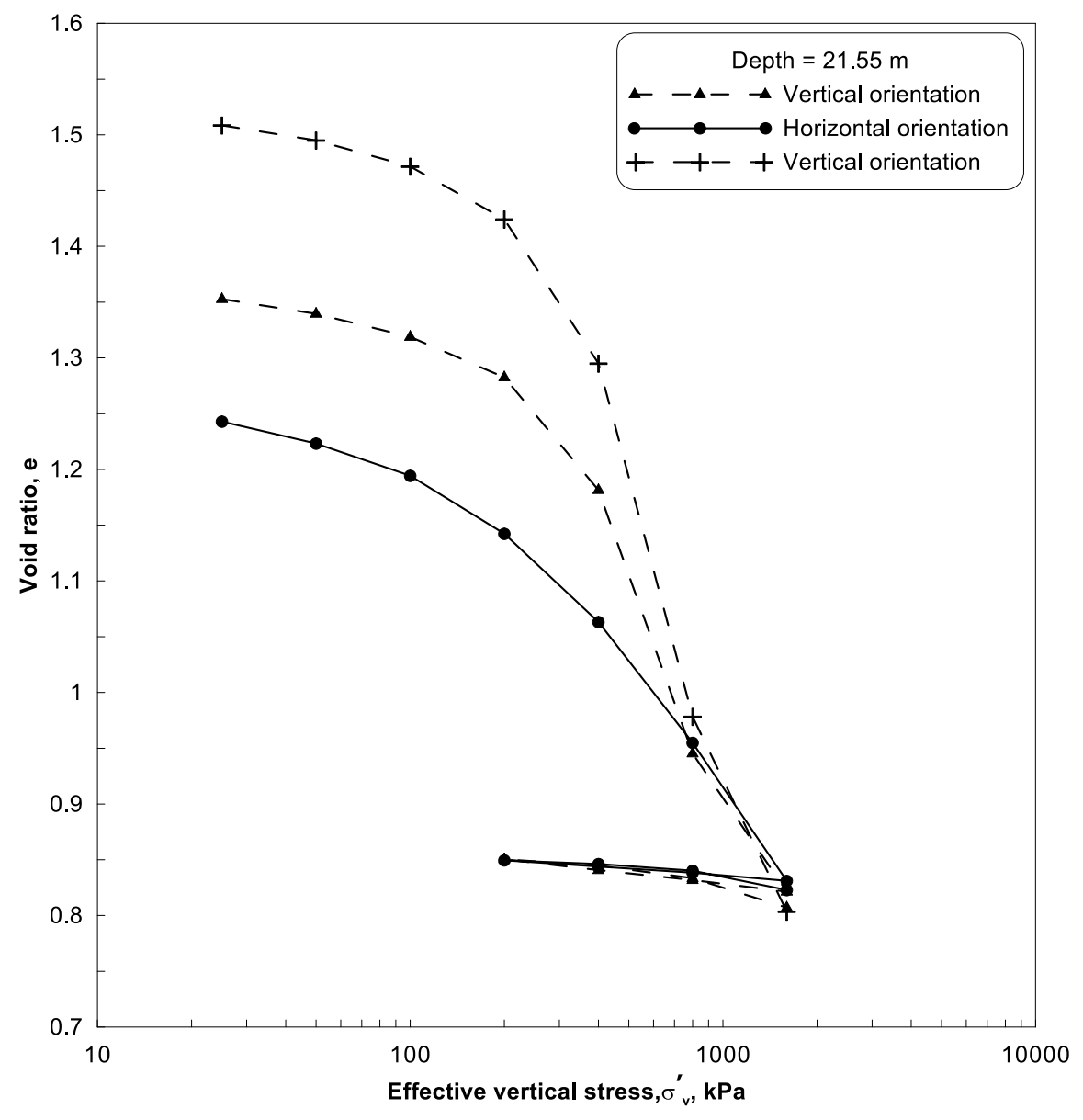

Figure A4: One-dimensional consolidation curves for vertical and horizontal orientations $($ depth $=21.55 \mathrm{~m})$. 


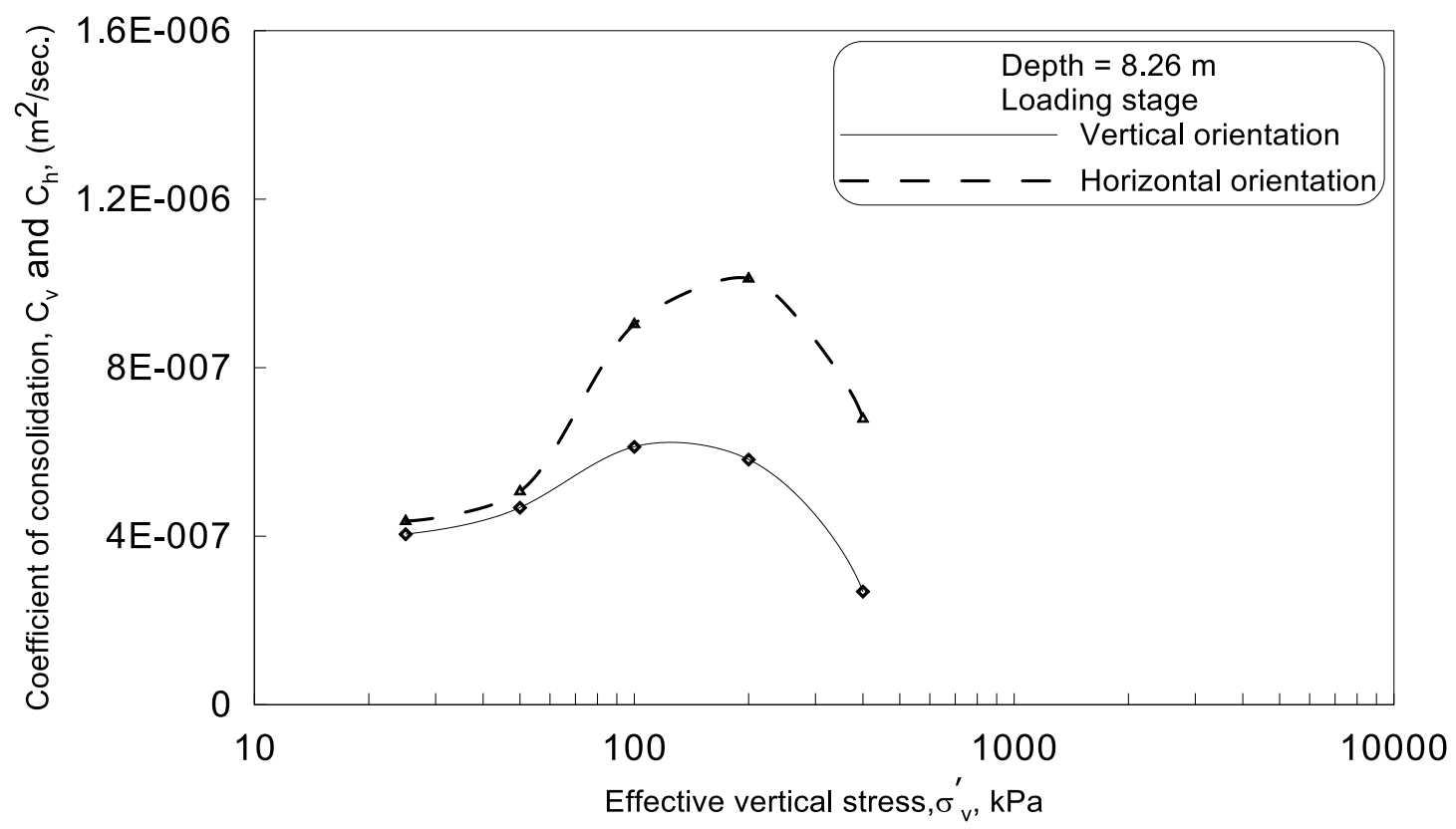

Figure A5: Typical plots of the vertical and horizontal coefficients of consolidation versus the logarithm of effective vertical stress by using Casagrande's method during the loading stage at depth of $8.26 \mathrm{~m}$.

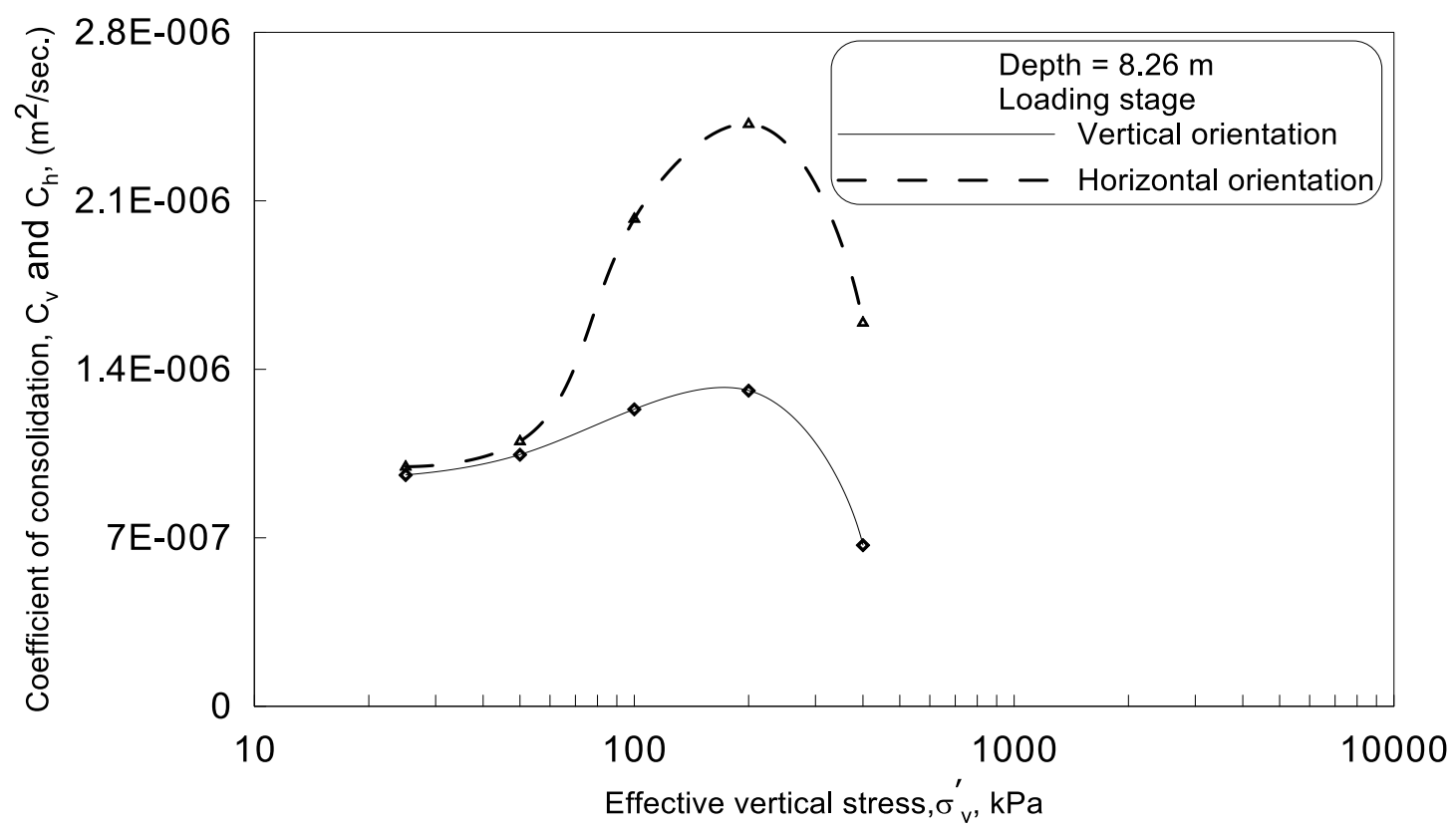

Figure A6: Typical plots of the vertical and horizontal coefficients of consolidation versus the logarithm of effective vertical stress by using Taylor's method during the loading stage at depth of $8.26 \mathrm{~m}$. 


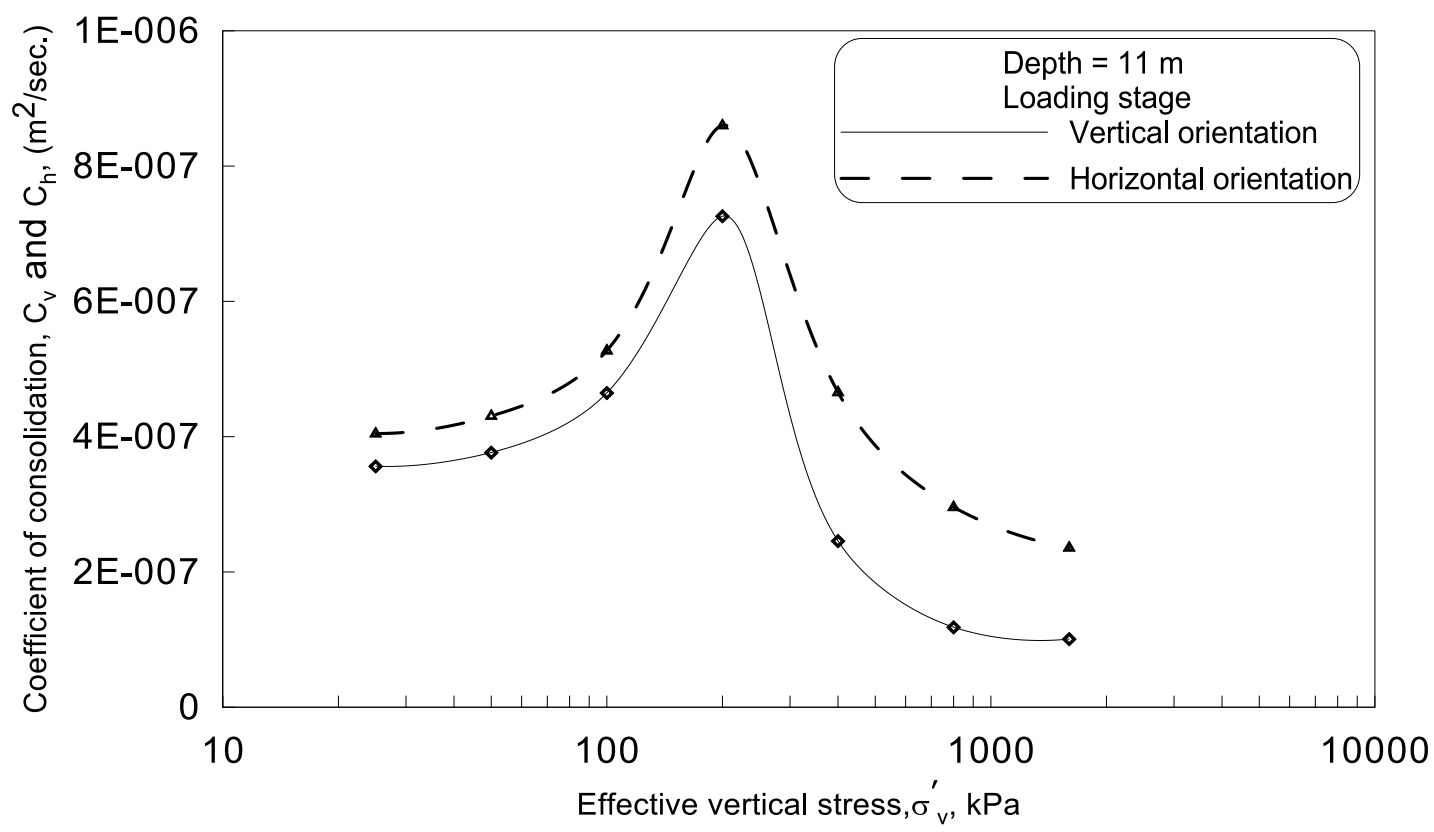

Figure A7: Typical plots of the vertical and horizontal coefficients of consolidation versus the logarithm of effective vertical stress by using Casagrande's method during the loading stage at depth of $11 \mathrm{~m}$.

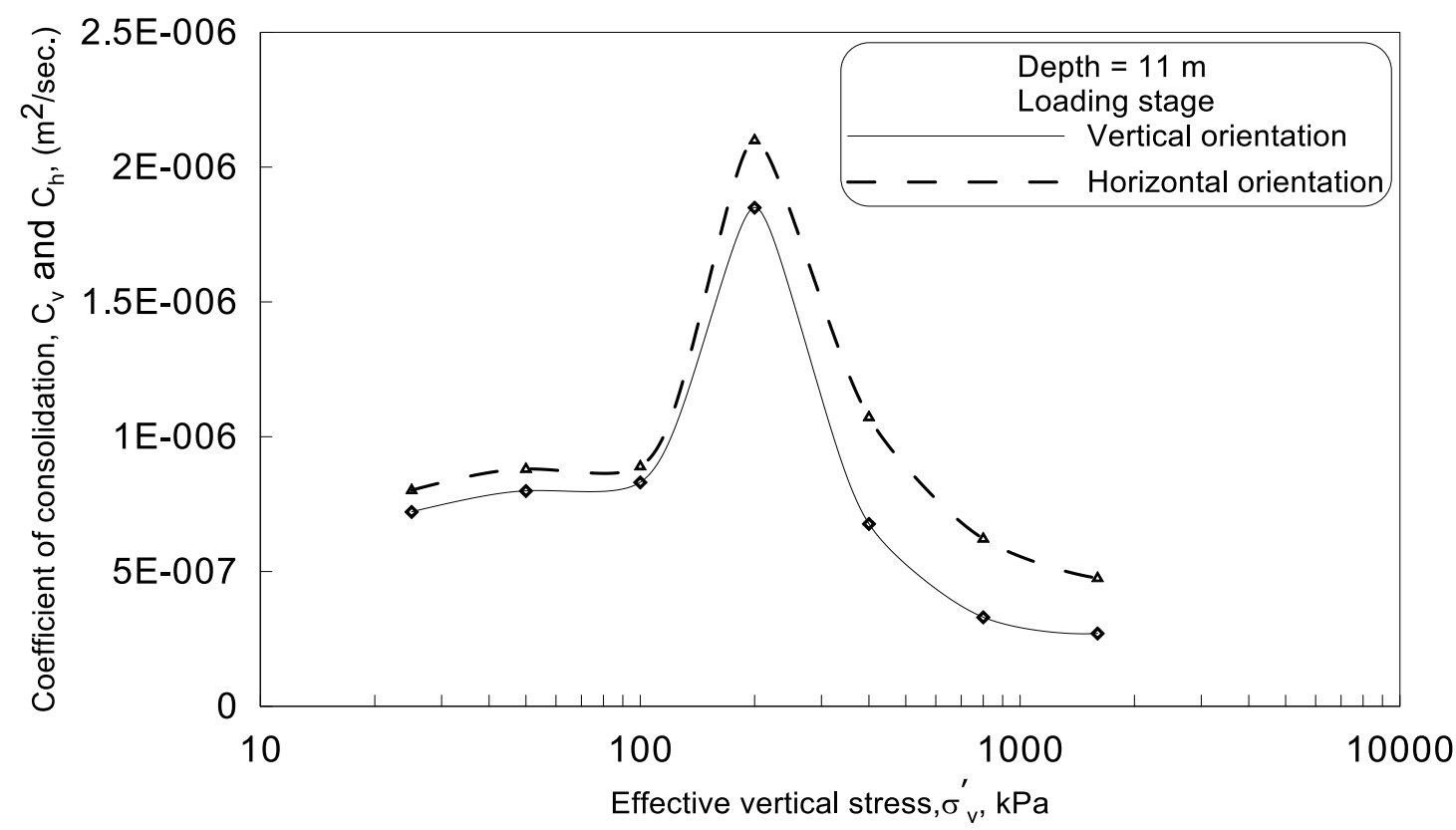

Figure A8: Typical plots of the vertical and horizontal coefficients of consolidation versus the logarithm of effective vertical stress by using Taylor's method during the loading stage at depth of $11 \mathrm{~m}$. 


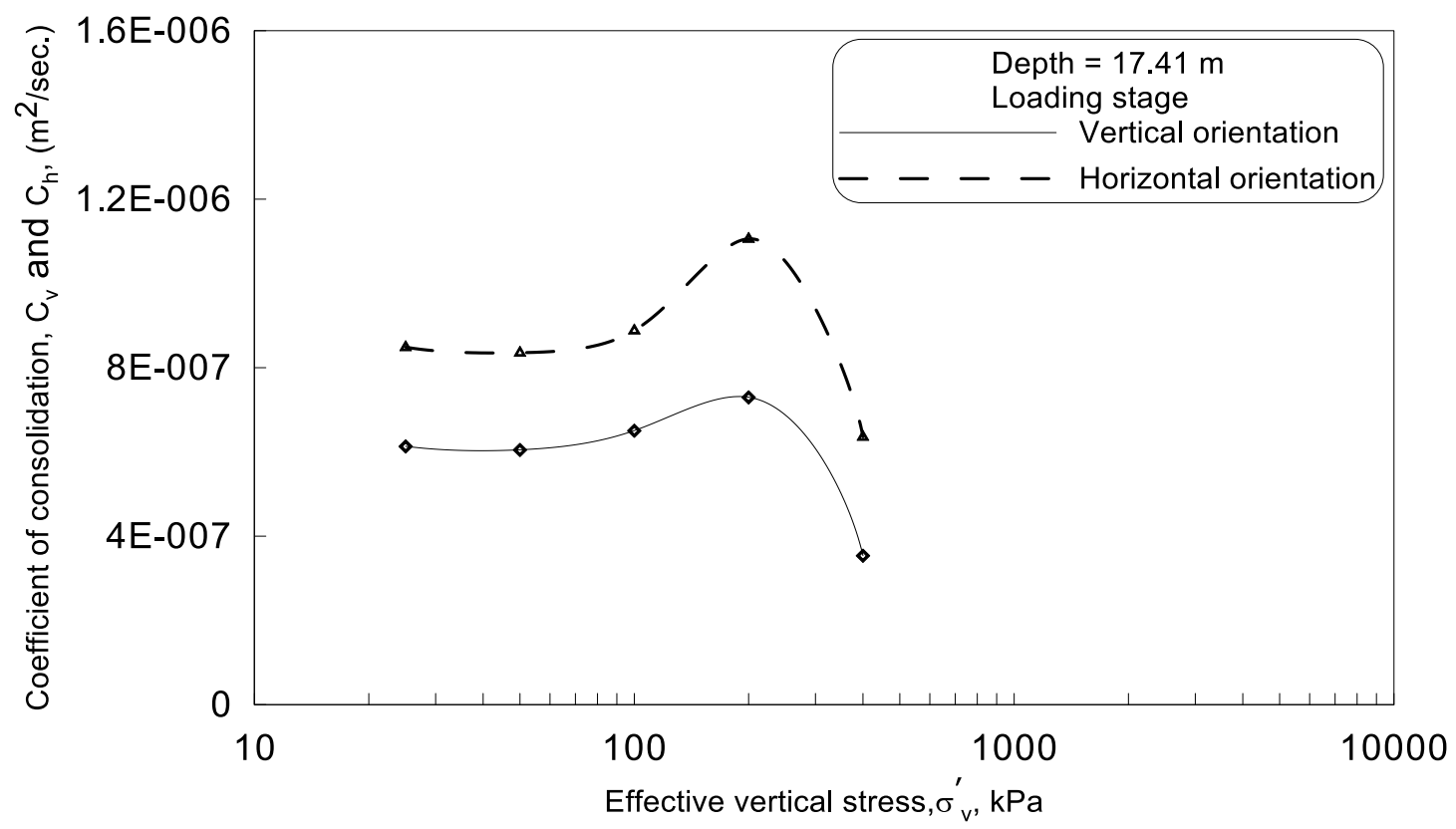

Figure A9: Typical plots of the vertical and horizontal coefficients of consolidation versus the logarithm of effective vertical stress by using Casagrande's method during the loading stage at depth of $17.41 \mathrm{~m}$.

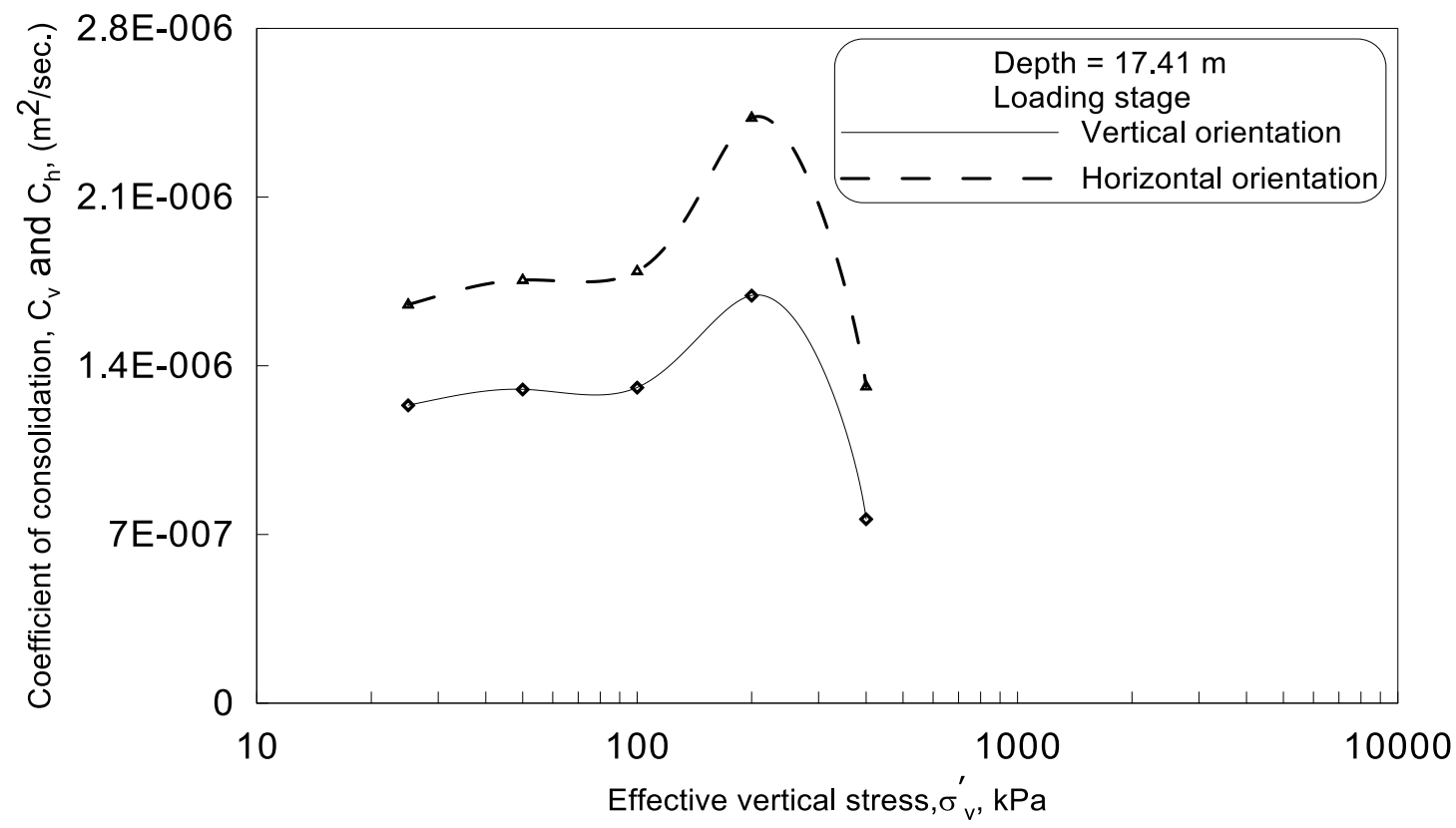

Figure A10: Typical plots of the vertical and horizontal coefficients of consolidation versus the logarithm of effective vertical stress by using Taylor's method during the loading stage at depth of $17.41 \mathrm{~m}$. 


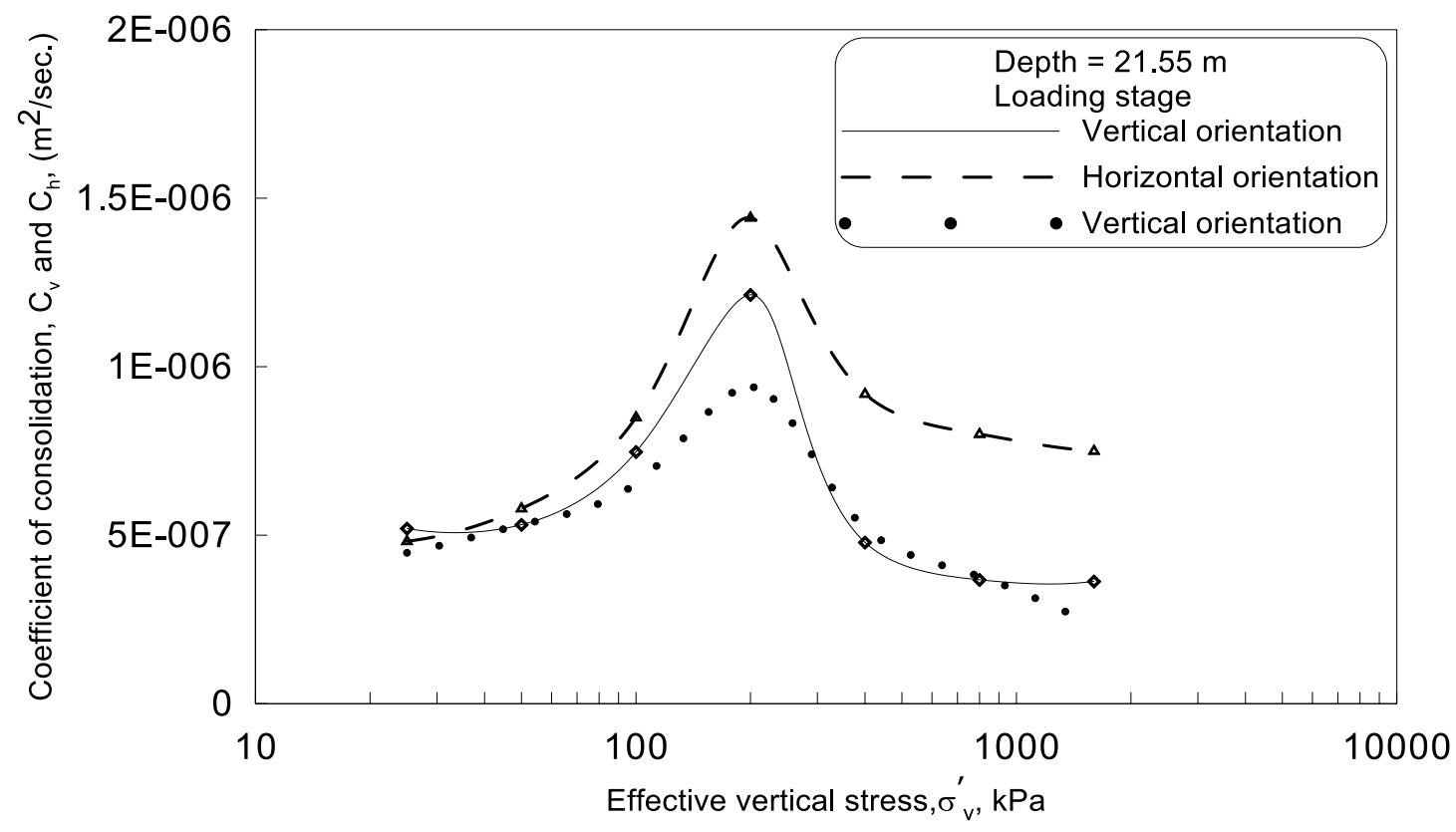

Figure A11: Typical plots of the vertical and horizontal coefficients of consolidation versus the logarithm of effective vertical stress by using Casagrande's method during the loading stage at depth of $21.55 \mathrm{~m}$.

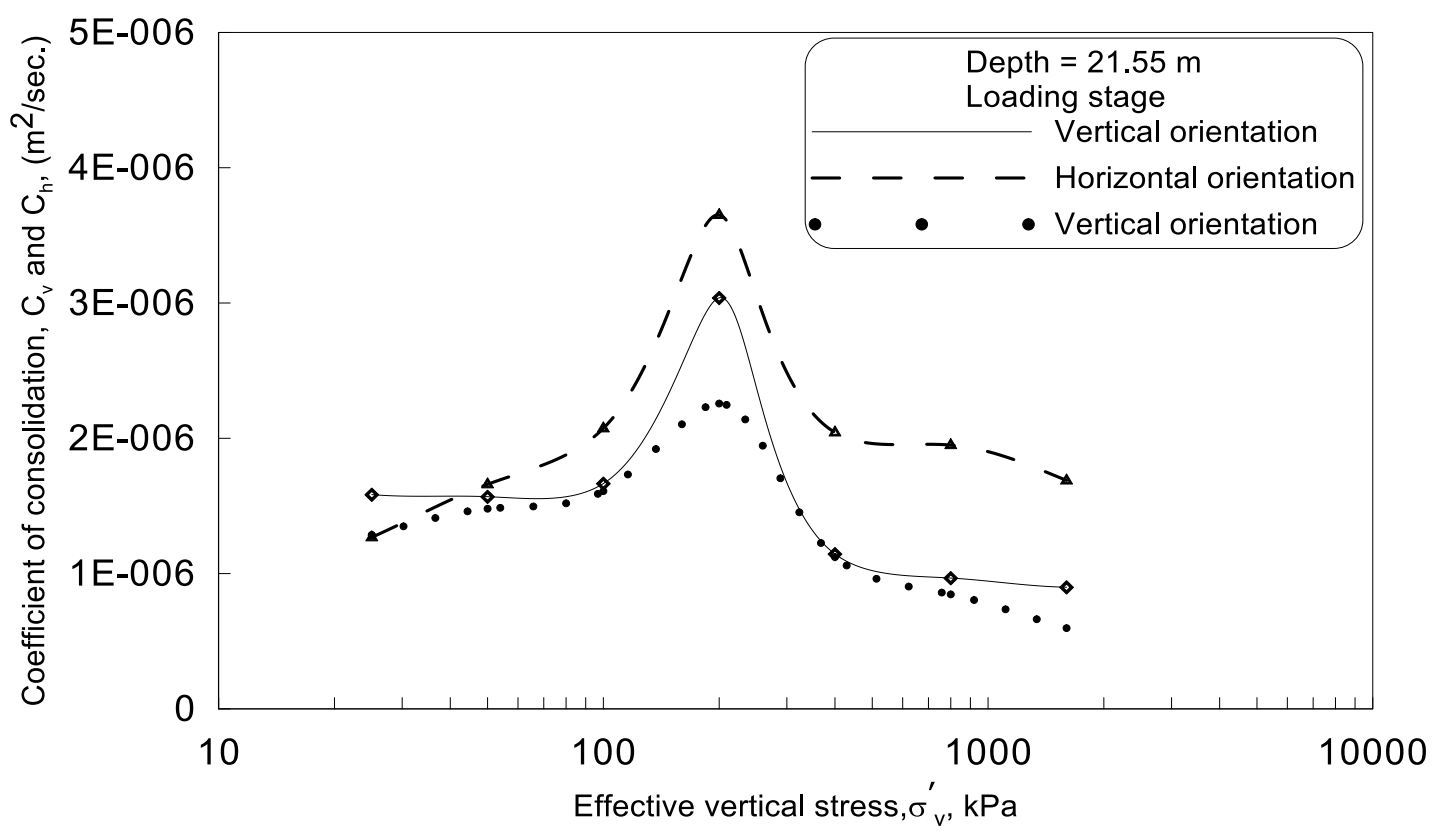

Figure A12: Typical plots of the vertical and horizontal coefficients of consolidation versus the logarithm of effective vertical stress by using Taylor's method during the loading stage at depth of $21.55 \mathrm{~m}$. 


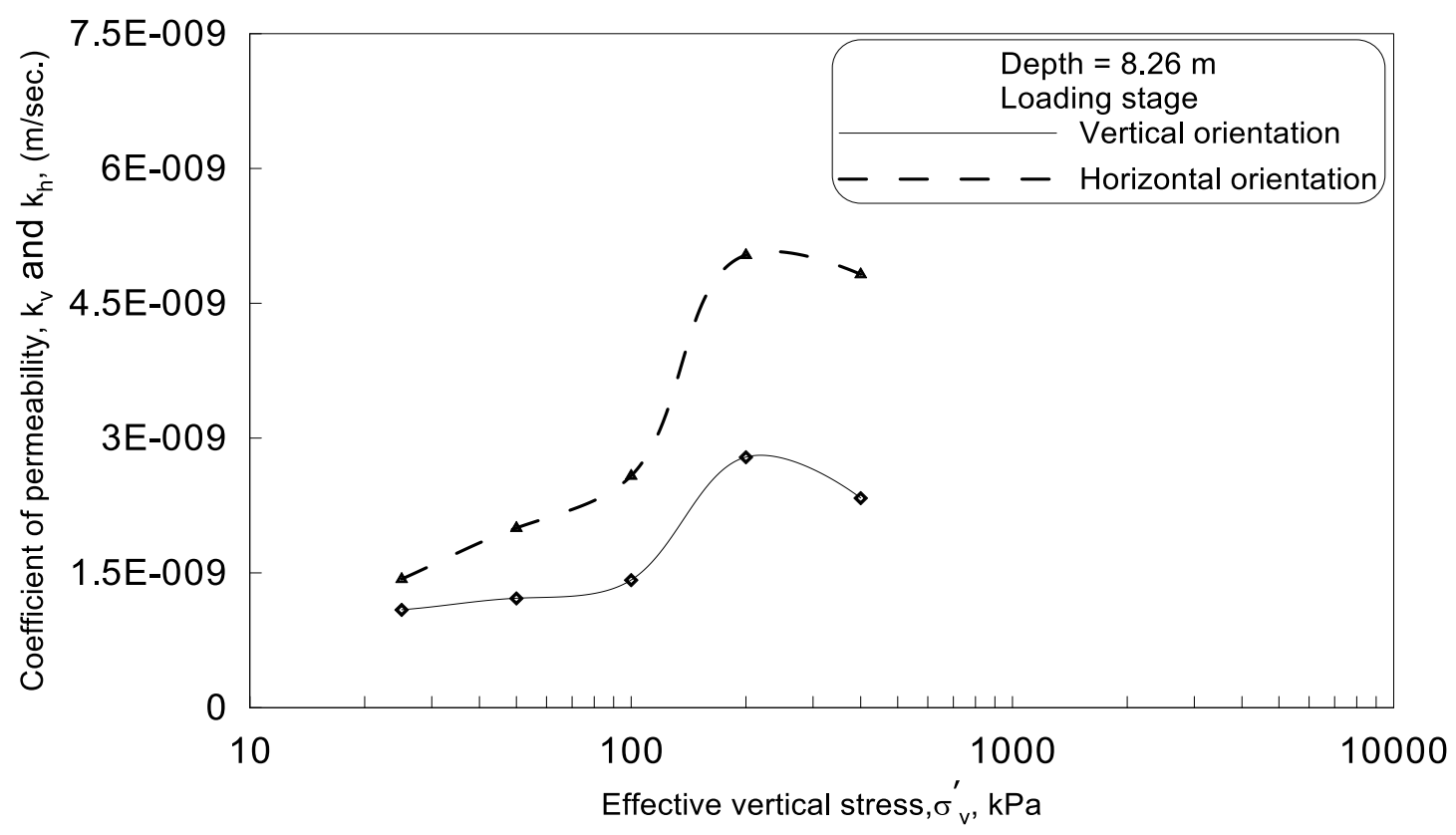

Figure A13: Typical plots of the vertical and horizontal coefficients of permeability versus the logarithm of effective vertical stress by using Casagrande's method during the loading stage at depth of $8.26 \mathrm{~m}$.

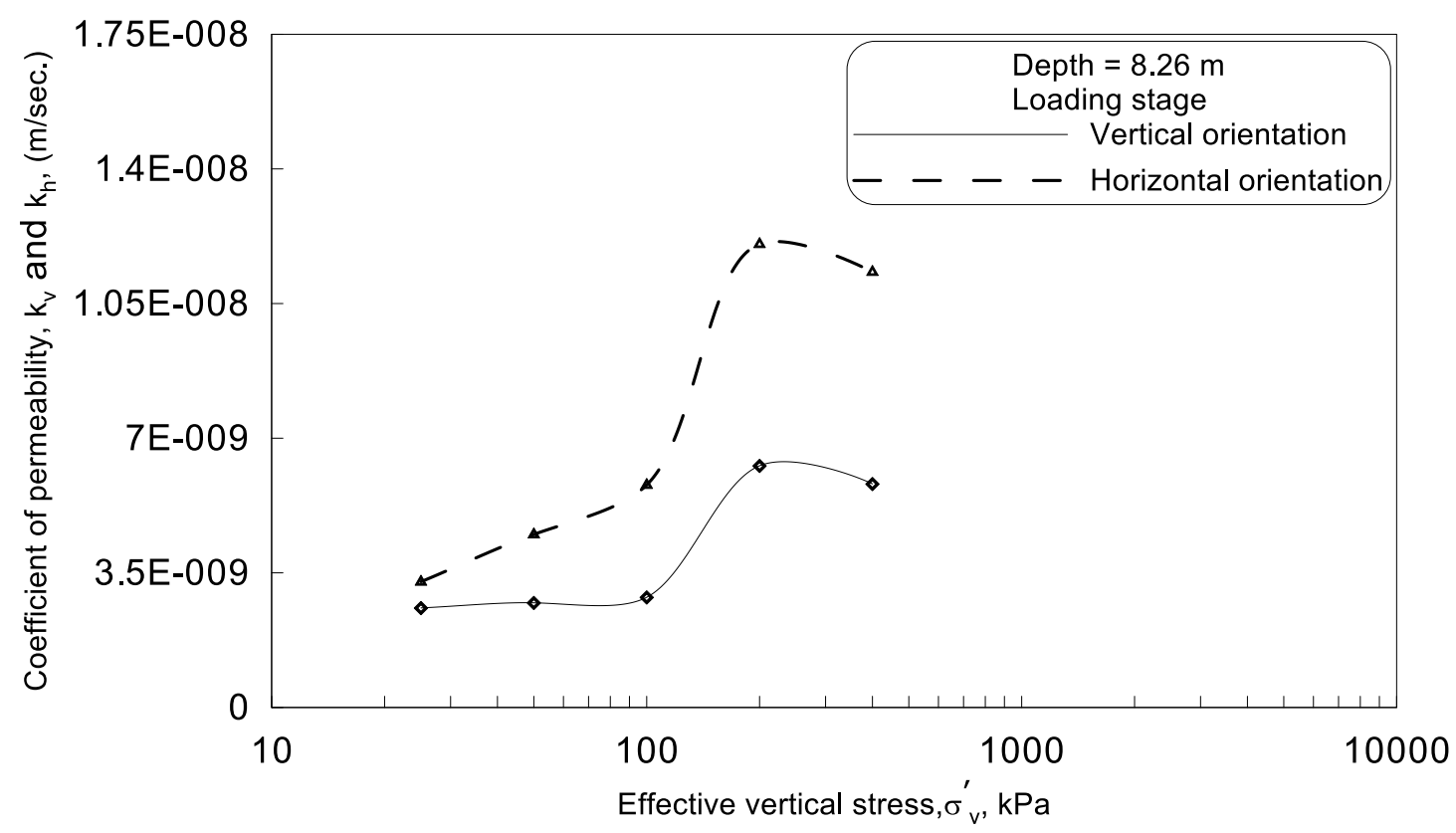

Figure A14: Typical plots of the vertical and horizontal coefficients of permeability versus the logarithm of effective vertical stress by using Taylor's method during the loading stage at depth of $8.26 \mathrm{~m}$. 


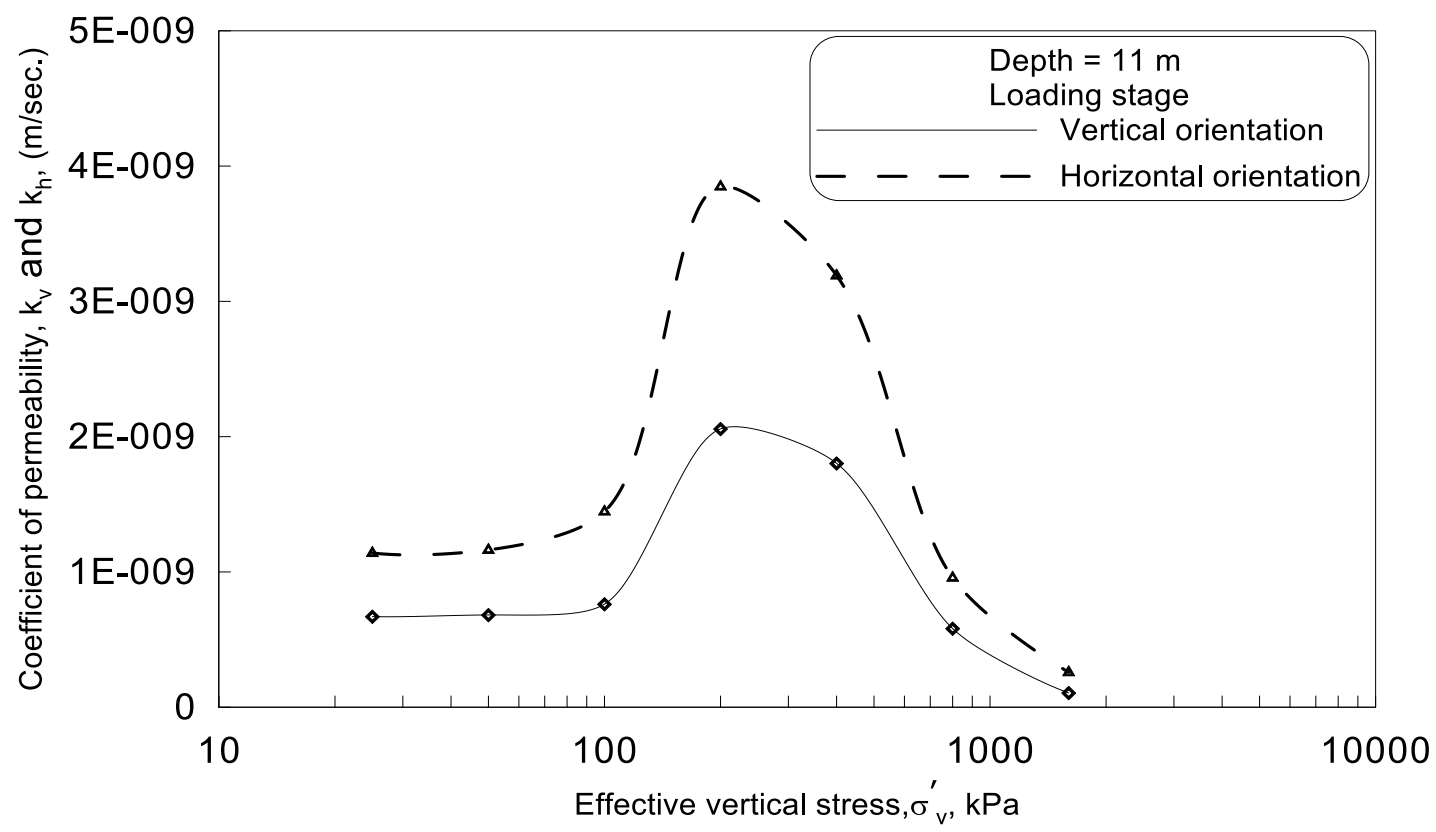

Figure A15: Typical plots of the vertical and horizontal coefficients of permeability versus the logarithm of effective vertical stress by using Casagrande's method during the loading stage at depth of $11 \mathrm{~m}$.

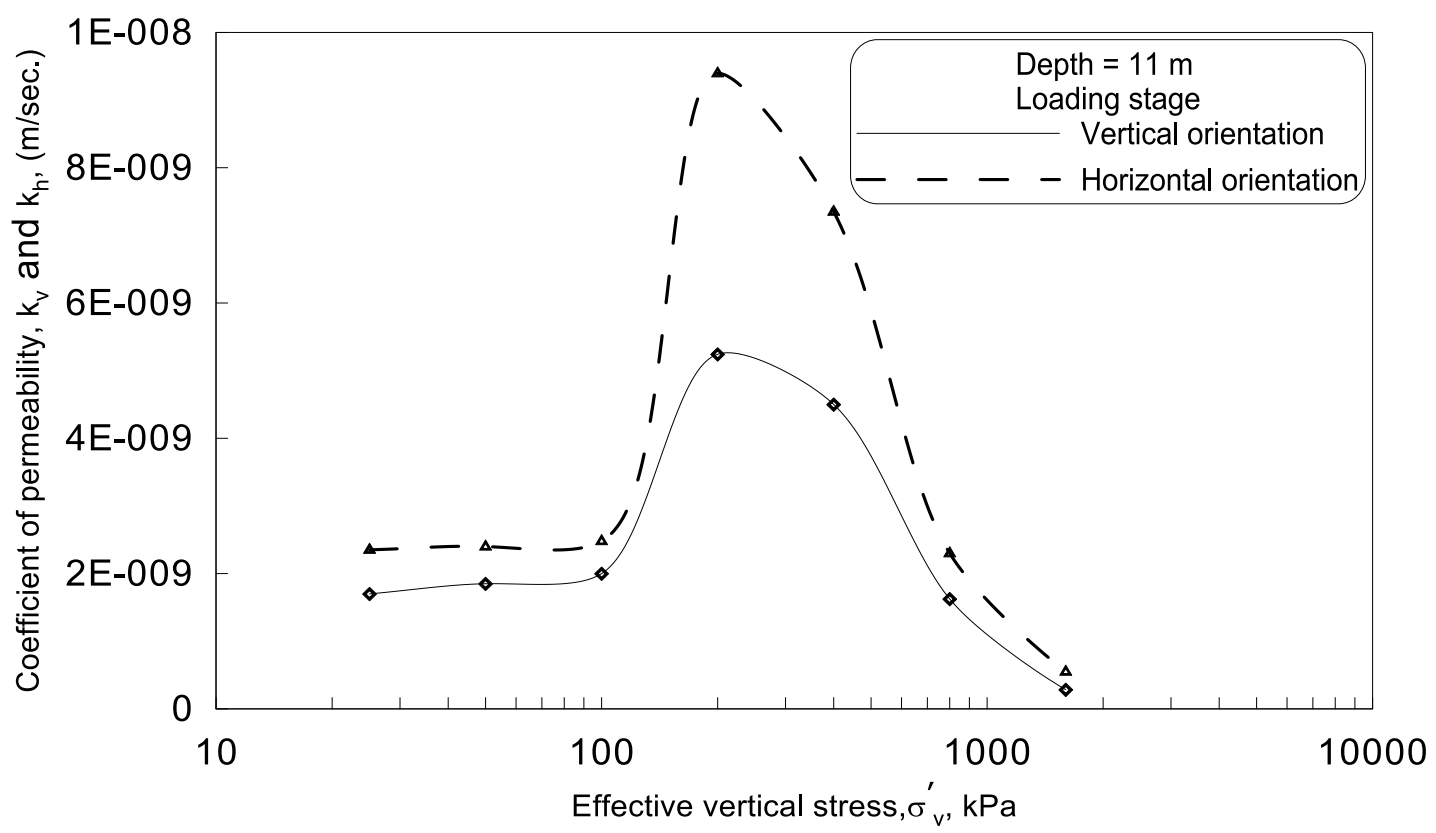

Figure A16: Typical plots of the vertical and horizontal coefficients of permeability versus the logarithm of effective vertical stress by using Taylor's method during the loading stage at depth of $11 \mathrm{~m}$. 


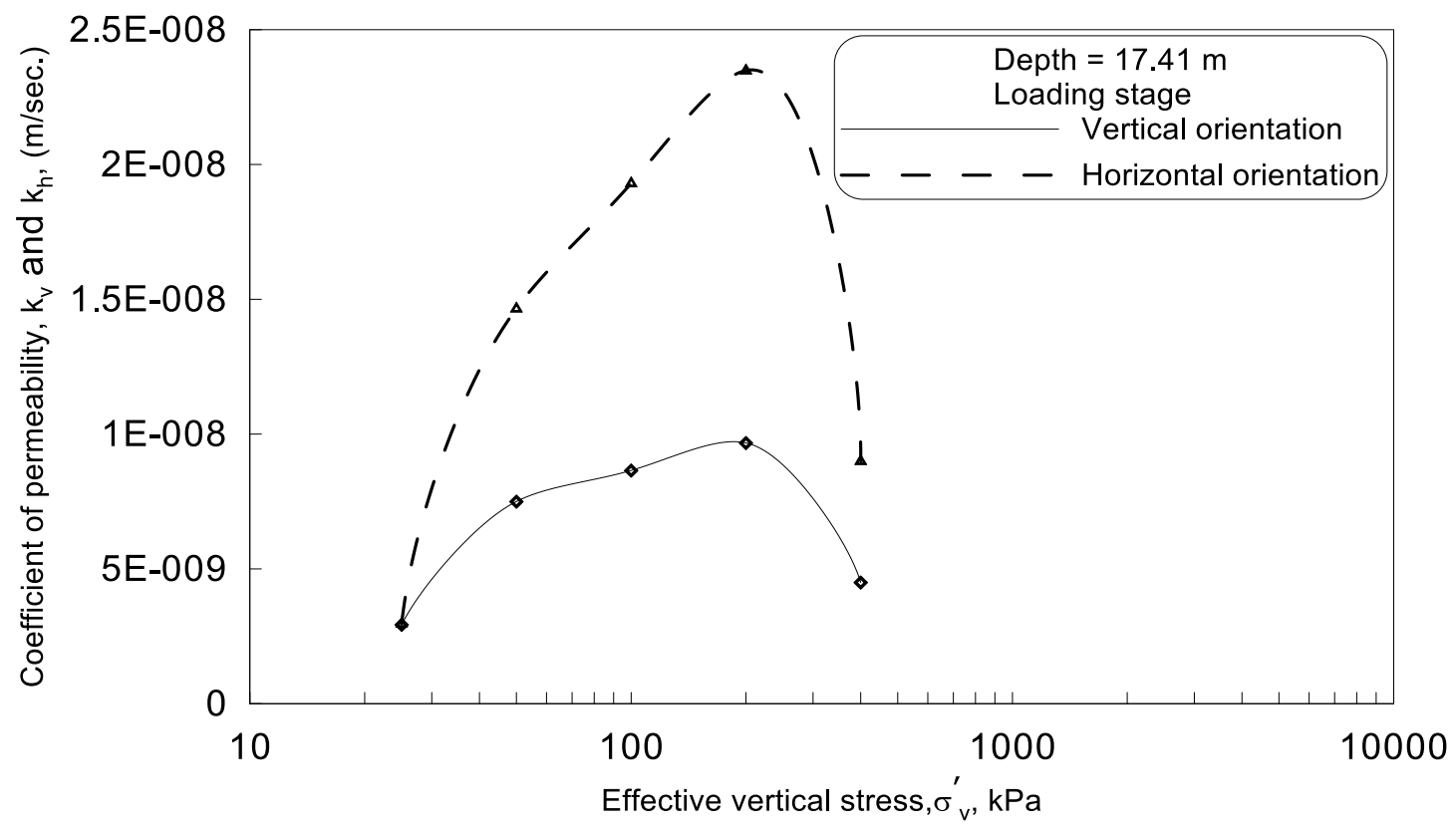

Figure A17: Typical plots of the vertical and horizontal coefficients of permeability versus the logarithm of effective vertical stress by using Casagrande's method during the loading stage at depth of $17.41 \mathrm{~m}$.

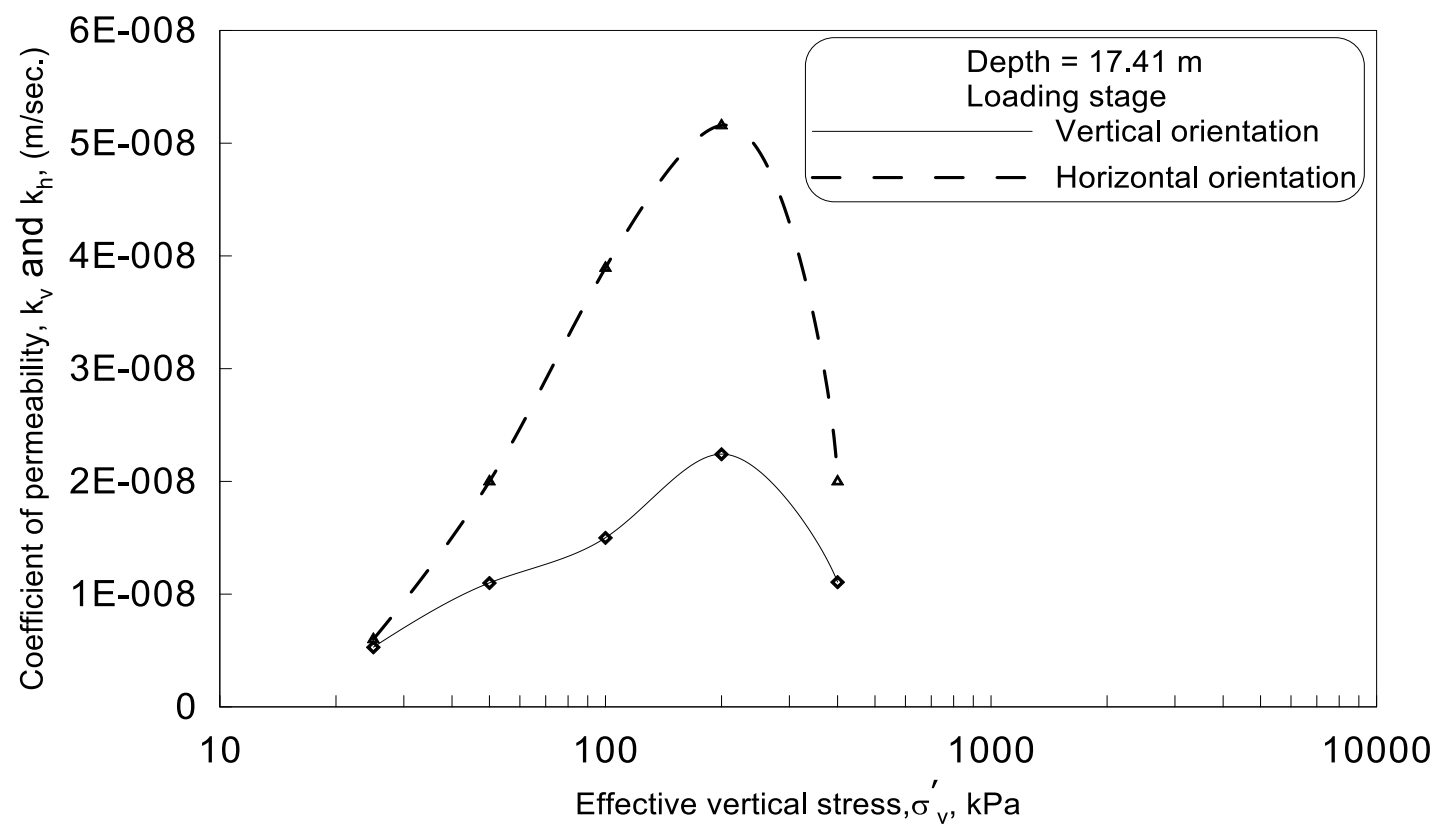

Figure A18: Typical plots of the vertical and horizontal coefficients of permeability versus the logarithm of effective vertical stress by using Taylor's method during the loading stage at depth of $17.41 \mathrm{~m}$. 


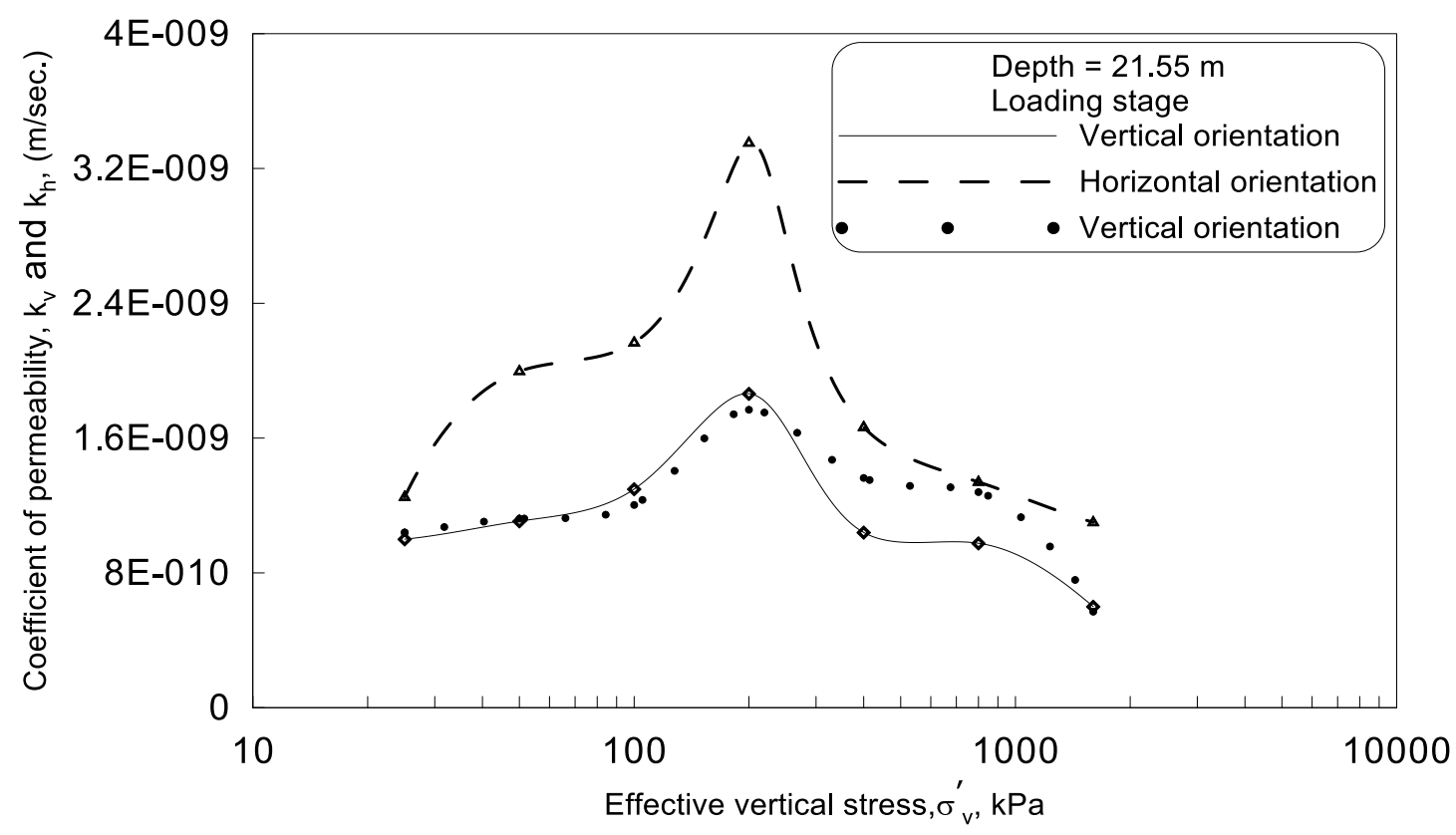

Figure A19: Typical plots of the vertical and horizontal coefficients of permeability versus the logarithm of effective vertical stress by using Casagrande's method during the loading stage at depth of $21.55 \mathrm{~m}$.

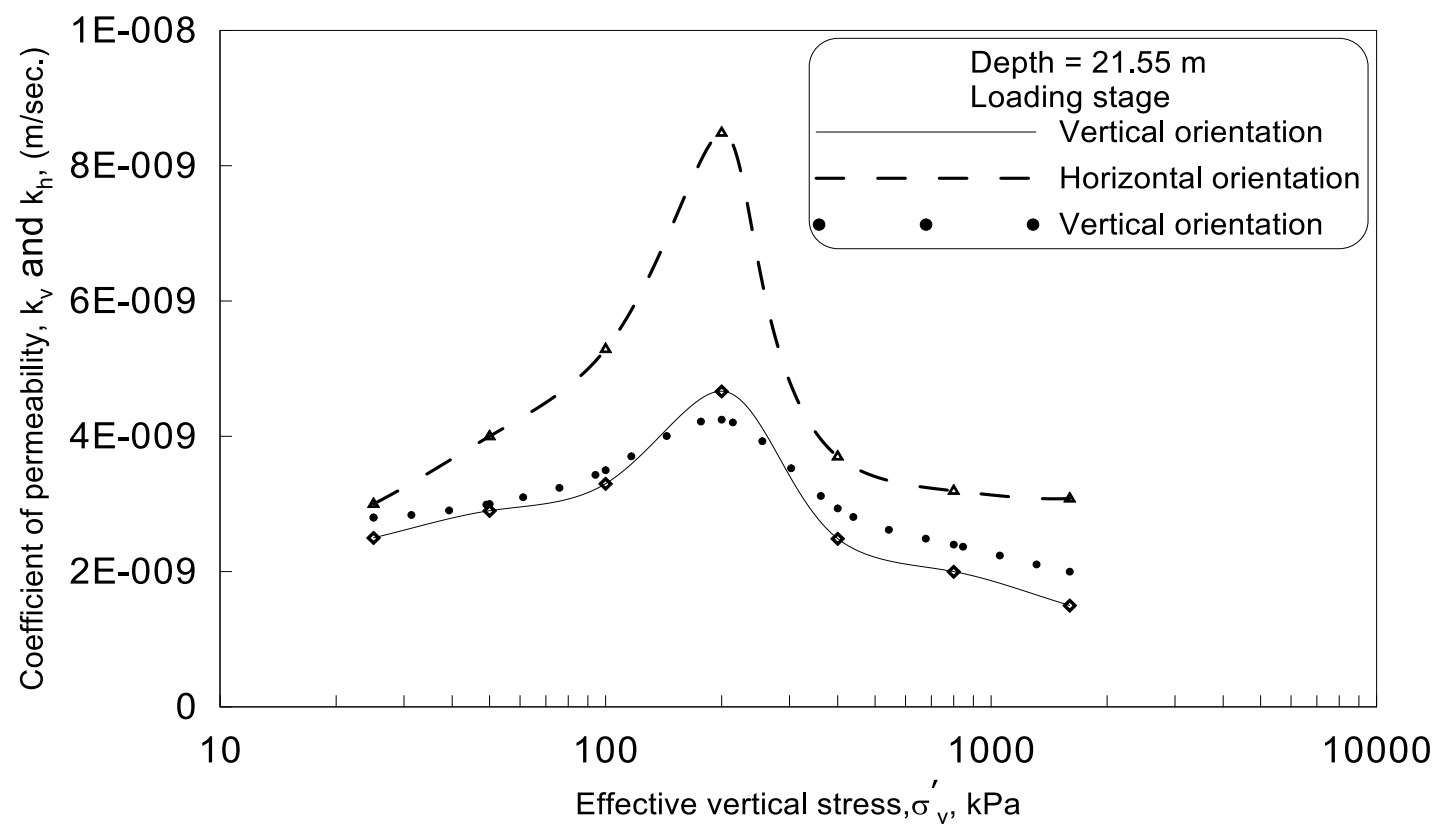

Figure A20: Typical plots of the vertical and horizontal coefficients of permeability versus the logarithm of effective vertical stress by using Taylor's method during the loading stage at depth of $21.55 \mathrm{~m}$. 

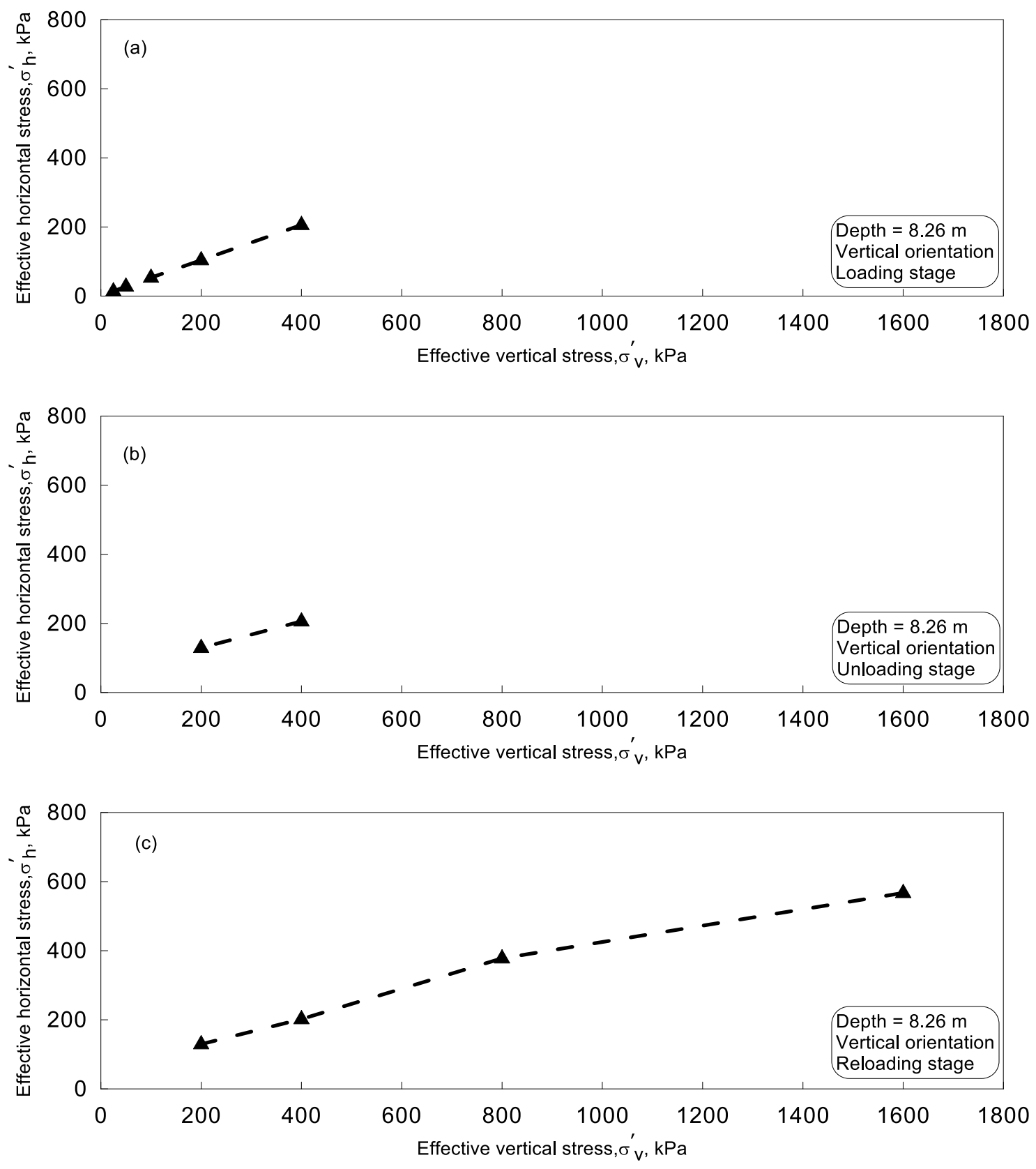

Figure A21: Typical plots of the effective horizontal stress versus the effective vertical stress during the (a) loading, (b) unloading, and (c) reloading stages for vertical orientation $($ depth $=8.26 \mathrm{~m})$. 

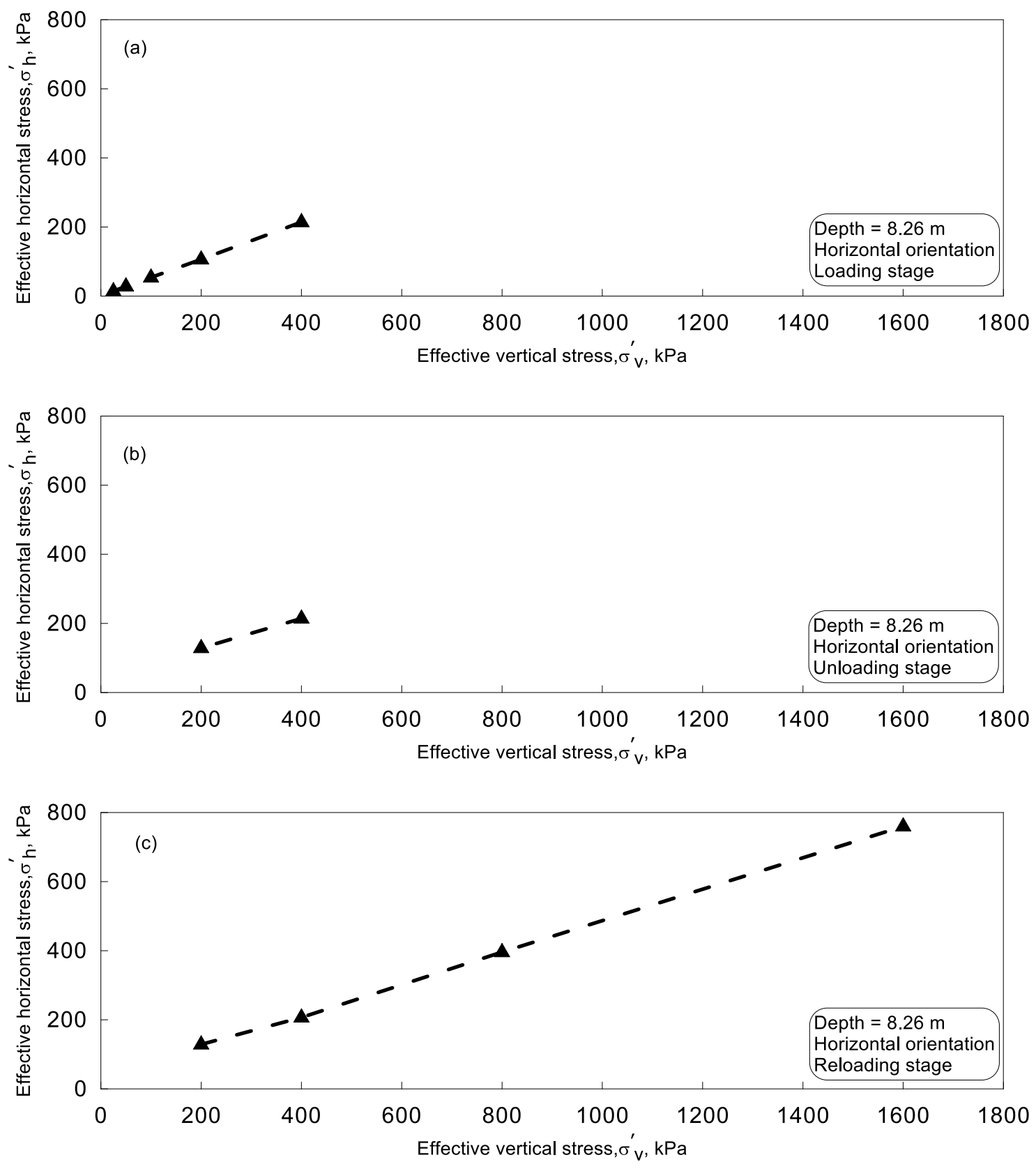

Figure A22: Typical plots of the effective horizontal stress versus the effective vertical stress during the (a) loading, (b) unloading, and (c) reloading stages for horizontal orientation $($ depth $=8.26 \mathrm{~m})$. 

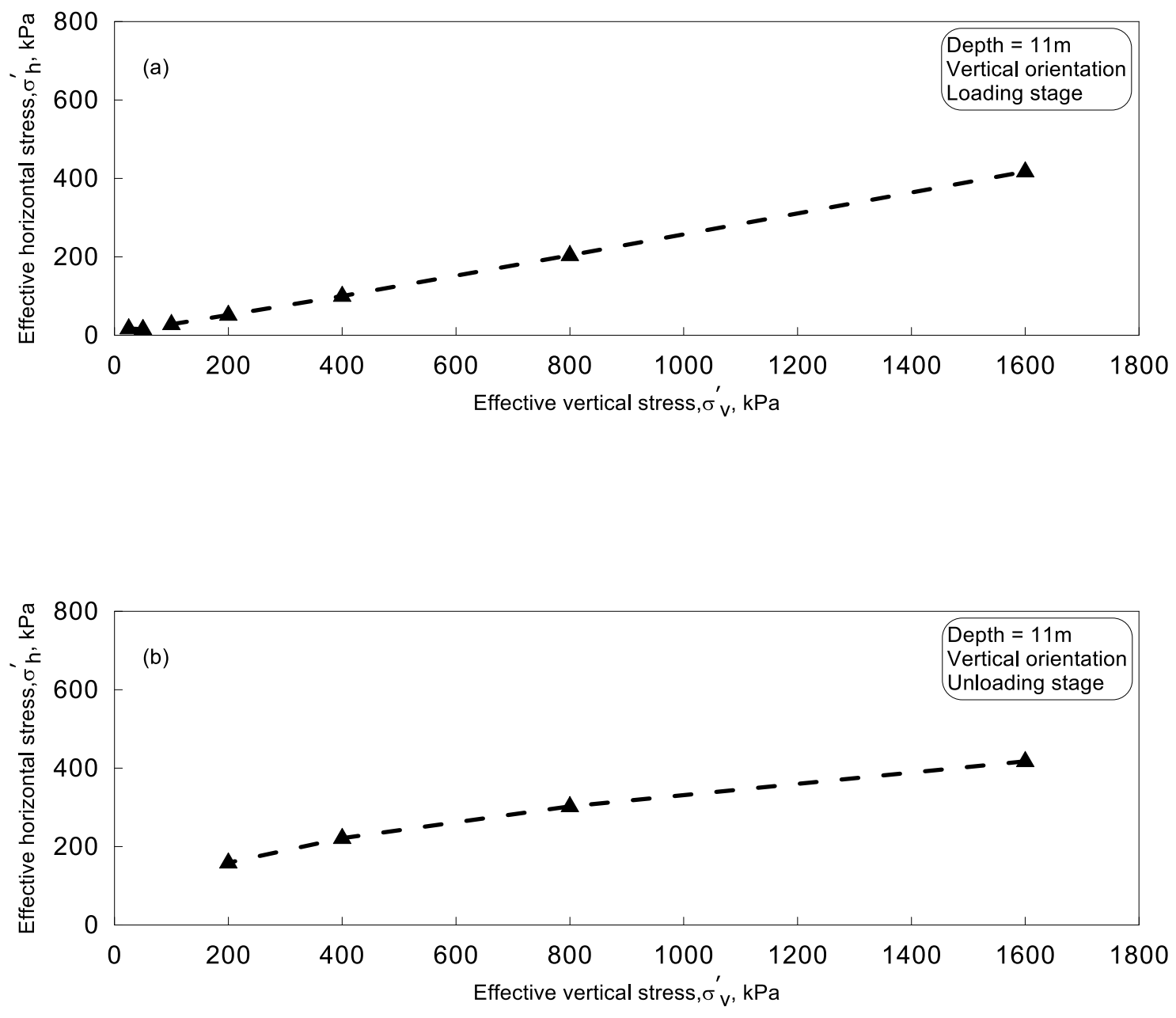

Figure A23: Typical plots of the effective horizontal stress versus the effective vertical stress during the (a) loading, and (b) unloading stages for vertical orientation (depth $=11$ $\mathrm{m})$. 

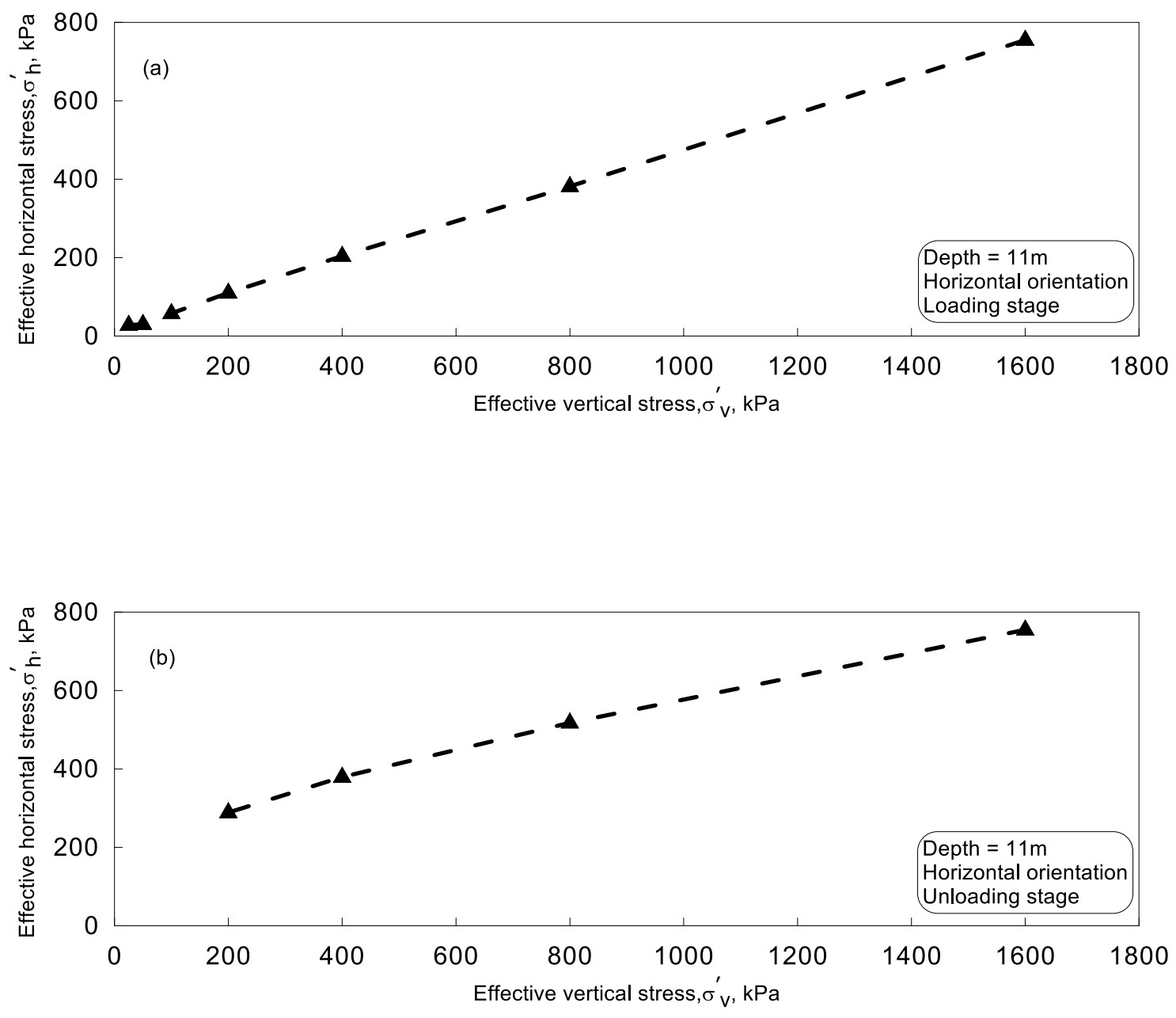

Figure A24: Typical plots of the effective horizontal stress versus the effective vertical stress during the (a) loading, and (b) unloading stages for horizontal orientation (depth $=$ $11 \mathrm{~m})$. 

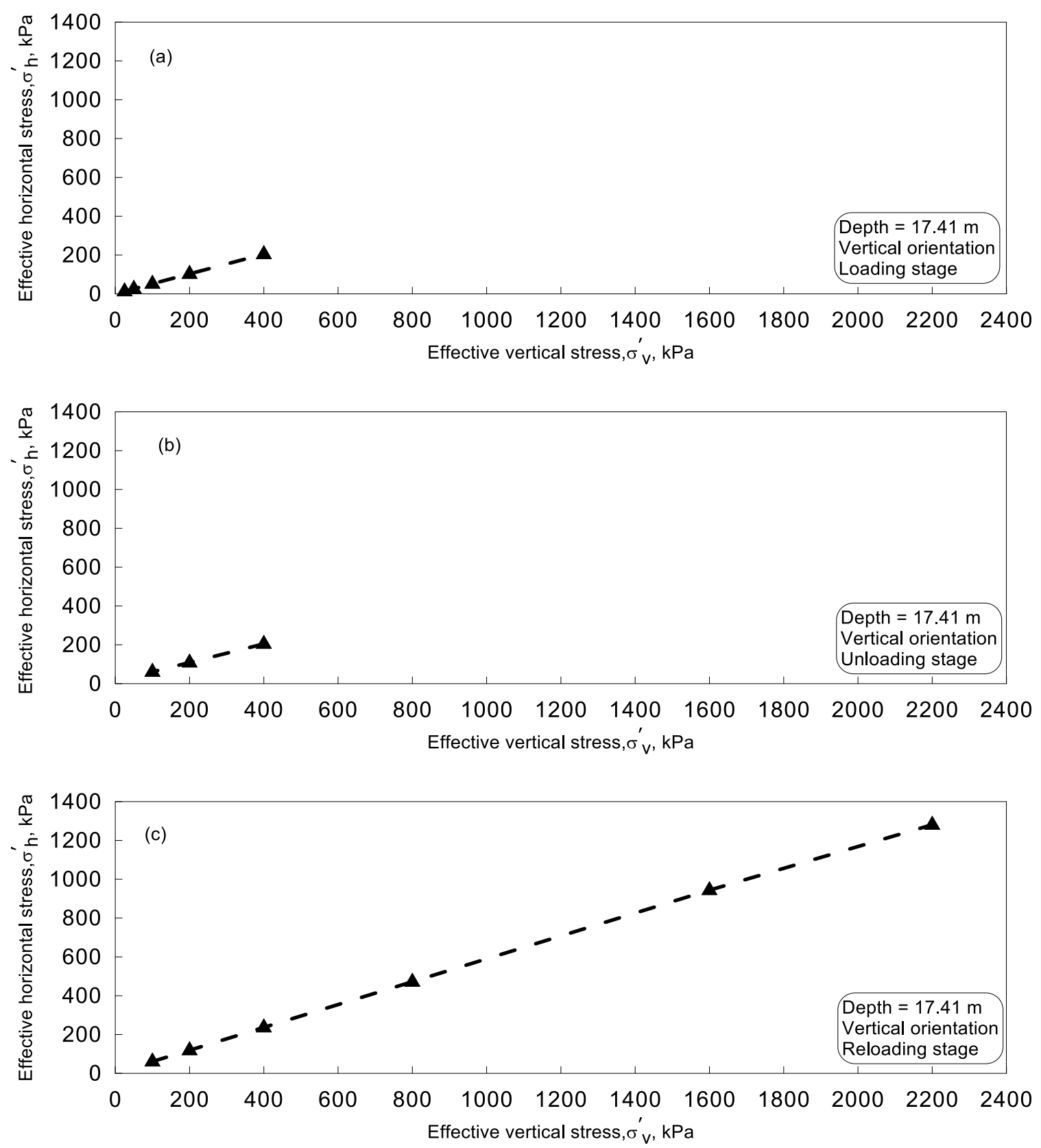

Figure A25: Typical plots of the effective horizontal stress versus the effective vertical stress during the (a) loading, (b) unloading, and (c) reloading stages for vertical orientation $($ depth $=17.41 \mathrm{~m})$. 

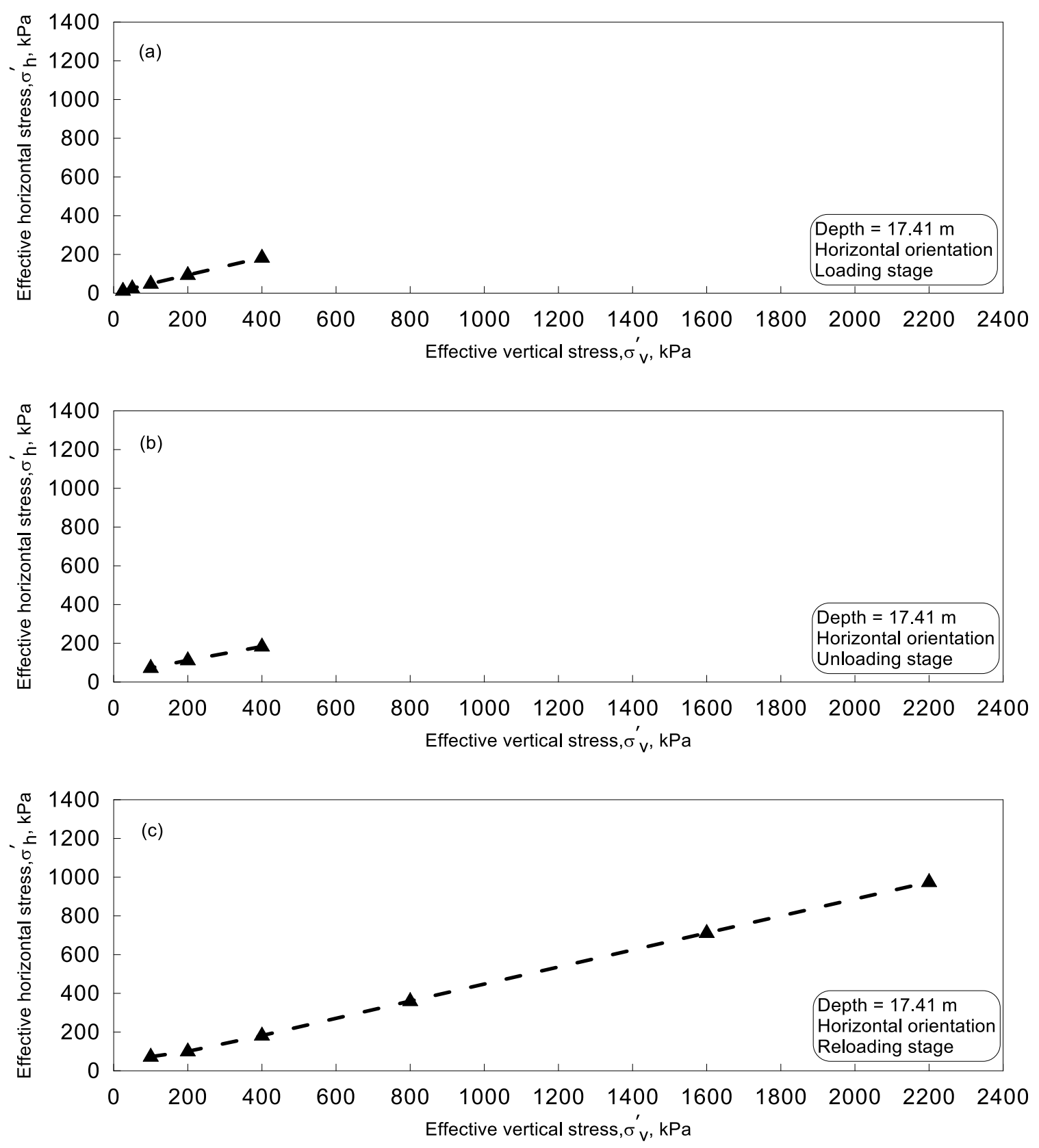

Figure A26: Typical plots of the effective horizontal stress versus the effective vertical stress during the (a) loading, (b) unloading, and (c) reloading stages for horizontal orientation $($ depth $=17.41 \mathrm{~m})$. 

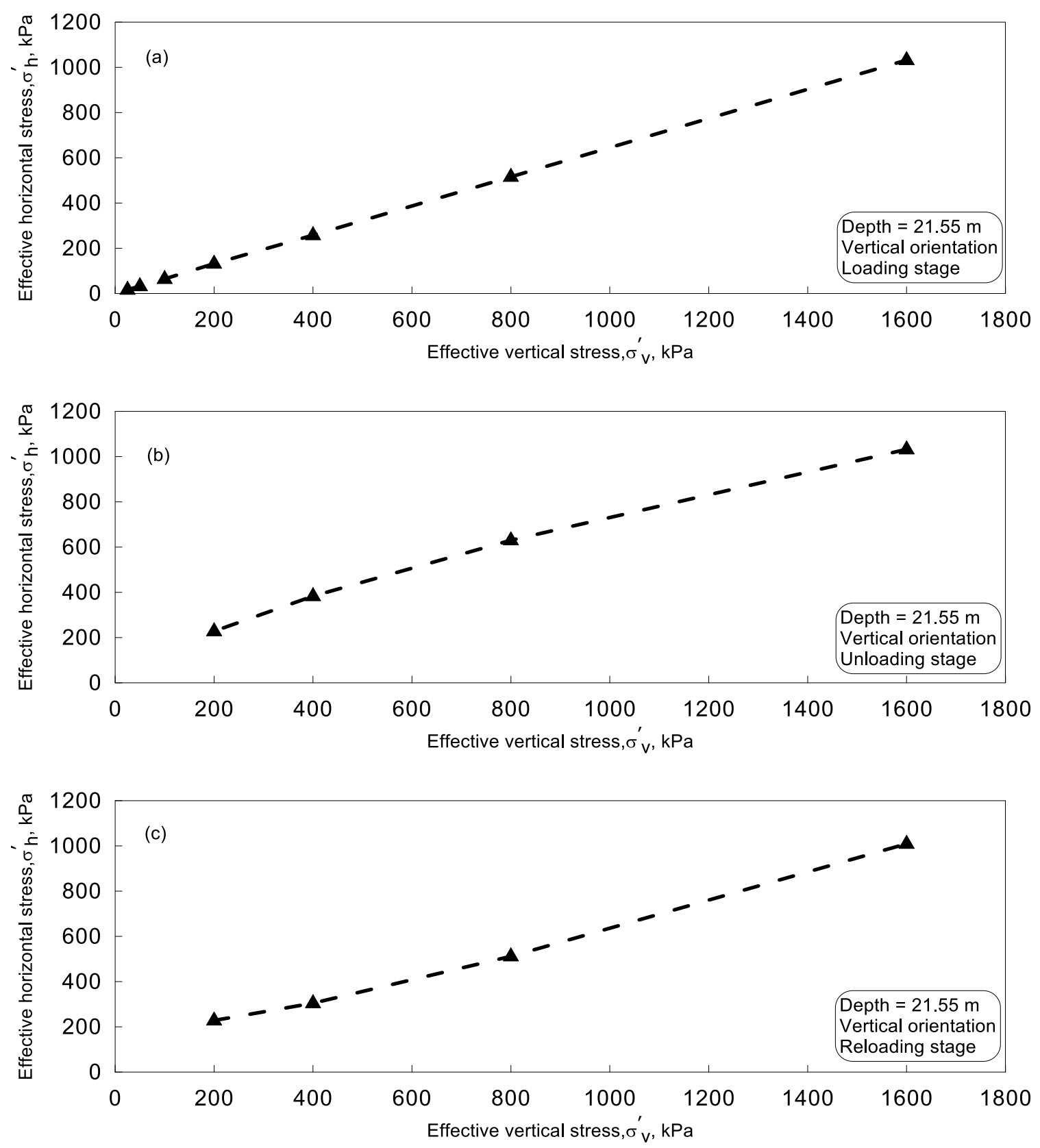

Figure A27: Typical plots of the effective horizontal stress versus the effective vertical stress during the (a) loading, (b) unloading, and (c) reloading stages for vertical orientation $($ depth $=21.55 \mathrm{~m})$. 

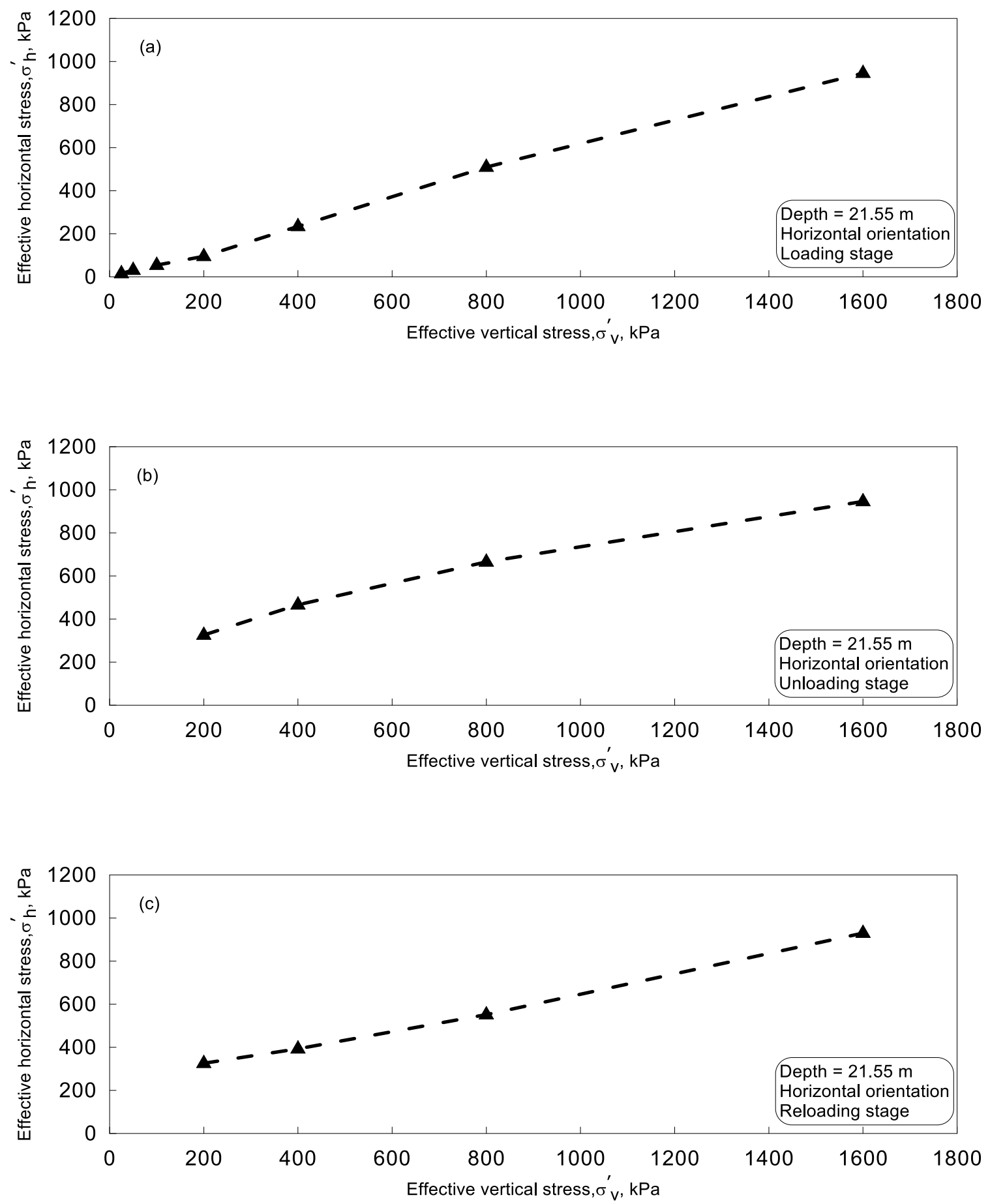

Figure A28: Typical plots of the effective horizontal stress versus the effective vertical stress during the (a) loading, (b) unloading, and (c) reloading stages for horizontal orientation $($ depth $=21.55 \mathrm{~m})$. 


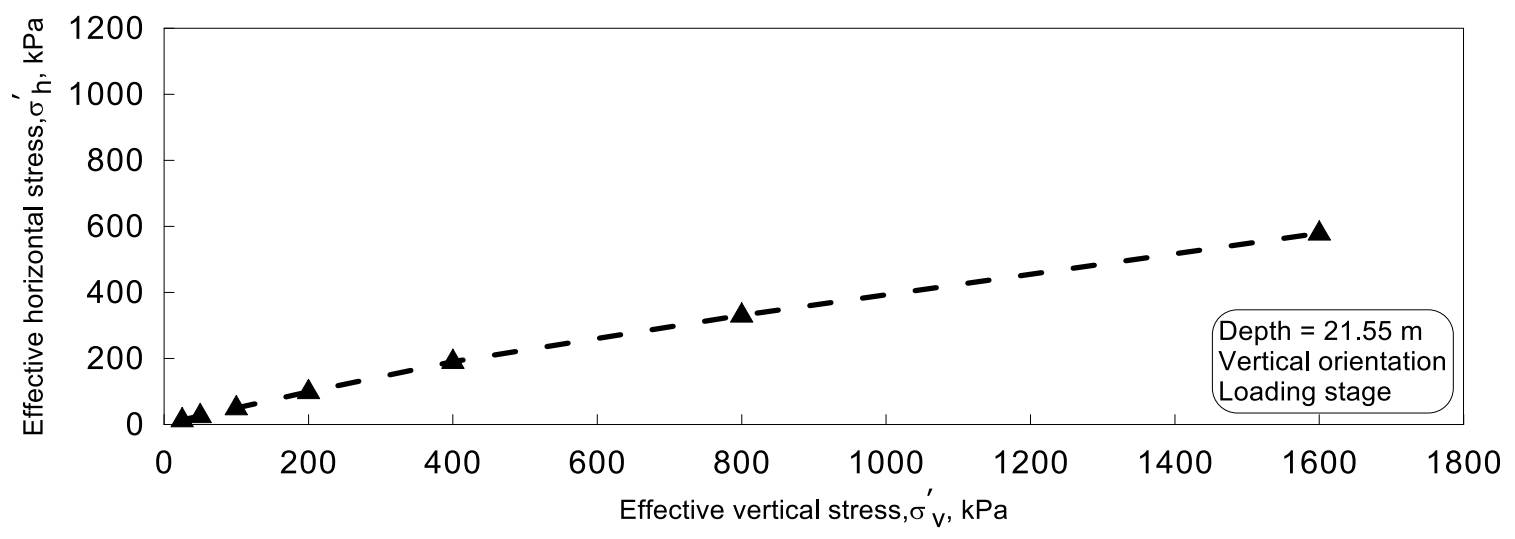

Figure A29: Typical plots of the effective horizontal stress versus the effective vertical stress during the loading for vertical orientation $($ depth $=21.55 \mathrm{~m})$. 

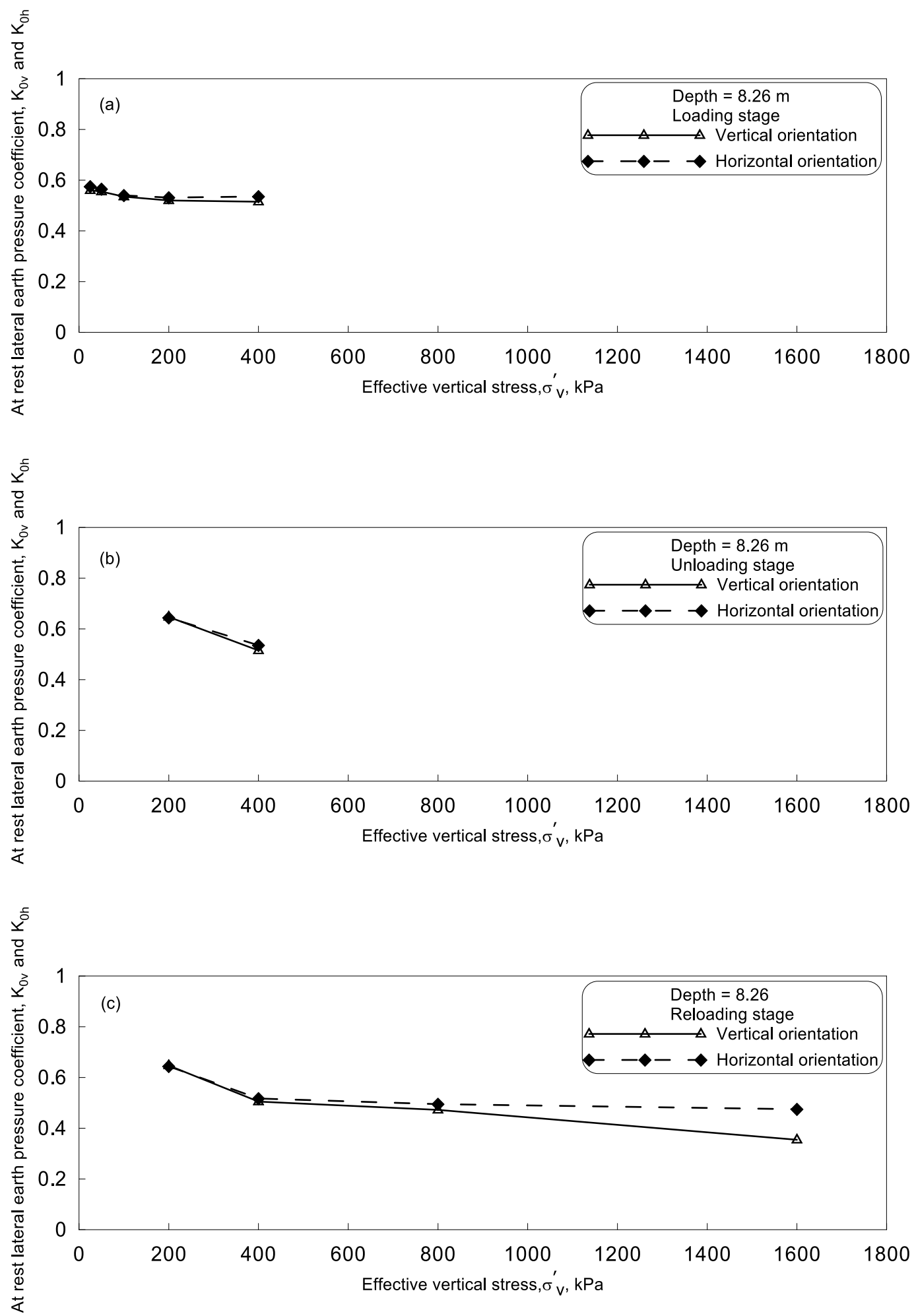

Figure A30: Typical plots of the at-rest lateral earth pressure coefficient versus the effective vertical stress for vertical and horizontal orientations during the (a) loading, (b) unloading, and $(\mathrm{c})$ reloading stages $($ depth $=8.26 \mathrm{~m})$. 

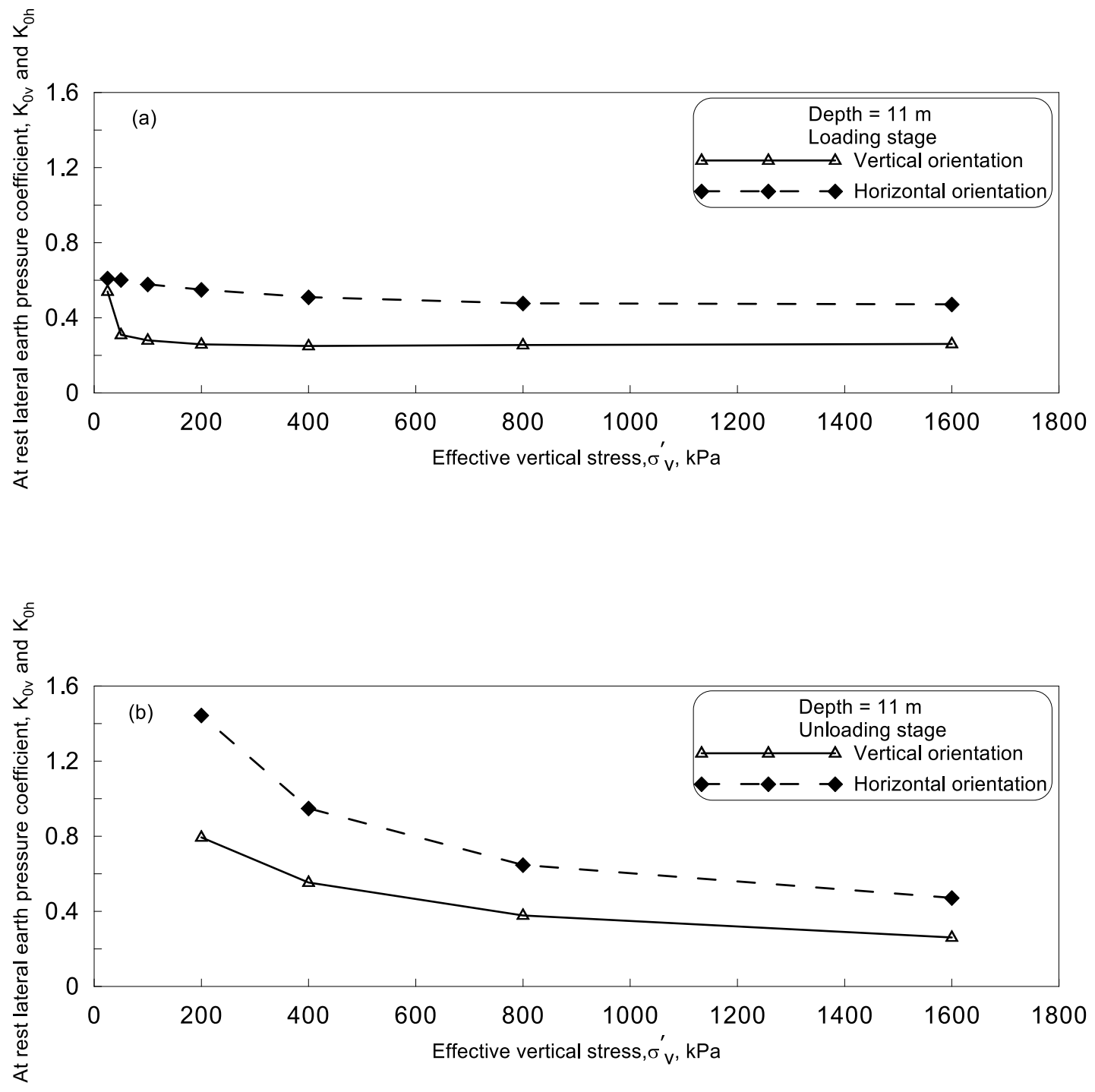

Figure A31: Typical plots of the at-rest lateral earth pressure coefficient versus the effective vertical stress for vertical and horizontal orientations during the (a) loading, and (b) unloading stages $($ depth $=11 \mathrm{~m})$. 

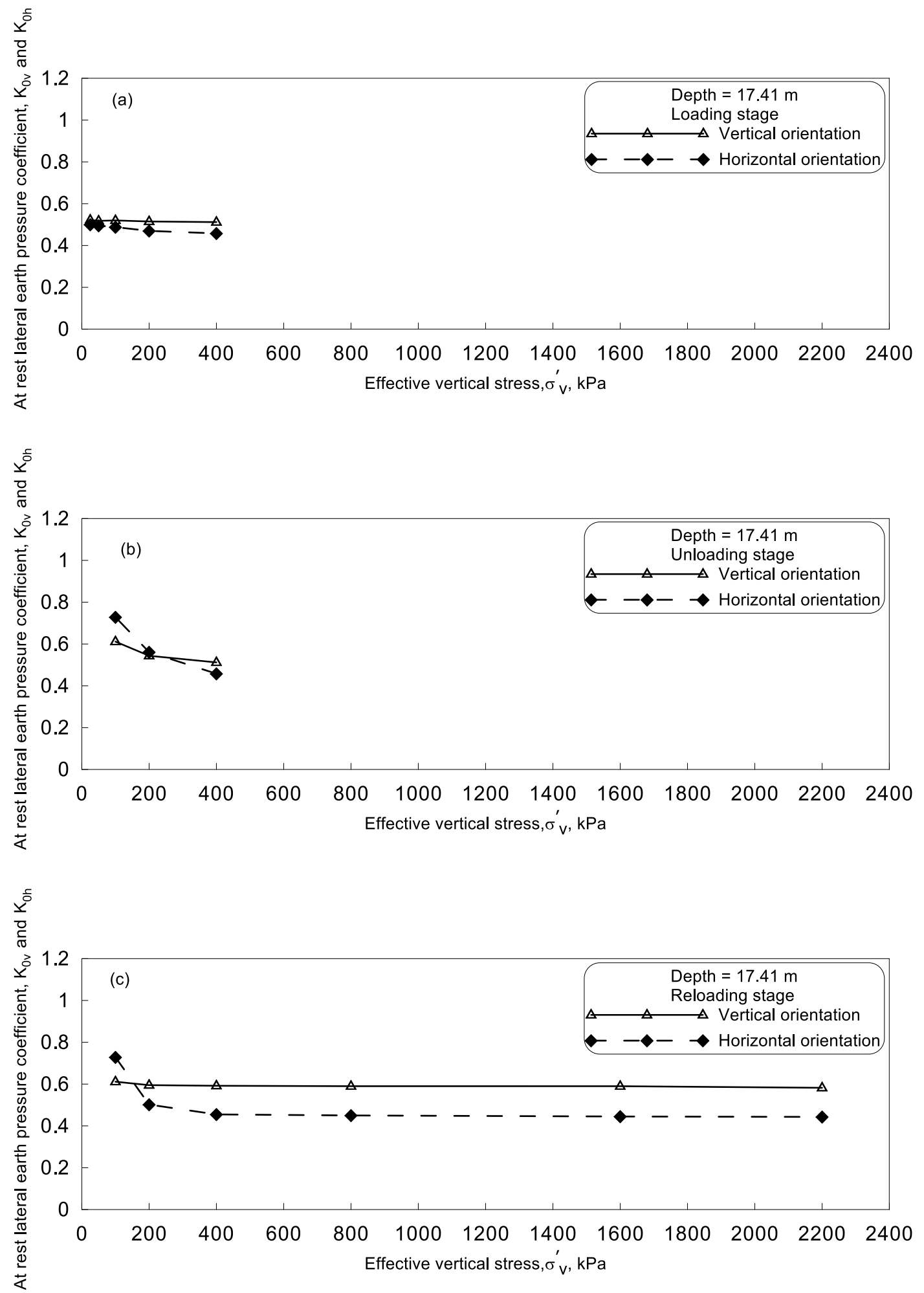

Figure A32: Typical plots of the at-rest lateral earth pressure coefficient versus the effective vertical stress for vertical and horizontal orientations during the (a) loading, (b) unloading, and $(\mathrm{c})$ reloading stages $($ depth $=17.41 \mathrm{~m})$. 

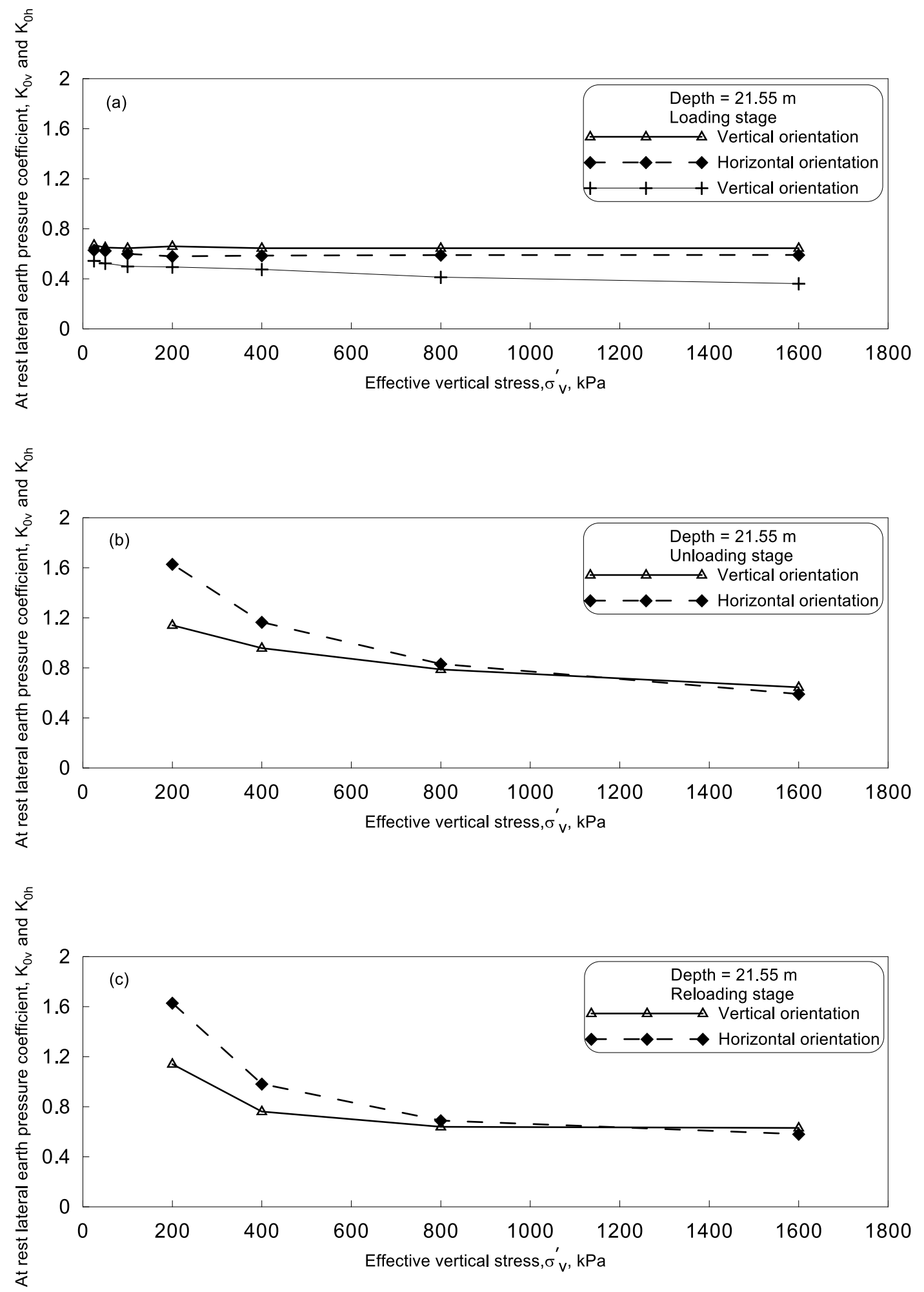

Figure A33: Typical plots of the at-rest lateral earth pressure coefficient versus the effective vertical stress for vertical and horizontal orientations during the (a) loading, (b) unloading, and $(\mathrm{c})$ reloading stages $($ depth $=21.55 \mathrm{~m})$. 


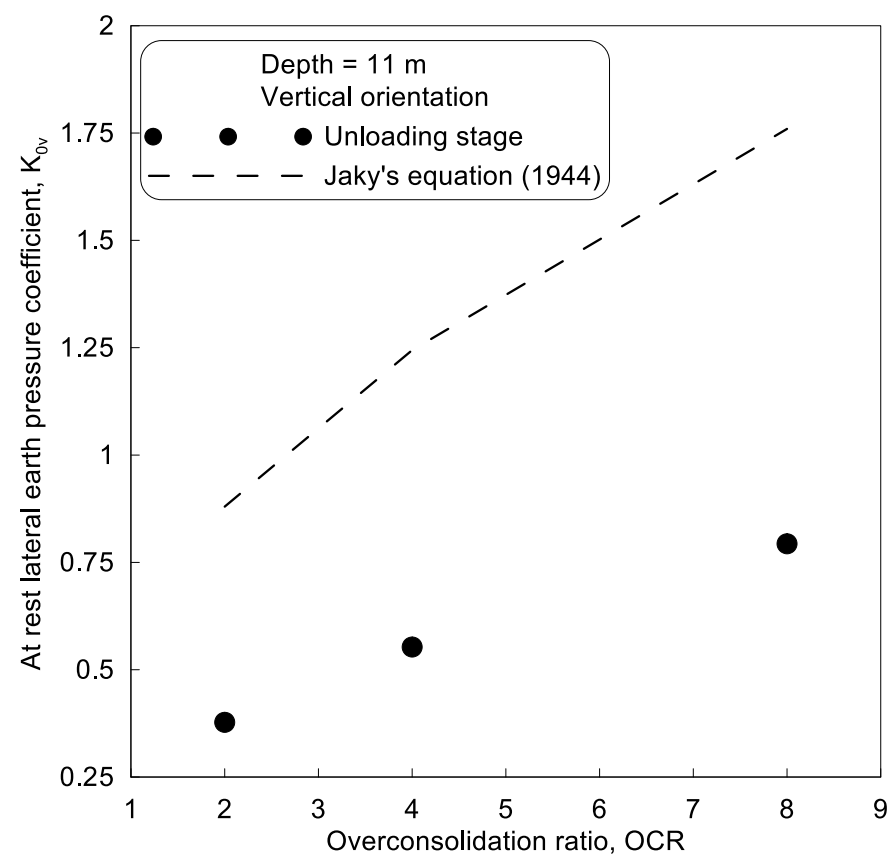

Figure A34: The variation of the at-rest lateral earth pressure coefficient, for the vertical orientation at depth of $11 \mathrm{~m}$, with the overconsolidation ratio (OCR) during the unloading stage.

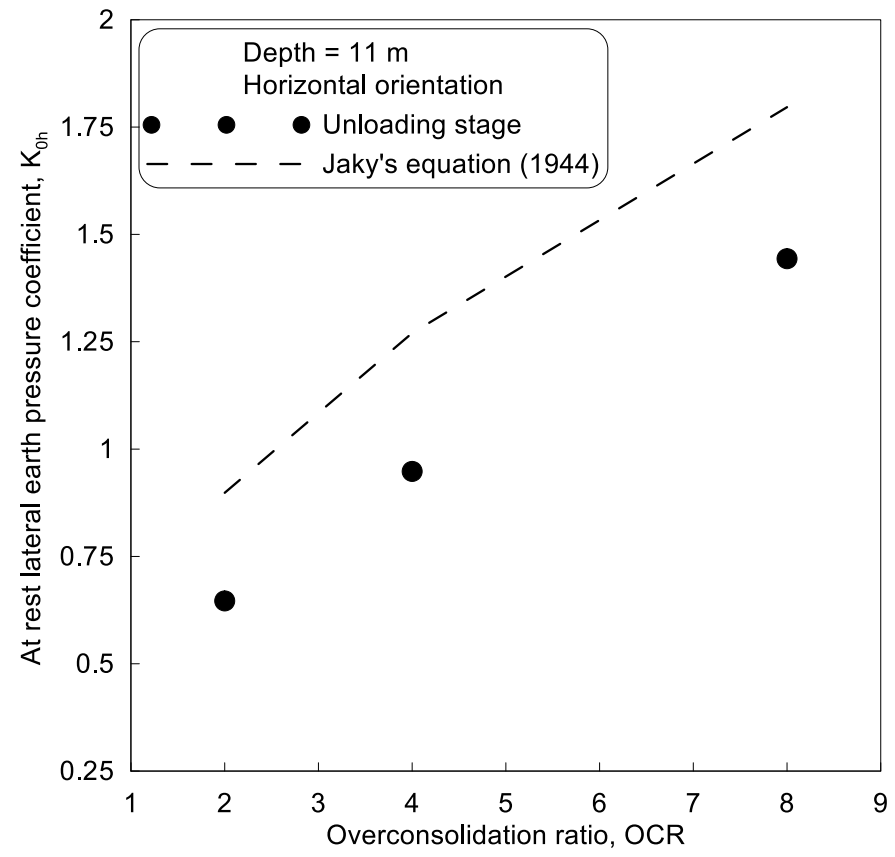

Figure A35: The variation of the at-rest lateral earth pressure coefficient, for the horizontal orientation at depth of $11 \mathrm{~m}$, with the overconsolidation ratio (OCR) during the unloading stage. 


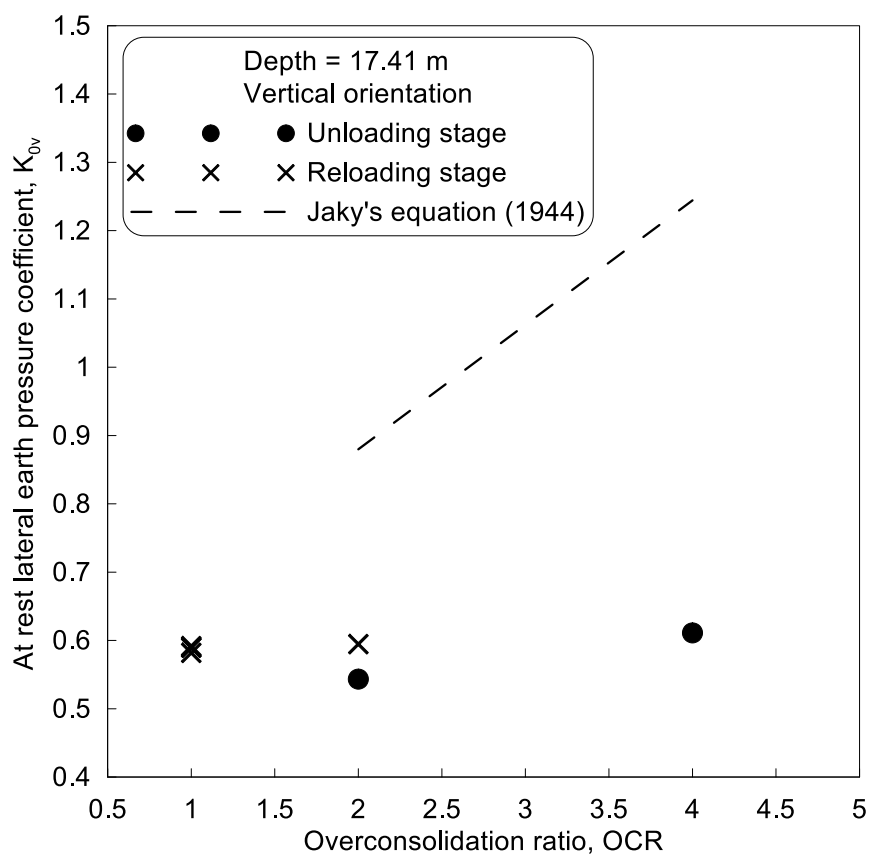

Figure A36: The variation of the at-rest lateral earth pressure coefficient, for the vertical orientation at depth of $17.41 \mathrm{~m}$, with the overconsolidation ratio (OCR) during the unloading and reloading stages.

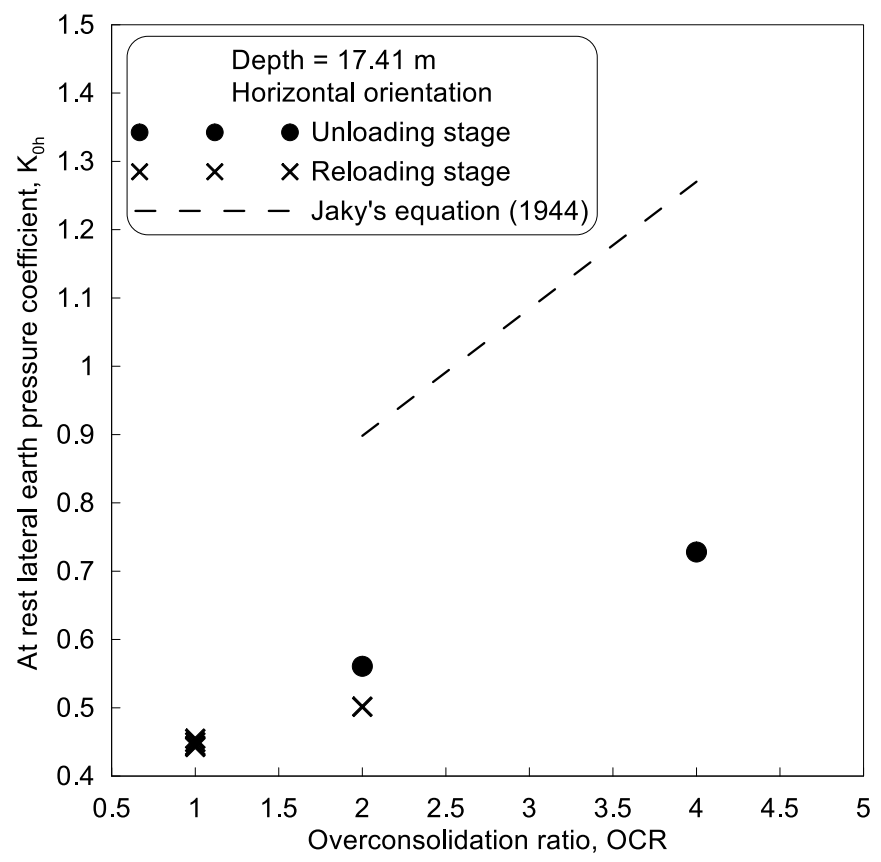

Figure A37: The variation of the at-rest lateral earth pressure coefficient, for the horizontal orientation at depth of $17.41 \mathrm{~m}$, with the overconsolidation ratio (OCR) during the unloading and reloading stages. 


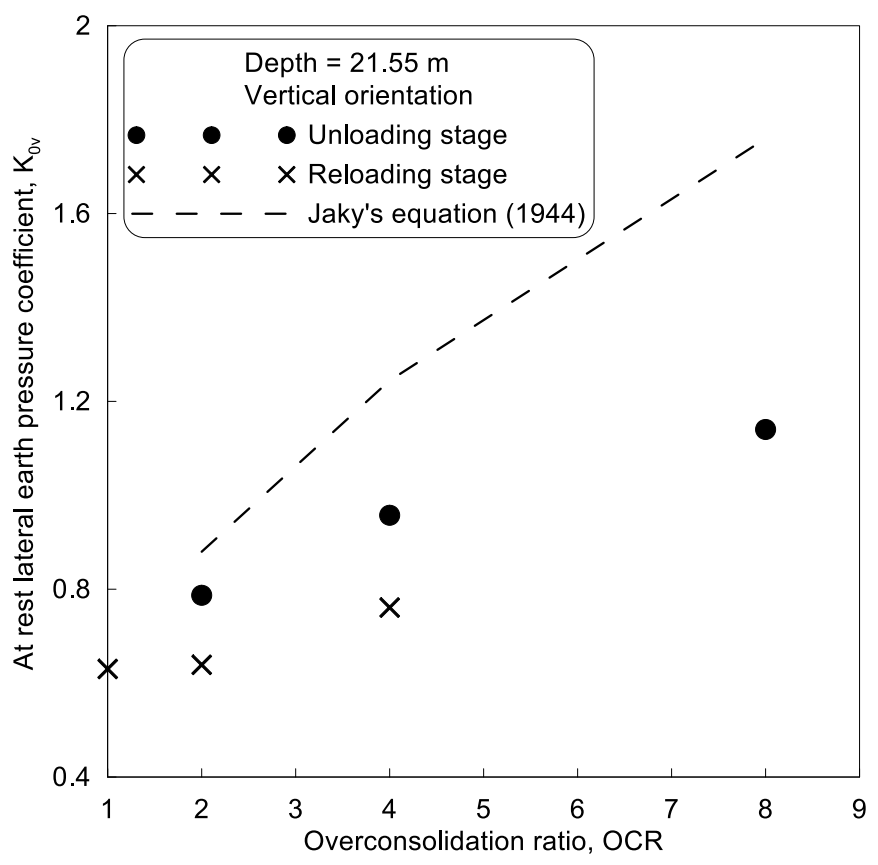

Figure A38: The variation of the at-rest lateral earth pressure coefficient, for the vertical orientation at depth of $21.55 \mathrm{~m}$, with the overconsolidation ratio (OCR) during the unloading and reloading stages.

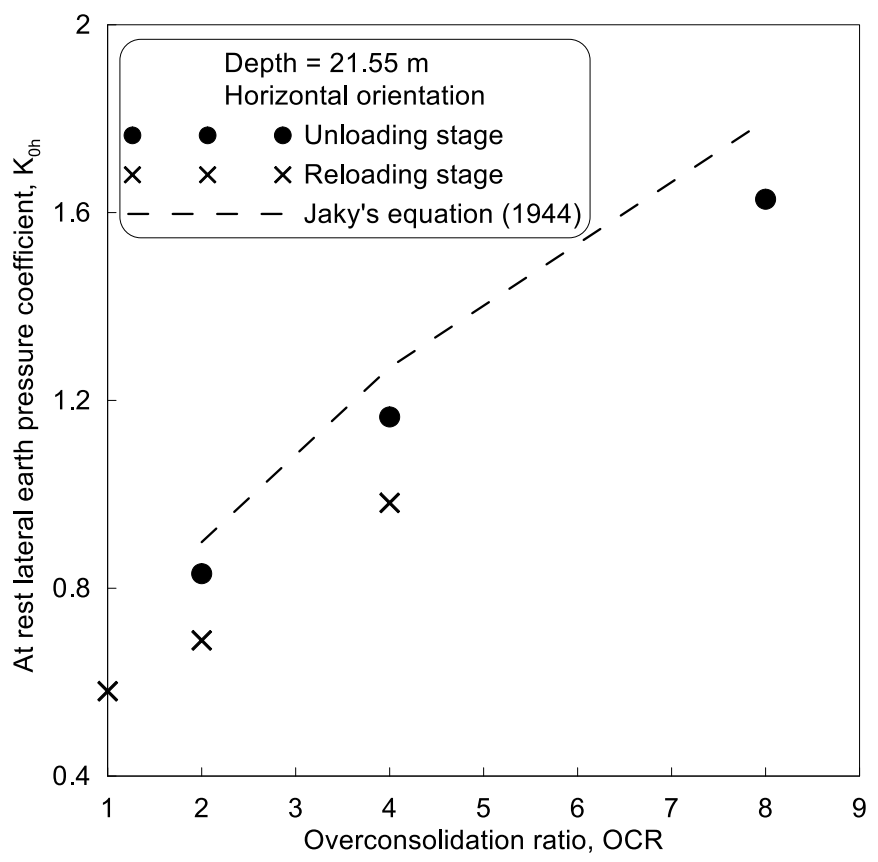

Figure 39: The variation of the at-rest lateral earth pressure coefficient, for the horizontal orientation at depth of $21.55 \mathrm{~m}$, with the overconsolidation ratio (OCR) during the unloading and reloading stages. 


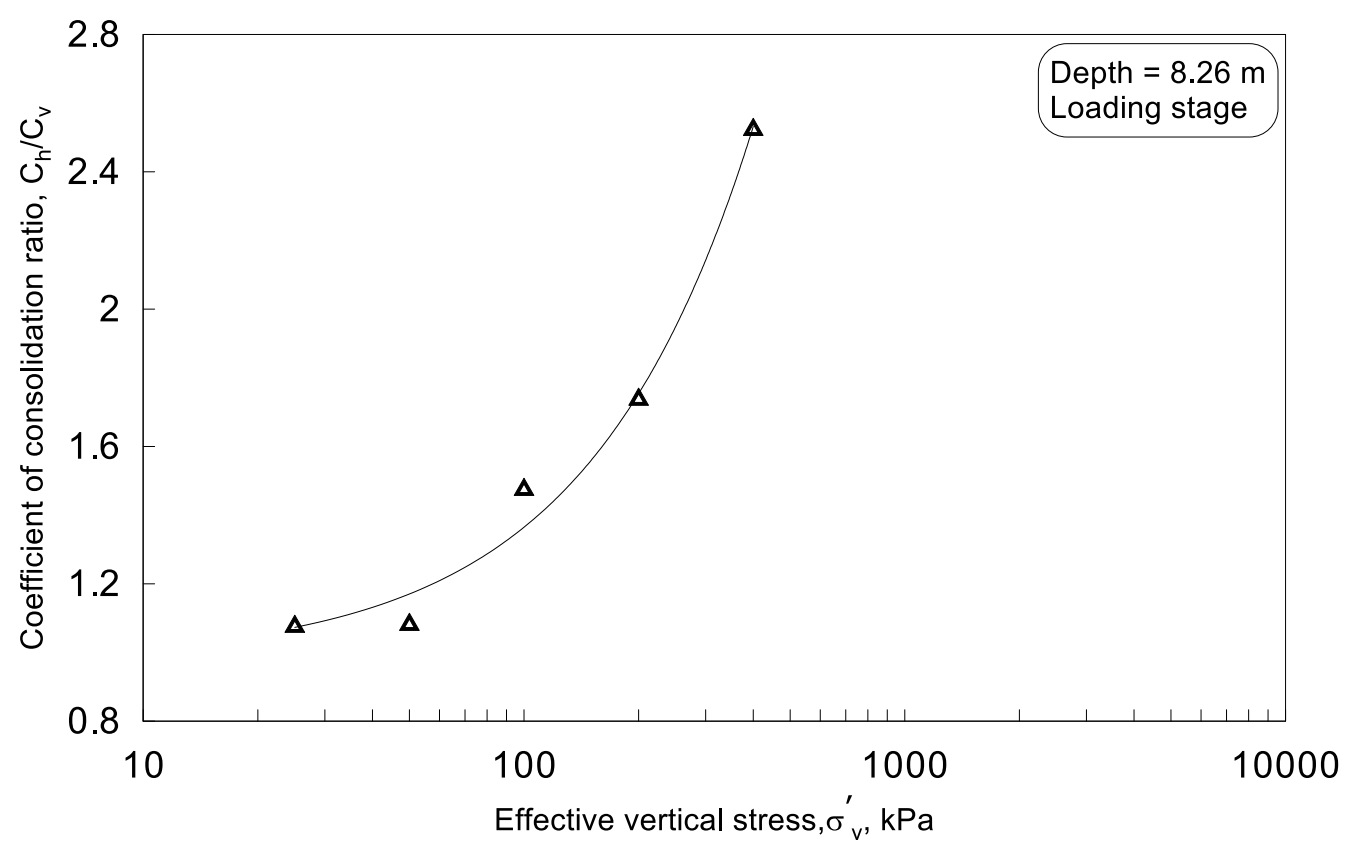

Figure A40: Typical plots of the coefficient of consolidation ratio versus the effective vertical stress during the loading stage at depth of $8.26 \mathrm{~m}$ (by Casagrande's method).

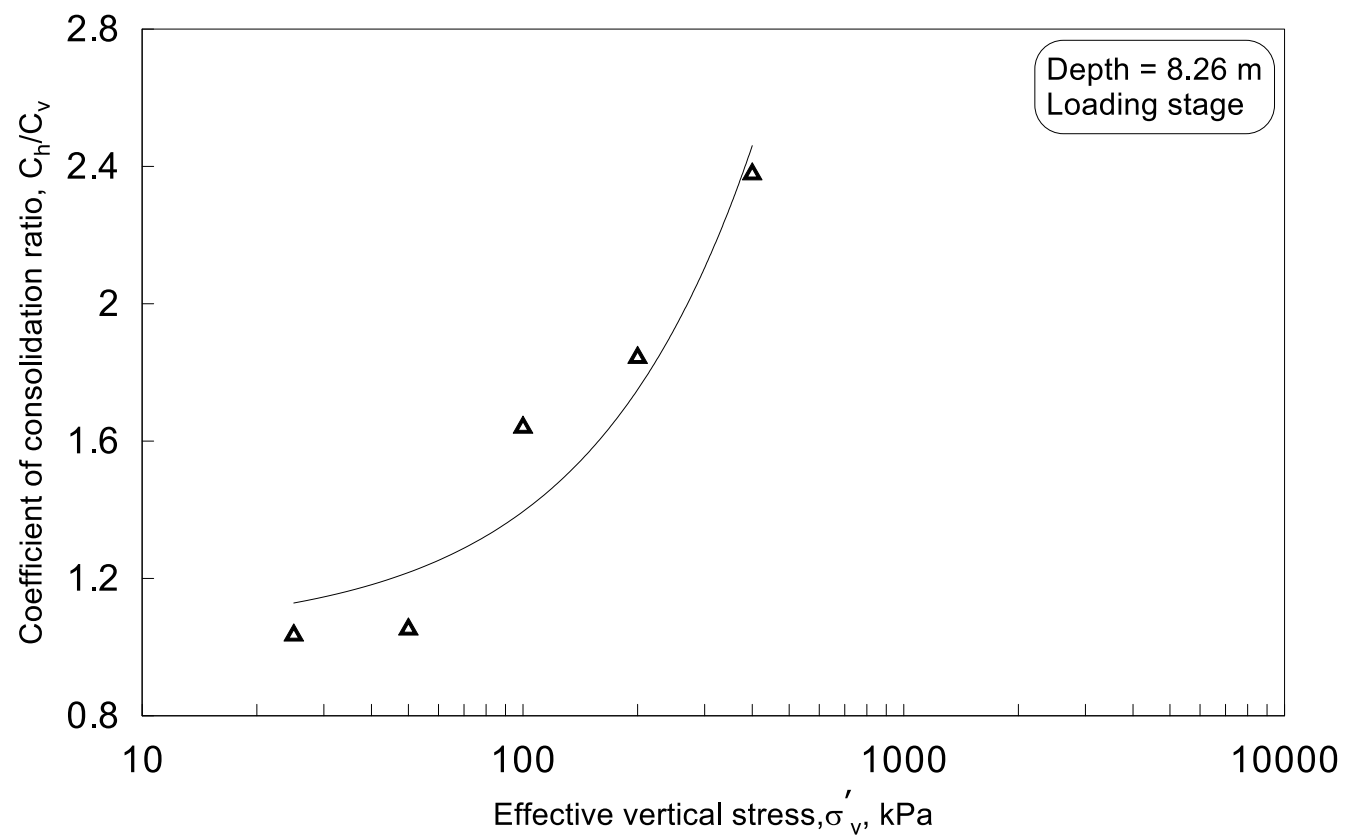

Figure A41: Typical plots of the coefficient of consolidation ratio versus the effective vertical stress during the loading stage at depth of $8.26 \mathrm{~m}$ (by Taylor's method). 


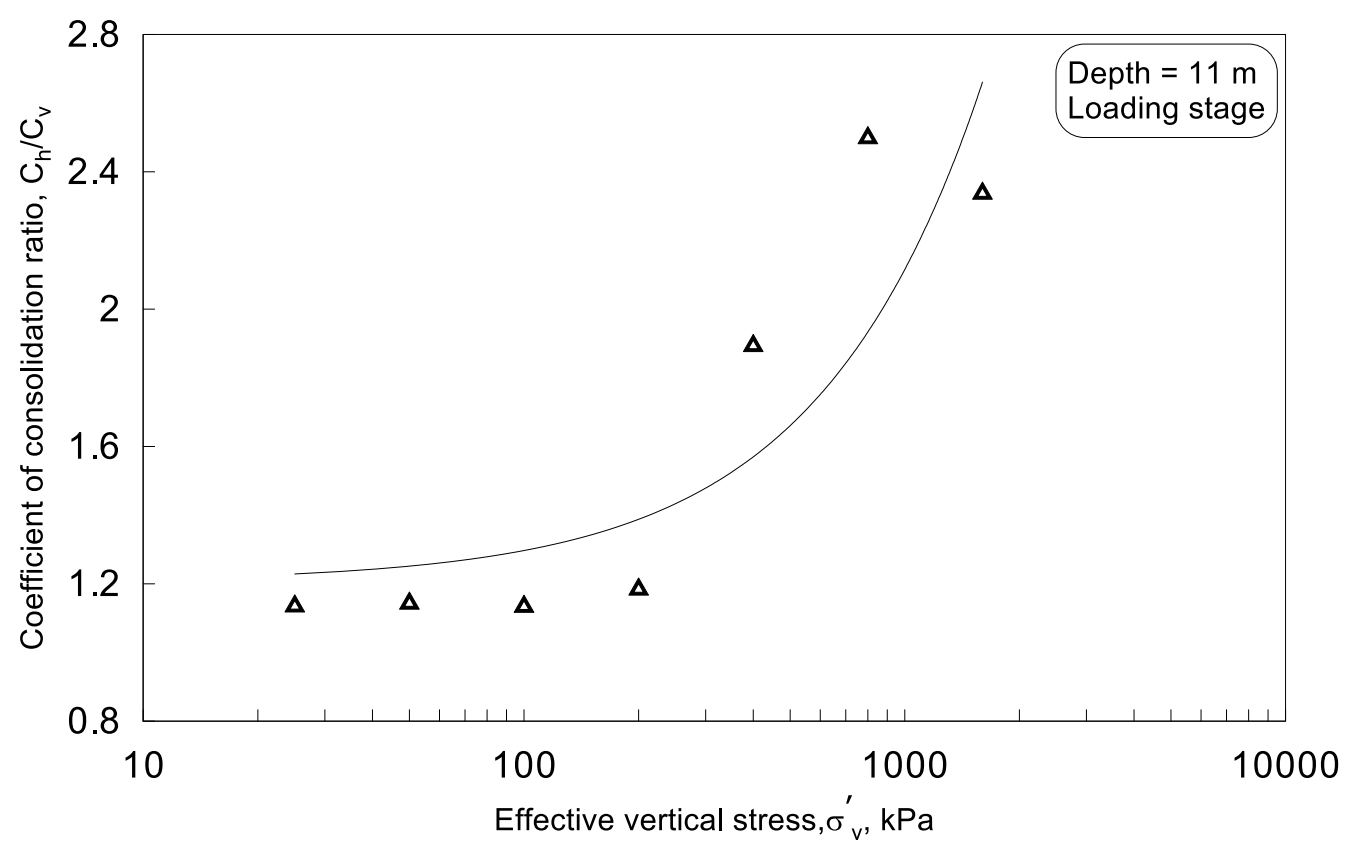

Figure A42: Typical plots of the coefficient of consolidation ratio versus the effective vertical stress during the loading stage at depth of $11 \mathrm{~m}$ (by Casagrande's method).

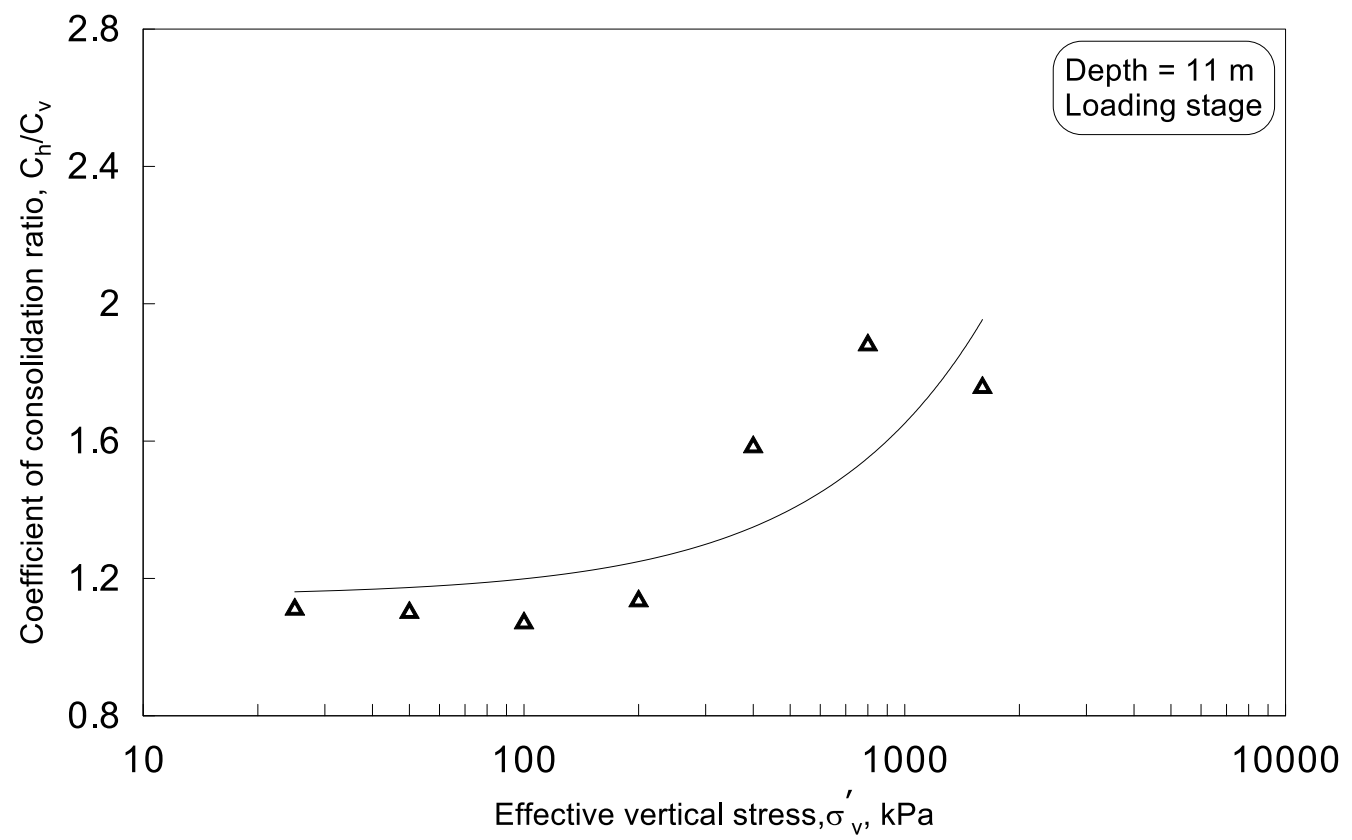

Figure A43: Typical plots of the coefficient of consolidation ratio versus the effective vertical stress during the loading stage at depth of $11 \mathrm{~m}$ (by Taylor's method). 


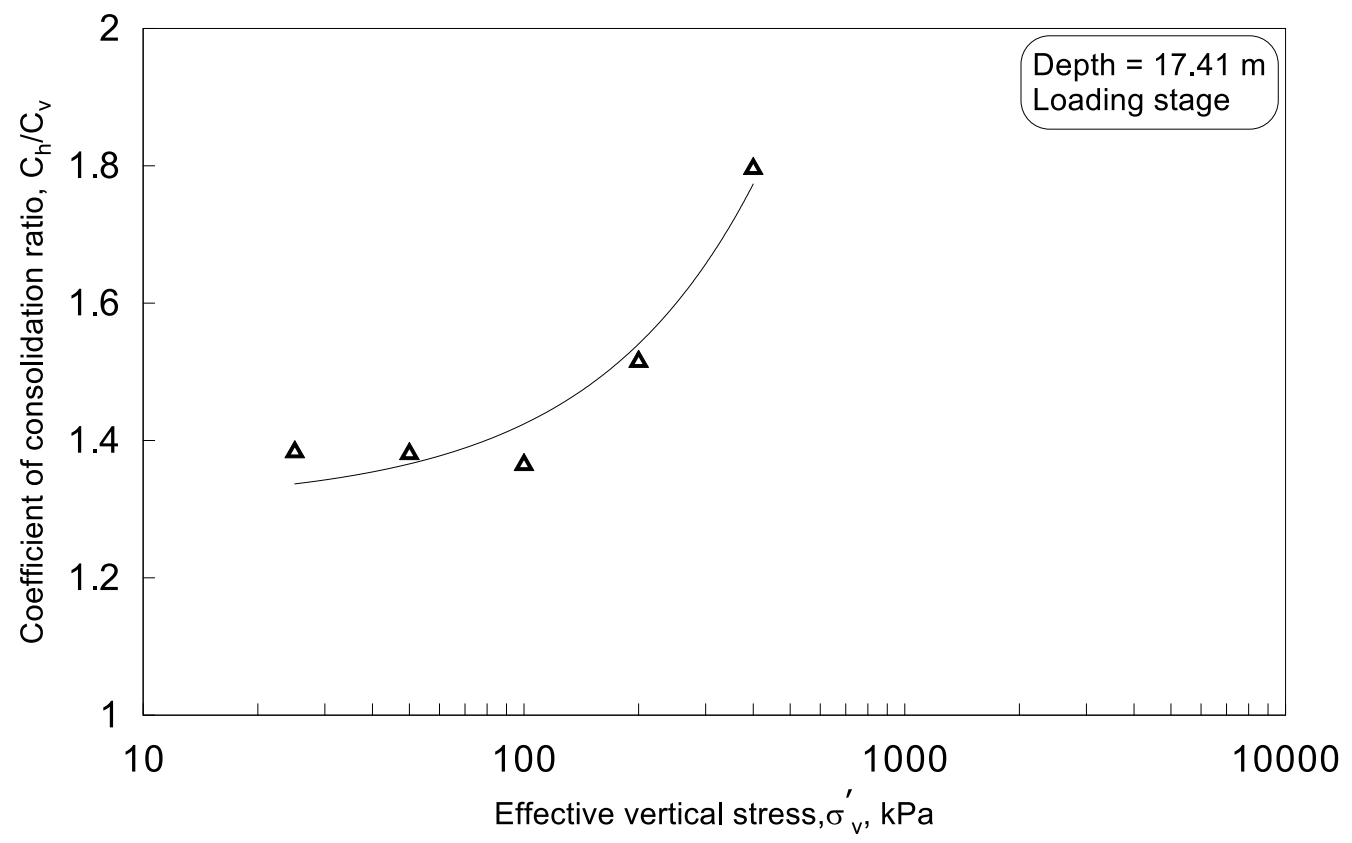

Figure A44: Typical plots of the coefficient of consolidation ratio versus the effective vertical stress during the loading stage at depth of $17.41 \mathrm{~m}$ (by Casagrande's method).

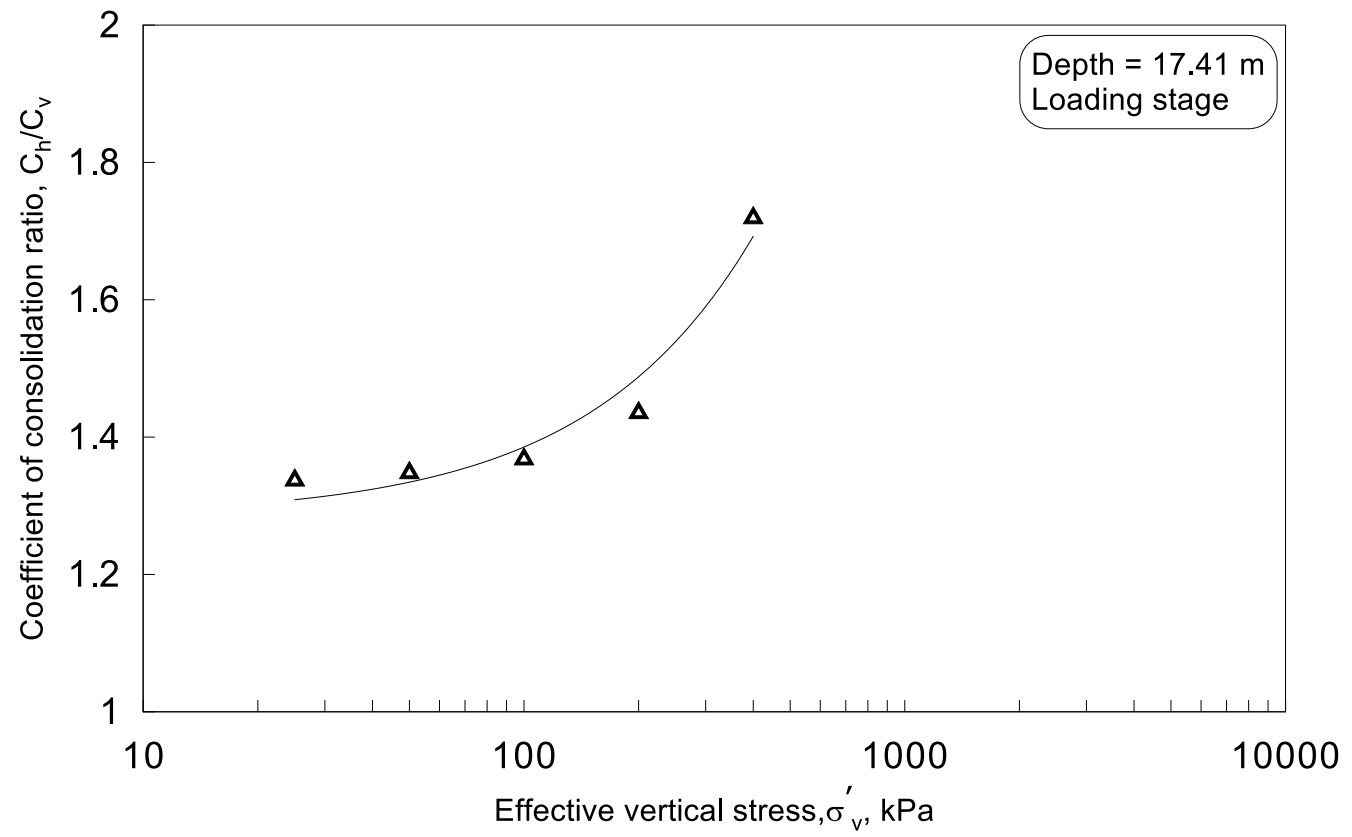

Figure A45: Typical plots of the coefficient of consolidation ratio versus the effective vertical stress during the loading stage at depth of $17.41 \mathrm{~m}$ (by Taylor's method). 


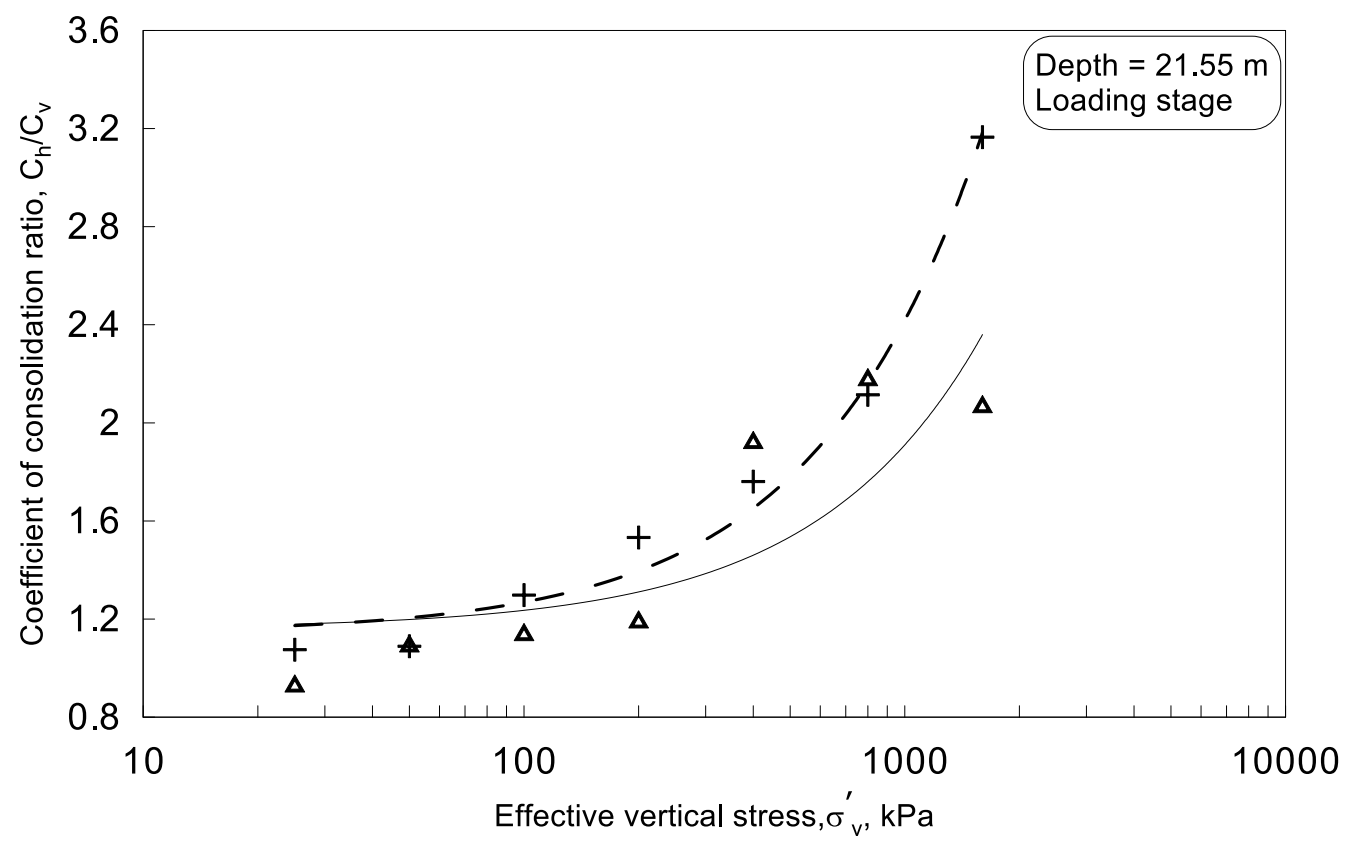

Figure A46: Typical plots of the coefficient of consolidation ratio versus the effective vertical stress during the loading stage at depth of $21.55 \mathrm{~m}$ (by Casagrande's method).

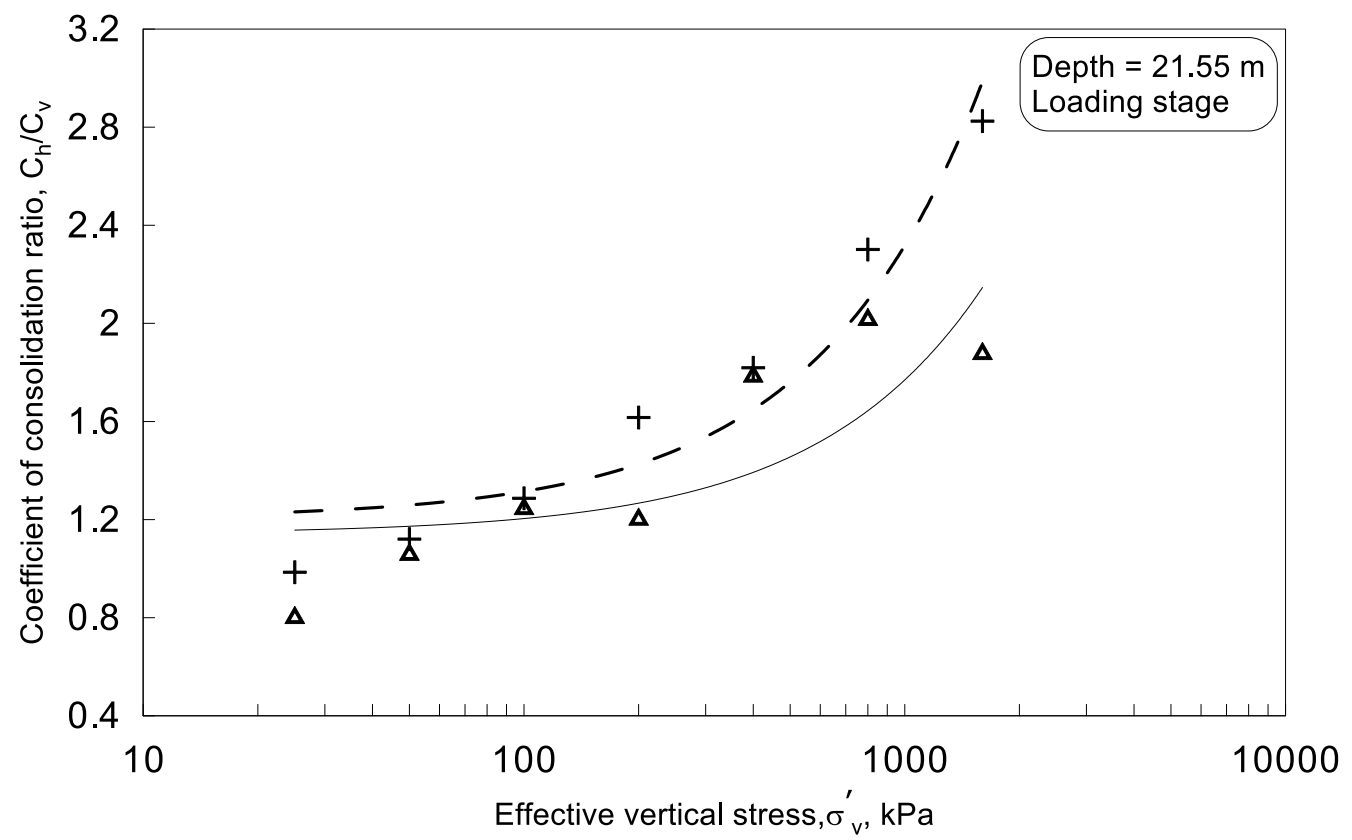

Figure A47: Typical plots of the coefficient of consolidation ratio versus the effective vertical stress during the loading stage at depth of $21.55 \mathrm{~m}$ (by Taylor's method). 


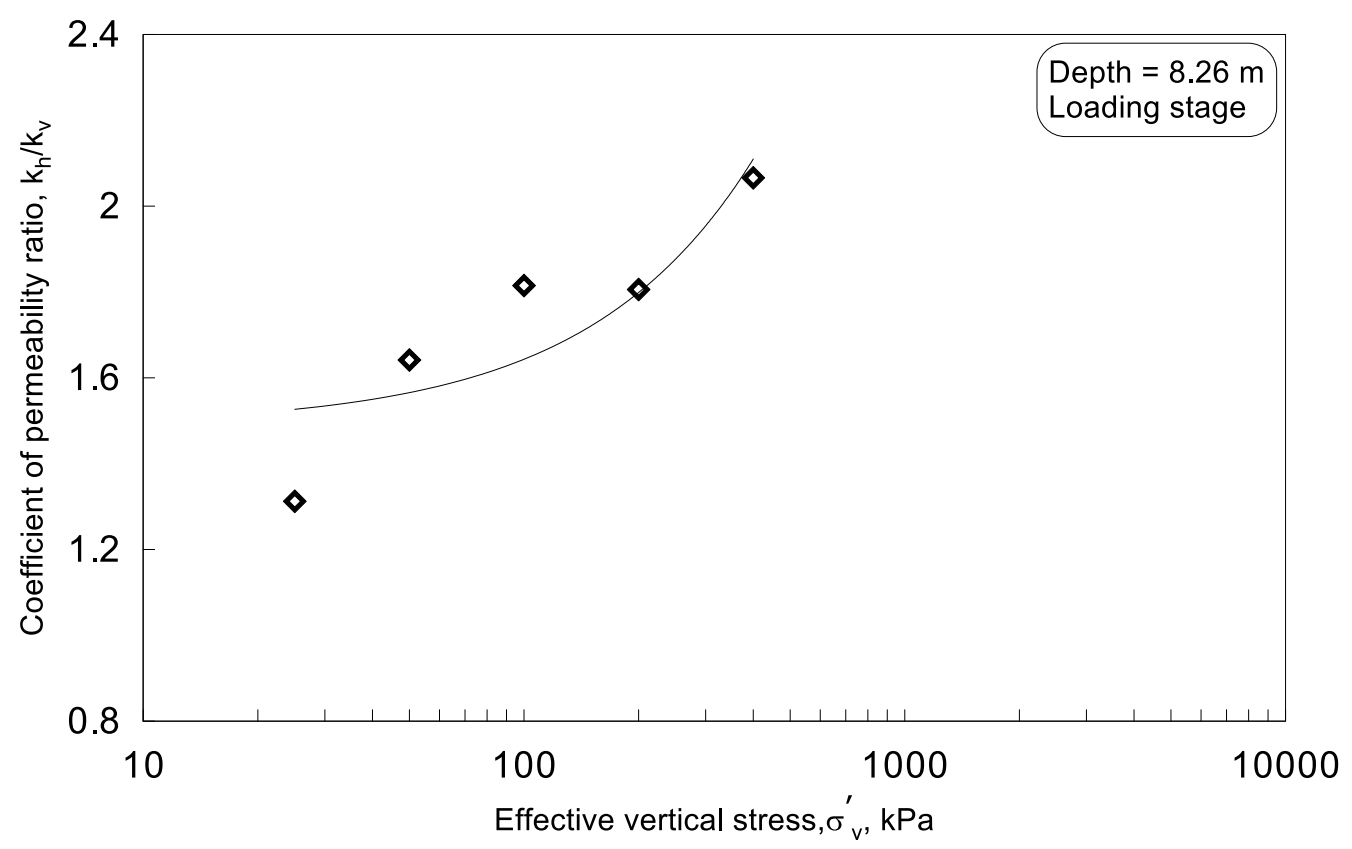

Figure A48: Typical plots of the coefficient of permeability ratio versus the effective vertical stress during the loading stage at depth of $8.26 \mathrm{~m}$ (by Casagrande's method).

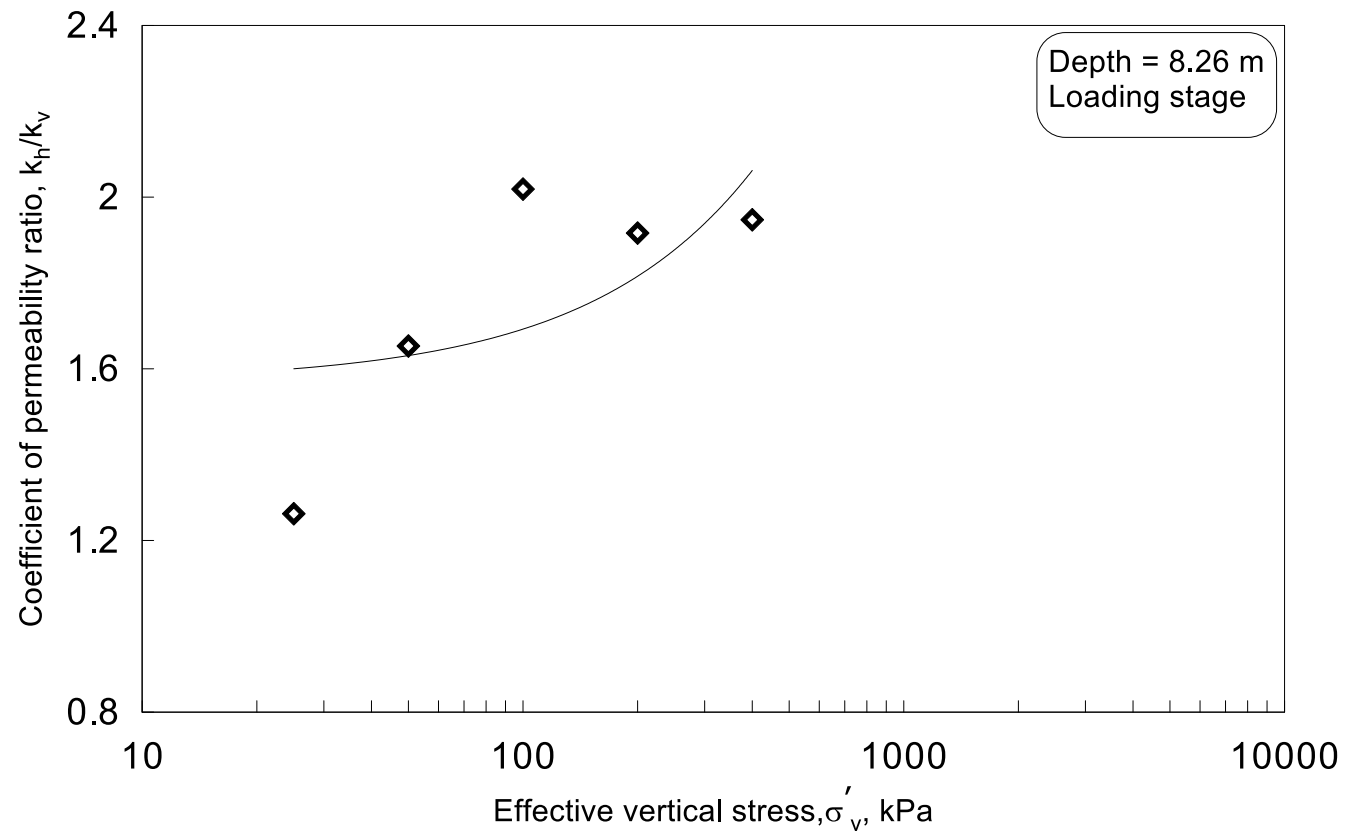

Figure A49; Typical plots of the coefficient of permeability ratio versus the effective vertical stress during the loading stage at depth of $8.26 \mathrm{~m}$ (by Taylor's method). 


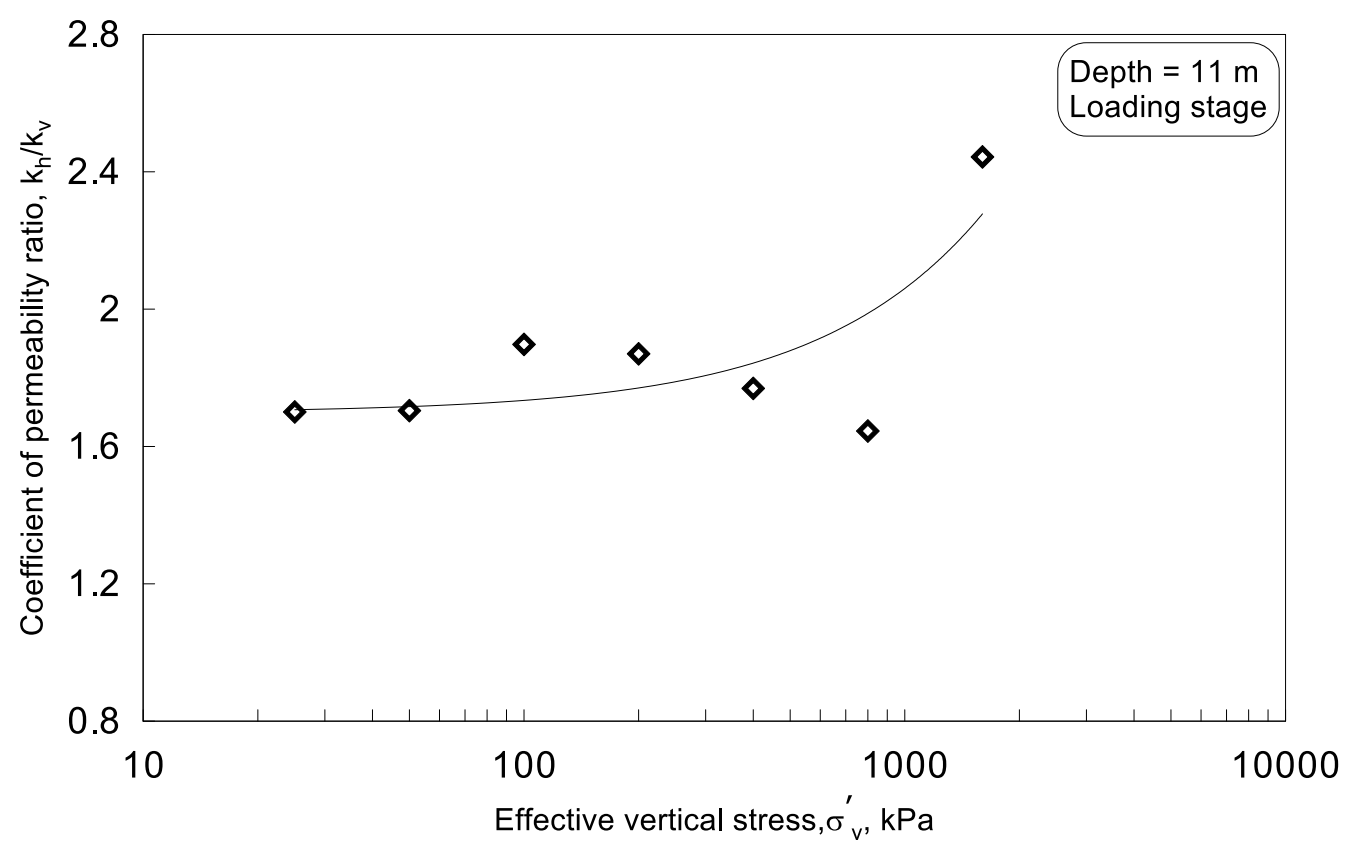

Figure A50: Typical plots of the coefficient of permeability ratio versus the effective vertical stress during the loading stage at depth of $11 \mathrm{~m}$ (by Casagrande's method).

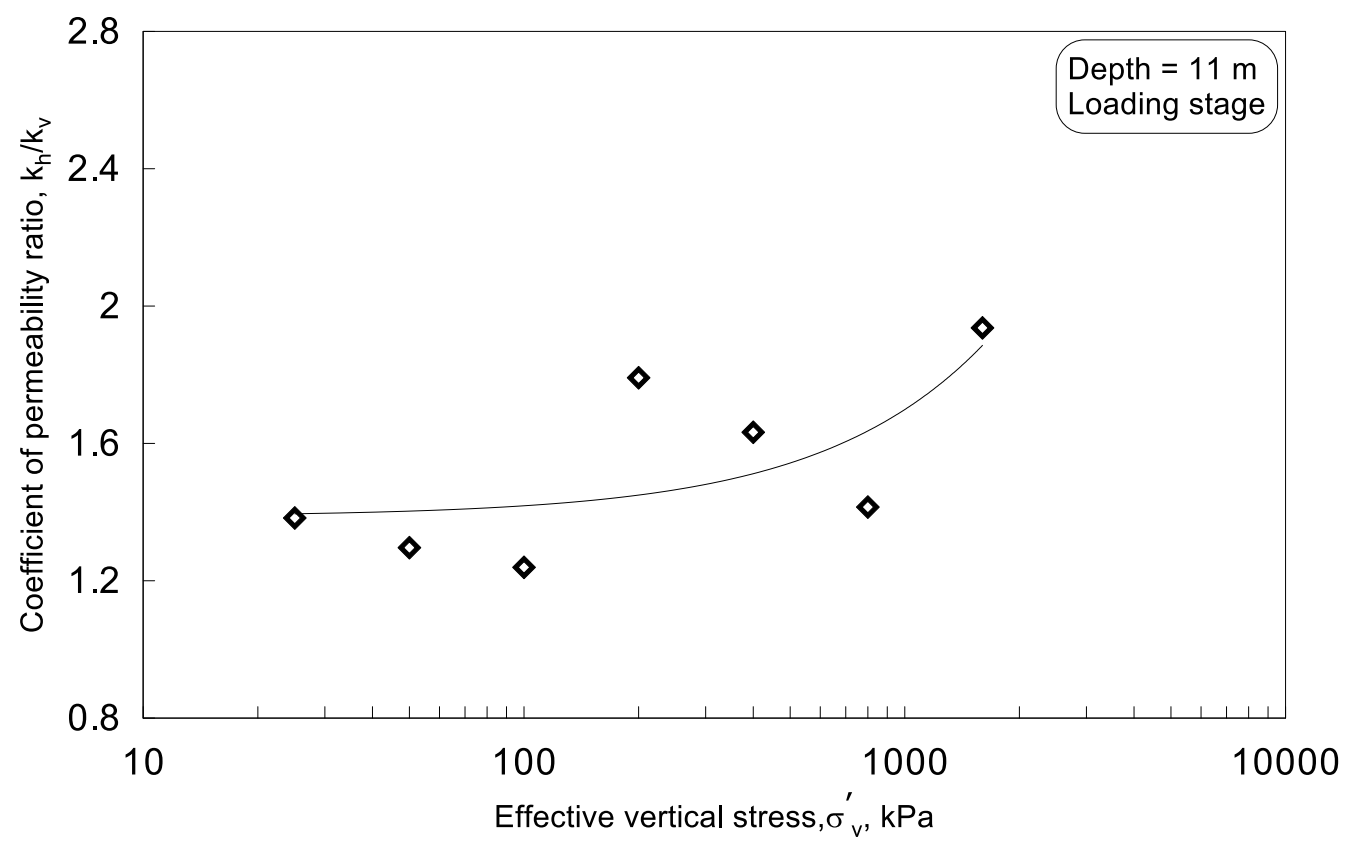

Figure A51: Typical plots of the coefficient of permeability ratio versus the effective vertical stress during the loading stage at depth of $11 \mathrm{~m}$ (by Taylor's method). 


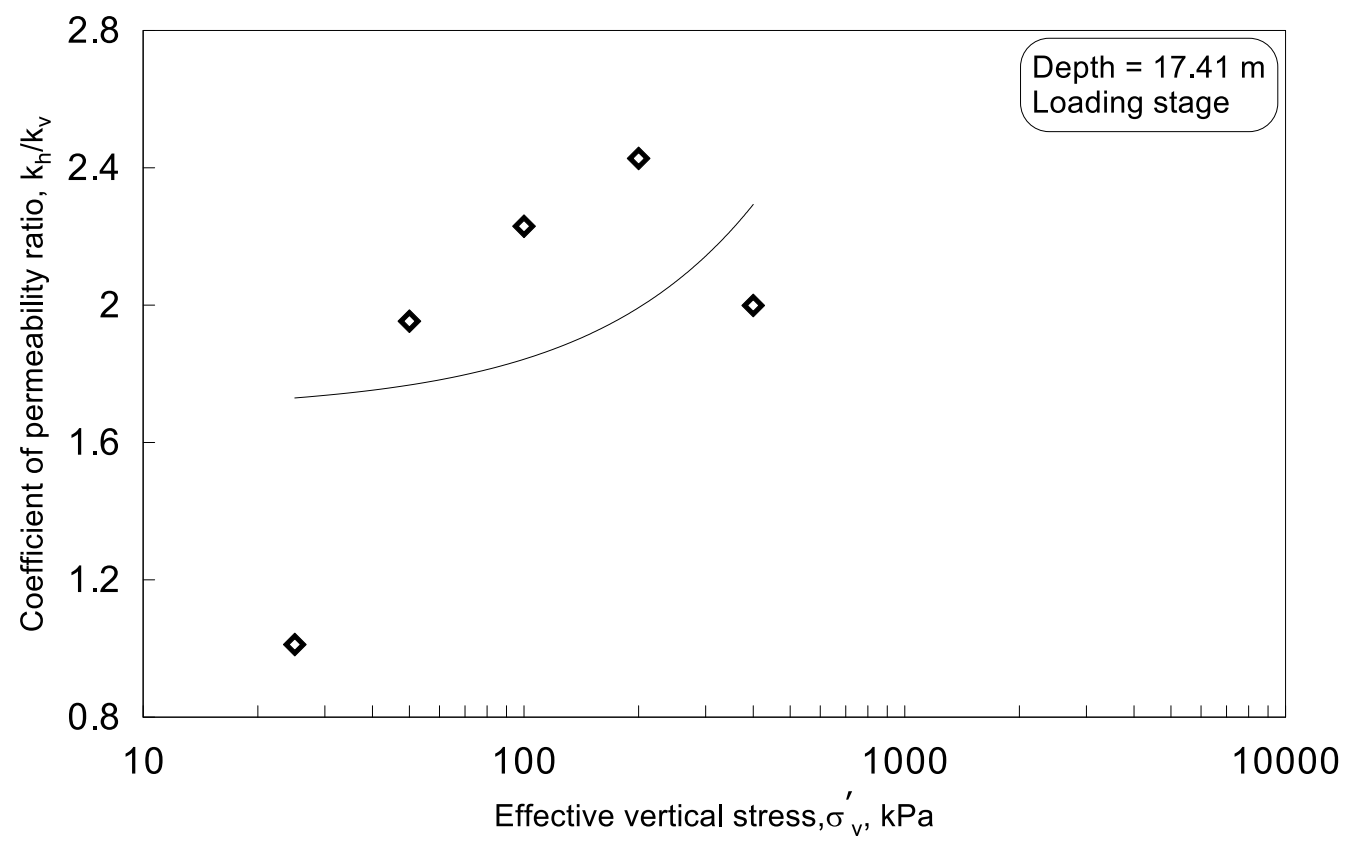

Figure A52: Typical plots of the coefficient of permeability ratio versus the effective vertical stress during the loading stage at depth of $17.41 \mathrm{~m}$ (by Casagrande's method).

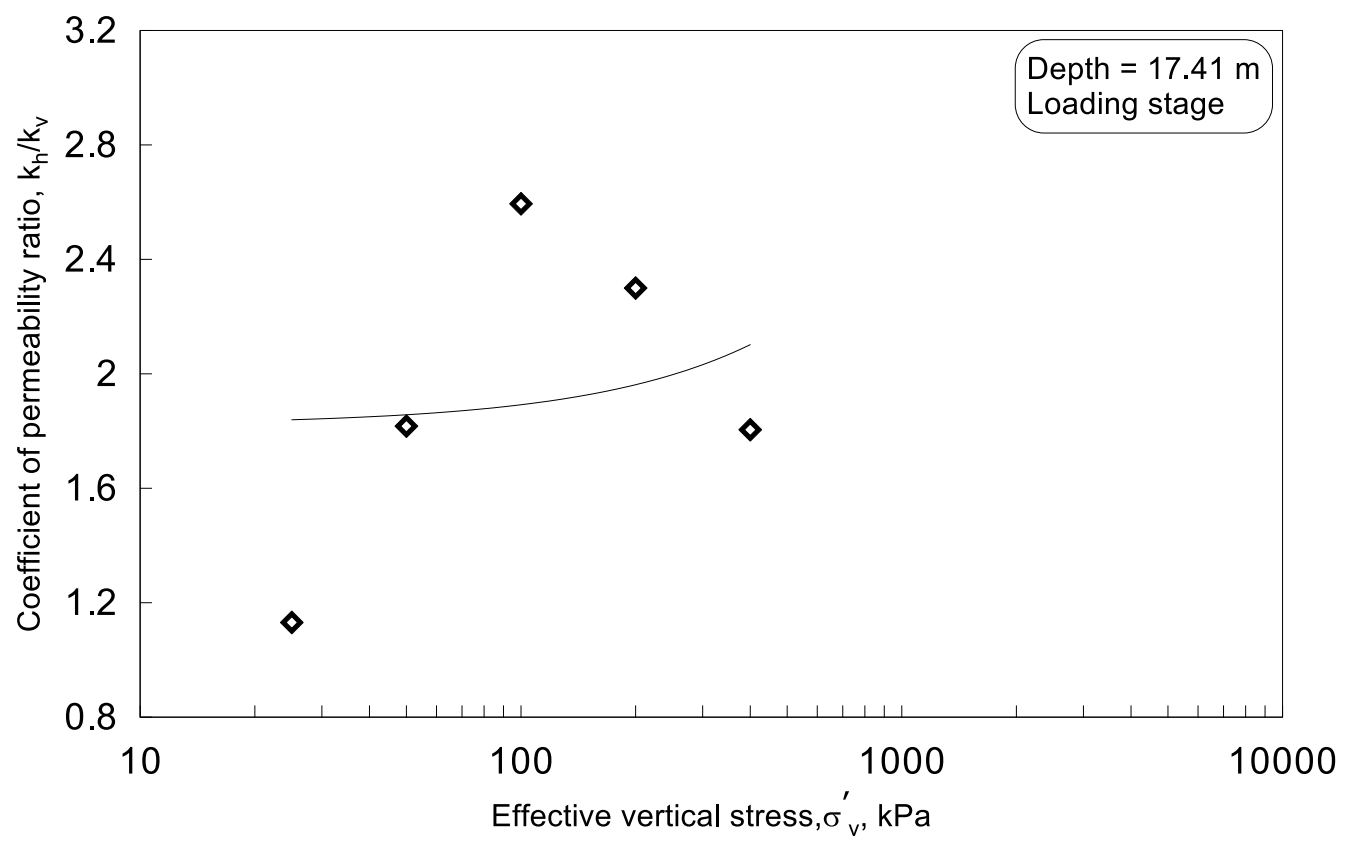

Figure A53: Typical plots of the coefficient of permeability ratio versus the effective vertical stress during the loading stage at depth of $17.41 \mathrm{~m}$ (by Taylor's method). 


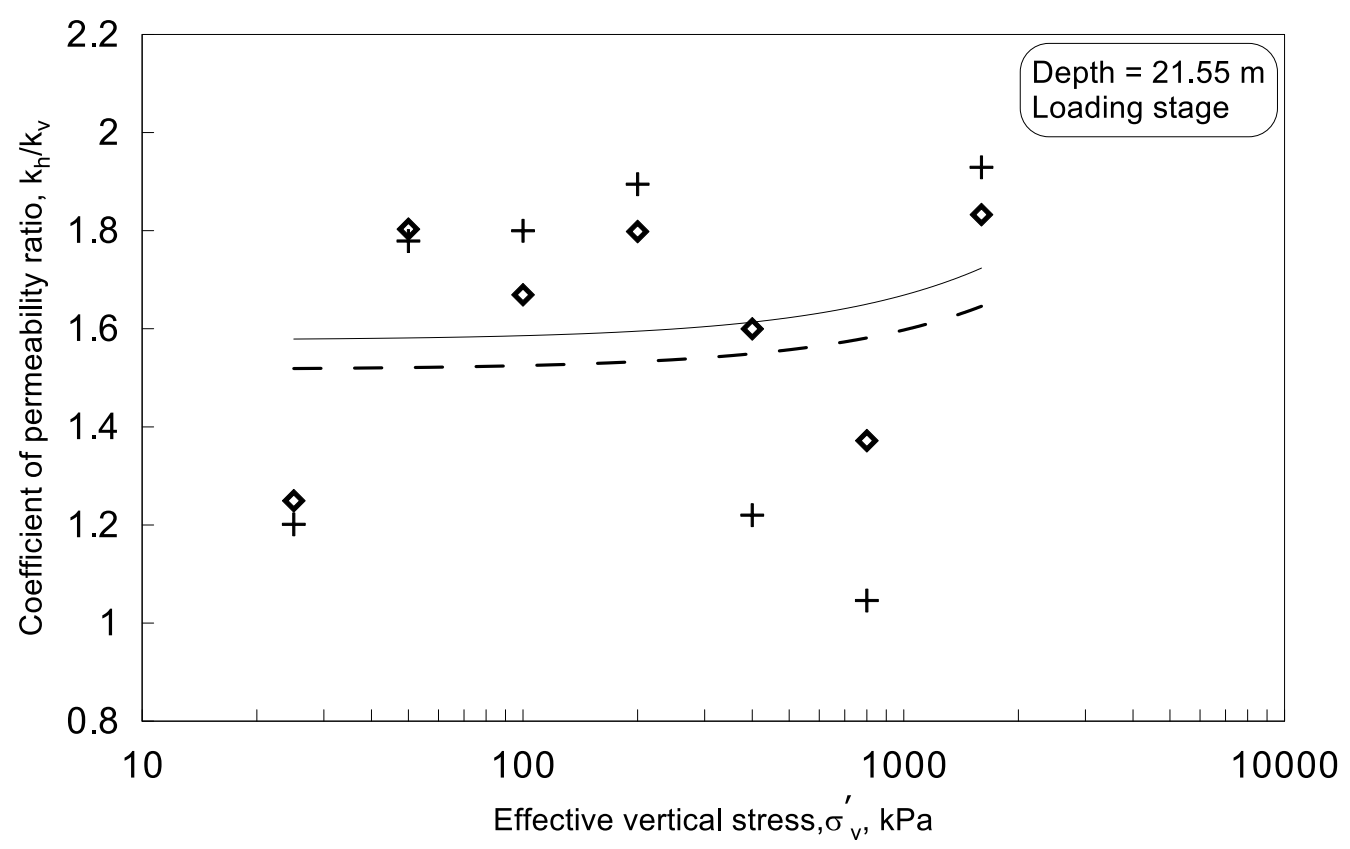

Figure A54: Typical plots of the coefficient of permeability ratio versus the effective vertical stress during the loading stage at depth of $21.55 \mathrm{~m}$ (by Casagrande's method).

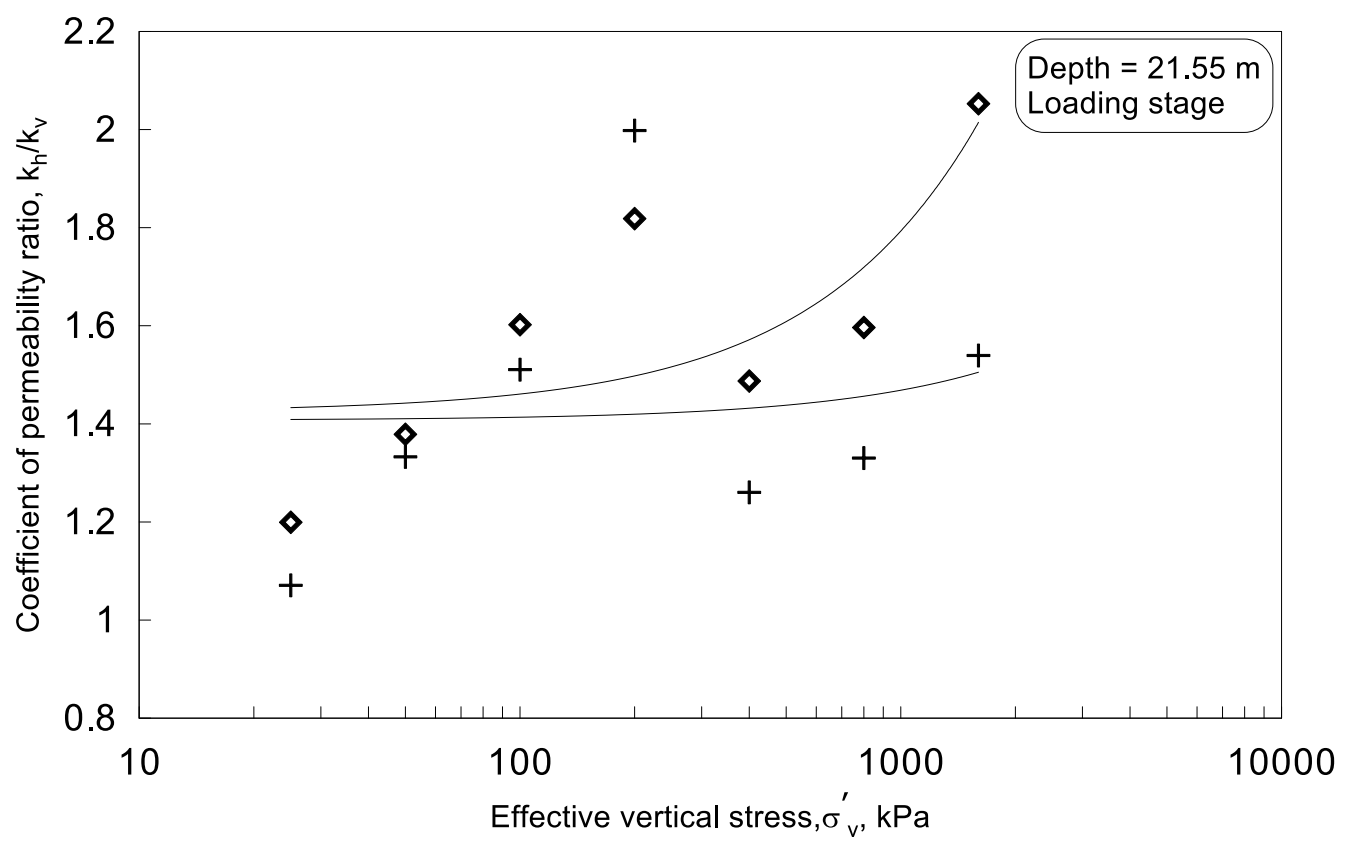

Figure A55: Typical plots of the coefficient of permeability ratio versus the effective vertical stress during the loading stage at depth of $21.55 \mathrm{~m}$ (by Taylor's method). 


\section{Appendix B}

(The plots of the simple shear results-Consolidation stage) 


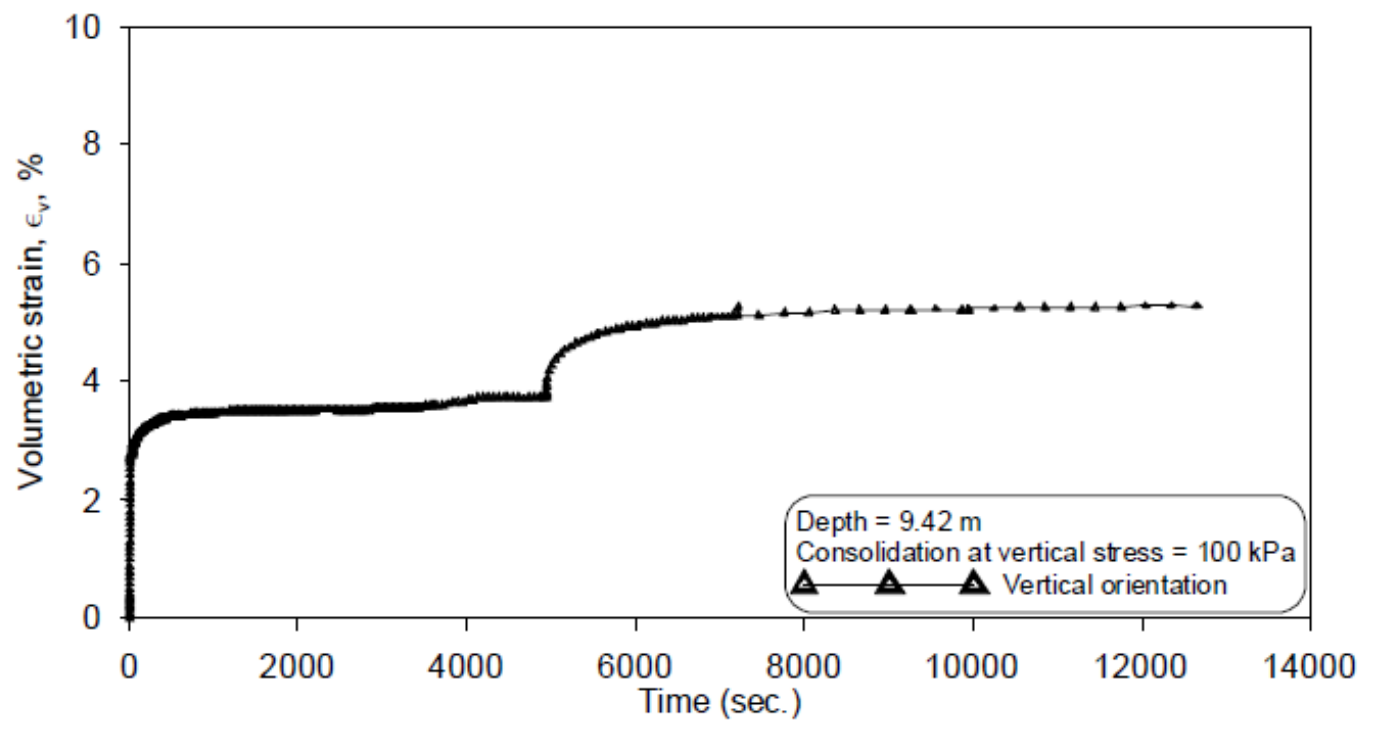

Figure B1: Volumetric strain versus time in the vertical orientation at vertical consolidation of $100 \mathrm{kPa}$.

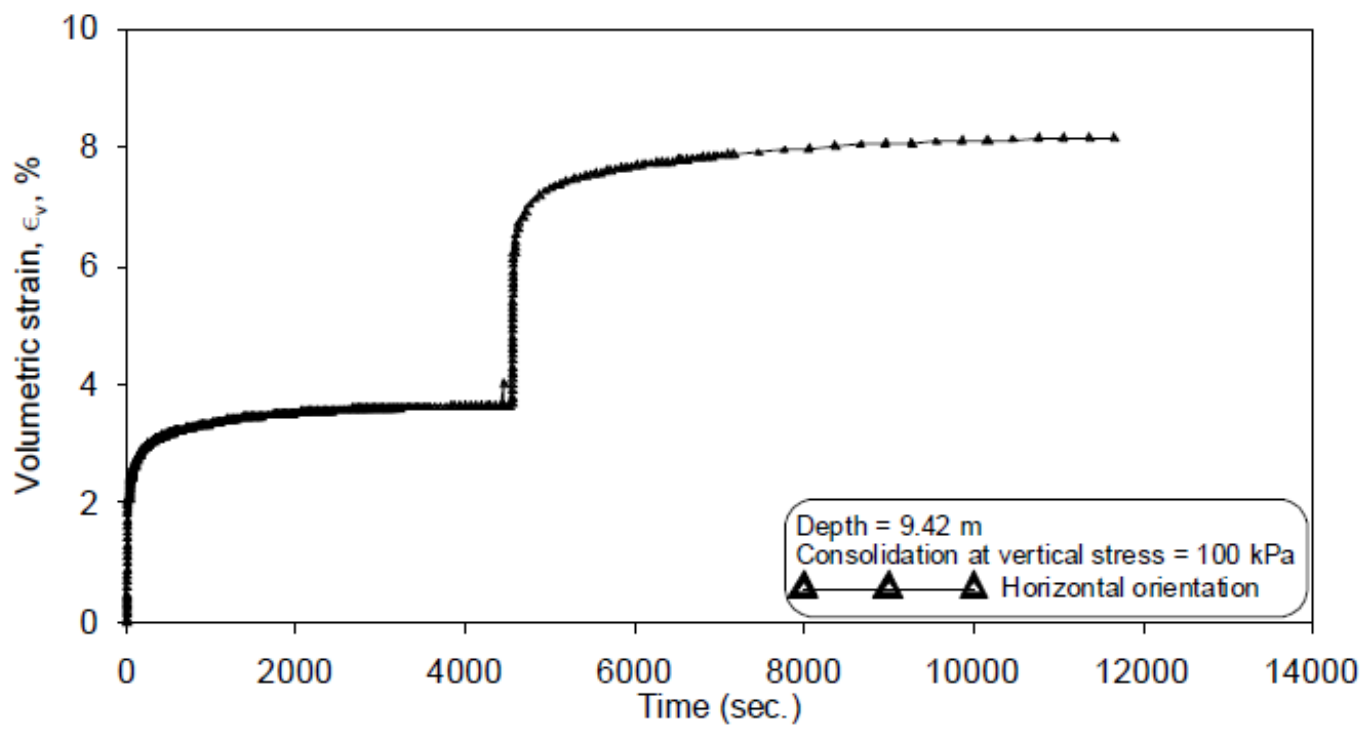

Figure B2: Volumetric strain versus time in the horizontal orientation at vertical consolidation of $100 \mathrm{kPa}$. 


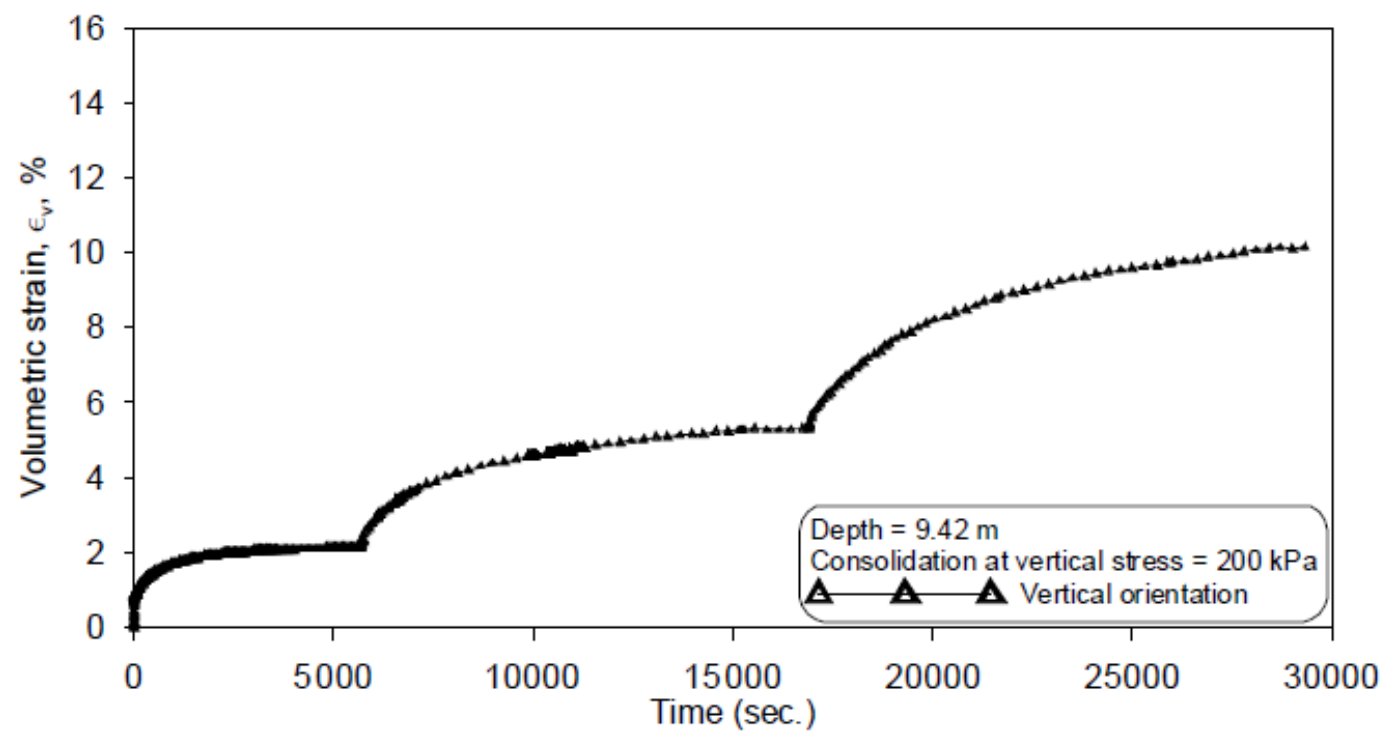

Figure B3: Volumetric strain versus time in the vertical orientation at vertical consolidation of $200 \mathrm{kPa}$.

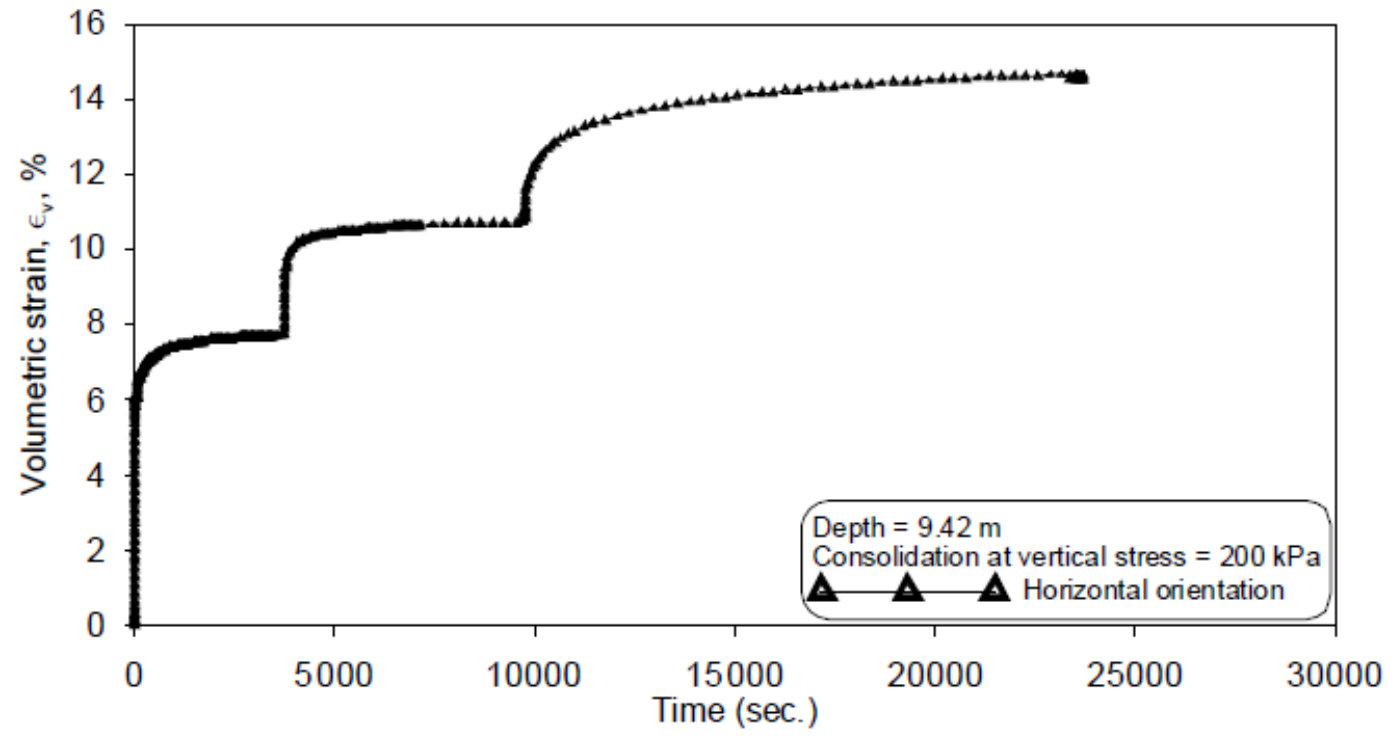

Figure B4: Volumetric strain versus time in the horizontal orientation at vertical consolidation of $200 \mathrm{kPa}$. 


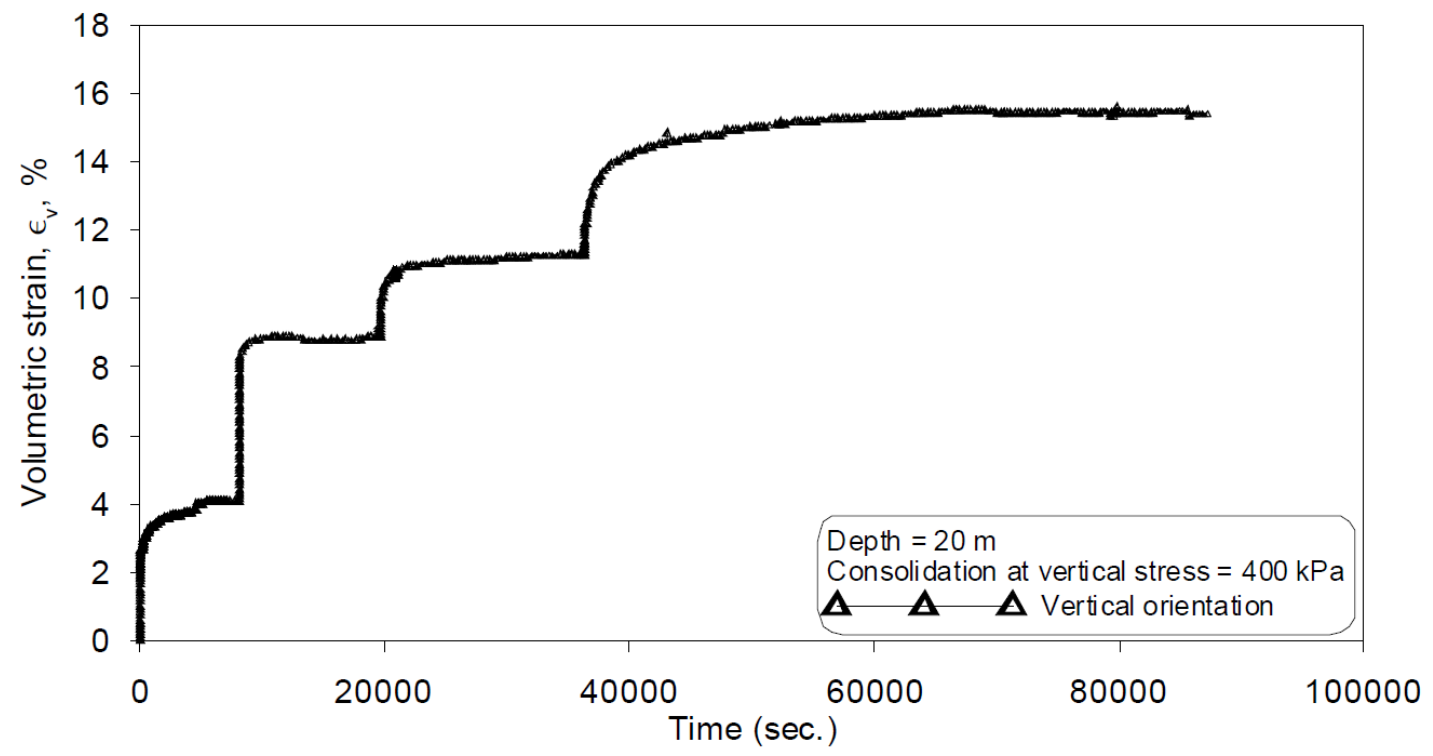

Figure B5: Volumetric strain versus time in the vertical orientation at vertical consolidation of $400 \mathrm{kPa}$.

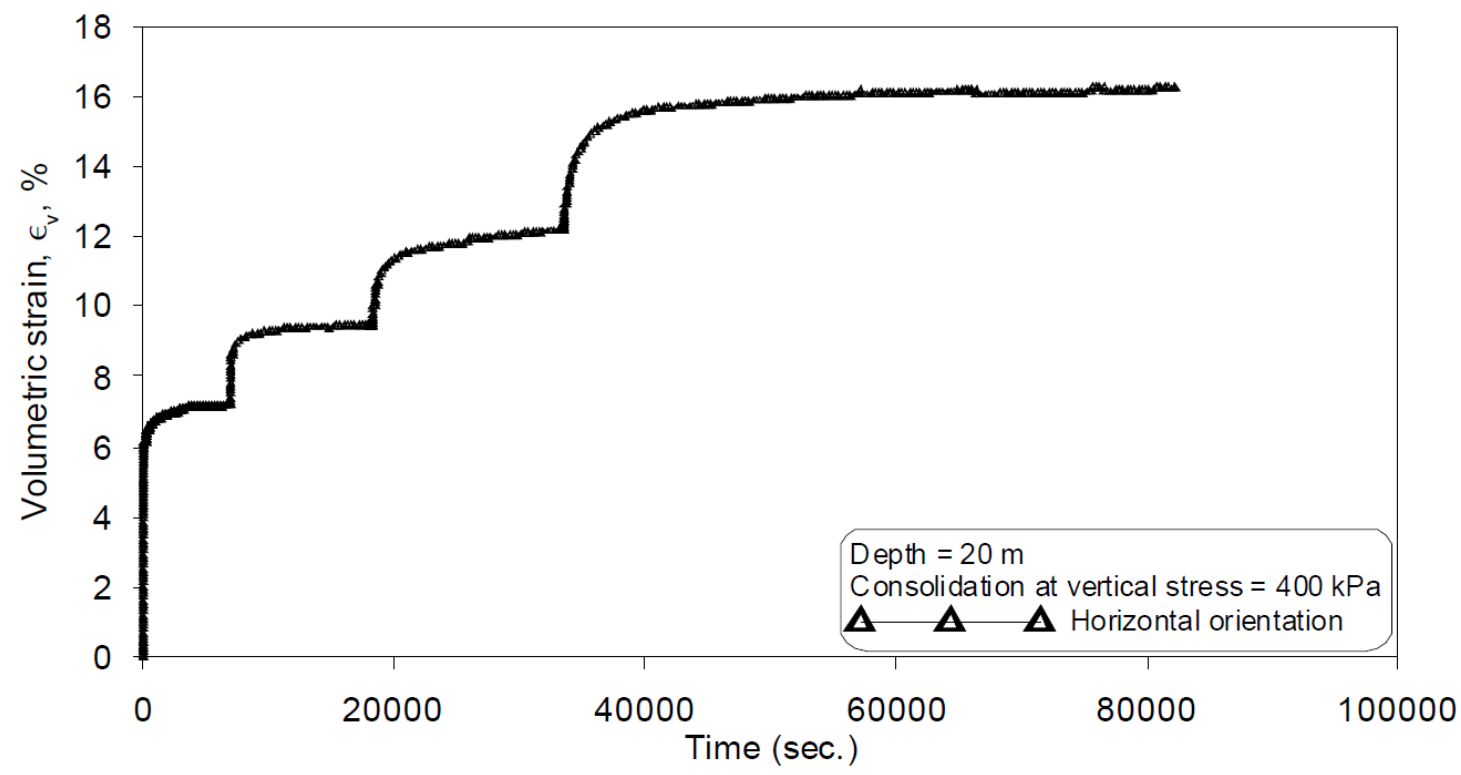

Figure B6: Volumetric strain versus time in the horizontal orientation at vertical consolidation of $400 \mathrm{kPa}$. 